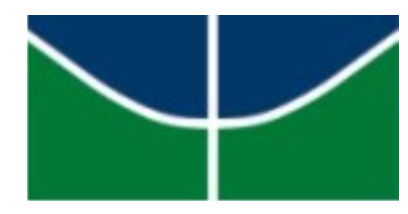

UNIVERSIDADE DE BRASÍLIA

FACULDADE DE TECNOLOGIA DEPARTAMENTO DE ENGENHARIA CIVIL E AMBIENTAL

\title{
IMPACTO SONORO PROVOCADO POR POLO GERADOR DE VIAGEM: AEROPORTO INTERNACIONAL DE BRASÍLIA
}

\section{WESLEY CÂNDIDO DE MELO}

\author{
ORIENTADORA: FABIANA SERRA DE ARRUDA \\ CO-ORIENTADOR: SÉRGIO LUIZ GARAVELLI
}

DISSERTAÇÃO DE MESTRADO EM TRANSPORTES ENGENHARIA CIVIL E AMBIENTAL

PUBLICAÇÃO: T. DM - 010/2015 BRASÍLIA/DF: JULHO - 2015 
UNIVERSIDADE DE BRASÍLIA

FACULDADE DE TECNOLOGIA DEPARTAMENTO DE ENGENHARIA CIVIL

IMPACTO SONORO PROVOCADO POR POLO GERADOR DE VIAGEM: AEROPORTO INTERNACIONAL DE BRASÍLIA

WESLEY CÂNDIDO DE MELO

DISSERTAÇÃO SUBMETIDA AO DEPARTAMENTO DE ENGENHARIA CIVIL E AMBIENTAL DA FACULDADE DE TECNOLOGIA DA UNIVERSIDADE DE BRASÍLIA COMO PARTE DOS REQUISÍTOS NECESSÁRIOS PARA A OBTENÇÃO DO GRAU DE MESTRE EM TRANSPORTES.

APROVADA POR:

Profa. Fabiana Serra de Arruda, Doutora (PPGT-UnB)

(Orientadora)

Prof. Sérgio Luiz Garavelli, Doutor (UNIP)

(Co-Orientador)

Prof. José Matsuo Shimoishi, Doutor (PPGT-UnB)

(Examinador Interno)

Prof ${ }^{\text {a }}$ Ludmila Rodrigues de Moraes, Doutora (UnUCET-UEG)

(Examinador Externo)

BRASÍLIA/DF, 15 DE JULHO DE 2015 


\section{FICHA CATALOGRÁFICA}

\begin{tabular}{|c|c|}
\hline \multicolumn{2}{|c|}{ MELO, WESLEY CÂND } \\
\hline \multicolumn{2}{|c|}{$\begin{array}{l}\text { Impacto Sonoro Provocado por Polo Gerador de Viagem: Aeroporto Internacional de Brasília } \\
\text { [Distrito Federal] } 2015 .\end{array}$} \\
\hline \multicolumn{2}{|c|}{ xiii, 117p., 210 x 297 mm (ENC/FT/UnB, Mestre, Transportes, 2015). } \\
\hline \multicolumn{2}{|c|}{ Dissertação de Mestrado - Universidade de Brasília. Faculdade de Tecnologia. } \\
\hline \multicolumn{2}{|c|}{ Departamento de Engenharia Civil e Ambiental. } \\
\hline 1. Poluição Sonora & 2. PGV \\
\hline 3. Ruído Combinado & 4. Cartas de Ruído \\
\hline I. ENC/FT/UnB & II. Título (série) \\
\hline
\end{tabular}

\section{REFERÊNCIA BIBLIOGRÁFICA}

MELO, W. C. (2015). Impacto Sonoro Provocado por Polo Gerador de Viagem: Aeroporto Internacional de Brasília, Publicação T. DM - 010/2015, Departamento de Engenharia Civil e Ambiental, Universidade de Brasília, Brasília, DF, 117p.

\section{CESSÃO DE DIREITOS}

AUTOR: Wesley Cândido de Melo

TÍTULO: Impacto Sonoro Provocado por Polo Gerador de Viagem: Aeroporto Internacional de Brasília

GRAU: Mestre ANO: 2015

É concedida à Universidade de Brasília permissão para reproduzir cópias desta dissertação de mestrado e para emprestar ou vender tais cópias somente para propósitos acadêmicos e científicos. $\mathrm{O}$ autor reserva outros direitos de publicação e nenhuma parte dessa dissertação de mestrado pode ser reproduzida sem autorização por escrito do autor.

Wesley Cândido de Melo

Programa de Pós-graduação em Transportes. Departamento de Engenharia Civil e Ambiental. Faculdade de Tecnologia, Anexo SG-12, $1^{\circ}$ Andar, Campus Universitário Darcy Ribeiro. Universidade de Brasília, Brasília - DF, Brasil.

CEP: 70.910-900

wesleycandido@gmail.com 


\section{AGRADECIMENTOS}

À Deus, por ter permitido que o impossível se tornasse possível em minha vida, fornecendo fé, paciência e inspiração.

A minha estimada esposa Pollyanne Melo e ao meu querido filho Bernardo Cândido, pois apesar da minha ausência, sempre estiveram presentes em meu coração, propiciando força para finalização deste estudo.

Aos meus pais Najimar Cândido e Maria Abadia, pelo exemplo de amor, dedicação e perseverança, me motivando sempre a buscar meus objetivos com honestidade e dedicação.

Ao meu irmão Weverton Cândido e minha sobrinha Olivia Melo por me motivarem a continuar esta árdua caminhada.

À professora, Fabiana Serra de Arruda, por ter aceitado esse desafio, pela paciência, atenção, tranquilidade e por cada lição aprendida ao longo desse período.

Ao professor Sérgio Luiz Garavelli, que com alegria, paciência e sabedoria, incentivou e acompanhou a realização deste estudo, confiando e acreditando em mim.

Aos demais professores e à coordenação do Programa de Pós-Graduação em Transportes da Universidade de Brasília, pelos ensinamentos e auxílios ofertados. Não poderia deixar de agradecer a Lucinete e a Camila, pelos auxílios administrativos e alegria de sempre.

A direção, coordenação e professores do Curso de Física da Universidade Católica de Brasília, por permitirem a utilização do espaço, softwares e computadores do Laboratório de Física Aplicada ao Meio Ambiente.

Aos amigos Ângela Bertazzo, Cleber Alves, Edson Benício, Luiz Soares e Ly Freitas pela amizade sincera, estímulo e ajuda na realização deste estudo. Em especialmente ao Edwin Silva, pelo companheirismo e parceria nos estudos realizados aos sábados, domingos e feriados.

A todos os colegas das turmas de 2012 e 2013 do PPGT/UnB, nossas discussões contribuíram significativamente em minha formação e na realização deste estudo.

Agradeço ao CNPq processo 474594/2013-0 e a CAPES pelo financiamento e apoio ao desenvolvimento deste estudo.

Às demais pessoas que, de uma forma ou de outra, contribuíram na elaboração deste trabalho. 


\section{RESUMO}

\section{IMPACTO SONORO PROVOCADO POR POLO GERADOR DE VIAGEM: AEROPORTO INTERNACIONAL DE BRASÍLIA}

A relação entre o clima acústico de uma região aeroportuária e a caracterização de um aeroporto como Polo Gerador de Viagens (PGV), ainda é pouco estudada no Brasil. Porém, já é visto como um grande desafio para os gestores dos aeroportos. Neste sentido, este estudo, o qual se refere ao mapeamento de ruído, avaliando em um primeiro momento o ruído rodoviário e o aéreo separadamente e posteriormente de forma combinada em dois cenários distintos, tem por objetivo avaliar a paisagem sonora da região de influência do Polo Gerador de Viagens do Aeroporto Internacional de Brasília, considerando como fontes de ruído os tráfegos aéreo, rodoviário e ferroviário. O método de pesquisa utilizado foi baseado em simulações de "curvas de ruído", para assim, obter as cartas acústicas, de modo a determinar o ruído combinado devido os modais que influenciam o clima acústica da região. Com essas cartas, também foi possível determinar a população exposta e dentre estas, o percentual das pessoas incomodadas, das altamente incomodadas e também das pessoas com distúrbio do sono, pelo ruído aeroviário e rodoviário para as métricas $\mathrm{L}_{n}$ e $\mathrm{L}_{d e n}$. Percebe-se, assim que o uso de transportes de maior capacidade (modal ferroviário), no acesso aos aeroportos, tende a proporcionar benefícios significativos não só para o meio ambiente, mas também para todos que residem no entorno deste Polo Gerador de Viagens. Por fim, ressalta-se que a abordagem apresentada nesta dissertação é complexa e os resultados encontrados poderão subsidiar na gestão de conflitos entre os atores envolvidos, gerir e preservar a qualidade do conforto acústico da região, bem como proporcionar a articulação com o planejamento de transporte e de ordenamento territorial.

PALAVRAS-CHAVE: Poluição Sonora; PGV; Ruído Combinado; Cartas de Ruído. 


\section{ABSTRACT \\ NOISE IMPACT CAUSED IN POLO TRAVEL GENERATOR: INTERNATIONAL AIRPORT BRASILIA}

The relationship between the acoustic atmosphere of an airport area and the characterization of an airport as Polo Trips Generator, is not well known in Brazil. However, it is seen as a major challenge for the managers of the airports. Thus, this study, which refers to noise mapping, evaluating at first the road noise and air separately and then combined to form two distinct scenarios, aims to assess the soundscape of the influence of region Polo Trips Generator Brasilia International Airport, considering how noise sources the air, road and rail traffic. The research method used was based on simulations of "noise curves", to thus obtain the acoustic letters in order to determine the combined noise due modal influencing the acoustic climate. With these letters, it was also possible to determine the exposed population and among these, the percentage of troubled people, highly disturbed and that of people with sleep disorders, the air transportation and road noise for $\mathrm{L}_{d e n}$ and $\mathrm{L}_{n}$ metrics. It is clear, so the use of larger capacity transport (railways), access to airports, tends to provide significant benefits not only the environment but also for all who reside in the vicinity of this Polo Travel generator. Finally, it stresses that the approach presented in this work is complex and the results may support the management of conflicts between stakeholders, manage and preserve the quality of the acoustic comfort of the region and provide liaison with the transportation planning and land use planning.

KEYWORDS: Noise Pollution; PGV; Combined Noise; Noise Letters. 


\section{SUMÁRIO}

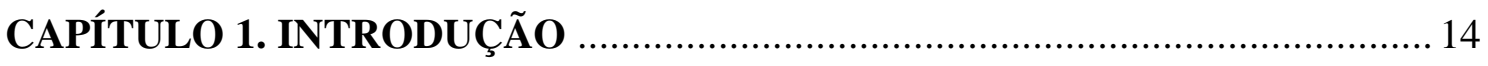

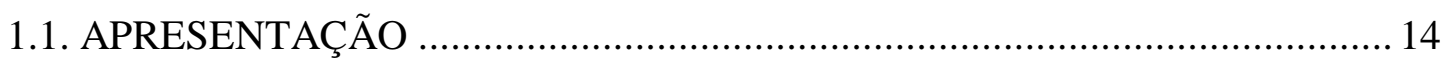

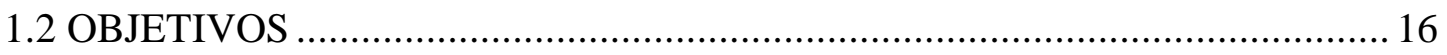

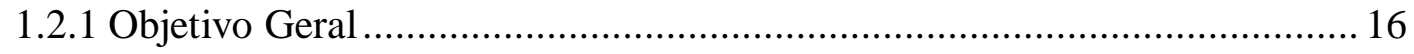

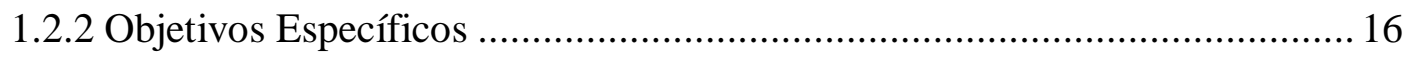

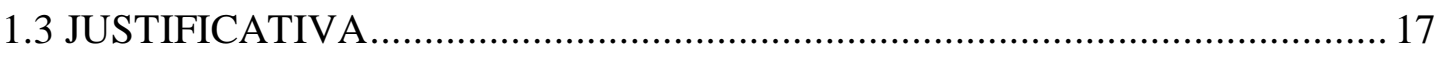

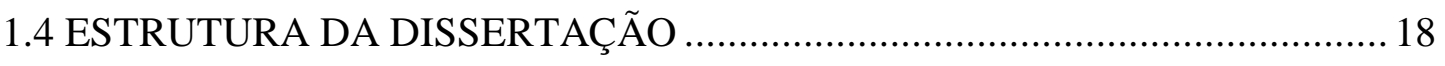

CAPÍTULO 2. REVISÃO BIBLIOGRÁFICA .................................................... 19

2.1 POLOS GERADORES DE VIAGENS (PGV's).............................................. 19

2.2 CARACTERIZAÇÃO DO AEROPORTO COMO PGV ................................. 21

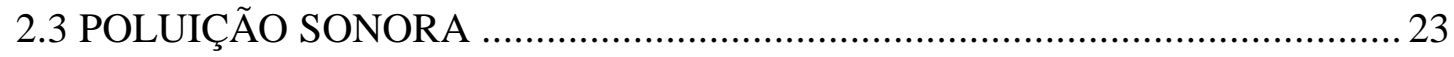

2.4 NÍVEIS DE POTÊNCIA e INTENSIDADE .................................................. 29

2.4.1 Nível de Potência Sonora ........................................................................ 29

2.4.2 Nível de Intensidade Sonora (NIS) …................................................ 30

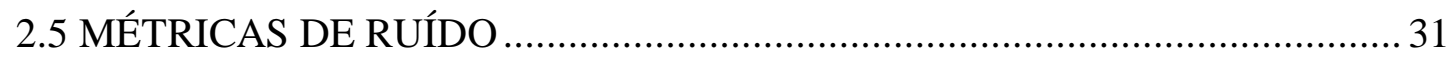

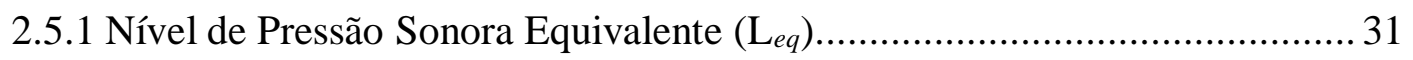

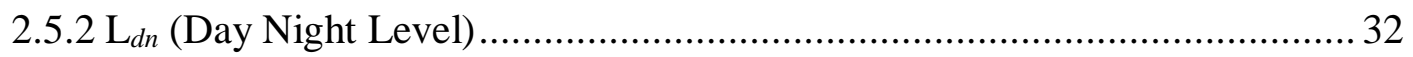

2.5.3 L eq, den (Indicador do Nível de Pressão Sonora dia-entardecer-noite) ............ 33

2.6 RUÍDO DEVIDO AOS MODAIS DE TRANSPORTE ................................... 33

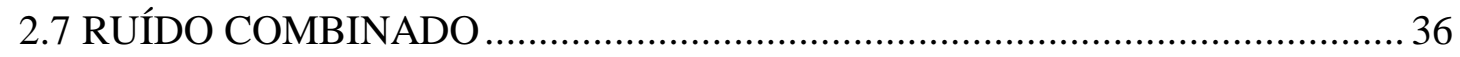

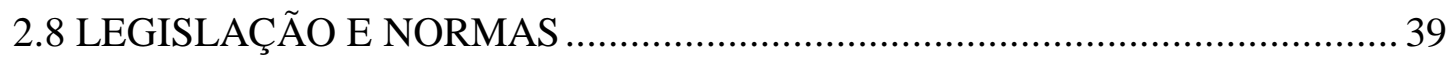

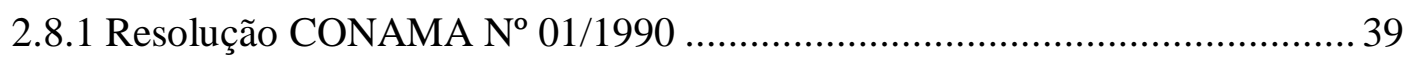

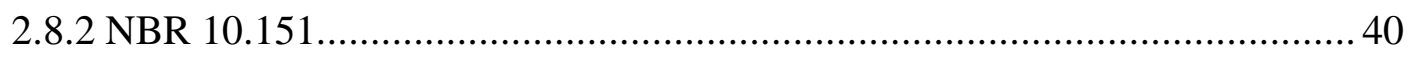

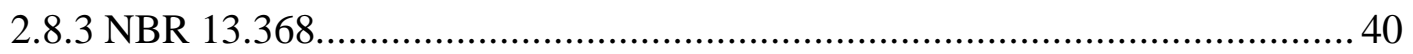

2.8.4 Organização Mundial de Saúde .................................................................. 41

2.8.5 Diretiva Europeia 2002/49/CE ............................................................. 41

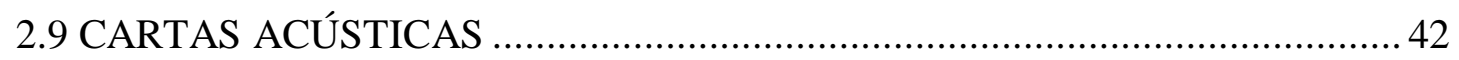

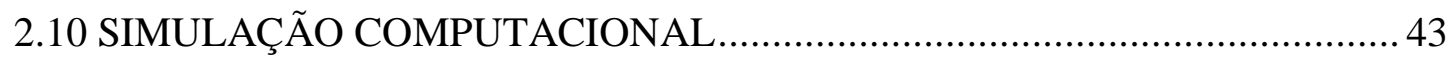

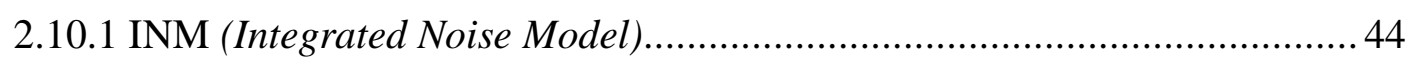

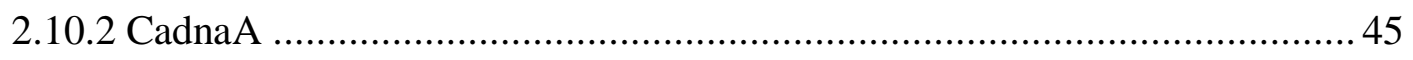

2.11 PERCENTUAL DE PESSOAS INCOMODADAS ...................................... 46

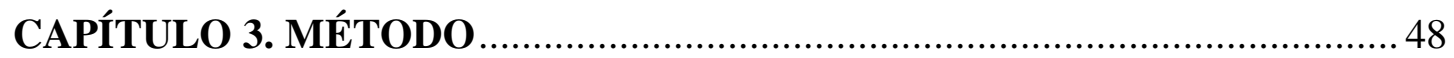

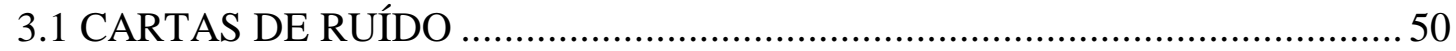

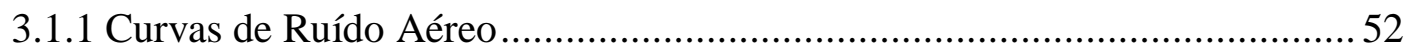




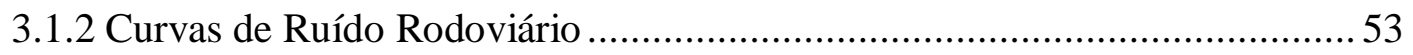

3.1.3 Curvas de Ruído Ferroviário ................................................................ 54

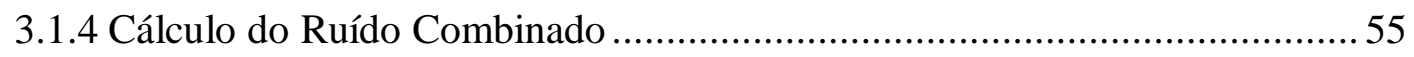

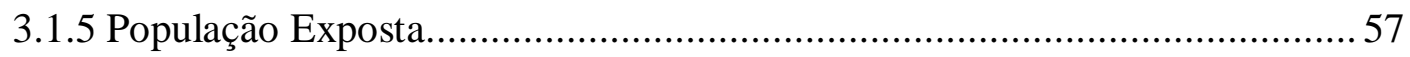

CAPÍTULO 4. ANÁLISE DOS RESULTADOS E DISCUSSÕES ….................... 58

4.1 CARACTERIZAÇÃO DA ÁREA DE ESTUDO............................................ 58

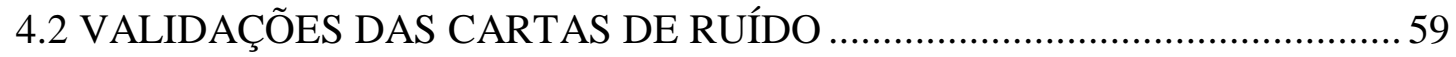

4.3 CENÁRIOS ACÚSTICOS DA ÁREA DE ESTUDO ....................................... 60

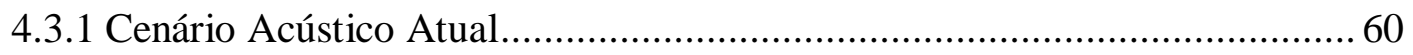

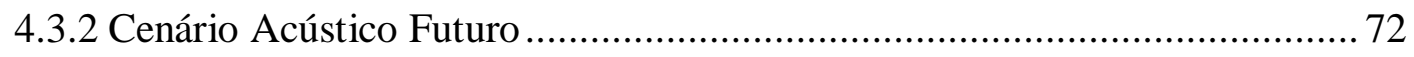

4.3.3 Diferenças entre os Cenários Acústicos.................................................. 83

4.4 RELAÇAO RUÍDO E POLO GERADOR DE VIAGENS ................................. 86

CAPÍTULO 5. CONCLUSÕES E RECOMENDAÇÕES .................................. 88

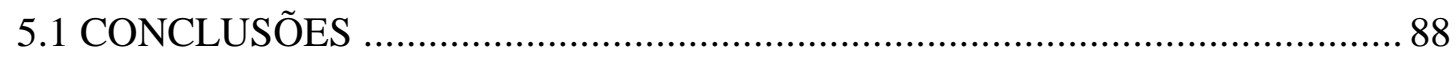

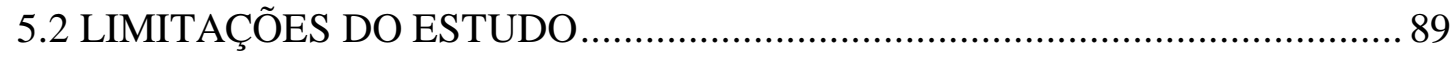

5.3 RECOMENDAÇÕES PARA TRABALHOS FUTUROS ............................... 89

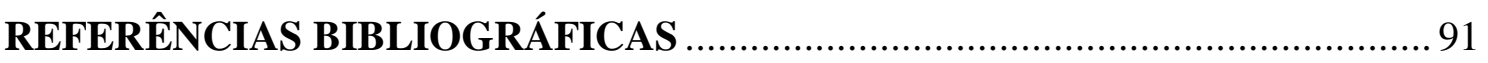

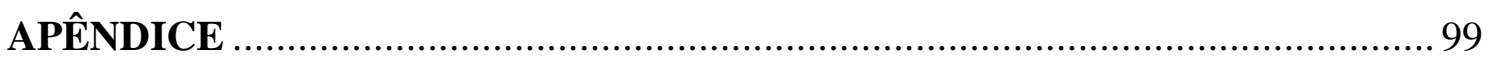

APÊNDICE A - DADOS DE ENTRADA SIMULAÇÃO AÉREA ........................... 99

APENDICE B - DADOS DE ENTRADA SIMULAÇÃO RODOVIÁRIA ................ 106

APENDICE C - RESULTADOS DAS SIMULAÇÕES ....................................... 113 


\section{LISTA DE TABELAS}

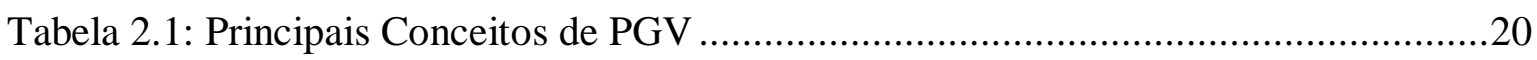

Tabela 2.2: Impactos Causados pela Implantação de PGVs ............................................21

Tabela 2.3: Geração de Viagens, Horizonte e Área de Abrangência .................................22

Tabela 2.4: Efeitos na Saúde da População para Diferentes Intervalos de NPS .................26

Tabela 2.5: Efeitos do Ruído na Saúde e Bem Estar .......................................................29

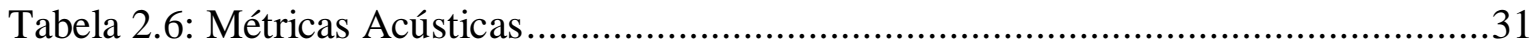

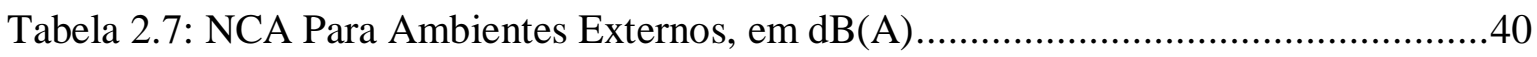

Tabela 2.8: Avaliação do Incômodo Gerado Pelas Operações Aeroportuárias....................41

Tabela 2.9: Valores Limites de Exposição .................................................................... 41

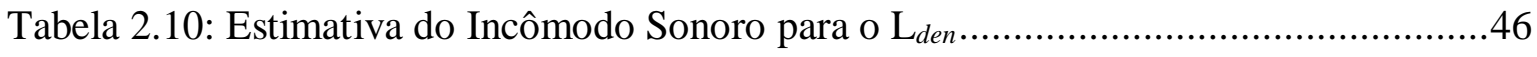

Tabela 2.11: $\mathrm{L}_{n}$ e Polinômios para Distúrbios do Sono - Tráfego Aéreo e Rodoviário ......47

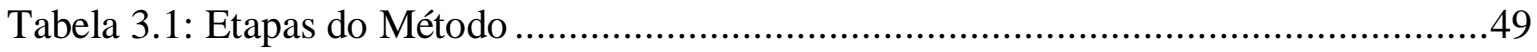

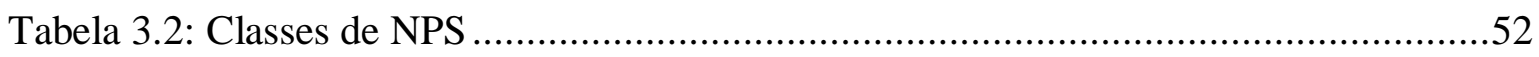

Tabela 4.1: Áreas das Curvas de Ruído Aéreo/Rodoviário - Cenário Atual $\left(\mathrm{L}_{d e n}\right)$............64

Tabela 4.2: Pop. Exposta Curva de Ruído Aéreo/Rodoviário - Cenário Atual $\left(\mathrm{L}_{d e n}\right)$.........64

Tabela 4.3: Pop. Incomodada Curva de Ruído Aéreo/Rodoviário - Cenário Atual L den.....65

Tabela 4.4: Áreas das Curvas de Ruído Aéreo/Rodoviário - Cenário Atual $\left(\mathrm{L}_{n}\right)$............... 70

Tabela 4.5: Pop. Exposta Curva de Ruído Aéreo/Rodoviário - Cenário Atual $\left(\mathrm{L}_{n}\right)$...........70

Tabela 4.6: Pessoas Distúrbios no Sono Ruído Aéreo/Rodoviário - Cenário Atual $\left(\mathrm{L}_{n}\right) \ldots . .71$

Tabela 4.7: Área das Curvas de Ruído Rodoviário - Cenário Futuro $\left(\mathrm{L}_{d e n}\right) \ldots \ldots \ldots \ldots \ldots \ldots \ldots . . . . . . . .76$

Tabela 4.8: Pop. Exposta Curva de Ruído Rodoviário - Cenário Futuro $\left(\mathrm{L}_{d e n}\right)$..................76

Tabela 4.9: Pop. Incomodada Ruído Rodoviário - Cenário Futuro $\left(\mathrm{L}_{d e n}\right) \ldots \ldots \ldots \ldots \ldots \ldots \ldots \ldots \ldots . . . . . . . . . . . . .77$

Tabela 4.10: Área das Curvas de Ruído Rodoviário - Cenário Futuro $\left(\mathrm{L}_{n}\right)$....................... 81

Tabela 4.11: Pop. Exposta para Curva de Ruído Rodoviário - Cenário Futuro $\left(\mathrm{L}_{n}\right)$..........81

Tabela 4.12: Ruído Rodoviário Cenário Futuro $\mathrm{L}_{n}-$ Pessoas com Distúrbios no Sono .....82

Tabela 4.13: Diferença “PE” entre os Cenários para o Modal Rodoviário $\left(\mathrm{L}_{d e n}\right)$................83

Tabela 4.14: Diferença Pop. Incomodada entre os Cenários Modal Rodoviário $\left(\mathrm{L}_{d e n}\right) \ldots . . . .83$

Tabela 4.15: Diferença PE entre os Cenários para o Modal Rodoviário $\left(\mathrm{L}_{n}\right)$.................... 84

Tabela 4.16: Diferença Distúrbios no Sono entre os Cenários Modal Rodoviário $\left(\mathrm{L}_{n}\right)$......84

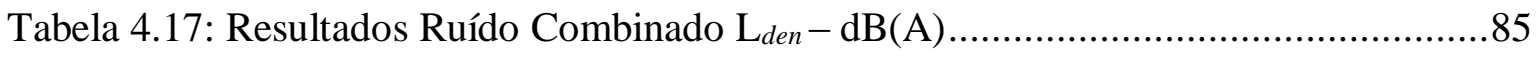

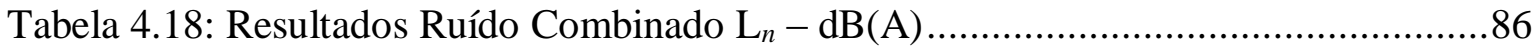

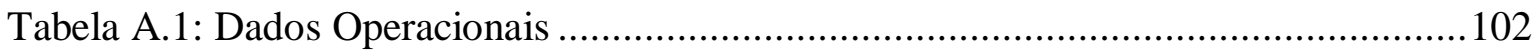




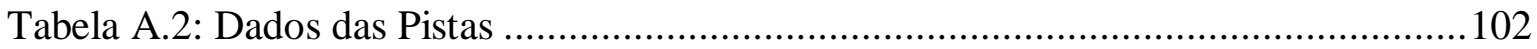

Tabela A.3: Percentuais de Operações nas Cabeceiras .................................................. 103

Tabela A.4: Composição da Frota de Aeronaves em 2012 ............................................... 103

Tabela A.5: Principais Rotas de Pouso de Decolagem ................................................... 103

Tabela A.6: Locais das EMR's do SBBR ..................................................................... 104

Tabela A.7: Indicadores Acústicos Calculados para a Validação das Cartas Acústicas.... 105

Tabela B.1: Volume de Tráfego Veículo/Hora - Dia...................................................... 106

Tabela B.2: Volume de Tráfego Veículo/Hora - Entardecer.......................................... 106

Tabela B.3: Pontos das Contagens do Volume de Tráfego Rodoviário.............................107

Tabela B.4: Pontos dos Contadores Fixos do DETRAN-DF ........................................... 108

Tabela B.5: Dados Contadores DETRAN-DF e DER/DF Veículo/Hora - Dia .................109

Tabela B.6: Dados Contadores DETRAN-DF e DER/DF Veículo/Hora - Entardecer ..... 109

Tabela B.7: Dados Contadores DETRAN-DF e DER/DF Veículo/Hora - Noite ..............110

Tabela B.8: BRT Gama-Rodoviária do Plano Piloto....................................................... 110

Tabela B.9: BRT Santa Maria-Rodoviária do Plano Piloto .............................................110

Tabela B.10: BRT Gama/Santa Maria/Rodoviária do Plano Piloto .................................111

Tabela B.11: Validação do Mapa de Ruído Rodoviário ..................................................112

Tabela C.1: Pontos de Medidas - Ruído Combinado ......................................................... 113

Tabela C.2: Resultados das Simulações para os Modais - dB(A).................................. 114

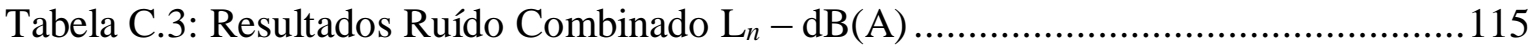

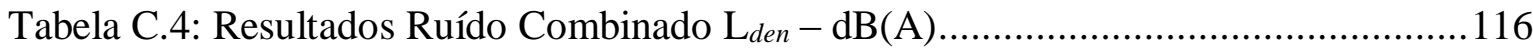




\section{LISTA DE FIGURAS}

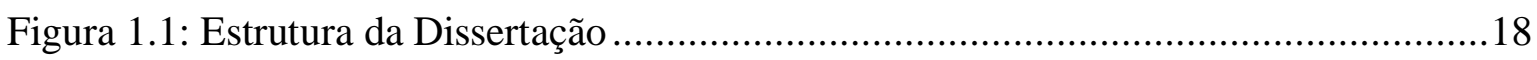

Figura 2.1: Relação entre Severidade dos Efeitos do Ruído e Número de Afetados .........26

Figura 2.2: Esquema das Reações Produzidas pelo Ruído..............................................28

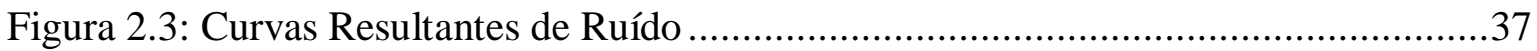

Figura 2.4: Carta Acústica em Leq/Matutino/Área Central de Brasília-DF........................43

Figura 3.1: Método para Determinação do Ruído Combinado e da População Exposta.....50

Figura 3.2: Etapas para Elaboração de Cartas Acústicas ................................................51

Figura 3.3: Traçado Completo do VLT Brasília.............................................................54

Figura 3.4: Pontos de Somatória do Ruído Combinado....................................................56

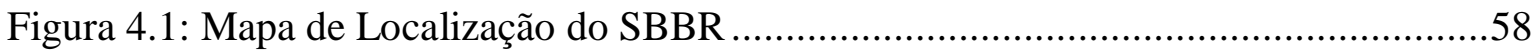

Figura 4.2: Carta de Ruído Aéreo - Cenário Atual $\left(\mathrm{L}_{d e n}\right)$................................................61

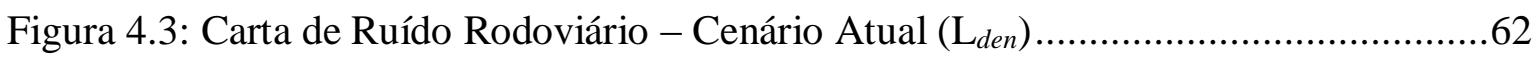

Figura 4.4: Carta de Ruído Combinado (Aéreo e Rodoviário) - Cenário Atual $\left(\mathrm{L}_{d e n}\right)$.......63

Figura 4.5: Carta de Ruído Aéreo - Cenário Atual $\left(\mathrm{L}_{n}\right)$.................................................67

Figura 4.6: Carta de Ruído Rodoviário - Cenário Atual $\left(\mathrm{L}_{n}\right)$........................................68

Figura 4.7: Carta de Ruído Combinado (Aéreo e Rodoviário) - Cenário Atual $\left(\mathrm{L}_{n}\right)$.........69

Figura 4.8: Carta de Ruído Rodoviário - Cenário Futuro $\left(\mathrm{L}_{d e n}\right)$......................................73

Figura 4.9: Carta de Ruído Ferroviário - Cenário Futuro $\left(\mathrm{L}_{d e n}\right)$......................................74

Figura 4.10: Carta de Ruído Combinado (Aéreo, Rodoviário e Ferroviário) - Cenário Futuro

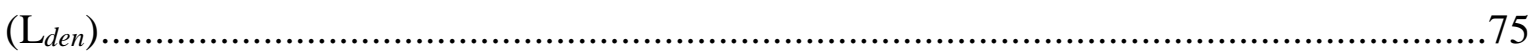

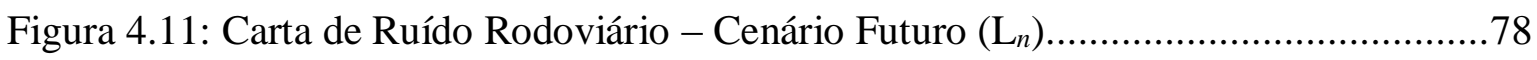

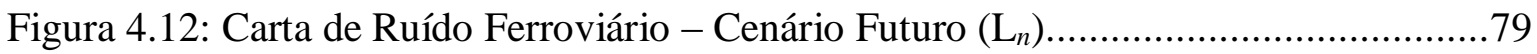

Figura 4.13: Carta de Ruído Combinado (Aéreo, Rodoviário e Ferroviário) - Cenário Futuro

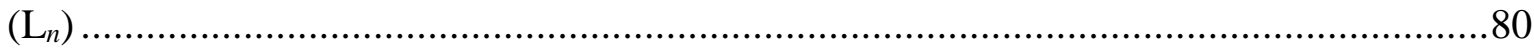

Figura A.1: Aeroporto Internacional de Brasília ...........................................................99

Figura A.2: Rotas de Chegadas e Saídas do SBBR por Cabeceiras ................................. 100

Figura A.3: Movimentação de Passageiros-SBBR Últimos 10 Anos................................101

Figura A.4: Movimentação de Aeronaves-SBBR Últimos 10 Anos ...............................102

Figura A.5: Localização dos pontos de medidas ............................................................ 104

Figura B.1: Pontos das Contagens do Volume de Tráfego Rodoviário ............................ 107

Figura B.2: Pontos dos Contadores Fixos do DETRAN-DF......................................... 108

Figura B.3: Pontos dos Contadores Fixos do DER/DF ..................................................109 


\section{LISTA DE ABREVIATURAS}

A - Número de Pessoas Incomodadas

AIB - Aeroporto Internacional de Brasília

ARIE - Santuário da Vida Silvestre do Riacho Fundo

CONAMA - Conselho Nacional do Meio Ambiente

DER/DF - Departamento de Estradas e Rodagem do Distrito Federal

DETRAN - Departamento de Trânsito

DF - Distrito Federal

DFTRANS - Transporte Urbano do Distrito Federal

FAA- Federal Aviation Administration

GDF - Governo do Distrito Federal

IBGE - Instituto Brasileiro de Geografia e Estatística

HA - Número de Pessoas Altamente Incomodadas

IATA - Internacional Air Transport Association

ICAO - International Civil Aviation Organization

INM - Integrated Noise Model

IPR - Índice Ponderado de Ruído

IBRAM - Instituto Brasília Ambiental

MDT - Mapa Digital do Terreno

NIS - Nível de Intensidade Sonora

NPD - Noise Power and Distance

NPS - Nível de Potência Sonora

PBZR - Plano Básico de Zoneamento de Ruído

PDTU/DF - Plano Diretor de Transporte Urbano e Mobilidade do Distrito Federal PEZR - Plano Específico de Zoneamento de Ruído

PGV - Polos Geradores de Viagens 
PGT - Polos Geradores de Tráfegos

PE - População Exposta

PDS - Pessoas com Distúrbios o Sono

PADS - Pessoas com o Sono Altamente Perturbado

PSAP - Pessoas com o Sono Levemente Pertubado

PZR - Plano de Zoneamento de Ruídos de Aeródromos

RA - Região Administrativa

RBAC - Regulamento Brasileiro da Aviação Civil

REDEPGV - Rede Ibero-Americana de Estudos em Polos Geradores de Viagens

ONU - Organização das Nações Unidas

VLP - Veículo Leve sobre Pneu

VLT - Veículo Leve sobre Trilho

$\% \mathrm{~A}$ - Percentual de Pessoas Incomodadas

$\% \mathrm{HA}$ - Percentual de Pessoas Altamente Incomodadas

\%PDS - Percentual de Pessoas com Distúrbios no Sono

\%PE - Percentual da População Exposta

\%PSAP - Percentual de Pessoas com o Sono Altamente Perturbado

\%PSLP - Percentual de Pessoas com o Sono Levemente Perturbado 


\section{CAPÍTULO 1. INTRODUÇÃO}

\subsection{APRESENTAÇÃO}

No Brasil existe uma tendência presente, assim como nos países Estados Unidos e Canadá, de transformar aeródromos em cidades-aeroportos, com a implantação nos sítios aeroportuários de atividades comerciais (Vasconcelos, 2007; Silva, 2008). Isto favorece o surgimento de grandes centros econômicos que além de atender as necessidades básicas dos usuários, atende ainda a demanda de moradores da região, pois permite ao usuário realizar negócios, trocar conhecimentos, fazer compras, alimentar-se, dormir e ter também, opções de entretenimento sem se distanciar mais de 15 minutos do aeroporto (Kasarda, 2006).

Nesse cenário, os aeroportos se consolidam como Polos Geradores de Viagens (PGV's) (Coelho, 2011). PGV's são empreendimentos de grande porte que possuem a capacidade de atrair um número significativo de viagens terrestres e geram impactos positivos para o seu entorno, como o desenvolvimento e valorização de uma região (RedePGV, 2014). No entanto, também, causam impactos negativos na circulação viária, e em seu entorno imediato, implicando na redução da capacidade das vias e interferência com o tráfego de passagem (que é devido a movimentação de pessoas que utilizam os serviços oferecidos por esta região). Em alguns casos, esses reflexos prejudicam a acessibilidade da região, além de agravar as condições de segurança de veículos e pedestres (Portugal, et al., 2007).

Os aeroportos estão se tornando importantes PGV's, e quando suas vias de acesso não estão bem dimensionadas, produzem atrasos e congestionamentos, implicando aumento do tempo de viagem como um todo (Goldner et al., 2014). Além disso, os PGV's aeroportos também causam impactos ao meio ambiente, sendo o ruído aeronáutico uma das principais externalidades negativas, pois é facilmente identificável e frequentemente impacta o meio ambiente com energia sonora excessiva (GROUP, 2003). Ressalta-se, que no Brasil e no mundo estudos têm indicado um crescimento no número de reclamações por parte das populações circunvizinhas aos aeroportos devido ao incômodo causado pela emissão de ruído (Silva, 2010; Carvalho Jr. et al., 2012a; Carvalho Jr. et al., 2013b).

Acrescido ao incômodo sonoro causado pela movimentação de aeronaves, a maior parte das viagens realizadas aos aeroportos ocorrem pelo meio terrestre. Como consequência, tem-se 
a emissão de gases nocivos aos seres humanos e indesejados ao meio ambiente e a geração de ruídos provenientes dos veículos (Costa, 2011).

Com o intuito de diminuir esses impactos ambientais, seus efeitos à saúde, bem como amenizar o ruído proveniente do tráfego rodoviário e viabilizar a movimentação de passageiros nas regiões dos grandes aeroportos é indicado que seus acessos sejam realizados por meio de um transporte rápido e de massa, como, por exemplo, o uso de metrôs, Veículo Leve Sobre Trilhos (VLT) e trens urbanos ou ainda, de alta velocidade, os quais apresentam menor quantidade de emissão de ruído, como tem acontecido na Europa e nos Estados Unidos (Santos, 2009; Albuquerque, 2011).

Em países da Europa, por exemplo, é comum ter o modal ferroviário como opção de acesso ao aeroporto, oferecendo um serviço de qualidade e rapidez na movimentação de passageiros e aumentando a participação do transporte público nos deslocamentos envolvidos. Essa maior oferta de transporte público proporciona mobilidade e acessibilidade aos usuários que se movimentam nessas regiões (Szwarc et al., 2011).

Desse modo, o tráfego aéreo, rodoviário e ferroviário nas regiões de influências dos aeroportos, penalizam as comunidades por propiciarem alterações no clima acústico. Essas mudanças ocorrem principalmente devido ao ruído combinado: combinação do ruído emitido pelos modais de transporte (aéreo, rodoviário e ferroviário). Estudos indicam que o clima acústico em uma determinada região tem sido modificado ao combinar o ruído aéreo com o ruído rodoviário ou o ruído rodoviário ao ser combinado com o ruído ferroviário. Sendo assim, torna-se necessário avaliar conjuntamente o impacto do ruído desses modais, no intuito de que seus efeitos sobre a saúde e o meio ambiente possam ser minimizados (Öhrström et al., 2007; Yano et al., 2011; Nguyen et al., 2012).

O Aeroporto Internacional de Brasília (AIB) possui grande movimentação de aeronaves e passageiros devido à sua localização estratégica, pois este aeroporto é um ponto de conexão para outros destinos no país. Com isso, é caracterizado como o segundo maior aeroporto em movimentação no Brasil (INFRAERO, 2014). Ele é classificado como PGV e o ruído proveniente da crescente demanda por operações, em conjunto com a grande movimentação do tráfego rodoviário no sítio aeroportuário, tem provocado alterações no panorama acústico da região. 
Uma das propostas do Plano Diretor de Transporte Urbano e Mobilidade do Distrito Federal (PDTU/DF, 2011) para a movimentação de passageiros na região do AIB, é a implantação do modal ferroviário por meio do VLT. Com a implantação deste modal será ampliado o serviço de transporte público na região a partir da integração dos sistemas de transportes: VLT, ônibus e táxi com o objetivo de proporcionar agilidade e fluidez no escoamento de passageiros, além da minimização dos impactos ambientais, como poluição sonora. Cabe destacar que em Brasília, o adensamento urbano próximo a regiões circunvizinhas ao AIB, o qual configura um problema para as autoridades de difícil solução, devido à incompatibilidade da atividade aeroportuária com o uso do solo para fins residenciais, educacionais e para atividades hospitalares (Carvalho Jr. et al., 2012).

De posse das informações citadas, é importante uma atenção mais direcionada ao cenário acústico na região do entorno do AIB, levando em consideração a expectativa de crescimento das operações aéreas para o futuro próximo, em que, áreas com maior vulnerabilidade acústica deverão aumentar em função do tráfego rodoviário, com o crescimento do número de passageiros e dos serviços que estão sendo oferecidos no sítio aeroportuário. Portanto, estudos que viabilizem a mobilidade e acessibilidade nesta região podem contribuir para se minimizar o impacto sonoro e promover qualidade de vida urbana.

\subsection{OBJETIVOS}

\subsubsection{Objetivo Geral}

Avaliar o impacto sonoro causado pelo ruído combinado do tráfego aéreo, rodoviário e ferroviário em regiões circunvizinhas ao Polo Gerador de Viagens Aeroporto Internacional de Brasília.

\subsubsection{Objetivos Específicos}

- Elaborar cartas acústicas para os modais de transporte aéreo, rodoviário e ferroviário.

- Determinar os níveis de pressão sonora (NPS) gerados pelos tráfegos aéreo, rodoviário e ferroviário.

- Identificar as áreas vizinhas ao sítio aeroportuário mais afetadas pelo ruído dos tráfegos aéreo, rodoviário e ferroviário.

- Estimar o percentual de pessoas incomodadas pelos modais de transporte. 


\subsection{JUSTIFICATIVA}

O crescimento da utilização do transporte aéreo no Brasil foi de $81 \%$ entre os anos de 2005 e 2013, alcançando o nível de 487 mil novos voos no ano 2013 (ANAC, 2015). Devido a essa demanda, o governo brasileiro tem investido na melhoria da infraestrutura dos aeroportos. Nas grandes cidades, como São Paulo e Rio de Janeiro, esses números têm consolidado os aeroportos como principais PGV's existentes em áreas urbanas, que como tal tem atraído um grande número de viagens terrestres aos seus acessos, ocasionando em suas regiões circunvizinhas congestionamentos crescentes e a deterioração da qualidade de vida, além de alterações ambientais.

Especificamente esses congestionamentos tem ocorrido devido ao fato da maioria das viagens serem realizadas por automóveis ou ônibus até os aeroportos, principalmente quando estes se localizam no perímetro urbano. Com base em alguns estudos acerca do dimensionamento de transporte em regiões aeroportuárias (Coelho e Portugal, 2010; Monteiro e Goldner, 2011; RedePGV, 2014; Goldner et al., 2014), verifica-se que no Brasil, o modal rodoviário, exclusivamente, tem atendido às demandas de viagens nas regiões aeroportuárias. Em outros países, as viagens aos aeroportos, em muitos casos, podem ser realizadas por diferentes modais, incluindo além do automóvel e do ônibus, os trens e metrôs (Monteiro e Goldner, 2011).

Atualmente na literatura pesquisada no Brasil poucos estudos relacionam o aeroporto com PGV (Portugal, 2007 e Goldner et al., 2014), e não foram encontrados até o momento trabalhos que relacionem PGV aeroporto com ruído combinado entre os modais aéreo, rodoviário e ferroviário em sua região de influência. De acordo com Nguyen et al., (2012) para determinar a poluição sonora e tentar minimizar os seus efeitos sobre a saúde e o meio ambiente, deve-se avaliar a paisagem sonora na região de influência de um aeroporto pela combinação dos modais presentes na região.

Desta forma, a alteração na paisagem sonora na região aeroportuária possui potencial de provocar efeitos nocivos à saúde humana que contribui diretamente para o desenvolvimento de doenças como hipertensão, problemas cardíacos, psicológicos, emocionais, estresses e males associados aos distúrbios no sono (Babisch et al., 2009).

Assim, este estudo contribuirá para a discussão no Brasil, do ruído combinado entre esses modais de transporte, como indicação de ferramenta suporte à tomada de decisão na adoção 
de medidas mitigadoras que minimizem os efeitos nocivos dos transportes sobre a população e o meio ambiente.

\subsection{ESTRUTURA DA DISSERTAÇÃO}

A presente dissertação está estruturada em cinco capítulos, incluindo este introdutório. O segundo capítulo aborda a fundamentação teórica de Polo Gerador de Viagens, conceitos relacionados a som, ruído, métricas acústicas, legislação nacional referente ao monitoramento acústico e controle do ruído aeronáutico, rodoviário e ferroviário.

O terceiro capítulo determina a metodologia aplicada para definir o ruído combinado devido aos modais (aéreo, rodoviário e ferroviário) na região do AIB, assim como a determinação da população exposta ao ruído. Dessa forma o método utilizou modelagens e elaboração de cartas de ruído, as quais possibilitam a determinação das áreas das faixas de ruído e as populações expostas para cada uma das curvas.

O quarto capítulo apresenta a análise dos cenários acústicos (cartas de ruídos, populações expostas por faixa de ruído), e os resultados e discussões dos dados obtidos. Por fim, o quinto capítulo apresenta a conclusão deste trabalho, assim como a contribuição deste estudo sobre o tema "ruído combinado". A Figura 1.1 apresenta a estrutura adota para a realização desta dissertação:

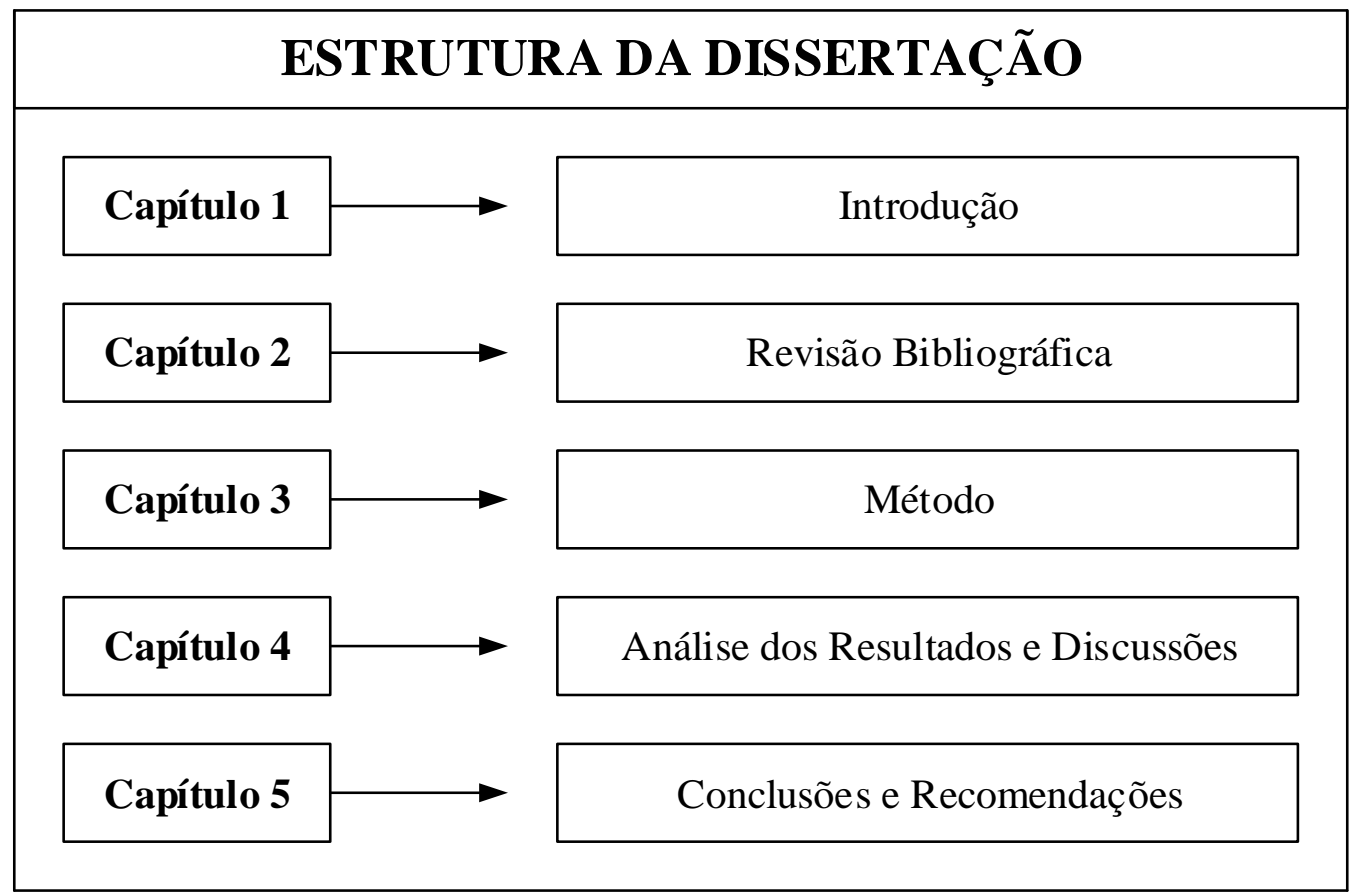

Figura 1.1: Estrutura da Dissertação 


\section{CAPÍTULO 2. REVISÃO BIBLIOGRÁFICA}

Para que sejam realizados estudos de "acústica ambiental" de uma região aeroportuária, inicialmente será abordado o conceito de "empreendimento aeroportuário", uma vez que tal conceito é colocado tradicionalmente em estudos de transporte onde o aeroporto é visto como Polo Gerador de Viagens. Tal conceituação é necessária para que a implantação de tal empreendimento seja avaliada no contexto dos múltiplos impactos gerados por ele.

Na descrição dos impactos gerados, como os impactos na acessibilidade e os impactos ambientais na região aeroportuária, a ênfase deste trabalho se dará no impacto acústico. Para tal são descritos em sequência os conceitos básicos sobre acústica, que é o ramo da física que estuda os fenômenos relacionados ao som e seus efeitos, ou seja, a produção, transmissão, armazenamento, percepção ou reprodução de som.

\subsection{POLOS GERADORES DE VIAGENS (PGV's)}

Em meio às diversas transformações que o ambiente urbano vem sofrendo, os impactos associados às atividades urbanas, principalmente aquelas consideradas Polos Geradores de Viagens (PGV's), têm penalizado significativamente a mobilidade nas cidades.

Os empreendimentos e atividades caracterizados como PGV's possuem grande poder de atratividade de viagens por diferentes modos de transporte, principalmente de automóveis. Produz impactos de intensidades distintas, repercutindo diferentemente no espaço e no tempo, requerendo abordagens também diferentes para a previsão e para o tratamento dos mesmos (Gonçalves et al., 2012).

Sendo assim, os PGVs, originalmente foram denominados Polos Geradores de Tráfego (PGT), sendo definido pala Rede PGV (2014) como locais ou instalações de distintas naturezas que têm em comum o desenvolvimento de atividades em um porte e escala capazes de exercer grande atratividade sobre a população, bem como produzir um contingente significativo de viagens, necessitando de grandes espaços para estacionamento, carga/descarga e embarque/desembarque, promovendo, consequentemente, potenciais impactos.

Em síntese, no primeiro momento, a conceituação dos PGV's destacava a interferência do tráfego no sistema viário e na circulação. No segundo, passou a considerar, também, a 
geração e atração de viagens de automóveis e, no terceiro, o conceito passa a incluir viagens nos demais modos (em especial as não motorizadas e as de transporte público) e abranger, ainda, os impactos sobre o uso e a ocupação do solo da área de influência, que pode alterar as características de centralidade de determinada área (Portugal, 2012). A Tabela 2.1 mostra a evolução do conceito de PGV:

Tabela 2.1: Principais Conceitos de PGV

\begin{tabular}{cl}
\hline Fonte & \multicolumn{1}{c}{ Conceito } \\
\hline & $\begin{array}{l}\text { Empreendimentos de grande porte que atraem ou produzem grande número de } \\
\text { viagens, causando reflexos negativos na circulação em seu entorno imediato, } \\
\text { podendo prejudicar a acessibilidade de uma região, ou agravar condições de }\end{array}$ \\
CET-SP & $\begin{array}{l}\text { segurança de veículos e pedestres, ou ainda edificações ou instalações que exercem } \\
\text { grande atratividade sobre a população, mediante a oferta de bens ou serviços, } \\
\text { gerando elevado número de viagens, com substanciais interferências no tráfego do } \\
\text { entorno e a necessidade de grandes espaços para estacionamento ou carga e } \\
\text { descarga. }\end{array}$ \\
\hline \multirow{2}{*}{$\begin{array}{l}\text { (1983) } \\
\text { (2001) }\end{array}$} & $\begin{array}{l}\text { Empreendimentos de grande porte que atraem ou produzem grande número de } \\
\text { viagens, causando reflexos negativos na circulação viária em seu entorno imediato } \\
\text { e, em alguns casos, prejudicando a acessibilidade da região, além de agravar as } \\
\text { condições de segurança de veículos e pedestres. }\end{array}$ \\
\hline Portugal e Goldner & $\begin{array}{l}\text { Locais ou instalações de distintas naturezas que desenvolvem atividades de porte e } \\
\text { escala capazes de produzir um contingente significativo de viagens. }\end{array}$ \\
\hline
\end{tabular}

Fonte: RedePGV, 2014.

No âmbito nacional, o planejamento urbano e de transportes tem dado ênfase à mobilidade urbana aplicada aos PGVs, por meio da Lei N॰ 12.587/2012. Em Brasília, a Lei Distrital 1.890 de 1998, conceitua PGV como "toda edificação onde são desenvolvidas atividades de oferta de bens ou serviços que geram elevada rotatividade de veículos e interferem no tráfego do entorno e estabelece o número mínimo de vagas de estacionamento ou garagem de veículos dentro dos limites do lote das edificações".

Desta forma, tais PGV's produzem diversos tipos de impactos no meio ambiente em que estão inseridos. Duas classificações de impactos gerados por PGVs diferenciam a qualidade deste impacto.

Em primeiro plano, impacto positivo, ao agregar valor e desenvolvimento à área influenciada. Impacto negativo, prejudicar o deslocamento de pessoas pelos diversos modos de transporte, comprometendo assim, a mobilidade e acessibilidade da área impactada, além do aumento da demanda de estacionamentos em sua área de influência.

O segundo tipo de classificação dos impactos é serem diretos ou derivados. Os impactos diretos impactam na circulação e no sistema viário, causados especificamente pelo empreendimento gerador de viagens. Já os impactos derivados são os demais impactos 
decorrentes da implantação e operação do empreendimento gerador de viagens, que se dão no ambiente urbano e são provenientes do próprio empreendimento ou das alterações provocadas pelo empreendimento (Kneib et al., 2006; Tavares, 2011).

Kneib (2004) afirma que os impactos decorrentes das instalações de PGV's não se limitam apenas ao sistema de transportes e circulação, mas também se projetam sobre a estrutura urbana do entorno, sobre o desenvolvimento econômico e também sobre a qualidade de vida da população em horizontes de curto, médio e longo prazo. A Tabela 2.2 (adiante) apresenta a partir do trabalho de Kneib uma proposta de sistematização dos impactos causados por PGVs.

Tabela 2.2: Impactos Causados pela Implantação de PGVs

\begin{tabular}{cl}
\hline Impactos & \multicolumn{1}{c}{ Descrição } \\
\hline & - Aumento do fluxo de veículos \\
& - Demanda por transporte público \\
Mobilidade & - Aumento do tempo de viagem \\
& - Congestionamentos \\
& - Conflito de tráfego \\
& - Estacionamento \\
& - Número de acidentes \\
\hline \multirow{4}{*}{ Socioeconômico } & - Alteração do valor do solo e dos imóveis \\
& - Níveis de emprego e renda \\
& - Fiscais \\
& - Custo de viagens \\
& - Uso de equipamentos urbanos e comunitários \\
\hline \multirow{2}{*}{ Uso do Solo } & - Alterações no uso e dos imóveis (atividades) \\
& - Alterações na ocupação do solo e densidade \\
\hline & - Paisagem urbana e patrimônio natural e cultural \\
& - Ecossistemas \\
& - Qualidade do Ar \\
Socioambiental & - Nível de ruído \\
& - Vibrações \\
& - Ventilação e iluminação
\end{tabular}

Fonte: RedePGV, 2011 (Adaptado por Tavares, 2011).

Assim, pode-se afirmar, nesta perspectiva, que os aeroportos são PGV's importantes no contexto urbano. Porém, pouco se estuda sobre este tema, até mesmo devido à complexidade e diversificação do comportamento do usuário em relação às viagens de acesso/egresso as regiões aeroportuárias. (Goldner e Goldner, 2006; Coelho, 2011; Coelho e Portugal, 2012; Goldner et al., 2014).

\subsection{CARACTERIZAÇÃO DO AEROPORTO COMO PGV}

A importância estratégica que, atualmente, um aeroporto tem no sistema regional, nacional e mundial, se traduz em grandes impactos territoriais. Por isso, torna-se importante prever as consequências que o funcionamento deste empreendimento tem, no mínimo, em seu 
entorno. No âmbito do planejamento e do ordenamento do território, o processo de avaliação é fundamental para prever comportamentos futuros de modo a tornarem-se estratégias e medidas mais adequadas para o território (Aniceto, 2010).

De acordo com o Institute of Transport Engineers-ITE (2008), um aeroporto comercial é considerado PGV quando sua capacidade gera 18,1 viagens diárias por empregado; 150,3 viagens diárias por voo, e 150,2 viagens diárias por aeronave. O ITE (2008) classifica ainda o porte das atividades em baixo (menos de 500 viagens veiculares na hora do pico), moderado (de 500 a 1000 viagens veiculares na hora do pico) e alto (acima de 1000 viagens veiculares na hora do pico). Os aeroportos internacionais têm como características serem classificados como de "porte de atividades alto", é o caso do aeroporto estudado neste trabalho.

Para a definição da área de estudo (aeroporto), são consideradas apenas influências relativas à geração/atração de viagens do empreendimento. Isto contribui para análise dos impactos nos sistemas viários e de circulação e, para o planejamento operacional do sistema. A classificação reflete o grau de atração de viagens e, consequentemente, o grau de impacto no sistema viário causado pelo empreendimento.

Outras variáveis tais como: acessibilidade, natureza e tamanho do empreendimento, densidade, características socioeconômicas da população, barreiras físicas, limitações de tempo, distância de viagem, poder de atração e competição do empreendimento, distância ao centro da cidade, são também utilizadas para o cálculo das áreas de influência primária, secundária e terciária (Kneib, 2004).

Na Tabela 2.3 Coelho (2011) relaciona os aeroportos, a partir da geração de viagens, com o horizonte de estudo e a sua área de abrangência:

Tabela 2.3: Geração de Viagens, Horizonte e Área de Abrangência

\begin{tabular}{|c|c|}
\hline Geração de Viagens & Horizonte \\
\hline $\begin{array}{l}\text { Geração acima de } 100 \\
\text { veículos/hora pico e inferior } \\
\text { a } 499 \text { viagens/hora pico. }\end{array}$ & $\begin{array}{l}\text { É o ano de abertura do empreendimento e a área de abrangência está } \\
\text { em torno de } 800 \text { metros. }\end{array}$ \\
\hline $\begin{array}{l}\text { Geração acima de } 500 \\
\text { veículo/hora pico e inferior a } \\
999 \text { viagens/hora pico }\end{array}$ & $\begin{array}{l}\text { Está entre o ano de abertura do empreendimento e cinco anos após a } \\
\text { sua inauguração e, a área de abrangência está entorno de } 1.600 \\
\text { metros. }\end{array}$ \\
\hline $\begin{array}{l}\text { Geração acima de } 1000 \\
\text { veículos/hora pico }\end{array}$ & $\begin{array}{l}\text { Está entre o ano de abertura do empreendimento e cinco anos após a } \\
\text { inauguração e, a área de abrangência está entorno de } 3.200 \text { metros. }\end{array}$ \\
\hline
\end{tabular}


Para os aeroportos de média e grande dimensão, a sua influência (área de abrangência) pode alcançar um raio de vinte quilômetros; enquanto para os maiores aeroportos, como os hubs, o impacto pode chegar a cerca de sessenta quilômetros. Em todos os casos, há uma área mais crítica de menor extensão, que abrange os principais corredores de acesso associado a rede estruturadora de transportes (Aniceto, 2010).

A questão do tráfego rodoviário nesta região não é só um problema de geração de viagens, e sim das consequências ambientais que podem ser sentidas pela implantação do aeroporto em sua área de influência. Com as novas características das cidades-aeroportos as movimentações destas regiões tendem a aumentar e como consequência impactar o sistema viário até mesmo nas regiões circunvizinhas, alterando a paisagem acústica do entorno dos aeroportos.

O crescimento de uma cidade e o aumento no número de veículos nas vias de acesso e adjacentes ao aeroporto reduz a confiabilidade do transporte aéreo (Alves e Strambi, 2011). Portanto, para um desempenho satisfatório da infraestrutura aeroportuária, é necessário um planejamento adequado dos acessos terrestres aos aeroportos por meio de transportes intermodais. Trata-se de um problema que necessita ser enfrentado pelo órgão gestor da cidade e pela própria administração do aeroporto.

\subsection{POLUIÇÃO SONORA}

Por meio do crescimento, do desenvolvimento urbano que ocorreu mais significativamente a partir do século $\mathrm{XX}$, obviamente, como consequência, surgiram fábricas, apareceram veículos automotores e a poluição sonora acompanha tais desenvolvimentos. Sendo assim, a "poluição sonora" pode ser considerada como qualquer onda sonora capaz de provocar desconforto, causando prejuízo à saúde humana.

A poluição sonora, assim como a poluição visual é considerada como uma forma mais "recente" de poluição porque está fortemente relacionada a grande concentração de pessoas, indústrias, veículos, meios de comunicação e outros ruidosos integrantes dos grandes centros urbanos. Bistafa (2011) conceitua "som" como sensação produzida no sistema auditivo, a partir das vibrações das partículas do ar que se propagam por meio de estruturas vibrantes. Cada som que compõe a paisagem sonora é importante para a interação do ser humano com o meio que o cerca, através da troca de informações. 
A onda de som transporta energia de um ponto ao outro do espaço, através das oscilações de vibrações, as quais se propagam em um meio elástico (líquido, gasoso ou sólido), sem que ocorra o transporte de matéria; já as suas dimensões físicas estão associadas à altura e intensidade. A altura, por meio da frequência, classifica os sons em graves ou agudos, e a intensidade caracteriza o som em forte ou fraco. $\mathrm{O}$ som forte está relacionado à maior amplitude, energia e pressão, já o som fraco à menor amplitude, energia e pressão.

Retomando a ideia de "poluição sonora", este termo é subjetivo, pois nem todo som é caracterizado como poluição sonora. Para que o som possa ser determinado como tal, ele necessita alterar a condição normal de audição em um ambiente, ou seja, tornar-se desagradável, de conotação negativa e sem harmonia, passando a ser denominado ruído. Esse entendimento depende de uma variedade de fatores físicos e não físicos (Paul, 2010).

Na vida urbana a poluição sonora é proveniente, principalmente da construção civil e dos tráfegos: rodoviário, aéreo e ferroviário. Atualmente é considerado um dos maiores agentes impactantes da vida moderna, merecendo destaque pela magnitude da população exposta, seja em atividades ocupacionais, escolares ou de lazer (Carvalho Jr. et al., 2010). O ruído pode ocasionar efeitos negativos no ser humano quando mascara uma informação, ocasionando dificuldades de comunicação ou entendimento, de direção e efeitos na saúde diretamente auditivos e não auditivos (Barbosa, 2011). O EEA, em 2010, define ruído como um som audível que causa distúrbios, disfunção ou danos à saúde.

Informações no nível físico do som, na forma de ondas sonoras, são captadas, processadas e codificadas em nível fisiológico pela orelha, e enviadas ao cérebro pelas fibras nervosas auditivas. No nível psíquico, o cérebro interpreta as informações recebidas e determina seu significado e importância. O sistema auditivo transforma sons em sensações psíquicas, o som é caracterizado por grandezas físicas, enquanto as sensações são caracterizadas por grandezas psicoacústicas. Para Bistafa, (2011), são grandezas físicas: o nível sonoro e a frequência, já as grandezas psicoacústicas são: a audibilidade e a tonalidade.

O ruído age sobre o organismo humano de várias maneiras. Uma delas é prejudicar não só o funcionamento do aparelho auditivo como o comprometimento da atividade física, e também a fisiológica e mental do indivíduo a ele exposto. Sabe-se que ruídos acima de 60 dB(A), são prejudiciais aos seres humanos, ocasionando extremo desconforto, proporcionando problemas de concentração e resultando em alterações fisiológicas (FIEP, 2011). Os efeitos 
não auditivos do ruído se manifestam na função cardiovascular (hipertensão, variações da pressão sanguínea e/ou dos batimentos cardíacos), provocando adicionalmente distúrbios respiratórios, perturbação e alteração na saúde física e mental, inclusive, quando diz respeito ao aprendizado de uma criança que, para ser adequado, principalmente no ensino básico, deve-se ter condições necessárias físicas, psicológicas e intelectuais.

Desta forma, as crianças em idade escolar, podem ser também afetadas pela exposição ao ruído, influenciando de forma negativa na leitura, na memorização, na comunicação e na atenção. Assim este ruído gera também inquietação, dificuldade de aprendizado, frustação, incômodo e distúrbio do sono. Essa ampla gama de efeitos faz com que o ruído seja considerado fator de "estresse" generalizado (WHO, 2011; Basner et al., 2013).

Esses efeitos não auditivos do ruído são classificados em fisiológicos e de desempenho. Os efeitos fisiológicos podem ser temporários ou permanentes. Os permanentes ocasionam loucura, distúrbios cardiovasculares e insônias. Já os efeitos temporários, em exposição ao ruído são: sobressaltos causados por elevados níveis de ruído, provocando tensões musculares, com intenção de ativar algumas proteções, reflexos respiratórios quando o ritmo da respiração se altera em resposta a elevados níveis de ruído, alterações no padrão dos batimentos cardíacos e alterações no diâmetro dos vasos sanguíneos, particularmente daqueles mais próximos da superfície da pele (Basner et al., 2013).

No período noturno, são apresentadas evidências dos danos do ruído na saúde por meio "perturbação do sono", com possível detrimento de eficiência durante o dia e até mesmo prejuízo à saúde em longo prazo. Em 2007, WHO publicou diretrizes do ruído para esse período, recomendando valores limites que devem ser respeitados, sendo recomendado uma exposição média anual noturna inferior a $40 \mathrm{~dB}(\mathrm{~A})$. A Tabela 2.4 indica os diferentes efeitos na saúde para a população exposta a diferentes NPS de ruído externo no período noturno para a métrica $\mathrm{L}_{n}$.

Para estes intervalos, os modais de transporte destacam-se como fontes de ruído, sendo o ruído das aeronaves considerado o que mais produz incômodo, devido à sua natureza intermitente (Jones, 2009). Já o tráfego de uma rodovia é caracterizado como quasecontínuos. Ambos os tipos de ruído apresentam, como resultado, a diminuição do tempo em que pessoas se encontram em sono profundo e também afetam as fases iniciais do sono (Ising et al., 2005). 
Tabela 2.4: Efeitos na Saúde da População para Diferentes Intervalos de NPS

\begin{tabular}{cl}
\hline$<30 \mathrm{~dB}(\mathrm{~A})$ & $\begin{array}{l}\text { Embora as sensibilidades individuais e as circunstâncias sejam diferentes, parece que } \\
\text { até este nível não são observados efeitos biológicos substanciais. }\end{array}$ \\
\hline & $\begin{array}{l}\text { Uma série de efeitos são observados: aumento nos movimentos do corpo, auto relatos } \\
\text { de distúrbios de sono e despertares. A intensidade do efeito depende da natureza da } \\
\text { fonte e do número de eventos. Os grupos mais vulneráveis (crianças, idosos e pessoas } \\
\text { com doenças crónicas) são mais suscetíveis. No entanto, mesmo nos piores casos, os } \\
\text { efeitos parecem modestos. }\end{array}$ \\
\hline $40-55 \mathrm{~dB}(\mathrm{~A})$ & $\begin{array}{l}\text { São observados efeitos adversos na saúde entre a população exposta. Os grupos } \\
\text { vulneráveis são severamente afetados. }\end{array}$ \\
\hline \multirow{2}{*}{$>55 \mathrm{~dB}(\mathrm{~A})$} & $\begin{array}{l}\text { A situação é considerada cada vez mais perigosa para a saúde pública. Os efeitos } \\
\text { adversos na saúde ocorrem com maior frequência e uma porção considerável da } \\
\text { população é perturbada durante o sono. }\end{array}$ \\
\hline
\end{tabular}

Fonte: Torbjörn, et al., 2009.

Os efeitos adversos sobre o sono tornaram-se uma das queixas mais comuns, apontadas por populações expostas ao ruído ambiente. A OMS estima 903.000 dias de vida são afetados e/ou perdidos devido a questões relacionadas com perturbações do sono, em cidades da Comunidade Europeia com menos de 50.000 habitantes (WHO, 2011).

Durante a exposição noturna, o ruído atua diretamente no sistema neurovegetativo nas horas de folga, no sono, afetando a saúde, o bem-estar e favorecendo o surgimento de doenças. A Figura 2.1 representa de forma esquemática a relação entre o número de pessoas afetadas em função da severidade dos efeitos provocados pela exposição ao ruído.

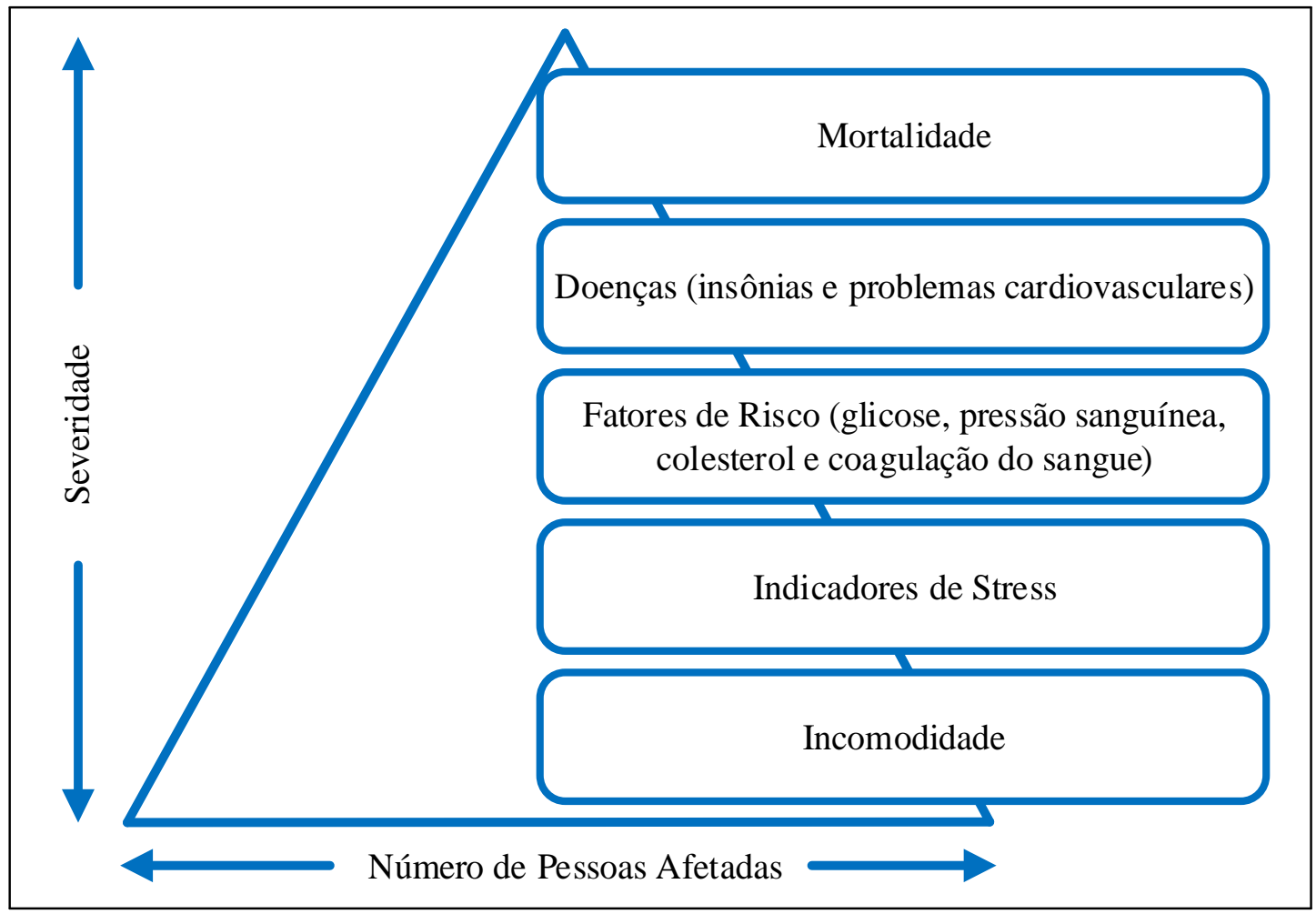

Figura 2.1: Relação entre Severidade dos Efeitos do Ruído e Número de Afetados Fonte: Babisch, 2002 (Adaptado). 
A severidade dos efeitos do ruído e suas principais reações no organismo são mostradas no esquema ilustrado pela Figura 2.2. Para um melhor entendimento desta figura, torna-se necessário aqui, diferenciar indicadores de estresse (por exemplo, hormônios relacionados ao estresse), fatores de risco (hipertensão e pressão sanguínea) e manifestação de doenças (como infarto do miocárdio). Os indicadores de estresse não são, diretamente, muito relevantes clinicamente, mas servem para avaliar os mecanismos do efeito. São como parâmetros reagindo em curto prazo, ou seja, aparece primeiro dentro da cadeia de reaçãoefeito. Já os fatores de risco são diretamente relevantes para a saúde, porque agem, na maioria dos casos, como variáveis contínuas (Babisch, 2002).

Ainda de acordo com esse autor, para uma estimação quantitativa do risco, dados de fontes externas têm que ser levados em conta. A manifestação de doenças é o passo seguinte onde o resultado do efeito para a saúde é imediato. Nesta etapa, há uma quantificação direta do risco com base em dados armazenados. Porém, desde que os dados disponíveis consistam somente de incidências discretas e raras, serão necessários levantamentos com grande número de amostras para se ter alguma evidência estatística do resultado.

O principal efeito da exposição ao ruído ambiente é a perturbação do sono durante a noite que, o qual é considerado um período propício para a consolidação de funções endócrinas, psicológicas, intelectuais, de memória, de aprendizagens entre outras. Ter um sono suficientemente tranquilo é condição necessária para a manutenção de um bom desempenho durante o dia e contribui para uma boa saúde (Banks e Dinges, 2007). 


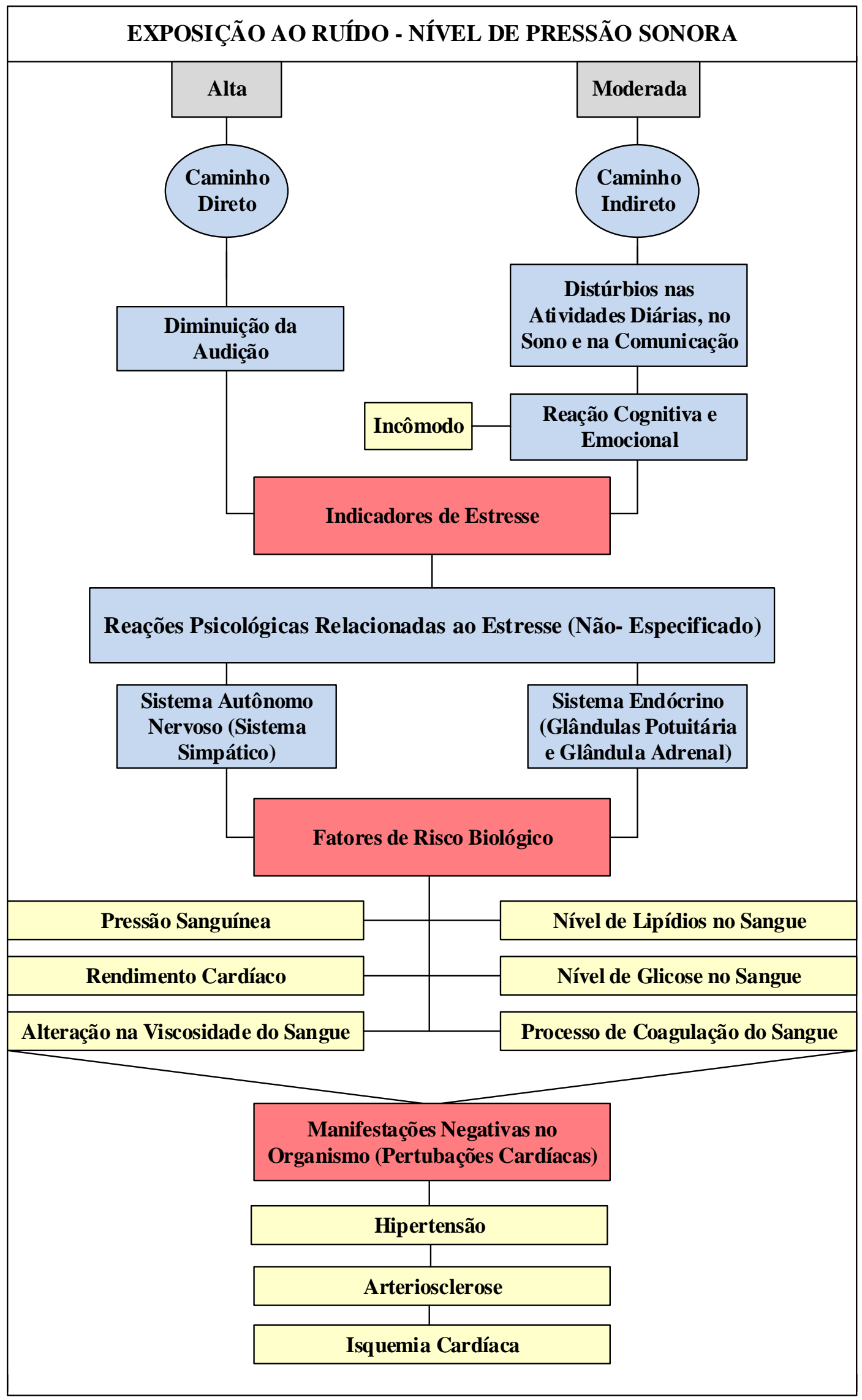

Figura 2.2: Esquema das Reações Produzidas pelo Ruído Fonte: Babisch, 2002 (Adaptado). 
Os principais efeitos do ruído na saúde e no bem estar podem ser observado na Tabela 2.5 , que monstra o impacto na qualidade do sono e desempenho das atividades cotidianas:

Tabela 2.5: Efeitos do Ruído na Saúde e Bem Estar

\begin{tabular}{|c|c|c|c|c|}
\hline Efeito & Dimensão & $\begin{array}{l}\text { Indicador } \\
\text { Acústico }\end{array}$ & $\begin{array}{c}\text { Limiar } \\
\text { dB(A) }\end{array}$ & $\begin{array}{c}\text { Persistência } \\
\text { Temporal }\end{array}$ \\
\hline Incômodo/Distúrbio & Psicossocial & $\mathrm{L}_{d e n}$ & 42 & Crônico \\
\hline $\begin{array}{c}\text { Distúrbios no Sono } \\
\text { Relatados } \\
\end{array}$ & $\begin{array}{l}\text { Qualidade de Vida, Saúde } \\
\text { Somática }\end{array}$ & $\mathrm{L}_{n}$ & 42 & Crônico \\
\hline Aprendizagem/Memória & Desempenho & $\mathrm{L}_{e q}$ & 50 & $\begin{array}{l}\text { Agudo/ } \\
\text { Crônico }\end{array}$ \\
\hline $\begin{array}{l}\text { Hormônios Relacionados } \\
\text { ao Estresse }\end{array}$ & Indicador de Estresse & $\mathrm{L}_{\max } / \mathrm{L}_{e q}$ & $\begin{array}{c}\text { Não } \\
\text { Disponível }\end{array}$ & $\begin{array}{l}\text { Agudo/ } \\
\text { Crônico }\end{array}$ \\
\hline Sono & $\begin{array}{c}\text { Estimulação/Despertar/Qualidade } \\
\text { no Sono }\end{array}$ & $\begin{array}{l}\mathrm{L}_{\max } \text { no } \\
\text { Interior }\end{array}$ & 32 & $\begin{array}{l}\text { Agudo/ } \\
\text { Crônico }\end{array}$ \\
\hline $\begin{array}{l}\text { Interrupções no Sono } \\
\text { Relatadas }\end{array}$ & Sono & $\begin{array}{l}\text { SEL no } \\
\text { Interior }\end{array}$ & 53 & Agudo \\
\hline Saúde Relatada & Bem-Estar/Saúde & $\mathrm{L}_{d e n}$ & 50 & Crônico \\
\hline Hipertensão & Saúde Fisiológica Somática & $\mathrm{L}_{d e n}$ & 50 & Crônico \\
\hline Doenças Cardíacas & Saúde Clínica & $\mathrm{L}_{d e n}$ & 60 & Crônico \\
\hline
\end{tabular}

Notas: $\mathrm{L}_{d e n}$ e $\mathrm{L}_{n}$ são definidos com nível de exposição no exterior/ $\mathrm{L}_{\max }$ pode ser tanto no interior como no exterior. Fonte: EEA, 2010; Bento, 2011 (Adaptado).

Assim, os efeitos do ruído na população que reside ou trabalha em regiões próximas a aeroportos estão sendo estudados em muitos países e, com isso, viu-se a necessidade de adotar medidas de proteção à saúde, visando reduzir ao máximo a intensidade da pressão sonora nestes ambientes (FIEP, 2011).

\subsection{NÍVEIS DE POTÊNCIA e INTENSIDADE}

A potência sonora está relacionada com a energia acústica total emitida pela fonte sonora por intervalo de tempo e sua unidade de medida é o Watt (W).

\subsubsection{Nível de Potência Sonora}

O Nível de Potência Sonora (NWS - Sound Power Level) é uma grandeza relativa que utiliza como valor de referência o nível mínimo $\mathrm{W}_{0}=10^{-12} \mathrm{~W}$ (1 picowatt), tais níveis podem ser expressos em decibel $(\mathrm{dB})$ pela expressão:

$$
\mathrm{NWS}=10 \times \log \frac{\mathrm{W}}{\mathrm{W}_{0}}
$$

A Intensidade Sonora pode ser entendida como o produto da pressão pela velocidade das partículas em um meio fluido e definida como o valor médio do fluxo de energia por unidade 
de área perpendicular à direção de propagação. Utiliza-se como unidade de medida o Watt por metro quadrado $\left(\mathrm{W} / \mathrm{m}^{2}\right)$.

\subsubsection{Nível de Intensidade Sonora (NIS)}

O Nível de Intensidade Sonora (NIS) é uma grandeza relativa que considera como referência a intensidade $\mathrm{I}_{0}=10^{-12} \mathrm{~W} / \mathrm{m}^{2}$ (corresponde no NPS a $0 \mathrm{~dB}$ ), sendo expresso em decibéis pela expressão:

$$
\mathrm{NIS}=10 \times \log \frac{\mathrm{I}}{\mathrm{I}_{0}}
$$

Para uma frequência fixa de $1000 \mathrm{~Hz}$, os níveis mínimo e máximo de intensidades sonoras percebidas pela audição humana são de $\mathrm{I}_{0}=10^{-12} \mathrm{~W} / \mathrm{m}^{2}$ para o limiar de audibilidade e $\mathrm{I}=1 \mathrm{~W} / \mathrm{m}^{2}$ para o limiar de dor, respectivamente. A intensidade sonora percebida pelo ouvido humano abrange 12 ordens de grandeza, para um tom de referência de $1000 \mathrm{~Hz}$. A pressão sonora é a variação média de pressão em relação à pressão atmosférica, sua unidade de medida é o Pascal $\left(\mathrm{N} / \mathrm{m}^{2}\right)$.

O NPS em um determinado ponto do espaço é uma grandeza relativa, tendo como referência o valor de $\mathrm{P}_{0}=20 \mathrm{mPa}\left(2 \times 10^{-5} \mathrm{~N} / \mathrm{m}^{2}\right)$, expresso em $\mathrm{dB}(\mathrm{A})$. O quadrado da média de variação da pressão sonora é proporcional à Intensidade Sonora:

$$
\frac{\mathrm{I}_{1}}{\mathrm{I}_{2}}=\frac{\mathrm{P}_{1}^{2}}{\mathrm{P}_{2}^{2}}
$$

Portanto, o nível de intensidade sonora está relacionado ao nível de pressão sonora pela expressão:

$$
\mathrm{NIS}=10 \times \log \frac{\mathrm{I}}{\mathrm{I}_{0}}=10 \times \log \frac{\mathrm{P}^{2}}{\mathrm{P}_{0}^{2}}=10 \times \log \left(\frac{\mathrm{P}}{\mathrm{P}_{0}}\right)^{2}=20 \times \log \frac{\mathrm{P}}{\mathrm{P}_{0}}
$$

Assim a relação entre o nível de intensidade sonora e o nível de pressão sonora é apresentado:

$$
\mathrm{NPS}=20 \times \log \frac{\mathrm{P}}{\mathrm{P}_{0}}
$$

$\mathrm{Na}$ realização dos estudos de ruído em comunidades, nos tráfegos (aéreo, rodoviário, ferroviário ou hidroviário) e em conforto acústico, é indicado a utilização da curva de 
ponderação “A”, por melhor representar a sensação de audição humana, além de ser utilizada nas normas técnicas em todo o mundo (Scherer, 2005).

\subsection{MÉTRICAS DE RUÍDO}

As métricas de ruído qualificam de que forma e em que nível a comunidade está exposta a determinado ruído, sendo, portando, uma ferramenta utilizada em estudos, avaliações de impactos e gerenciamentos de ruído. Existem diversas métricas de acordo com seus objetivos e natureza. A Tabela 2.6 resume as principais Métricas Acústicas utilizadas pela Comunidade Europeia e a OMS:

Tabela 2.6: Métricas Acústicas

\begin{tabular}{|c|c|c|}
\hline $\begin{array}{c}\text { Indicador } \\
\text { Acústico }\end{array}$ & Descrição & $\begin{array}{l}\text { Constante } \\
\text { de Tempo }\end{array}$ \\
\hline $\mathrm{L}_{\max }$ & $\begin{array}{l}\text { Nível máximo de pressão sonora que ocorre em determinado } \\
\text { intervalo, normalmente indicando a passagem de um veículo }\end{array}$ & $125 \mathrm{~ms}$ \\
\hline $\mathrm{L}_{d i a}\left(\mathrm{~L}_{d}\right)$ & $\begin{array}{l}\text { Nível de pressão sonora médio durante o dia. O dia pode ser } \\
\text { escolhido de modo que represente um período maior - por } \\
\text { exemplo, } \mathrm{L}_{d} \text { também ocorre no } \mathrm{L}_{d e n} \text { e nesse caso é utilizado o } \\
\text { nível médio anual para o dia. }\end{array}$ & 12 ou $16 \mathrm{~h}$ \\
\hline $\mathrm{L}_{\text {noite }}\left(\mathrm{L}_{n}\right)$ & $\begin{array}{l}\text { Nível de pressão sonora médio durante a noite. A noite pode ser } \\
\text { escolhido de modo que represente um período maior - por } \\
\text { exemplo, } \mathrm{L}_{\mathrm{n}} \text { também ocorre no } \mathrm{L}_{\text {den }} \text { e nesse caso é utilizado o } \\
\text { nível médio anual para noite. Este é o indicador acústico para o } \\
\text { período noturno utilizado pela CE (Diretiva } 2002 / 49 / \mathrm{CE} \text { ) e pela } \\
\text { OMS. }\end{array}$ & $8 \mathrm{~h}$ \\
\hline $\mathrm{L}_{24 h}$ & $\begin{array}{l}\text { Nível de pressão sonora médio ao longo de um dia interiro. Este } \\
\text { dia inteiro pode ser escolhido de modo que seja representativo } \\
\text { de um período mais longo. }\end{array}$ & $24 \mathrm{~h}$ \\
\hline $\operatorname{DNL}\left(\mathrm{L}_{d n}\right)$ & $\begin{array}{l}\text { Nível de pressão sonora médio ao longo de um dia inteiro. Este } \\
\text { dia inteiro pode ser escolhido de modo que seja representativo } \\
\text { de um período mais longo. Neste indicador acústico o período } \\
\text { da noite recebe uma penalização de } 10 \mathrm{~dB} \text {. }\end{array}$ & $24 \mathrm{~h}$ \\
\hline $\operatorname{DENL}\left(\mathrm{L}_{\mathrm{den}}\right)$ & $\begin{array}{l}\text { Nível de pressão sonora médio dias, entardeceres e noites em } \\
\text { um ano. Neste indicador acústico o período do entardecer é } \\
\text { penalizado em } 5 \mathrm{~dB} \text { e o período noturno recebe uma } \\
\text { penalização de } 10 \mathrm{~dB} \text {. Esse é o indicador acústico, para uso } \\
\text { geral de avaliação do ruído ambiental, adotado pela CE } \\
\text { (Diretiva 2002/49/CE). }\end{array}$ & Anual \\
\hline
\end{tabular}

Fonte: EEA, 2010 (Adaptado).

\subsubsection{Nível de Pressão Sonora Equivalente $\left(\mathrm{L}_{e q}\right)$}

Em relação à medição do nível de pressão sonora, em um único instante, não é suficiente a avaliação de um ambiente, sendo necessário a medição do Nível Equivalente de Pressão Sonora $\left(\mathrm{L}_{e q}\right)$, em unidades de $\mathrm{dB}(\mathrm{A})$. Este parâmetro é utilizado para analisar o ambiente pelas suas características sonoras e tem o mesmo potencial de lesão auditiva que um nível variável considerado no mesmo intervalo de tempo. Os critérios para lesão permitem essa 
equivalência até aproximadamente $115 \mathrm{~dB}(\mathrm{~A})$ de nível máximo, a partir do qual pode ocorrer lesão com exposição de curta duração (Calixto, 2002; Bistafa, 2011).

O L L $_{e}$ é definido como o índice contínuo de exposição a vários níveis de pressão durante um determinado período de tempo. Esse nível representa por um único valor a mesma energia sonora dos níveis flutuantes de ruído no intervalo considerado (Costa, 2011), matematicamente é descrito pela expressão:

$$
\mathrm{L}_{e q}=10 \times \log \left[\frac{1}{\mathrm{~T}} \int_{0}^{T}\left(\frac{P_{t}^{2}}{P_{0}^{2}}\right) \mathrm{dt}\right]
$$

A variável "T" representa a duração do período de referência (tempo total de medida); " $\mathrm{P}(\mathrm{t})$ " é a pressão sonora instantânea; " $\mathrm{P}_{0}$ " é pressão sonora de referência $\left(2 \times 10^{-5} \mathrm{~N} / \mathrm{m}^{2}\right)$. O L $\mathrm{L}_{e q}$ é representado por um valor constante que durante o mesmo tempo " $\mathrm{T}$ ", resulta na mesma energia acústica produzida pelos valores instantâneos variáveis de pressão sonora.

Muitas vezes o $\mathrm{L}_{e q}$ não é capaz de mostrar com clareza todas as características sonoras de um determinado ambiente quando esses têm um grau de variabilidade alto, como consequência, ferramentas estatísticas são usadas para análise dos cenários acústicos recorrendo-se a histogramas que identificam as porcentagens do tempo total durante a realização da medição em que o NPS se mantem num determinado nível.

Esses NPS são chamados de Níveis Estatísticos e determinam a fração do tempo total de medição, os mais utiliados são: $\mathrm{L}_{10}, \mathrm{~L}_{50}$ e L 90 . Esses Níveis Estatísticos representam os níveis excedidos durante, respectivamente $10 \%, 50 \%$ ou $90 \%$ do tempo de averição, sendo geralmente utilizados para avaliar ruídos de sistemas de transporte, tais como de tráfego rodoviário, ferroviário e aéreo (Calixto, 2001; Bistafa, 2011; Costa, 2011).

\subsection{2 $\mathrm{L}_{d n}$ (Day Night Level)}

$\mathrm{O} \mathrm{L}_{d n}$ é uma medida cumulativa da energia total do som, geralmente compilada em uma base anual e representa uma média logarítmica dos NPS no local durante um período de 24 horas, com uma penalização de $10 \mathrm{~dB}(\mathrm{~A})$, adicionado a todos os sons que ocorram durante o horário noturno (das $22 \mathrm{~h}$ às $7 \mathrm{~h}$ ). A pena de $10 \mathrm{~dB}(\mathrm{~A})$ representa a intromissão do ruído adicionado à noite, pois os níveis de som ambiente durante as horas noturnas são, tipicamente cerca de $10 \mathrm{~dB}(\mathrm{~A})$ inferiores aos níveis medidos durante o dia, e por causa da irritação associada a distúrbios do sono (FAA, 2011). 
De acordo com a NBR 11.415 (ABNT, 1990), o nível de incômodo sonoro medido pelo método $\mathrm{L}_{d n}$ é determinado pelo $\mathrm{L}_{e q}$ para $24 \mathrm{~h}$, adicionando $10 \mathrm{~dB}(\mathrm{~A})$ a todos os níveis medidos. É definido da seguinte forma:

$$
\mathrm{L}_{d n}=10 \times \log \left[\frac{1}{24}\left(15 \times 10^{\frac{\mathrm{L}_{\mathrm{d}}}{10}}+9 \times 10^{\frac{\mathrm{L}+10}{10}}\right)\right]
$$

Nessa equação o número 24 corresponde às horas medidas, 15 ao período diurno e 9 ao noturno.

\subsection{3 $\mathrm{L}_{\text {eq, den }}$ (Indicador do Nível de Pressão Sonora dia-entardecer-noite)}

A Diretiva Europeia 2002/49/EC indica os parâmetros L $_{\text {Aeq,den }}$ (indicador do NPS diaentardecer-noite) e $\mathrm{L}_{\text {Aeq,noite }}$ (indicador do NPS noturno) como indicadores de longo prazo

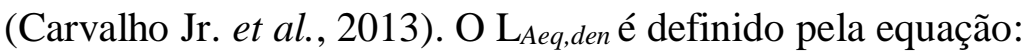

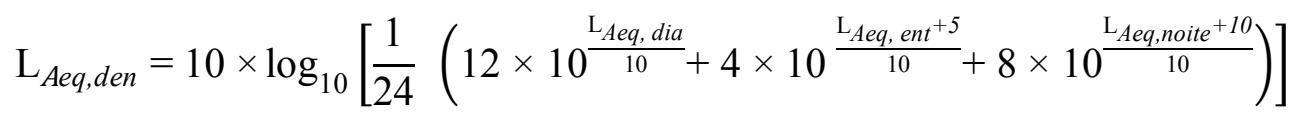

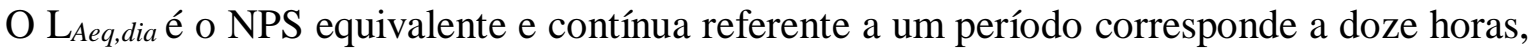
avaliado entre $7 \mathrm{~h}$ e $19 \mathrm{~h}$ (dia), medido com o filtro de frequências na ponderação A; $\mathrm{L}_{\text {Aeq,ent }}$ é o NPS equivalente e contínua referente a um período corresponde quatro horas, avaliado entre $19 \mathrm{~h}$ e $23 \mathrm{~h}$ (entardecer), medido com o filtro de frequências na ponderação " $\mathrm{A}$ "; $\mathrm{L}_{\text {Aeq, noite }}$ é o NPS equivalente e contínua referente a um período corresponde a oito horas avaliado entre $23 \mathrm{~h}$ e $7 \mathrm{~h}$, medido com o filtro de frequências na ponderação "A" (Costa, 2011).

Essa equação mostra que o indicador $\mathrm{L}_{\text {Aeq,den }}$ representa o NPS médio nas $24 \mathrm{~h}$ do dia, com a aplicação de uma ponderação diferenciada para os ruídos emitidos durante o período do anoitecer/entardecer (correção $+5 \mathrm{~dB}(\mathrm{~A})$ ) e da noite (correção + $10 \mathrm{~dB}(\mathrm{~A})$ ).

Para estudos ou pesquisas que exigem medições longas com duração de dias ou até meses, os NPS durante o dia podem ser divididos em classes ou períodos, que são conhecidos como indicadores $\mathrm{L}_{\text {Aeq,dia, }} \mathrm{L}_{\text {Aeq,ent, }} \mathrm{L}_{\text {Aeq,noite }}$ e $\mathrm{L}_{\text {Aeq,den. }}$

\subsection{RUÍDO DEVIDO AOS MODAIS DE TRANSPORTE}

O ruído que as aeronaves produzem, aeronáutico, são devido as decolagens/aterrizagens, taxiamentos, circulações e testes de motores. Podem ser provocado pelas aeronaves tanto em operações no ar quanto no solo. As principais fontes que geram ruído em uma aeronave em 
operação derivam do funcionamento dos motores e do deslocamento do ar em altas velocidades pela estrutura da aeronave (Carvalho Jr. e Garavelli, 2010).

De acordo com Barbosa (2011), o ruído aeronáutico é caracterizado por elevados NPS, principalmente em baixas frequências, sendo uma das principais causas de incômodo para os indivíduos que residem ou transitam próximo de aeroportos comerciais e militares. Isso ocorre porque afeta principalmente as zonas próximas às trajetórias de pouso, decolagem e voos de baixa altitude.

Nas últimas décadas, com o intuito de reduzir a emissão dos níveis de ruído, os motores dos aviões e suas estruturas tem passado por evoluções tecnológicas, até mesmo para obter as certificações das aeronaves, as fabricantes tem que diminuir os limites de ruído externos (Bonatto, 2013). Contudo, mesmo com essas melhorias, o ruído aeroportuário tem aumentado, devido a crescente movimentação de aeronaves (Rocha e Slama, 2008).

Vale destacar também que os efeitos adversos do ruído aeronáutico sobre as populações vizinhas aos aeroportos são de natureza não auditiva, podendo ser imediato ou cumulativo. Dentre tais efeitos, destacam-se, entre outros, três principais: interferência na comunicação pela fala, interferência no sono e incômodo sonoro (Rocha, 2009).

Já o ruído do tráfego rodoviário se tornou o principal incômodo sonoro em ambientes urbanos e o seu gerenciamento, tarefa que é desafiante para os administradores ambientais e planejadores urbanos (Li et al., 2002). Este ruído é o resultado da combinação do ruído gerado por veículos em seus deslocamentos pelas vias (Costa, 2011). Assim, este som indesejável pode apresentar dois componentes: um, devido à linha principal de tráfego de veículos, comportando-se como uma fonte linear e o ruído gerado por cada veículo, assemelhando-se a uma fonte pontual (OUIS, 2001). Existem estudos que analisam o nível de incômodo provocado por cada fonte específica no meio urbano, e o rodoviário está entre as que mais causam desconforto.

O ruído gerado pelos veículos depende de fatores como: tipo e classe do veículo, condições mecânicas de funcionamento, modo de operação, condições da superfície de rolamento, pavimento e pneus. Vários estudos já demonstraram que, em termos de emissão de ruído, os carros de passeio, apesar de mais numerosos, são mais silenciosos. Depois destes se encontram os ônibus e os caminhões de até 3,5 t, seguidos das motocicletas. Por último, estão os caminhões mais pesados, com mais de 3,5 t (Costa, 2011). 
Ao analisar o meio urbano, o ruído de tráfego veicular é considerado o mais comum e é decorrente das instabilidades no trânsito, ocasionadas pelas acelerações e desacelerações, devido às condições dos tráfegos, bem como as condições das estradas. Segundo Ouis (2001), estudos sobre o tráfego veicular urbano têm mostrado que as acelerações repentinas são responsáveis pelos picos de ruído, os quais podem ser vistos no histórico temporal típico do ruído de tráfego em centros urbanos.

Quanto ao ruído do tráfego ferroviário, este é gerado e irradiado lateralmente em relação a linha férrea, que, se soma ao ruído existente dentro das próprias composições. Neste ruído, a passagem de um comboio tem uma evolução no tempo distinta de outro tipo de ruído, por se encontrar bem situada no espaço (Kohler et al., 2012). Este ruído é proveniente da contribuição de diferentes fontes sonoras: vibração da carroceria do comboio, ruído do motor (motor a diesel ou elétrico), ruído de rolamento originado pela interação roda-carril, ruído aerodinâmico e vibração da carroceria. A dinâmica do sistema composto determina os níveis de ruído emitido, em que os mecanismos de transmissão por via aérea e por via estrutural são responsáveis pela radiação e propagação de estímulos sonoros (Alarcão e Coelho, 2008).

Nos grandes centros, para que se possa melhorar a mobilidade e acessibilidade nas regiões centrais, é possível pensar em uma proposta de implantação de Veículo Leve sobre Trilhos (VLT). Estes são pequenos trens urbanos, normalmente movidos a eletricidade, são equivalentes a bondes modernos, e devido às suas características (leveza, conforto, rapidez e segurança; minimização dos impactos ambientais), eles têm se tornado cada vez mais uma alternativa de transporte nas grandes cidades. O seu custo de construção é mais em conta que o do metrô, produz menos ruído e possui maior flexibilidade em curvas apertadas. Além disso, seu tamanho permite que a estrutura de trilhos se encaixe no meio urbano, permitindo grande flexibilidade para os usuários. Eles podem circular em vias próprias isoladas ou dividindo o tráfego nas ruas com os ônibus e automóveis, sendo considerado também, uma boa alternativa na solução de problemas, tais como congestionamentos e ligação entre as regiões de uma cidade (Albuquerque, 2011; Maroja et al., 2013).

Os modernos VLT's estão em sua quarta geração e são $10 \mathrm{~dB}(\mathrm{~A})$ mais silenciosos que os da primeira geração (1990-2000). O desenvolvimento tecnológico atual permite reduzir a níveis mais aceitáveis os ruídos e vibrações provenientes dos motores elétricos e demais maquinários dos trens, como sistema de ar condicionado e freios, bem como do arrasto aerodinâmico (Maroja et al., 2014). 
Um estudo realizado na cidade de Denver nos Estados Unidos entre 1992 e 2008, comprovou por meio de uma avaliação espacial do tráfego nas rodovias próximas aos três corredores de VLT, que houve uma redução na taxa de aumento do tráfego rodoviário dentro da sua zona de influência, em comparação às rodovias fora da zona de influência (Bhattacharjee e Goetz, 2012 apud Maroja et al., 2013).

Já o trabalho de Mamede e Alves (2009), relata que o Aeroporto de Zurique na Suíça, fez grande investimento em acesso ferroviário, esperando que por volta de $60 \%$ optassem pela utilização deste modal. Porém, atualmente, em torno de $60 \%$ do acesso é feito pelo modal rodoviário, este fato reduziu o otimismo em torno da utilização do modal ferroviário para os acessos aos aeroportos. Quando o Aeroporto Londres Heathrow na Inglaterra criou sua via de acesso ferroviário foi estimado que em torno de $30 \%$ dos passageiros acessariam o aeroporto por este modal. Depois de pronto, foi realizado estudos estatísticos que comprovaram apenas $20 \%$ dos acessos a esta região aeroportuária estarem sendo realizados por meio do modal ferroviário.

\subsection{RUÍDO COMBINADO}

O ruído ambiental proporciona um problema na saúde crescente e bem reconhecido. No entanto, em muitos casos, a população está exposta a mais de uma fonte de ruído, o chamado ruído combinado, que é a resultante dos ruídos entre dois ou mais modais de transporte que se movimentam especialmente nas áreas urbanas das cidades densamente povoadas. Os efeitos da exposição a combinação destas fontes ainda são limitados e pouco se sabe sobre a relação entre ruído combinado e incômodo (Öhrström et al., 2007).

A percepção ao ruído combinado não depende apenas da sua intensidade, mas também de seus componentes, características da fonte emissora, regularidade, previsibilidade dos intervalos do evento e do comportamento das pessoas. Em relação aos modais de transporte que podem afetar na contrariedade as essas fontes. Têm-se determinado que o ruído das aeronaves é mais irritante e perturba mais o sono do que o ruído do tráfego rodoviário, que, por sua vez, é mais importuno do que o ruído ferroviário, além destes ruídos ao se somarem estarem modificando suas características, podendo assim, gerar um incômodo maior ou menor em relação ao ruído proveniente de uma única fonte (Miedema e Voz, 2004; Lam et al., 2008; Basner et al., 2011; Nguyen et al, 2012;). 
A Figura 2.3 ilustra a comparação entre as curvas dos modais (aéreo, rodoviário e ferroviário) com a porcentagem de indivíduos muito incomodados.

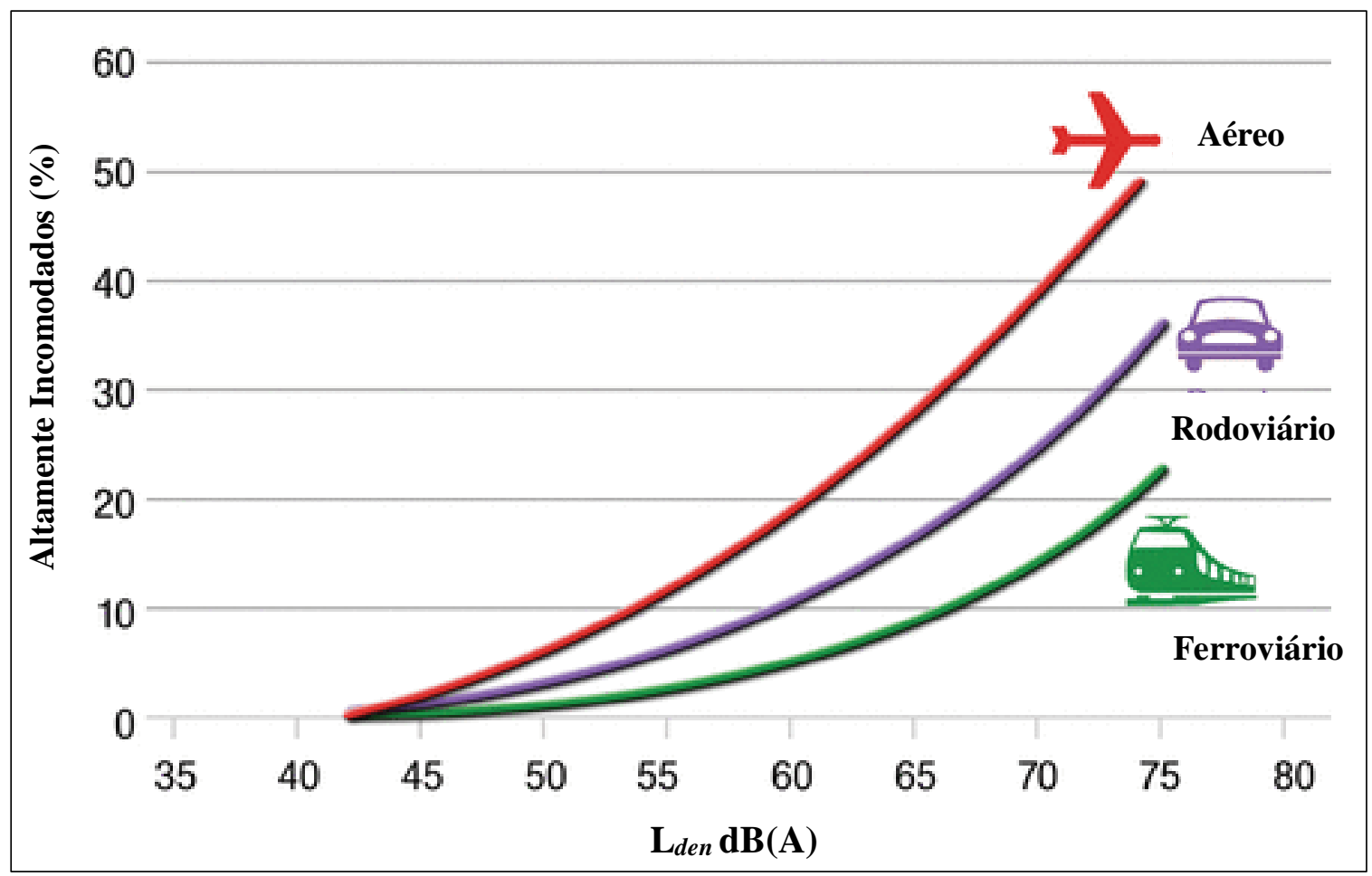

Figura 2.3: Curvas Resultantes de Ruído

Fonte: Miedema e Oudcshoorn, 2001 apud Munzel et al., 2014 (Adaptado).

Neste sentido, a comunidade científica ainda carece de uma melhor compreensão sobre o ruído combinado. Sua compreensão adequada é, no entanto, importante para fins de regulamentação. Portanto, na prática, avalia-se apenas o ruído proveniente de uma única fonte (Brink e Lercher, 2007). É importante determinar os diferentes fatores que afetam a população em um ambiente acústico influenciado pelo ruído combinado, para assim, minimizar o incômodo a população exposta e assim gerenciar o ambiente acústico urbano (Lam et al., 2008).

$\mathrm{Na}$ tentativa de compreender os efeitos do ruído combinado em comunidades expostas, é possível adotar modelos matemáticos para tentar prever este Incômodo sentido pela população. O estudo inicial de Taylor, realizado em 1982 na região do Aeroporto Internacional de Toronto, o de Nguyen, realizado em 2012 nas proximidades dos aeroportos do Vietnã e o do Elmehdi, realizado em 2014 na região do Aeroporto Internacional de Dubai, além de outros autores, testam vários modelos de previsão para o Incômodo devido ao ruído combinado. Suas descobertas relatam a importância das diferenças entre as fontes de nível 
absoluto e os resultados estimados devido a diferença entre os modelos utilizados (Taylor, 1982; Nguyen et al, 2012; Elmehdi, 2014).

No que se refere a estudos sobre "ruído combinado", existe um método padronizado ou comumente aceito para avaliar o ruído proveniente de fontes combinadas de ruído, embora vários outros modelos com determinadas especificações têm sido propostos como: modelo somatória de energia, modelo de efeitos independentes, modelo da diferença de energia, modelo resposta somatório, modelo soma e inibição, modelo aborrecimento equivalente, modelo fonte dominante, entre outros (Taylor, 1982; Lam et al., 2009; Nguyen et al., 2012; Elmehdi, 2014).

O modelo da somatória de energia tem sido mais aceito para o estudo do ruído combinado, apesar deste modelo não utilizar os níveis de ruído absoluto das fontes que contribuem para o nível do ruído total. O modelo somatório de energia baseia-se no pressuposto de que o incômodo provocado por fontes de ruído combinados podem ser previstos pela energia total (Taylor, 1982; Öhrström et al, 2007; Nguyen et al, 2012; Elmehdi, 2014).

O modelo Somatório de Energia é expresso pela Equação:

$$
A=f\left(L_{T}\right)
$$

Onde "A" é a resposta ao incômodo para as fontes combinadas e " $\mathrm{L}_{T}$ " o nível de ruído total calculado a partir da somatória da energia das fontes separadas " $\mathrm{L}_{e q}$ ' $\mathrm{s}$ ".

Sendo assim, se $\mathrm{L}_{1}$ e $\mathrm{L}_{2}$ são duas fontes sonoras diferentes e separadas, tem-se:

$$
\mathrm{L}_{1}=10 \times \log \frac{I_{1}}{I_{0}} \quad \mathrm{~L}_{2}=10 \times \log \frac{I_{2}}{I_{0}}
$$

A somatória das duas fontes $\mathrm{L}_{1}$ e $\mathrm{L}_{2}$ é descrita pela somatória de logaritmos, realizada a seguir.

$$
\mathrm{L}_{\mathrm{T}}=10 \times \log \frac{I_{1}+I_{2}}{I_{0}}
$$

Sendo assim, o nível de ruído é determinado pela somatória entre as fontes sonoras, sendo descrito a Equação 13. 


$$
\mathrm{L}_{\mathrm{T}}=10 \times \log \sum_{\mathrm{i}=1}^{\mathrm{n}} 10^{\mathrm{L}_{\mathrm{i}}} / 10
$$

"L" é a fonte separada de "Leq". Este modelo baseia-se na hipótese de que o contínuo " $\mathrm{L}_{e q}$ ", definido durante um período de tempo especificado, é um índice válido do potencial de indução do ruído ao incomodo a uma comunidade. Baseia-se no pressuposto de que o incomodo provocado por fontes de ruído combinados podem ser previstos pela energia total.

\subsection{LEGISLAÇÃO E NORMAS}

Os países desenvolvidos têm suas próprias normas e recomendações sobre níveis de ruído para diversos tipos de ambientes, as organizações internacionais International Organization for Standardization (ISO) e International Electrotechnical Commission (IEC) estabeleceram normatizações, metodologias e procedimentos para análise e avaliação do ruído e essas normas podem ser aplicadas diretamente ou como referência às normas nacionais. No Brasil temos como referência para a avaliação do ruído ambiental a norma NBR 10.151 a qual é referida pela resolução CONAMA nº 001 de 08 de março de 1990.

Para a Aviação Civil foi regulamentado em 2013 o Regulamento Brasileiro da Aviação Civil (RBAC) no 161. Neste estudo, não será levando em conta essa regulação para o ruído aéreo, pois a métrica utilizada é diferente da proposta pela NBR 10.151 e NBR 13.368 para a avaliação do ruído em áreas habitadas.

\subsubsection{Resolução CONAMA Nº 01/1990}

O Conselho Nacional do Meio Ambiente (CONAMA) considera que os problemas dos níveis excessivos de ruído estão inclusos no Controle da Poluição de Meio Ambiente e discorre sobre a degradação da qualidade de vida, acarretada pela poluição, que está continuamente sendo agravada nos grandes centros urbanos.

A resolução dispõe sobre a emissão de ruídos, em decorrência de qualquer atividade industrial, comercial, social ou recreativa, inclusive as de propaganda política. Para a resolução ter efeito de aplicabilidade, as medições deverão ser efetuadas conforme a NBR 10.151/2000, que fixa os níveis de ruído superiores que são prejudiciais à saúde e estabelece condições exigíveis para avaliação da aceitabilidade do ruído em áreas habitadas, visando o conforto das comunidades, além de especificar um método para a medição de ruído. $\mathrm{O}$ 
método de avaliação envolve as medições do nível de pressão sonora equivalente $\left(\mathrm{L}_{e q}\right)$, ponderados em $\mathrm{dB}(\mathrm{A})$, e são mostrados na Tabela 2.7 .

\subsubsection{NBR 10.151}

A NBR 10.151/2000 é a norma utilizada para avaliação do ruído em áreas habitadas visando o conforto da comunidade. Esta norma fixa as condições exigíveis para avaliação da aceitabilidade do ruído em comunidades independentemente da existência de reclamações. Fixando os níveis de ruído superiores que são prejudiciais à saúde e estabelece condições exigíveis para a avaliação da aceitabilidade do ruído em áreas habitadas, visando o conforto das comunidades e especifica um método para a medição de ruído.

O método de avaliação envolve as medições do $\mathrm{L}_{e q}$, ponderados em $\mathrm{dB}(\mathrm{A})$, estabelece níveis de ruídos em seis áreas distintas, sendo cinco áreas urbanas e uma área rural. A Tabela 2.7 apresenta os níveis de Critério de Avaliação (NCA) de ruído para Ambientes Externos, em $\mathrm{dB}(\mathrm{A})$ nos períodos diurno e noturno.

Tabela 2.7: NCA Para Ambientes Externos, em dB(A)

\begin{tabular}{lcc}
\hline \multicolumn{1}{c}{ Tipos de Áreas } & Diurno & Noturno \\
\hline Áreas de sítios e fazendas & 40 & 35 \\
\hline Área estritamente residencial urbana ou de hospitais ou de escolas & 50 & 45 \\
\hline Área mista, predominantemente residencial & 55 & 50 \\
\hline Área mista, com vocação comercial e administrativa & 60 & 55 \\
\hline Área mista, com vocação recreacional & 65 & 55 \\
\hline Área predominantemente industrial & 70 & 60 \\
\hline
\end{tabular}

Fonte: Associação Brasileira de Normas Técnicas, 2000.

No Distrito Federal, a lei $N^{\circ}$ 4.092/ 2008 dispõe sobre o controle da poluição sonora e os limites máximos de intensidade da emissão de sons e ruídos resultantes de atividades urbanas e rurais. Esta lei determina que os níveis máximos de pressão sonora permitidos em ambientes externos e internos e os métodos utilizados para sua medição e avaliação são os estabelecidos pela ABNT NBR 10.151 e pela ABNT NBR 10.152. Atualmente, a NBR 10.151 (ABNT, 2000) encontra-se em processo de reformulação.

\subsubsection{NBR 13.368}

A NBR 13.368/1995 prescreve o método a ser utilizado para monitorar o ruído aéreo, verificando se há existência do impacto sonoro devido ao modal aéreo. O valor encontrado para o NPS $\left(\mathrm{L}_{e q}\right)$ deve ser comparado com os valores da Tabela 2.8, visando à avaliação do incômodo gerado pela movimentação de aeronaves. 
Tabela 2.8: Avaliação do Incômodo Gerado Pelas Operações Aeroportuárias

\begin{tabular}{lcc}
\hline \multicolumn{1}{c}{ Reclamações Esperadas } & Diurno & Noturno \\
\hline Sem reação ou queixa esporádicas & $\mathrm{L}_{\mathrm{eq}}<65$ & $\mathrm{~L}_{\mathrm{eq}}<55$ \\
\hline Queixas generalizadas - Possíveis ações da comunidade & $75>\mathrm{L}_{\mathrm{eq}} 65$ & $65>\mathrm{L}_{\mathrm{eq}}>55$ \\
\hline Ações comunitárias vigorosas & $\mathrm{L}_{\mathrm{eq}}>75$ & $\mathrm{~L}_{\mathrm{eq}}>65$ \\
\hline
\end{tabular}

Fonte: NBR 13.368/1995 (Adaptado).

\subsubsection{Organização Mundial de Saúde}

A Organização Mundial de Saúde (OMS) recomenda que em áreas residenciais o NPS utilizando a métrica $\mathrm{L}_{e q}$, não ultrapasse os $55 \mathrm{~dB}(\mathrm{~A})$. No caso de existirem áreas residências às margens de rodovias de tráfego intenso, faz-se necessário uma redução do NPS, para que se adeque a recomendação.

De acordo com o órgão, NPS de $50 \mathrm{~dB}(\mathrm{~A})$ podem incomodar, mas o organismo se adapta facilmente a ele. A partir de $55 \mathrm{~dB}(\mathrm{~A})$ pode haver a ocorrência de estresse leve, acompanhado de desconforto. O NPS de $70 \mathrm{~dB}(\mathrm{~A})$ é tido como o nível de desgaste do organismo, aumentando os riscos à saúde. A $80 \mathrm{~dB}(\mathrm{~A})$ ocorre a liberação de endorfinas, causando uma sensação de prazer momentâneo, e a $100 \mathrm{~dB}(\mathrm{~A})$ pode haver perda da audição permanente.

\subsubsection{Diretiva Europeia 2002/49/CE}

A Comunidade Europeia, a Diretiva 2002/49/CE, recomenda, no Anexo II, aos Estados Membros, que não dispõem de métodos de cálculo nacionais ou que pretendem mudar o método de cálculo, a utilização das métricas $\mathrm{L}_{d e n}$ e $\mathrm{L}_{n}$ para o ruído gerado pelo setor industrial, pelas aeronaves e pelo tráfego rodoviário e ferroviário. Em Portugal, a partir da Diretiva 2002,49/CE, o Regulamento Geral do Ruído (RGR, 2007) estabelece os limites máximos de ruído para dois tipos de ocupação do solo: uma para zona sensíveis e outra para zonas mistas, como é apresentado na Tabela 2.9:

Tabela 2.9: Valores Limites de Exposição

\begin{tabular}{lccc}
\hline \multicolumn{1}{c}{ Tipo de Zona } & L den $_{\text {dB(A) }}$ & L $\mathbf{n} \mathbf{d B}(\mathbf{A})$ \\
\hline Zona Mista & $\leq 65$ & $\leq 55$ \\
\hline Zona Sensível & $\leq 55$ & $\leq 45$ \\
\hline $\begin{array}{l}\text { Zona Sensível com uma Grande Infraestrutura de } \\
\text { Transporte em Exploração na Proximidade }\end{array}$ & $\leq 65$ & $\leq 55$ \\
\hline $\begin{array}{l}\text { Zona Sensível com uma Grande Infraestrutura de } \\
\text { Transporte Aérea para a Proximidade }\end{array}$ & $\leq 65$ & $\leq 55$ \\
\hline $\begin{array}{l}\text { Zona Sensível com uma Grande Infraestrutura de } \\
\text { Transporte que não o Aéreo Projetada para a Proximidade }\end{array}$ & $\leq 60$ & $\leq 50$ \\
\hline Zona não Classificada & $\leq 63$ & $\leq 53$ \\
\hline
\end{tabular}

Fonte: RGR (2007). 
A zona sensível é destinada ao uso habitacional, escolas, hospitais e espaços de lazer, pequenos comércios (cafés, restaurantes, papelarias e outros sem funcionamento no período noturno), tendo como limites máximos $55 \mathrm{~dB}(\mathrm{~A})$ para o indicador $\mathrm{L}_{d e n}$ e $45 \mathrm{~dB}(\mathrm{~A})$ para o indicador $\mathrm{L}_{n}$. Já a zona mista é destinada aos outros usos existentes e previstos no plano municipal de ordenamento territorial, possuindo limites máximos de $65 \mathrm{~dB}(\mathrm{~A})$ para o indicador $\mathrm{L}_{d e n}$ e $55 \mathrm{~dB}(\mathrm{~A})$ para o indicador $\mathrm{L}_{n}$.

\subsection{CARTAS ACÚSTICAS}

Em se tratando de cartas acústicas (também chamadas cartas de ruído, mapas acústicos ou mapas de ruído), é possível a realização de previsões dos cenários acústicos futuros de uma região, ou representar a situação atual. Ela se dá pelo aprimoramento das tecnologias em informação, o desenvolvimento de softwares de modelagem e da ampla disponibilidade de dados topográficos digitais. Tal previsão ocorre por parâmetros que podem ser estimados a partir de modelos matemáticos.

Há décadas, a representação do ruído em uma determinada área consistia em medições de longa duração, as quais apresentavam resultados estáticos de situações detectadas. Isto impossibilitava uma previsão confiável dos níveis de ruído onde a região pesquisada estaria exposta. Atualmente estão disponíveis uma gama de softwares capazes de modelar e prever cenários acústicos de uma determinada área de interesse, onde os resultados são apresentados sob a forma de cartas (acústicas) que contém linhas isofônicas e/ou manchas coloridas e que representam os diferentes níveis de intensidade sonora. Essa ferramenta é designada cartas de ruídos (Almeida et al., 2004).

Neste sentido, a carta acústica é uma representação gráfica dos níveis sonoros na região, para um intervalo de tempo de referência. Estas podem ser utilizadas para a avaliação dos níveis sonoros, a longo prazo ou a curto prazo. Podem, também, ser usadas para a pré-avaliação dos planos de ação e medidas de controle de ruído, ou para a estimativa de exposição da população ao ruído. São muito úteis para o planejamento urbano acústico, para a avaliação do impacto ambiental de qualquer atividade anterior à sua execução. Torna-se uma ferramenta útil para apoio a decisões sobre planejamento e ordenamento do território, sendo fundamental para estruturação dos centros urbanos. Tal ferramenta fornece subsídios para o correto uso e ocupação do solo, reduzindo os usos conflitantes e prevenindo problemas ligados à poluição sonora (Costa, 2011). 
Segundo, Pinto et al., (2004), a carta acústica propicia a preservação de zonas com níveis sonoros regulares, no entanto, a correção de zonas com níveis sonoros não regulares, propicia a criação de novas zonas sensíveis ou mistas com níveis sonoros compatíveis com as emissões sonoras de infraestrutura de transportes existentes e de atividades econômicas instaladas. O seu uso identifica também a eventual necessidade de medidas de redução de ruído e a análise da influência sonora de projetos (incluindo alternativas) de futuras infraestruturas de transporte ou de projetos de desenvolvimento industriais, comerciais, possibilitando a escolha da alternativa de menor impacto, sendo essencial no apoio à decisão de planejamento e ordenamento territorial, pois permite a visualização de condicionantes relaciona à qualidade do ambiente acústico (APA, 2011).

A Figura 2.4 exemplifica uma Carta Acústica:

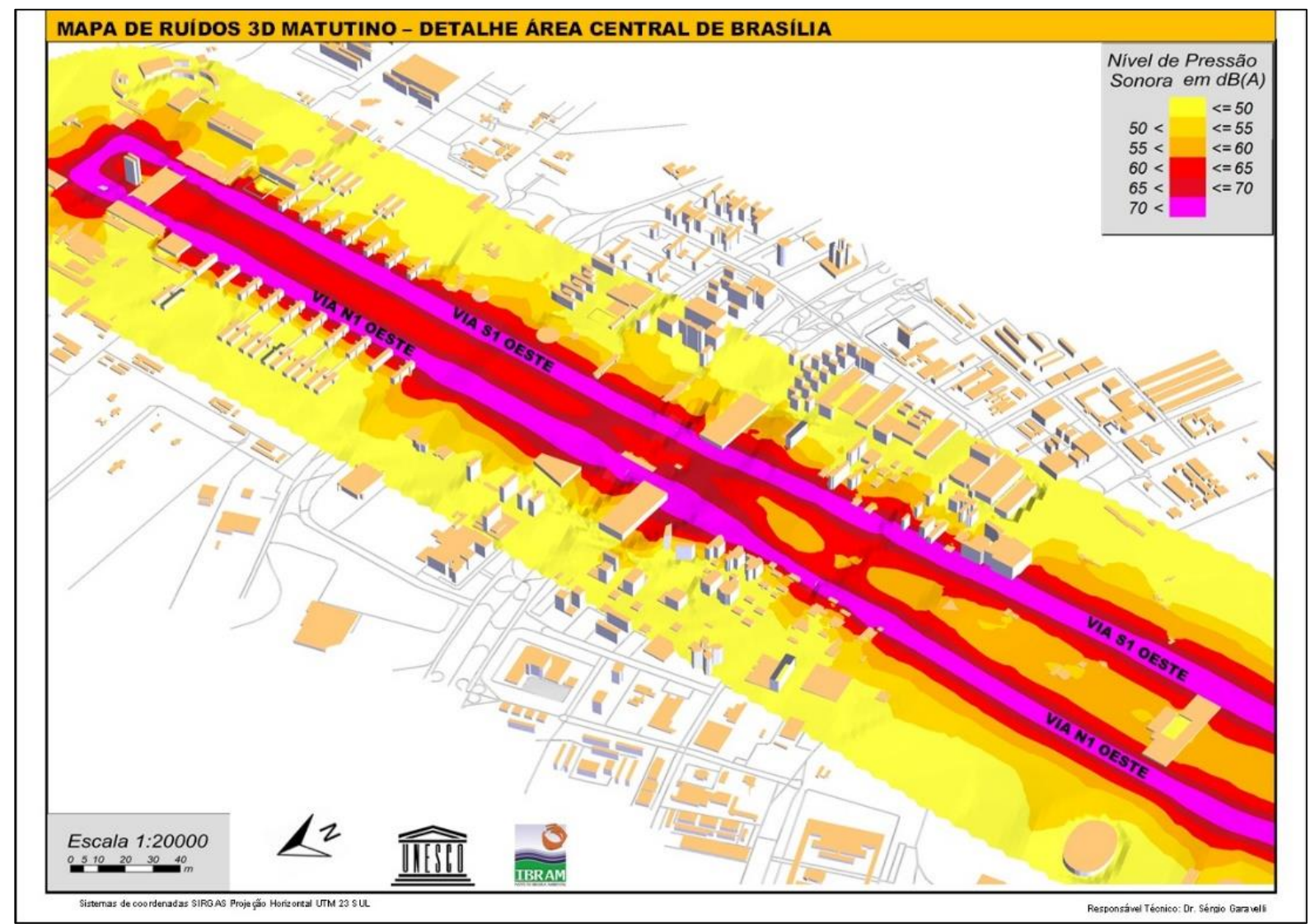

Figura 2.4: Carta Acústica em $\mathrm{L}_{e q} /$ Matutino/Área Central de Brasília-DF

Fonte: Garavelli et al., 2013.

\subsection{SIMULAÇÃO COMPUTACIONAL}

Existe diversas ferramentas de simulação acústica para a gestão de paisagens sonoras, graças ao uso de equações complexas e cálculos recursivos, o que somente um computador realiza com facilidade, em menor tempo e com maior confiabilidade. Os primeiros modelos de 
predição de ruído de tráfego foram desenvolvidos durante as décadas de 50 e 60 e eram usados para determinar o NPS de um único veículo em uma rodovia (Costa, 2011).

Existem diversos softwares que realizam simulações acústicas, com a finalidade de avaliar o impacto ambiental, como o SoundPlan, Predictor, CadnaA e INM (realiza apenas simulação do ruído aeronáutico). As diferenças entre esses softwares estão no tipo de geometria e topografia dos dados que podem ser importados e nos modelos de predição acústica utilizados.

Os modelos de predição acústica mais utilizados são, Calculation of Road Traffic Noise (CoRTN) - Reino Unido, Federal Highway Administration (FHWA) - Estados Unidos, Richtlinien für den Lärmschutz an StraBen (RLS-90) - Alemanha, OAL (Áustria), Statens Planverk 48 - Escandinávia, EMPA - (Suíça e Japão), cuidadosamente desenvolvidos e validados, sendo confiáveis por produzirem resultados com precisão (Li et al., 2002).

O uso dos modelos de predição possibilita a simulação e modelagem de situações hipotéticas levando cada vez mais os pesquisadores a um resultado coerente com a realidade. Esses resultados estão ligados à qualidade dos dados de entrada e com a habilidade do usuário (Costa, 2011).

\subsubsection{INM (Integrated Noise Model)}

É um software desenvolvido pelo Federal Aviation Administration (FAA), que avalia os impactos do ruído de aeronaves nas imediações de aeroportos. Utiliza como dados de entrada a movimentação diária do aeroporto, trajetórias de pouso e decolagem, características de ruído de cada modelo de aeronave operante no aeroporto, entre outras. O INM calcula a curva de ruído ao redor da pista em diversas métricas, de acordo com as escolhas de quem o manipula (Rocha e Slama, 2008).

É desenvolvido com base no algoritmo AIR-SAE-1845, apresentado em documentos publicados pela SAE International, que se referem à absorção atmosférica e a atenuação sonora. Esse modelo de avaliação média de ruído é desenvolvido para cálculos estimados de longo prazo, utilizando dados mensais ou anuais de entrada (Carvalho, 2010).

Esse software utiliza informações de dois bancos de dados internos, obtidas através de procedimentos utilizados na certificação de ruído das aeronaves. O primeiro banco de dados traz parâmetros de desempenho dos aviões, como velocidade, potência, flaps, peso máximo 
para pouso e decolagem, entre outros; elementos estes utilizados para os cálculos de trajetórias. O segundo banco de dados é constituído por várias tabelas, denominado Noise Power and Distance (NPD), relacionando os níveis de ruído com a potência do motor da aeronave e a distância existente entre a fonte aeronave e observador obtidos durante as operações de voo de teste de certificações das aeronaves (Heleno, 2010).

Os níveis sonoros utilizados no INM são baseados em quatro métricas, SEL, LAmax, EPNL e PNTLN. A partir destas o INM calcula os níveis sonoros em outras métricas, como por exemplo: DNL, TALA, $\mathrm{L}_{e q}$ e outras. (Heleno, 2010). São dados de entrada do INM: temperatura de referência, altitude das pistas, comprimento das pistas, coordenadas cartesianas das cabeceiras das pistas, trajetórias de pouso de decolagem, modelos das aeronaves, número de operações por aeronave (diurno e noturno) e indicador de ruído a ser utilizado. Com a entrada dos dados, o INM calcula os níveis de ruído para cada ponto da área estipulado pelo usuário. Ao terminar este procedimento, o programa une os pontos com os valores de níveis de ruído especificados.

\subsubsection{CadnaA}

CadnaA é um software alemão desenvolvido pela Datakustik, e serve para simulação da propagação de ruído; está no mercado desde a década de 80 e é uma ferramenta eficaz na modelagem ambiental do ruído (Paozalyte, 2012). Assim, ele realiza cálculos com predição e assessoria em relação à contaminação acústica. Possui integração com o Windows, que possibilita a comunicação com editores de texto, planilhas, softwares de Computer Aided Design (CAD), além do sistema informações geográficas (SIG), o que não o impede de ser um software potente e rápido. No Brasil, consideram as normas internacionais para os cálculos, pois a Normativa Brasileira não impõe regras, para considerar a propagação, reflexão, difração e outros efeitos na obtenção das cartas de ruído, provenientes das simulações.

De acordo com Mardones (2009), para realizar um estudo condicente com a realidade, é necessário utilizar parâmetros como dados de entrada para a simulação do ruído do trafego rodoviário, sendo estes: tipo de veículo, velocidade média da via, tipo de asfalto, altura das edificações, largura das ruas, coeficiente de absorção, umidade, temperatura, velocidade do vento, população por residência ou por edifício e etc. 
A versão utilizada deste software para modelar o ruído do tráfego rodoviário é o modelo alemão RLS-90 e para modelar o ruído do tráfego ferroviário, o modelo holandês SRM II. Esses modelos permitem cálculos mais rigorosos dos níveis sonoros para os tráfegos rodoviário e ferroviário e é sugerido suas utilizações pela Diretiva Europeia.

\subsection{PERCENTUAL DE PESSOAS INCOMODADAS}

A exposição ao ruído tem causado danos à saúde humana. Como intuito de minimizar esses danos e determinar o potencial de incômodos, é necessário desenvolver metodologias para melhor avaliar o impacto do ruído ambiente nas áreas habitadas no entorno de rodovias, ferrovias e aeroportos. Avaliar o impacto sonoro significa a estimação da quantidade de pessoas afetadas por diferentes NPS em áreas lindeiras a uma rodovia ou grande infraestrutura de transportes, como rodoviárias, estações de trem e aeroportos.

Em 1998, Miedema e Vos publicaram os resultados dos estudos dos pesquisadores do The Netherlands Organisation for Applied Scientific Research Prevention and Health in the Netherlands (TNO), relatando as equações para relação entre o indicador DNL e o percentual de pessoas altamente incomodadas para as três fontes de ruído (aéreo, rodoviário e ferroviário). Já em 2001, Miedema e Oudshoorn a partir dos mesmos estudos realizados por Miedema e Vos, 1998, apresentaram novas equações para os indicadores acústicos $D N L$ e $\mathrm{L}_{d e n}$, com aproximações polinomiais e com as estimativas dos intervalos de confiança melhoradas, estabelecendo a relação causa e efeito entre o ruído de uma fonte de transporte e o incômodo sonoro (Miedema e Oudshoorn, 2001).

Essas equações são aprovadas e recomendadas pela Comunidade Europeia e OMS na determinação do percentual de pessoas incomodadas (\%A) e altamente incomodadas (HA\%) para a estimativa do incômodo sonoro para a métrica $\mathrm{L}_{d e n}$ com base no nível de ruído (EC, 2002; WHO, 2011;), estando relacionadas na Tabela 2.10:

Tabela 2.10: Estimativa do Incômodo Sonoro para o $\mathrm{L}_{\text {den }}$

\begin{tabular}{cc}
\hline $\begin{array}{c}\text { Fonte } \\
\text { Sonora }\end{array}$ & $\begin{array}{c}\text { Aproximação polinomial }(\% \text { A e \% HA }) \\
\text { Indicador acústico } \boldsymbol{L}_{\text {den }}\end{array}$ \\
\hline \multirow{2}{*}{ Aéreo } & $\% A=8,588 \times 10^{-6}\left(L_{d e n}-37\right)^{3}+1,777 \times 10^{-2}\left(L_{d e n}-37\right)^{2}+1,221\left(L_{d e n}-37\right)$ \\
& $\% H A=-9,199 \times 10^{-5}\left(L_{d e n}-42\right)^{3}+3,932 \times 10^{-2}\left(L_{d e n}-42\right)^{2}+0,2939\left(L_{d e n}-42\right)$ \\
\hline \multirow{2}{*}{ Rodoviário } & $\% A=1,795 \times 10^{-4}\left(L_{d e n}-37\right)^{3}+2,110 \times 10^{-2}\left(L_{d e n}-37\right)^{2}+0,5353\left(L_{d e n}-37\right)$ \\
& $\% H A=9,868 \times 10^{-4}\left(L_{d e n}-42\right)^{3}-1,436 \times 10^{-2}\left(L_{d e n}-42\right)^{2}+0,5118\left(L_{d e n}-42\right)$ \\
\hline
\end{tabular}

Fonte: Miedema et al. (2003). 
Para estabelecer o percentual de pessoas com o sono altamente perturbado (\%PSAP), é utilizado o indicador de ruído $\mathrm{L}_{n}$, sendo um preditor de efeitos crônicos da exposição ao ruído noturno. Os polinômios que descrevem a relação entre o \%PSAP, \%PDS (percentual de pessoas com distúrbios no sono) e \%PSLP (percentual de pessoas com o sono levemente perturbado) para a métrica $\mathrm{L}_{n}$ nas fontes de tráfego aéreo e rodoviário estão expressos na Tabela 2.11.

Tabela 2.11: $\mathrm{L}_{n}$ e Polinômios para Distúrbios do Sono - Tráfego Aéreo e Rodoviário Ruído do Tráfego Aéreo Ruído do Tráfego Rodoviário

$$
\begin{array}{cl}
\% P S A P=18,147-0,956\left(L_{n}\right)+0,01482\left(L_{n}\right)^{2} & \% P S A P=20,8-1,05\left(L_{n}\right)+0,01482\left(L_{n}\right)^{2} \\
\% P D S=13,714-0,807\left(L_{n}\right)+0,01555\left(L_{n}\right)^{2} & \% P D S=13,8-0,85\left(L_{n}\right)+0,01670\left(L_{n}\right)^{2} \\
\% P S L P=4,465-0,411\left(L_{n}\right)+0,01395\left(L_{n}\right)^{2} & \% P S L P=-8,4+0,16\left(L_{n}\right)+0,01081\left(L_{n}\right)^{2}
\end{array}
$$

Fonte: Miedema et al., (2003); EC (2004). 


\section{CAPÍTULO 3. MÉTODO}

Neste capítulo será detalhado o método utilizado para determinar o ruído combinado devido aos modais aeroviário, rodoviário e ferroviário na região do Polo Gerador de Viagens Aeroporto Internacional de Brasília. Este método é sustentado por modelagens de cartas de ruído combinado.

Para melhor compreensão, o método foi dividido em quatro etapas. A primeira etapa trata sobre a obtenção dos dados de entrada necessários para a realização das simulações. A segunda etapa está relacionada com simulações e a elaborações das cartas de ruído. Já a terceira etapa detalha a metodologia utilizada para a determinação dos cenários acústicos, das cartas de ruído e do ruído combinado nos pontos pré-determinados. Na quarta etapa é determinado a população exposta por faixa de ruído e a área de cada isofônica, obtendo assim, o percentual da população incomodada e altamente incomodada por faixa de ruído para os modais aéreo e rodoviário.

Cabe destacar que na $3^{\text {a }}$ Etapa do estudo foram caracterizados dois cenários acústicos: "Cenário Atual”, que determina as curvas de ruído aéreo e rodoviário, e assim o combinado a partir da somatória das curvas de ruído destes modais. O "Cenário Futuro", que é determinado a partir da possível implantação do modal ferroviário contemplado no PDTU/DF (2011), sendo então determinada as curvas de ruído aérea, rodoviária e ferroviária, e assim o combinado a partir da somatória das curvas de ruído destes modais.

Neste estudo, apenas para as curvas de ruído simuladas para os modais aéreo e rodoviário, foram determinadas as populações expostas por faixa de ruído por meio de modelos matemático.

A Tabela 3.1 apresenta a estrutura do método fragmentado em etapas. 
Tabela 3.1: Etapas do Método

\begin{tabular}{|c|c|}
\hline $\begin{array}{c}\text { 1a Etapa }^{\text {a Ebtenção }} \\
\text { Oba de } \\
\text { da Base de } \\
\text { Dados }\end{array}$ & 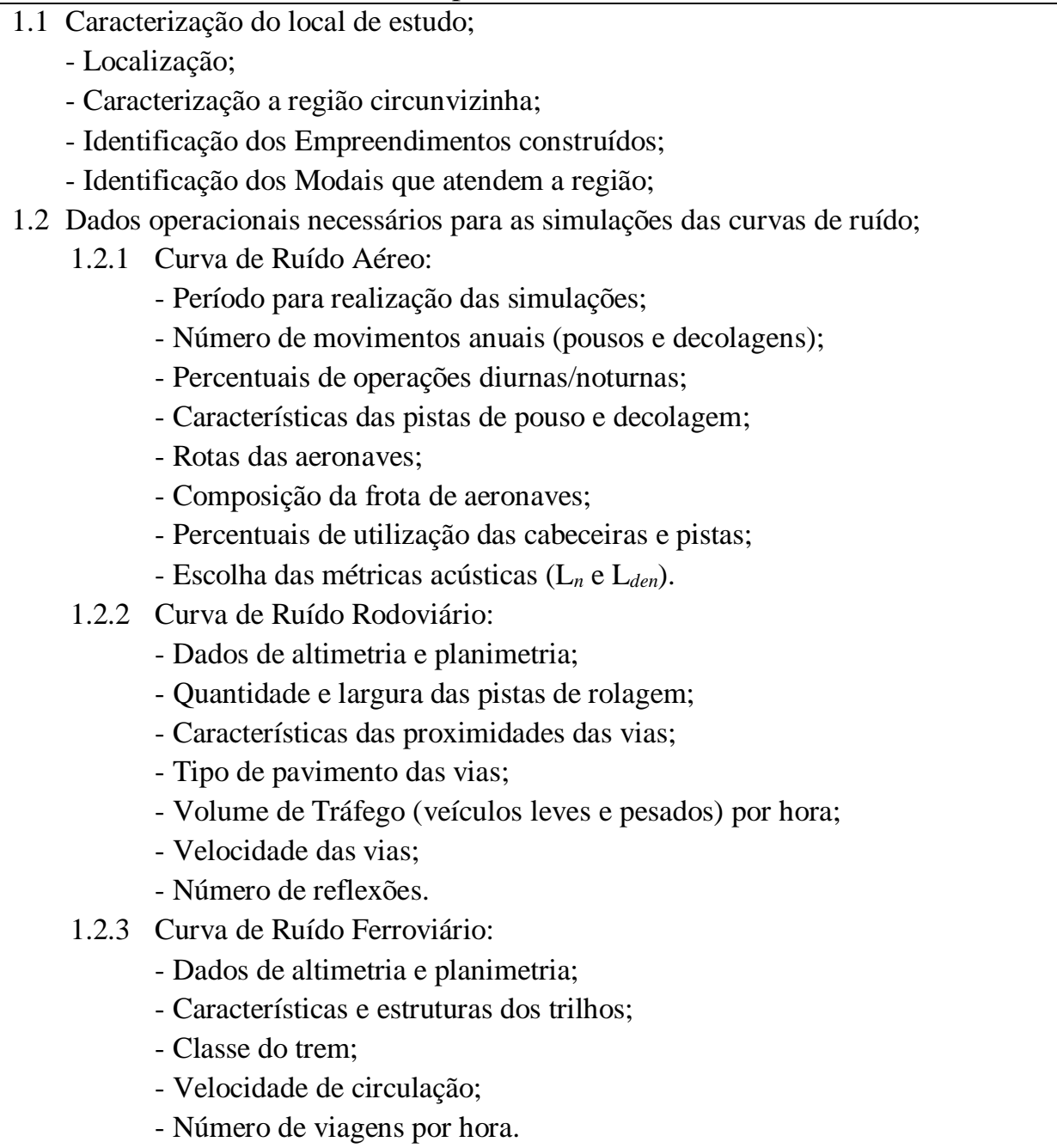 \\
\hline $\begin{array}{c}2^{\mathrm{a}} \text { Etapa } \\
\text { Modelagem }\end{array}$ & $\begin{array}{ll}\text { 2.1 Simulações das curvas de ruído: } \\
2.1 .1 \text { Ruído Aéreo - software INM; } \\
2.1 .2 \text { Ruído Rodoviário - software CadnaA; } \\
2.1 .3 \text { Ruído Ferroviário - software CadnaA; } \\
\text { 2.1.3 Ruído Combinado Rodoviário e Ferroviário - software CadnaA; } \\
\text { 2.2 Cartas Acústicas: metodologia indicada pela Agência Portuguesa do Ambiente } \\
\text { (APA, 2011) e Diretiva Europeia 2002/49 (CE); }\end{array}$ \\
\hline $\begin{array}{c}3^{\mathrm{a}} \text { Etapa } \\
\text { Ruído } \\
\text { Combinado }\end{array}$ & $\begin{array}{l}\text { 3.1 Cenário Atual: } \\
\text { 3.1.1 Sobreposição das Cartas de Ruído Aéreo com o Rodoviário no software } \\
\text { QGIS; } \\
\text { 3.2 Cenário Futuro: } \\
\text { 3.2.1 Sobreposição das Cartas de Ruído Aéreo com o Combinado do Rodoviário e } \\
\quad \text { Ferroviário no software QGIS; } \\
\text { 3.3 Determina os valores do ruído combinado por meio da Equação Somatória de } \\
\text { Energia em pontos pré-determinados das cartas de ruído. }\end{array}$ \\
\hline $\begin{array}{l}4^{\text {a }} \text { Etapa } \\
\text { Cálculo da } \\
\text { População } \\
\text { Exposta } \\
\text { por Faixa } \\
\text { de Ruído e } \\
\text { Área das } \\
\text { Curvas }\end{array}$ & $\begin{array}{l}\text { 4.1 Uso da metodologia indicada pela APA (2011) e Diretiva Europeia 2002/49/CE; } \\
\text { 4.2 Uso dos dados censitários da população residentes na região circunvizinha ao } \\
\text { aeroporto; } \\
\text { 4.3 Determinação da população residente distribuída no interior das curvas de ruído; } \\
\text { 4.4 Cálculo a população exposta e a área em diferentes faixas de ruído }\left(\mathrm{L}_{n} \text { e } \mathrm{L}_{d e n}\right) \text {; } \\
\text { 4.5 Cálculo a população incomodada e altamente incomodada }\left(\mathrm{L}_{n} \text { e } \mathrm{L}_{d e n}\right) \text {. }\end{array}$ \\
\hline
\end{tabular}


A Figura 3.1 sintetiza o método utilizado para a determinar o ruído combinado e o cálculo da população exposta.

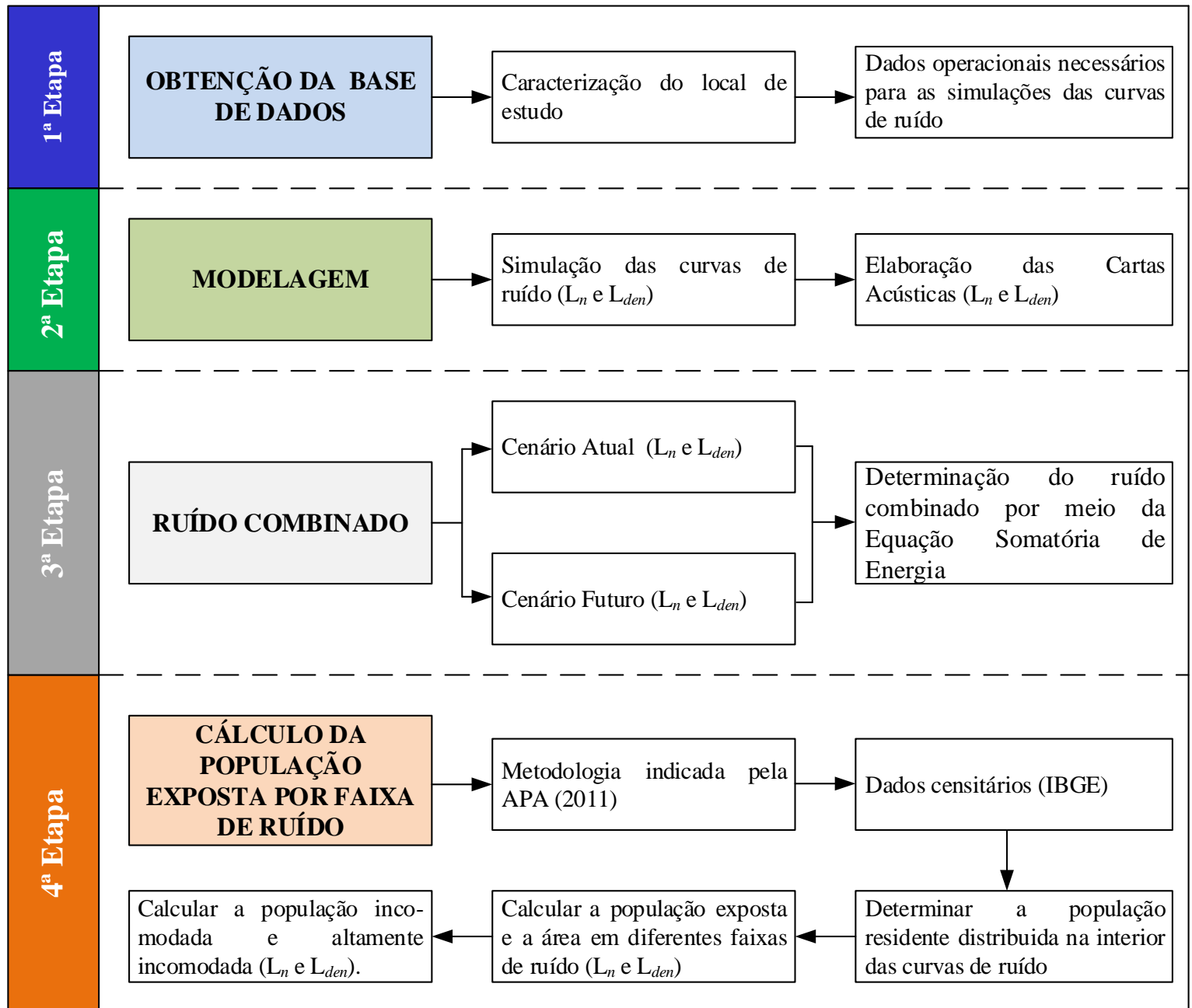

Figura 3.1: Método para Determinação do Ruído Combinado e da População Exposta

A compilação do Cenário Atual e Futuro permitiram a avaliação combinada dos níveis de pressão sonora para os tráfegos aéreo, rodoviário e ferroviário.

\subsection{CARTAS DE RUÍDO}

Para determinar os Níveis de Pressão Sonora (NSP) na região do Polo Gerador de Viagens (PGV) Aeroporto Internacional de Brasília (AIB) devido aos modais (aéreo, rodoviário e ferroviário), foram realizadas simulações acústicas em relação ao plano horizontal (Grip Noise Map) com visualização em 2D, através dos softwares INM e CadnaA.

O Brasil ainda não dispõe de termos de referências e nem metodologias para elaboração de cartas acústicas. Deste modo, para este estudo será adotado a metodologia proposta no ano de 2011 pela Agência Portuguesa do Ambiente (APA). A Agência segue as normas 
recomendadas pela Diretiva Europeia 2002/49/CE, que tem como prioridade minimizar os efeitos prejudiciais do ruído. A Figura 3.2 apresenta as etapas seguidas a partir da metodologia proposta pela APA (2011) para a elaboração das cartas de ruído.

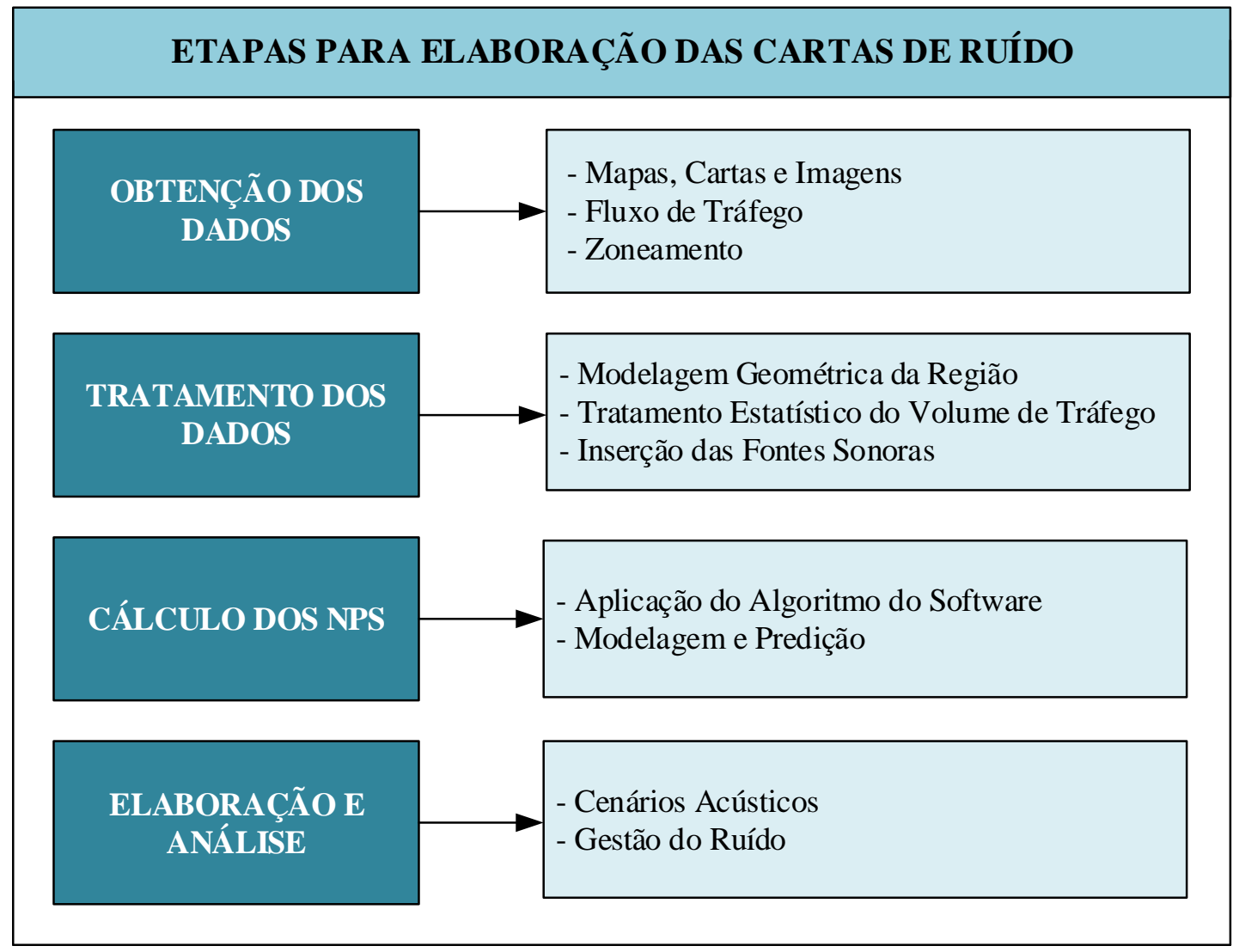

Figura 3.2: Etapas para Elaboração de Cartas Acústicas

Fonte: Costa, 2011 (Adaptado).

Após a simulação, com as curvas de ruído, por meio do software QGIS versão 2.8, para plataforma Windows, foram elaboradas as cartas acústicas. Para determinar a população exposta foi utilizado os seguintes arquivos: base de dados dos Setores Censitário do DF, em formato shapefile, dados com informações para cada subseção estatística (dados do Censo 2010, IBGE), curvas de ruído simulados no INM (curvas aéreas) e no CadnaA (curvas rodoviárias) e o dados matriciais (Mosaico do DF), em formato shapefile. Esses arquivos foram sobrepostos, e assim com o auxílio do software Microsoft Excel determinado a população exposta por faixa de cada curva de ruído.

As cartas de ruído foram construídas obedecendo os intervalos da "Classe de NPS" proposto pela APA (2011). Para auxiliar a interpretação das cartas de ruído, é exibida a Tabela 3.2, que indica as "Classes dos NPS" para os indicadores $\mathrm{L}_{n}$ e $\mathrm{L}_{d e n}$. 
Tabela 3.2: Classes de NPS

\begin{tabular}{c|c|c|c}
\hline \multicolumn{2}{c}{ Classes do Indicador $\mathrm{L}_{\boldsymbol{n}}$} & \multicolumn{2}{c}{ Classes do Indicador Lden } \\
\hline $\mathrm{L}_{n} 45$ & $45<\mathrm{L}_{n} \leq 50$ & $\mathrm{~L}_{\text {den }} 55$ & $55<\mathrm{L}_{\text {den }} \leq 60$ \\
$\mathrm{~L}_{n} 50$ & $50<\mathrm{L}_{n} \leq 55$ & $\mathrm{~L}_{\text {den }} 60$ & $60<\mathrm{L}_{\text {den }} \leq 65$ \\
$\mathrm{~L}_{n} 55$ & $55<\mathrm{L}_{n} \leq 60$ & $\mathrm{~L}_{d e n} 65$ & $65<\mathrm{L}_{d e n} \leq 70$ \\
$\mathrm{~L}_{n} 60$ & $60<\mathrm{L}_{n} \leq 65$ & $\mathrm{~L}_{\text {den }} 70$ & $70<\mathrm{L}_{\text {den }} \leq 75$ \\
$\mathrm{~L}_{n} 65$ & $65<\mathrm{L}_{n} \leq 70$ & $\mathrm{~L}_{d e n} 75$ & $\mathrm{~L}_{\text {den }}>75$ \\
$\mathrm{~L}_{n} 70$ & $\mathrm{~L}_{n}>70$ & - & - \\
\hline
\end{tabular}

Fonte: APA, 2011 (Adaptado).

Para melhor compreensão, a obtenção e construção das bases de dados para a realização das simulações serão detalhadas nos itens abaixo, que relatam o que foi realizado para a obtenção das curvas de ruído.

\subsubsection{Curvas de Ruído Aéreo}

O software inicia a sua rotina de cálculo a partir da determinação da trajetória e de todas as aeronaves desejadas. Trajetórias que são formadas por pequenos segmentos sucessivos, nos quais os parâmetros de potência, velocidade e posição, entre outros, são determinados. Além dos dados citados, são necessárias informações sobre: temperatura de referência do aeródromo, altitude do aeródromo, distância a ser cumprida pelas etapas de voo de cada uma das aeronaves, peso de decolagem, comprimento(s) de pista(s), incluindo as coordenadas cartesianas ou geográficas das cabeceiras, rotas de pouso e decolagem e os modelos de aeronaves.

O INM realiza o somatório do ruído produzido por todos os segmentos de voo da aeronave mediante a definição da área de entorno do aeródromo, número de movimentos diurnos e noturnos de aeronaves dentro de cada uma das rotas, métrica de incômodo a ser calculada e valores dos níveis de ruído desejados. Após incluir todas essas informações, o software calcula os níveis de ruído para cada ponto na área estipulada pelo usuário, na métrica acústica desejada (Abdala, 2005).

A simulação foi realizada para um total de 200.000 movimentos (pousos e decolagens), considerando que $85 \%$ dos movimentos acontecem no período diurno e $15 \%$ no período noturno (ANAC, 2013). A frota de aeronaves foi determinada a partir do percentual de operações realizadas no ano de 2012, levando em conta as operações mais expressivas, ou seja, as que apresentam mais de $1 \%$ da operação anual. Já as rotas (trajetórias) utilizadas para pousos e decolagens foram obtidas através das cartas de navegação aéreas. No Apêndice " $A$ " encontram-se os dados de entrada para a realização da simulação. 
Para os Cenários Atual e Futuro no modal aéreo foram utilizadas as mesmas curvas de ruído, pois neste estudo não está sendo levando em conta as alterações na movimentação aérea e sim as alterações na movimentação rodoviária com a implantação do modal ferroviário.

\subsubsection{Curvas de Ruído Rodoviário}

Para realizar as simulações do tráfego rodoviário na região circunvizinha e de acesso ao AIB foi necessário criar o modelo digital do terreno e realizar contagem volumétrica nas principais vias. Sendo também utilizado dados de fluxo de veículos dos dispositivos controladores eletrônicos de velocidade, que além de controlarem as velocidades realizam a contagem do volume de tráfego. Esses dados foram cedidos pelo Setor de Geoprocessamento do DETRAN-DF, pelo Setor de Estatística do DER/DF e do DFTrans devido a inclusão do BRT nesta região. Em paralelo, no momento da contagem volumétrica foi realizado um levantamento físico com intuito de identificar as características em torno do local da contagem: largura e quantidade de pistas nas vias, tipo de pavimento; direção do fluxo, forma de ocupação e tipos de uso do solo, vegetação relevante, topografia, posição geográfica (latitude e longitude).

A contagem volumétrica ocorreu no mês de fevereiro de 2015, realizada in situ em pontos das vias da região circunvizinha e de acesso ao AIB, que não possuem contadores eletrônicos. O resultado desta contagem também foi utilizado para validação dos dados cedidos pelo DETRAN-DF e DER/DF. A contagem foi realizada por meio de filmagem com estratificação horária de quinze minutos para a obtenção do volume tráfego em 1 hora. Essa metodologia já foi utilizada nos trabalhos de Costa (2011) e Maroja et al. (2011). Assim foi possível determinar o número de viagens realizadas por hora, que é um dos dados de entrada do modelo utilizado. No Apêndice "B" encontram-se os dados de entrada para a realização da simulação.

Para obtenção das curvas e ruídos devem ser inseridas na base de dados as informações sobre altimetria da região de estudo, curvas de nível para construção do Modelo Digital do Terreno (MDT). Todos os objetos virtuais necessários para realizar a simulação (fontes de ruído e receptores, sendo localizados sobre o modelo digital de terreno). Nos dados de ocupação do solo as vias são posicionadas sobre o MDT, incorporando a altura estabelecida pelo modelo digital, em seguida as características de cada objeto são incorporadas à base de dados, por exemplo, as estradas: largura das estradas, composição e fluxo do tráfego 
veicular, velocidade de veículos leves e pesados. São inseridas as áreas de atenuação, absorção do solo e uso do solo. O Apêndice "B" apresenta os dados utilizados.

\subsubsection{Curvas de Ruído Ferroviário}

O PDTU/DF contempla a região do AIB com a Linha 1 do Trecho 1 (representado por meio da linha verde na figura a seguir) do VLT, ligando o AIB a Asa Sul e região central de Brasília. A Figura 3.3 exibe os trechos propostos para o VLT em Brasília.

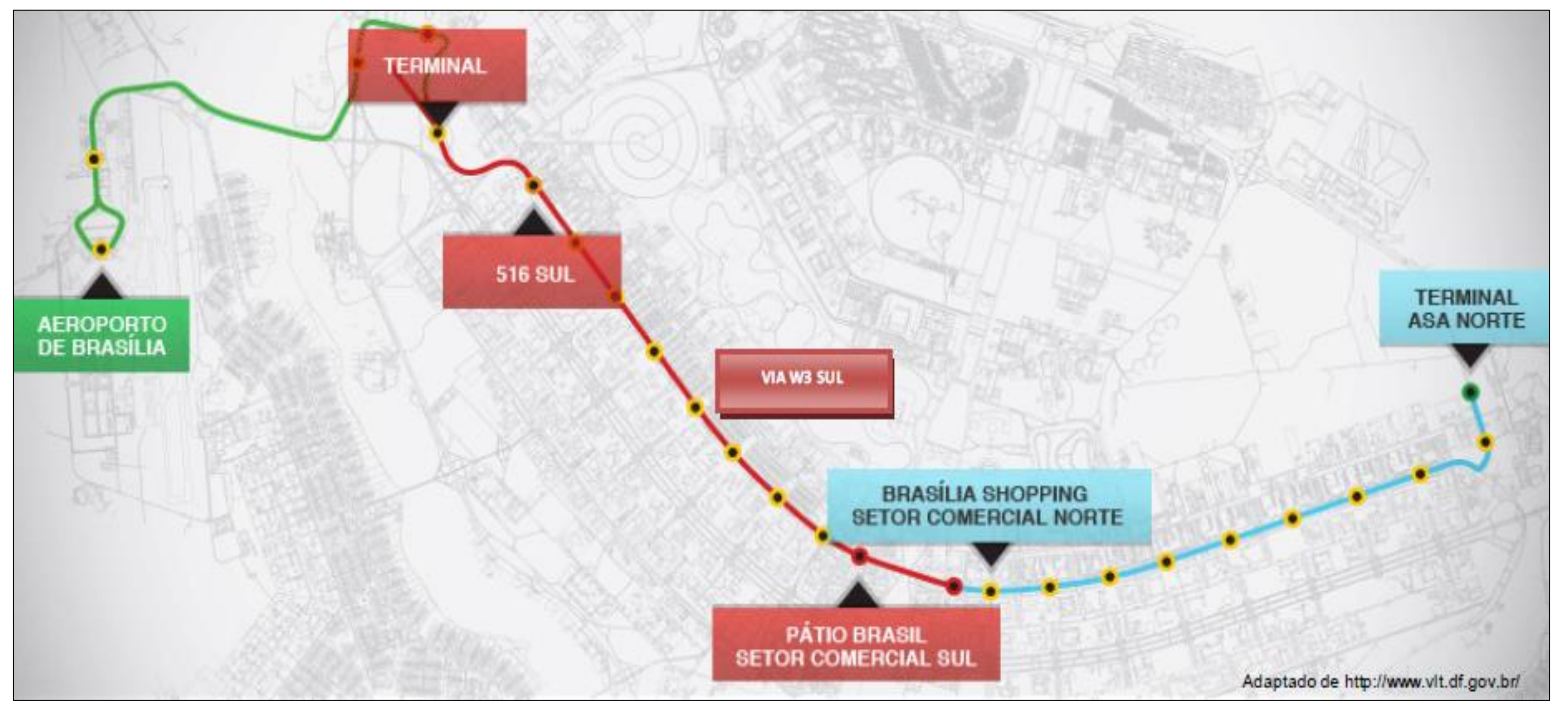

Figura 3.3: Traçado Completo do VLT Brasília

Fonte: http://doc.brazilia.jor/Trilhos-VLT-Brasilia/Mapa-do-VLT-Brasilia.shtml (Adaptado).

Com a construção do VLT, a partir de estimativas, é prevista uma atração de $30 \%$ dos usuários de automóvel que hoje circulam pela região de implantação. Entretanto há incertezas quanto à captação de usuários cativos do transporte coletivo. A velocidade máxima dos trens será de $70 \mathrm{~km} / \mathrm{h}$ e a média prevista de $30 \mathrm{~km} / \mathrm{h}$, cada trem terá o comprimento de 44 metros e a possibilidade de carregar 12 mil passageiros por hora/sentido no pico, o intervalo entre os trens durante o período dia será de 4 minutos. Cada módulo do veículo irá transportar a quantidade de passageiros equivalente a de 50 carros ou a que 3 ônibus transportam (Metrô DF, 2009; Santos et al., 2009; Maroja, et al., 2014).

Determinou-se as movimentações dos trens por meio da periodicidade, um trem partindo a cada 4 minutos durante o período dia, 07:00h às 19:00h, portanto 15 trens por hora. Para o período entardecer, 19:00h às 23:00h a média será de 10 trens por hora e para o período noite, 23:00h às 07:00h, em 5 trens por hora (VLT, 2012 apud Maroja et al., 2014). 
Com relação à simulação, inicialmente foi atualizada a base cartográfica da região mostrada na Figura 3.3, com a inserção da linha férrea referente ao Trecho 1 (trecho ligando o AIB a Estação Asa Sul). Foi utilizado como parâmetro de entrada para elaboração das curvas de ruído o número de viagens por períodos (dia, entardecer e noite) em ambos os sentidos e a velocidade de locomoção.

O modelo SMRII calcula o nível de emissão sonora recebido com base no ruído emitido por cada vagão supondo que todas as fontes estão concentradas no ponto central do segmento. A atenuação com a distância é calculada para cada ponto de fonte considerando que só existe emissão de ruído acima do nível do solo. Adicionalmente, a norma caracteriza cada tipo de composição com um valor para o nível de emissão sonora recebido a uma determinada distância, altura e velocidade.

\subsubsection{Cálculo do Ruído Combinado}

Para determinar o ruído combinado, foi realizada a sobreposição das curvas de ruído no software QGIS 2.8 provenientes aos modais aéreo, rodoviário e ferroviário por meio do método descrito na $3^{\text {a }}$ etapa da Figura 3.1. Esse método divide o estudo em dois cenários: Cenário Atual, que estudou o ruído proveniente do tráfego rodoviário e aéreo para a região e o Cenário Futuro, que determinou o ruído combinado em alguns pontos a partir da possível inclusão do modal ferroviário.

A versão do software CadnaA que foi utilizada para simulação das curvas de ruído, possui limitações e não foi possível simular e nem inserir as curvas de ruído aéreo, apenas rodoviária e ferroviária. Sendo assim, para determinar os valores do ruído combinado devido aos modais rodoviário e aéreo, foram distribuídos 60 pontos pela região circunvizinha ao AIB, dando ênfase principalmente nas vias de acesso/egresso, assim como, às áreas habitadas.

Com esses pontos distribuídos, por meio da Equação Somatória de Energia (Equação 13), foram somados os NPS para as métricas estabelecidas nos pontos determinados das duas curvas de ruído. Já com respeito a confecção da carta de ruído combinado para este cenário, foi feita uma sobreposição das curvas de ruído aérea e rodoviária, no software QGIS.

Na Figura 3.4 é apresentado a localização dos 60 pontos, nos quais foram realizadas as somatórias. 


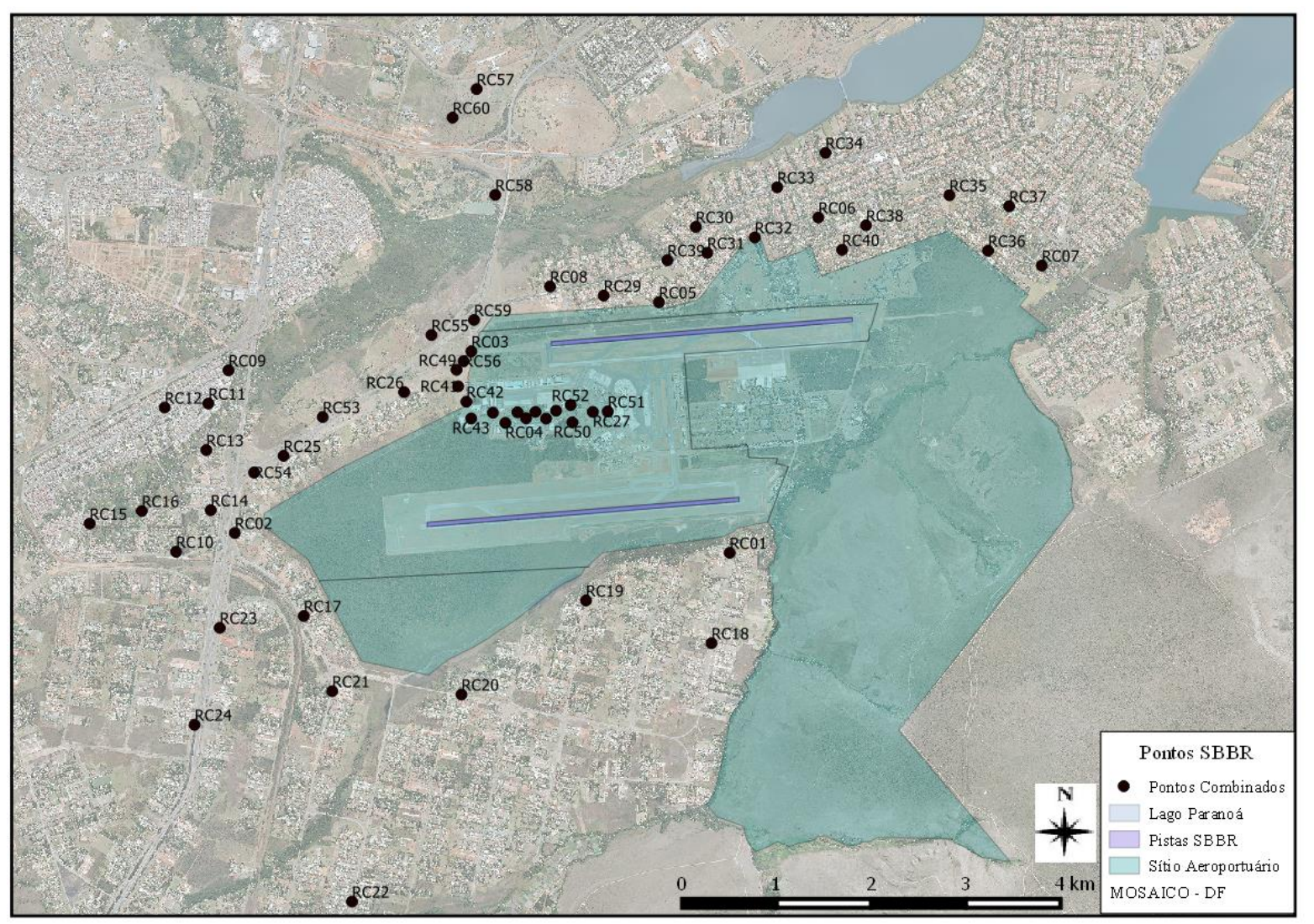

Figura 3.4: Pontos de Somatória do Ruído Combinado

Na simulação do ruído combinado para o Cenário Futuro, para os modais rodoviário e ferroviário, levou-se em consideração a possível implantação do VLT com as características propostas inicialmente, onde, é esperado que o modal ferroviário atraia a população que se movimenta nesta região, e assim, a migração do modal rodoviário para o ferroviário. Os estudos de Santos et al. (2009), Metrô DF (2012) e Maroja, et al. (2014), relatam a partir de estimativas que é previsto uma atração de $30 \%$ dos usuários de automóveis. A partir destas perspectivas, para a simulação do "Cenário Futuro" foi utilizado como base o estudo do Mamede e Alves (2009), por ele comprovar e relatar a partir de estudos estatísticos pósimplantação do modal ferroviário para acesso a região aeroportuária, a atratividade de $20 \%$ deste modal.

Neste cenário, a simulação do ruído combinado foi realizada em duas partes; primeiramente referente aos modais rodoviário $(-20 \%)$ e ferroviário combinados. Posteriormente com a curva de ruído combinado dos modais rodoviário (-20\%) e ferroviário combinados, foram utilizados os mesmos 60 pontos do "Cenário Atual", e somados pela Equação Somatória de Energia os NPS entre as curvas de ruído do modal aéreo e do combinado rodoviário (-20\%) com ferroviário. Para a carta de ruído combinado nesse cenário, também foi sobreposto as 
curvas aérea com o combinado das curvas rodoviária (-20\%) e ferroviária. No Apêndice "C" encontram-se os dados de entrada para a realização da simulação.

\subsubsection{População Exposta}

Para determinar a população exposta ao ruído aéreo e rodoviário por faixa dos indicadores de ruído foi utilizado o método proposto pela APA, (2011). Neste método o cálculo é realizado a partir das curvas de ruído as populações expostas foram calculadas em relação ao ano de 2014 e nas métricas $\mathrm{L}_{n}$ e $\mathrm{L}_{d e n}$, utilizando os softwares QGIS versão 2.8 e Excel versão 2013 e das bases de dados geométricos das subsecções dos Setores Censitários, informação de cada subsecção estatística (dados do Censo 2010, IBGE) e os dados geométricos das cartas acústicas (todos esses arquivos em formato shapefide).

As curvas de ruído aéreas e as curvas de ruído rodoviária foram sobrepostas individualmente com a camada de base censitária, sendo criados arquivos em separado para cada curva de ruído, e assim, realizar a intersecção de cada um dos arquivos das curvas de ruído com a base de dados censitária.

Em seguida, foram identificados os códigos censitários na planilha censitária que indica o número total de moradores por setor censitário. De posse do código censitário, dos valores dos indicadores $\mathrm{L}_{n}$ ou $\mathrm{L}_{d e n}$ e com o total populacional calculado para cada código censitário foi realizada o cálculo da população exposta por faixa de curva de ruído e por Regiões Administrativas.

Após realizar os cálculos das populações expostas para as curvas de ruído aéreas e rodoviárias, foram calculados para o período noturno a partir dos polinômios (Tabela 2.11) para distúrbios do sono o número de pessoas com distúrbios no sono, o número de pessoas com o sono levemente perturbado e o número de pessoas com o sono altamente perturbado. Para o período dia-entardecer-noite foi calculado a partir dos polinômios (Tabela 2.10) o incomodo sonoro, determinado assim, o número de pessoas incomodadas e altamente incomodadas. 


\section{CAPÍTULO 4. ANÁLISE DOS RESULTADOS E DISCUSSÕES}

Este capítulo apresenta a análise dos resultados obtidos a partir da aplicação do método utilizado na reprodução das curvas de ruído, elaboração das cartas acústicas para os cenários atual e futuro. Será discutida a sistemática sobre os cálculos de área e de população exposta, por faixa de ruído, determinando assim, a estimativa da população incomodada e altamente incomodada.

\subsection{CARACTERIZAÇÃO DA ÁREA DE ESTUDO}

O objeto de estudo está situado no Centro-Oeste do país, na cidade de Brasília, na região onde se encontra o PGV Aeroporto Internacional de Brasília. O sítio aeroportuário possui uma única via de acesso rodoviário, a DF 047, que está entre as vias de tráfego intermitente DF 002, DF 025, DF 051, DF 055, BR 450 e a via do BRT, como é mostrado na Figura 4.1:

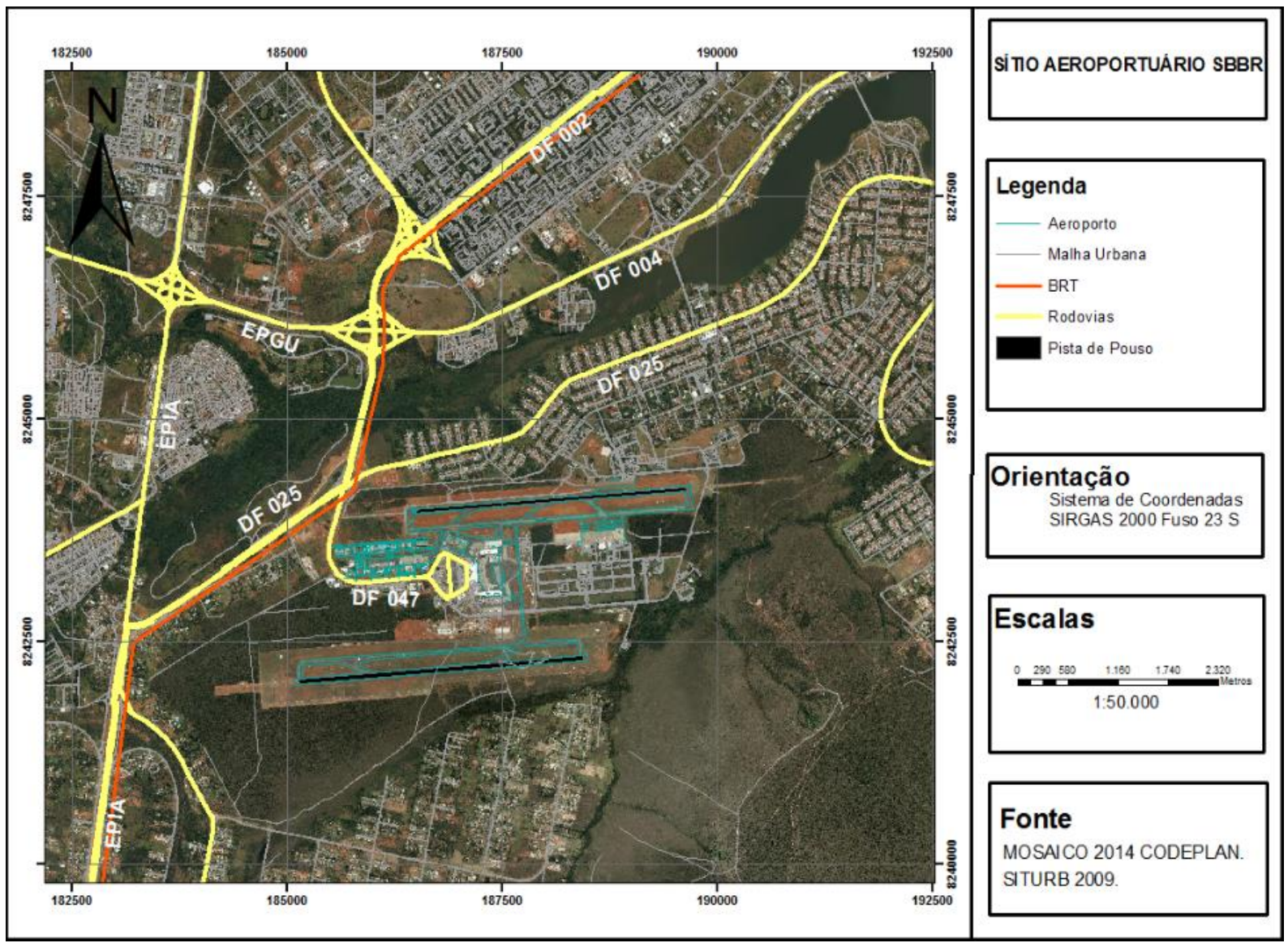

Figura 4.1: Mapa de Localização do SBBR

O Aeroporto Internacional de Brasília Presidente Juscelino Kubitschek, também conhecido como SBBR pela International Civil Aviation Organization (ICAO), possui altitude de 1.060 metros e está localizado nas coordenadas geográficas $15^{\circ} 51^{\prime} 46^{\prime \prime} \mathrm{S}$ de latitude e $047^{\circ} 54^{\prime} 46^{\prime} \mathrm{O}$ 
de longitude. Este aeroporto foi inaugurado oficialmente para operações comerciais em 3 de maio de 1957. Este aeroporto possui duas pistas designadas para pouso e decolagem. A primeira pista é a 11L/29R com 3.200 metros de comprimento e 45 de largura, já a segunda pista é a 11R/29L com 3.300 metros de comprimento e 45 de largura, como está representado na Figura A1 do "Apêndice A". A segunda pista foi inaugurada em dezembro de 2005, ampliando a capacidade operacional do aeroporto para até 555 mil pousos e decolagens por ano.

\subsection{VALIDAÇÕES DAS CARTAS DE RUÍDO}

Neste estudo, para a validação das curvas de ruído provenientes do modal aéreo, os resultados foram calibrados por meio do estudo realizado por Carvalho Jr. (2015). Nesse estudo os dados foram validados a partir de medidas de 24 horas realizadas por 3 estações de monitoramento, tendo a comparação entre os valores medidos e simulados uma diferença que não ultrapassou $\pm 2 \mathrm{~dB}(\mathrm{~A})$, obedecendo, assim, a APA (2011). Os dados referentes a esta validação constam no Apêndice "A”.

Já na validação das curvas de ruído provenientes ao modal rodoviário, os resultados foram calibrados a partir do estudo realizado por Garavelli et al., (2012). O estudo, realizado em parceria com a Organização das Nações Unidas para a Educação, a Ciência e a Cultura (UNESCO) e Instituto Brasília Ambiental (IBRAM) na parte central de Brasília, com o objetivo de determinar o ruído gerado pelo tráfego rodoviário nos horários de pico. Neste estudo, as curvas de ruído rodoviário foram validadas por meio de medição in situ em cinco pontos, através do sonômetro (medidor de NPS), obedecendo as normas da APA (2011). As comparações entre os valores medidos e simulados obteve uma diferença que não ultrapassou $\pm 3 \mathrm{~dB}(\mathrm{~A})$. Os dados referentes a esta validação constam no Apêndice "B".

Com respeito ao modal ferroviário, foram feitas simulações para predições e os resultados foram comparados aos estudos realizados por Maroja et al, (2011a) e Maroja et al., (2014b), Estes estudos utilizam como referência a metodologia proposta pela APA (2011) para determinar a influência no clima acústico na Asa Sul e Asa Norte em Brasília devido a implantação do VLT.

Os resultados das predições feitas a partir das simulações acústicas, foram confrontadas com os estudos citados e obtiveram valores próximos ou iguais, pode-se, assim, afirmar que estão em conformidade com os valores aceitáveis pela APA (2011), proporcionando 
confiabilidade na produção das cartas acústicas e no somatório dos NPS nos pontos escolhidos para determinação do ruído combinado, de acordo com os cenários acústicos.

\subsection{CENÁRIOS ACÚSTICOS DA ÁREA DE ESTUDO}

Na caracterização dos cenários acústicos da área pesquisada, serão apresentadas e analisadas a seguir as cartas de ruído de acordo com o modal de transporte. As cartas de ruído aéreo serão analisadas a partir da norma NBR 13.368 e da Diretiva Europeia 2002/49/CE, já as cartas de ruído rodoviário serão analisadas partir da norma NBR 10.151 e da Diretiva Europeia 2002/49/CE.

Para a simulação do ruído proveniente à instalação futura do VLT (predição), neste estudo foi levando em conta apenas o Trecho 1. Essas simulações são predições futuras, contempladas no PDTU/DF (2011), sem data de implantação.

\subsubsection{Cenário Acústico Atual}

Com as curvas de ruído para a métrica $\mathrm{L}_{d e n}$ simuladas, foram confeccionadas as cartas de ruído, a Figura 4.2 apresenta a Carta de Ruído Aéreo, Figura 4.3 exibe a Carta de Ruído Rodoviário e a Figura 4.4 mostra a Carta de Ruído Combinado para esse cenário. 


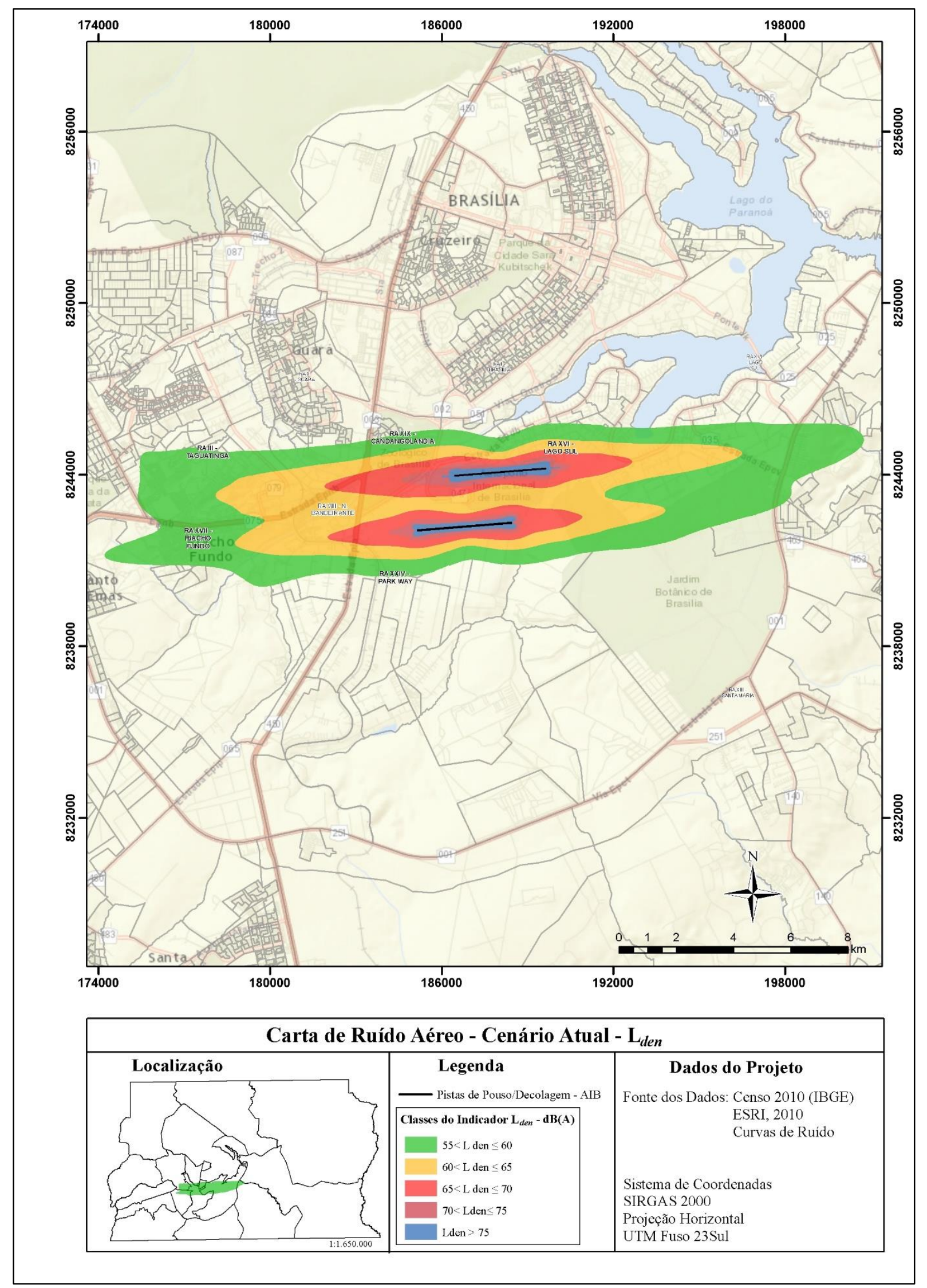

Figura 4.2: Carta de Ruído Aéreo - Cenário Atual $\left(\mathrm{L}_{d e n}\right)$ 


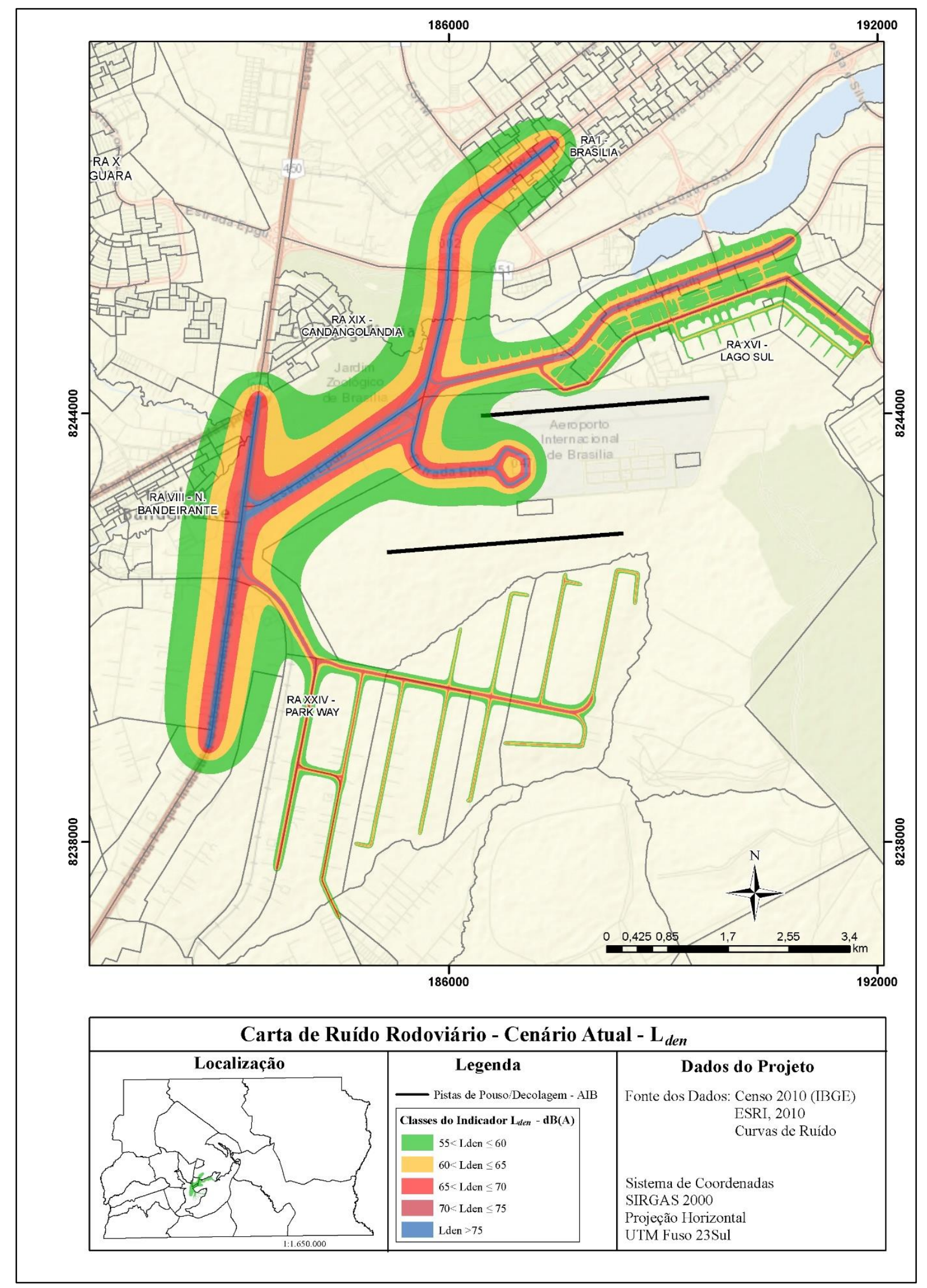

Figura 4.3: Carta de Ruído Rodoviário - Cenário Atual $\left(\mathrm{L}_{d e n}\right)$ 


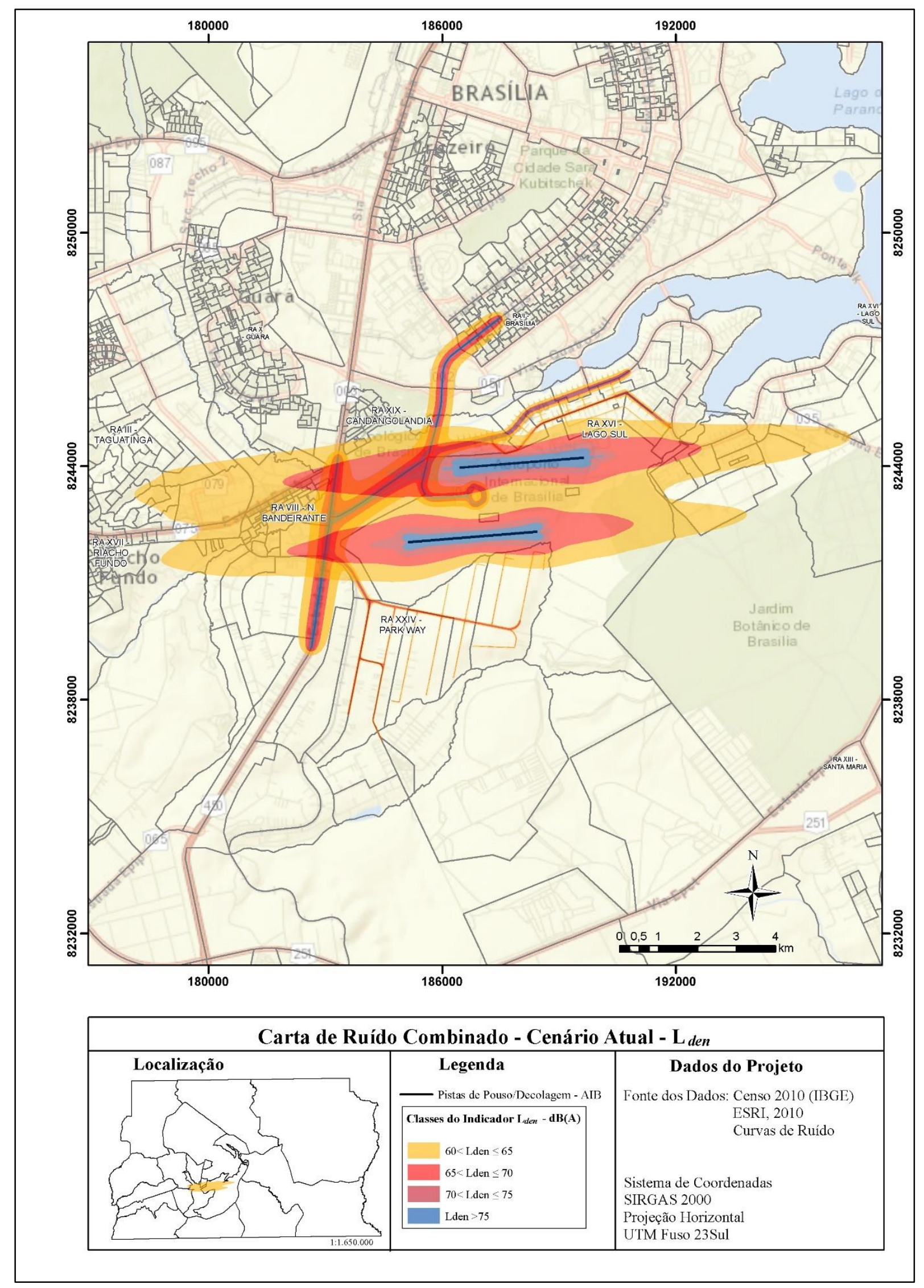

Figura 4.4: Carta de Ruído Combinado (Aéreo e Rodoviário) - Cenário Atual ( $\left.\mathrm{L}_{d e n}\right)$ 
A Figura 4.4 mostra a sobreposição das curvas de ruído aéreo e rodoviário, ou seja, sobreposição das curvas de ruído mostradas nas Figuras 4.2 e 4.3. Dessa figura, pode-se observar que as curvas no limite $65<\mathrm{L}_{d e n} \leq 75$ estão mais próximas ao sítio aeroportuário e áreas circunvizinhas. Já as curvas maiores que o $\mathrm{L}_{d e n} 75$ estão no entorno das pistas do SBBR.

A Tabela 4.1 expõem as áreas de cada faixa das curvas de ruído Aéreo e Rodoviário para a métrica $\mathrm{L}_{d e n}$.

Tabela 4.1: Áreas das Curvas de Ruído Aéreo/Rodoviário - Cenário Atual $\left(\mathrm{L}_{d e n}\right)$

\begin{tabular}{c|c|c|c}
\hline Curvas & Limites & Aéreo $\left(\mathbf{k m}^{\mathbf{2}}\right)$ & Rodoviário $\left.\mathbf{( k m}^{\mathbf{2}}\right)$ \\
\hline $\mathrm{L}_{\text {den }} 55$ & $55<\mathrm{L}_{\text {den }} \leq 60$ & 51,7 & 11,1 \\
$\mathrm{~L}_{\text {den }} 60$ & $60<\mathrm{L}_{\text {den }} \leq 65$ & 31,8 & 8,8 \\
$\mathrm{~L}_{\text {den }} 65$ & $65<\mathrm{L}_{\text {den }} \leq 70$ & 12,3 & 4,3 \\
$\mathrm{~L}_{\text {den }} 70$ & $70<\mathrm{L}_{d e n} \leq 75$ & 3,4 & 1,8 \\
$\mathrm{~L}_{\text {den }} 75$ & $\mathrm{~L}_{\text {den }}>75$ & 2,6 & 1,5 \\
\hline
\end{tabular}

Por meio da Tabela 4.1, percebe-se que as áreas das faixas das curvas de ruído $\mathrm{L}_{d e n} 70$ e $\mathrm{L}_{d e n}$ 75 para o modal aéreo possui valores próximos, isso também ocorre para o modal rodoviário. As curvas provenientes do modal aéreo alcançam Regiões Administrativas distantes do sítio aeroportuário. Já as curvas do modal rodoviário se encontram restritas ao sítio aeroportuário e regiões circunvizinhas.

Através das áreas de cada curva de ruído para o tráfego aéreo e rodoviário, foi possível obter a População Exposta (PE) por faixa de cada curva de ruído por modal, em relação as populações das Regiões Administrativas expostas, sendo apresentada na Tabela 4.2.

Tabela 4.2: Pop. Exposta Curva de Ruído Aéreo/Rodoviário - Cenário Atual $\left(\mathrm{L}_{d e n}\right)$

\begin{tabular}{|c|c|c|c|c|c|c|c|c|c|c|c|}
\hline \multirow{2}{*}{$\mathbf{R A}$} & \multirow{2}{*}{$\begin{array}{c}\text { Pop. } \\
\text { RA }\end{array}$} & \multicolumn{2}{|c|}{$\mathbf{L}_{d e n} \mathbf{5 5}$} & \multicolumn{2}{|c|}{$\mathbf{L}_{d e n} 60$} & \multicolumn{2}{|c|}{$\mathbf{L}_{d e n} 65$} & \multicolumn{2}{|c|}{$\mathbf{L}_{d e n} \mathbf{7 0}$} & \multicolumn{2}{|c|}{$\mathbf{L}_{d e n} \mathbf{7 5}$} \\
\hline & & Aéreo & Rod. & Aéreo & Rod. & Aéreo & Rod. & Aéreo & Rod. & Aéreo & Rod. \\
\hline Brasília & 221.223 & - & 7.430 & - & 4.442 & - & 3.414 & - & 1.435 & - & - \\
\hline Candangolândia & 16.799 & 3.595 & 1.050 & 1233 & 306 & 519 & - & - & - & - & - \\
\hline Guará & 125.808 & 878 & 350 & 594 & 350 & - & - & - & - & - & - \\
\hline Lago Sul & 31.206 & 6.818 & 2.975 & 3.259 & 3199 & 748 & 2.897 & 35 & 1.432 & - & 732 \\
\hline N. Bandeirante & 23.714 & 22.717 & 9.389 & 8.371 & 7.015 & 1.374 & 6.307 & - & 2.754 & - & - \\
\hline Paranoá & 45.613 & - & - & - & - & - & - & - & - & - & - \\
\hline Riacho Fundo & 37.278 & 1.737 & - & - & - & - & - & - & - & - & - \\
\hline São Sebastião & 97.977 & - & - & - & - & - & - & - & - & - & - \\
\hline Taguatinga & 214.282 & 3.817 & - & - & - & - & - & - & - & - & - \\
\hline TOTAL & 813.900 & 39.562 & 21.195 & 13.457 & 15.312 & 2.641 & 12.618 & 35 & 6.953 & - & 732 \\
\hline
\end{tabular}

Da Tabela 4.2, observa-se para o modal aéreo, na curva $\mathrm{L}_{d e n} 55$, que 39.562 pessoas estão expostas ao ruído aeronáutico. É importante destacar, que nas curvas $\mathrm{L}_{d e n} 60$ e $\mathrm{L}_{d e n} 65$ temse 16.098 pessoas expostas sendo as Regiões Administrativas do Lago Sul e Núcleo 
Bandeirante as mais impactadas pelo ruído das aeronaves. A curva $\mathrm{L}_{d e n} 55$ tem como particularidade o Núcleo Bandeirante possuir uma "PE" de 22.717, significando uma exposição de $95,8 \%$ de sua população total. Ainda para o ruído aeronáutico, foi observado que a curva $\mathrm{L}_{d e n} 70$ ultrapassa os limites da região aeroportuária em direção a áreas habitadas do Lago Sul, expondo 35 residentes. A curva $\mathrm{L}_{d e n} 75$ está contida na região aeroportuária.

Com respeito ao modal rodoviário, pode-se observar da Tabela 4.2, que a curva $\mathrm{L}_{\text {den }} 55$ possui a maior Área e "PE” em relação as demais curvas de ruído, expondo 21.195 pessoas ao ruído do tráfego rodoviário. Vale destacar que as curvas $\mathrm{L}_{d e n} 55$ e $\mathrm{L}_{d e n} 60$ abrangem parte de regiões densamente habitadas expondo uma população de 36.507 pessoas pertencentes a algumas Regiões Administrativas. A curva $\mathrm{L}_{d e n} 65$ expõem a população de 12.618 nas Regiões Administrativas Brasília, Lago Sul e Núcleo Bandeirante, já as curvas $\mathrm{L}_{d e n} 70$ e $\mathrm{L}_{d e n}$ 75 encontram-se nas faixas de rolamento das vias, influenciando a população residente em suas proximidades, além de possuírem áreas com valores bem próximos.

A análise da Figura 4.2 e da Tabela 4.2 permite verificar a alteração do clima acústico da região circunvizinha ao SBBR devido ao modal aéreo e rodoviário. O modal rodoviário expõe uma quantidade maior de habitantes nas curvas no limite $60<\mathrm{L}_{d e n} \leq 75$. Isso deve às residências estarem próximas às vias.

A Tabela 4.3 apresenta o número de pessoas incomodadas (I) e o número de pessoas altamente incomodadas (AI) para o incômodo sonoro com base no nível de ruído.

Tabela 4.3: Pop. Incomodada Curva de Ruído Aéreo/Rodoviário - Cenário Atual L $\mathrm{L}_{d e n}$

\begin{tabular}{c|r|r|r|r|r|r}
\hline \multirow{2}{*}{$\mathbf{L}_{\boldsymbol{d e n}}$} & \multicolumn{2}{|c|}{ PE } & \multicolumn{2}{c|}{ Aéreo } & \multicolumn{2}{c}{ Rodoviário } \\
\cline { 2 - 7 } & Aéreo & Rodoviário & \multicolumn{1}{c|}{$\mathbf{I}^{*}$} & \multicolumn{1}{c|}{ AI* } & \multicolumn{1}{c}{$\mathbf{I}^{*}$} & \multicolumn{1}{c}{ AI* } \\
\hline 55 & 39.562 & 21.194 & 10.993 & 4.061 & 3.713 & 1.354 \\
60 & 13.457 & 15.312 & 5.059 & 2.355 & 3.929 & 1.579 \\
65 & 2.641 & 12.618 & 1.276 & 698 & 4.476 & 2.042 \\
70 & 35 & 5.621 & 21 & 13 & 2.647 & 1.390 \\
75 & - & 732 & - & - & 444 & 269 \\
\hline TOTAL & 55.695 & 56.810 & 17.349 & 7.127 & 15.209 & 6.633 \\
\hline
\end{tabular}

*Percentual determinado com base nos Polinômios da Tabela 2.10

Da Tabela 4.3 tem-se que apesar do modal rodoviário possuir uma maior "PE" em relação ao aéreo, as curvas de ruído aéreo no limite $55<\mathrm{L}_{d e n} \leq 65$ possuem, respectivamente, 5.210 pessoas incomodadas e 2.139 pessoas altamente incomodadas a mais do que as curvas de ruído rodoviário. Todavia, as curvas de ruído rodoviário $\mathrm{L}_{d e n} 70$ e $\mathrm{L}_{\text {den }} 75$ possuem 3.070 pessoas incomodadas e 1.646 pessoas altamente incomodadas a mais do que as curvas de ruído aeroviários. Isso se deve às curvas de ruído aéreo, $\mathrm{L}_{d e n} 70$ e $\mathrm{L}_{d e n} 75$, estarem 
basicamente restritas ao sítio aeroportuário (Figura 4.2) e pelas residências estarem próximas as vias, sendo assim, expostas as curvas de ruído rodoviário mais intensas.

A Diretiva Europeia 2002/49/CE estabelece como valores limites de exposição para áreas estritamente residenciais um valor de $\mathrm{L}_{d e n} \leq 55$ e para áreas residenciais circunvizinhas a um aeroporto, grande infraestrutura de transporte, o limite máximo permitido é de $\mathrm{L}_{d e n} \leq 65$. Desse modo, adotando esses limites da CE como referência, constata-se que: 35 pessoas estão expostas a um valor superior ao $\mathrm{L}_{\text {den }} 65$ para o ruído aeronáutico, e 6.353 indivíduos estão expostos a um valor superior ao $\mathrm{L}_{d e n} 65$ para o ruído rodoviário. Sendo assim, o ruído proveniente do modal rodoviário é o que expõem um maior número de pessoas a limites superiores ao $\mathrm{L}_{d e n} 65$ impactando significativamente a paisagem sonora da região.

Com as curvas de ruído para a métrica $\mathrm{L}_{n}$ simuladas, foram confeccionadas as cartas de ruído, a Figura 4.5 apresenta a Carta de Ruído Aéreo, a Figura 4.6 exibe a Carta de Ruído Rodoviário e a Figura 4.7 mostra a Carta de Ruído Combinado para esse cenário. 


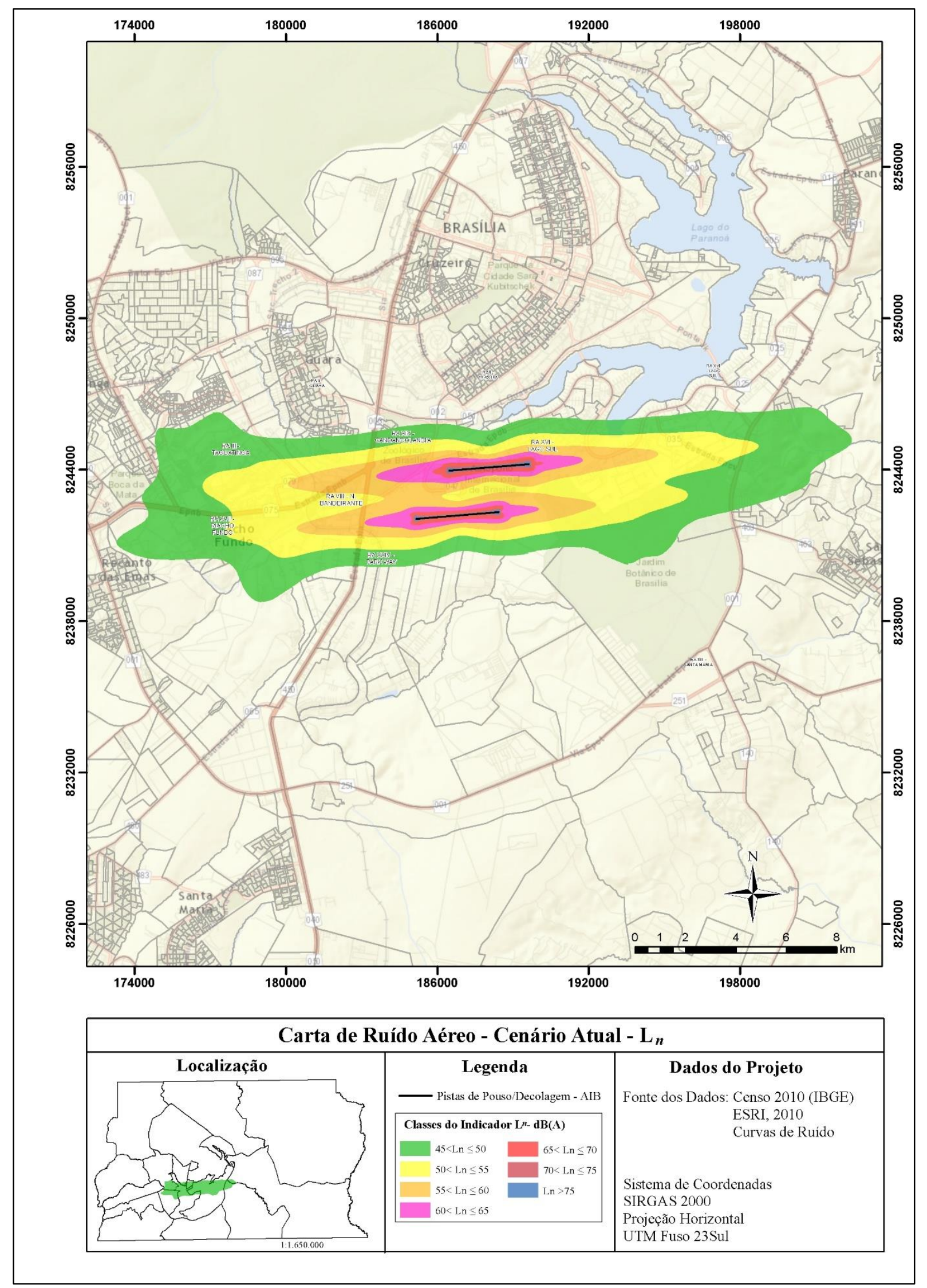

Figura 4.5: Carta de Ruído Aéreo - Cenário Atual $\left(\mathrm{L}_{n}\right)$ 


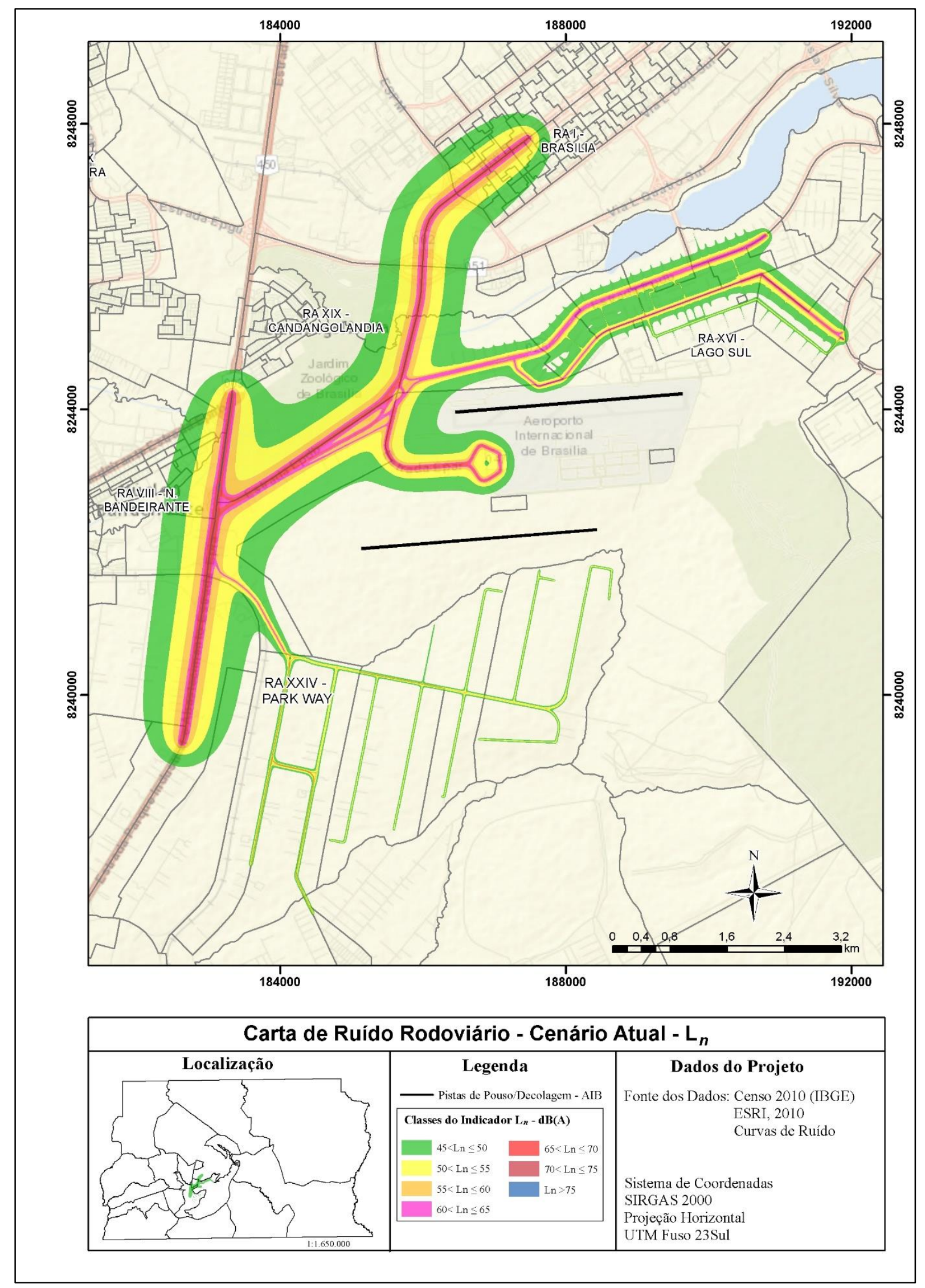

Figura 4.6: Carta de Ruído Rodoviário - Cenário Atual $\left(\mathrm{L}_{n}\right)$ 


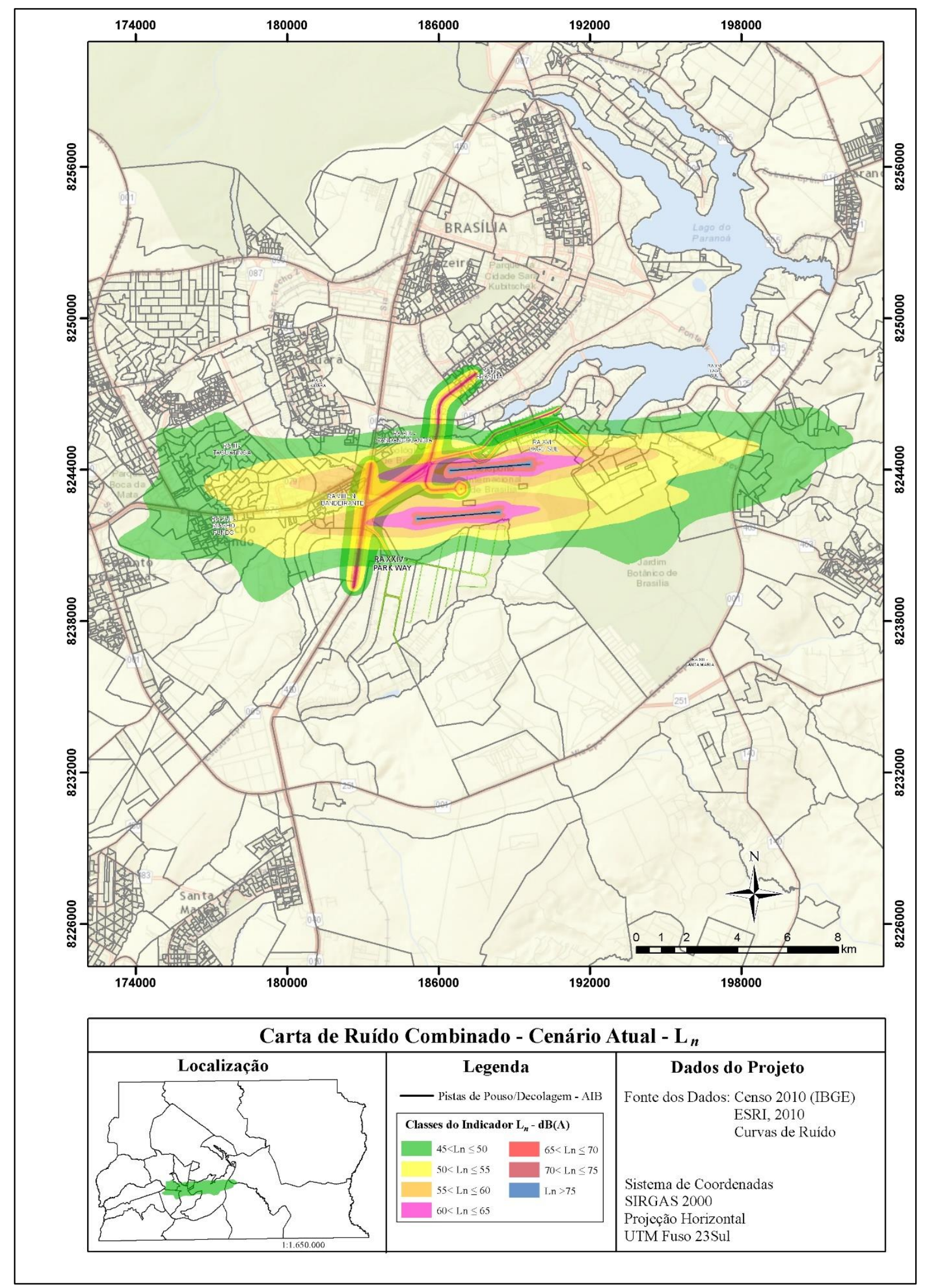

Figura 4.7: Carta de Ruído Combinado (Aéreo e Rodoviário) - Cenário Atual $\left(\mathrm{L}_{n}\right)$ 
A Figura 4.7 mostra a sobreposição das curvas de ruído aéreo e rodoviário, ou seja, sobreposição das curvas de ruído mostradas nas Figuras 4.5 e 4.6. Dessa figura, pode-se observar que as curvas no limite $55<\mathrm{L}_{n} \leq 65$ estão mais próximas ao sítio aeroportuário e áreas circunvizinhas, principalmente sobre as vias DF 047 e DF 025. Já as curvas maiores que o $\mathrm{L}_{n} 70$ estão no entorno das pistas do SBBR.

Na Tabela 4.4 expõem as áreas sobre cada faixa das curvas de ruído Aéreo e rodoviário para a métrica $\mathrm{L}_{n}$.

Tabela 4.4: Áreas das Curvas de Ruído Aéreo/Rodoviário - Cenário Atual $\left(\mathrm{L}_{n}\right)$

\begin{tabular}{c|c|c|c}
\hline Curvas & Limites & Aéreo $\left(\mathbf{k m}^{2}\right)$ & Rodoviário $\left(\mathbf{k m}^{2}\right)$ \\
\hline $\mathrm{L}_{n} 45$ & $45<\mathrm{L}_{n} \leq 50$ & 66,2 & 10,7 \\
$\mathrm{~L}_{n} 50$ & $50<\mathrm{L}_{n} \leq 55$ & 40,3 & 7,6 \\
$\mathrm{~L}_{n} 55$ & $55<\mathrm{L}_{n} \leq 60$ & 20,6 & 2,6 \\
$\mathrm{~L}_{n} 60$ & $60<\mathrm{L}_{n} \leq 65$ & 6,6 & 1,5 \\
$\mathrm{~L}_{n} 65$ & $65<\mathrm{L}_{n} \leq 70$ & 1,9 & 0,8 \\
$\mathrm{~L}_{n} 70$ & $\mathrm{~L}_{n}>70$ & 1,6 & 0,5 \\
\hline
\end{tabular}

Por meio da Tabela 4.4, percebe-se que as áreas das faixas das curvas de ruído $\mathrm{L}_{n} 65$ e $\mathrm{L}_{n} 70$ para o modal aéreo possui valores próximos, isso também ocorre para o modal rodoviário. As curvas provenientes do modal aéreo alcançam Regiões Administrativas distantes do sítio aeroportuário. Já as curvas do modal rodoviário se encontram restritas ao sítio aeroportuário e regiões circunvizinhas.

Por meio das áreas de cada curva de ruído para o tráfego aéreo e rodoviário, foi possível obter a População Exposta por faixa de cada curva de ruído por modal, em relação as populações das Regiões Administrativas expostas, sendo apresentada na Tabela 4.5. Por não apresentar nenhum dado, o $\mathrm{L}_{n} 70$ não consta nesta Tabela.

Tabela 4.5: Pop. Exposta Curva de Ruído Aéreo/Rodoviário - Cenário Atual $\left(\mathrm{L}_{n}\right)$

\begin{tabular}{|c|c|c|c|c|c|c|c|c|c|c|c|}
\hline \multirow{2}{*}{ RA } & \multirow{2}{*}{$\begin{array}{c}\text { Pop. } \\
\text { RA }\end{array}$} & \multicolumn{2}{|c|}{$L_{n} 45$} & \multicolumn{2}{|c|}{$\mathbf{L}_{n} \mathbf{5 0}$} & \multicolumn{2}{|c|}{$\mathbf{L}_{n} 55$} & \multicolumn{2}{|c|}{$\mathrm{L}_{n} 60$} & \multicolumn{2}{|c|}{$L_{n} 65$} \\
\hline & & Aéreo & Rod. & Aéreo & Rod. & Aéreo & Rod. & Aéreo & Rod. & Aéreo & Rod. \\
\hline Brasília & 221.223 & 1.702 & 9.249 & - & 5.683 & - & 4.367 & - & 3.345 & - & - \\
\hline Candangolândia & 16.799 & 9.674 & 856 & 4.342 & 392 & 1.370 & - & 627 & - & - & - \\
\hline Guará & 125.808 & 5.193 & 448 & 1.187 & 448 & 716 & - & - & - & - & - \\
\hline Lago Sul & 31.206 & 10.500 & 4.082 & 9.252 & 4.093 & 7.032 & 3.706 & 1.487 & 1.659 & 43 & - \\
\hline N. Bandeirante & 23.714 & 8.012 & 12.010 & 17.244 & 8.287 & 19.537 & 7.597 & 1.656 & 431 & - & - \\
\hline Paranoá & 45.613 & 2.997 & - & & - & - & - & - & - & - & - \\
\hline Riacho Fundo & 37.278 & 21.961 & - & 4.925 & - & - & - & - & - & - & - \\
\hline São Sebastião & 97.977 & 5.923 & - & 1.121 & - & - & - & - & - & - & - \\
\hline Taguatinga & 214.282 & 25.764 & - & 12.191 & - & - & - & - & - & - & - \\
\hline TOTAL & 813.900 & 91.726 & 26.645 & 50.263 & 18.901 & 28.655 & 15.670 & 3.770 & 5.435 & 43 & - \\
\hline
\end{tabular}


Da Tabela 4.5, observa-se para o modal aéreo, na curva $L_{n} 45$, que 91.726 pessoas estão expostas ao ruído aeronáutico, sendo as Regiões Administrativas Riacho Fundo e Taguatinga para essa curva as mais impactadas. Cabe ressaltar, que nas curvas $\mathrm{L}_{n} 50$ e $\mathrm{L}_{n} 55$ tem-se 78.918 pessoas expostas, sendo a RA Núcleo Bandeirante a mais impactada pelo ruído das aeronaves. Ainda para o ruído aeronáutico, foi observado que a curva $\mathrm{L}_{n} 60$ ultrapassa os limites da região aeroportuária em direção a áreas habitadas do Lago Sul, expondo 1.487 residentes. A curva $\mathrm{L}_{n} 65$ expõem 43 pessoas.

Com respeito ao modal rodoviário, pode-se observar na Tabela 4.5, que a curva $\mathrm{L}_{n} 45$ possui a maior Área e "PE” em relação as demais curvas de ruído, expondo 26.645 pessoas ao ruído do tráfego rodoviário. Vale destacar que as curvas $\mathrm{L}_{n} 45, \mathrm{~L}_{n} 50$ e $\mathrm{L}_{n} 55$ abrangem parte de regiões densamente habitadas expondo uma população de 61.216 pessoas pertencentes a algumas Regiões Administrativas. A curva $\mathrm{L}_{n} 60$ expõem a população de 12.618 nas Regiões Administrativas Brasília, Lago Sul e Núcleo Bandeirante, já as curvas $\mathrm{L}_{n} 65$ e $\mathrm{L}_{n} 70$ encontram-se nas faixas de rolamento das vias, influenciando a população residente em suas proximidades.

A Tabela 4.6 apresenta o número de pessoas com o sono levemente perturbado (PSLP), quantidade de pessoas com distúrbios no sono (PDS), e o número de pessoas com o sono altamente perturbado (PSAP).

Tabela 4.6: Pessoas Distúrbios no Sono Ruído Aéreo/Rodoviário - Cenário Atual $\left(\mathrm{L}_{n}\right)$

\begin{tabular}{|c|c|c|c|c|c|c|c|c|}
\hline \multirow{2}{*}{$\mathbf{L}_{n}$} & \multicolumn{2}{|c|}{ PE } & \multicolumn{3}{|c|}{ Aéreo } & \multicolumn{3}{|c|}{ Rodoviário } \\
\hline & Aéreo & Rod. & PSLP* & PDS* & PSAP* & PSLP* & PDS* & PSAP* \\
\hline $\mathrm{L}_{n} 45$ & 28.655 & 26.645 & 4.074 & 2.547 & 1.472 & 5.516 & 2.505 & 959 \\
\hline $\mathrm{L}_{n} 50$ & 50.263 & 18.901 & 9.444 & 6.152 & 3.718 & 5.028 & 2.476 & 1.021 \\
\hline $\mathrm{L}_{n} 55$ & 28.655 & 15.670 & 6.894 & 4.690 & 2.979 & 5.187 & 2.758 & 1.238 \\
\hline $\mathrm{L}_{n} 60$ & 3.770 & 5.435 & 1.132 & 802 & 533 & 2.179 & 1.245 & 609 \\
\hline $\mathrm{L}_{n} 65$ & 43 & - & 16 & 12 & 8 & - & - & - \\
\hline $\mathrm{L}_{n} 70$ & - & - & - & - & - & - & - & - \\
\hline TOTAL & 111.429 & 66.651 & 21.560 & 14.203 & 8.711 & 17.910 & 8.984 & 3.827 \\
\hline
\end{tabular}

Da Tabela 4.6, tem-se que modal aéreo possui maior quantidade de "PE", as curvas aéreas no limite $45<\mathrm{L}_{n} \leq 50$ possuem respectivamente 8.699 pessoas com distúrbios no sono, 8.026 pessoas com o sono levemente perturbado e 3.512 pessoas com o sono altamente perturbado. De acordo com norma NBR 13.368 (ABNT,1995), destas curvas não são esperadas reclamações, reações ou queixas esporádicas por parte da população exposta. Já as curvas aéreas no limite $55<\mathrm{L}_{n} \leq 60$ possuem 5.492 pessoas com distúrbios no sono, 13.518 pessoas com o sono levemente perturbado e 5.190 pessoas com o sono altamente 
perturbado e de acordo com a norma, são esperadas queixas generalizadas e possíveis ações da comunidade, podendo ocorrer principalmente na curva $\mathrm{L}_{n} 60$.

A Diretiva Europeia 2002/49/CE estabelece como valores limites de exposição para áreas estritamente residenciais um valor de $\mathrm{L}_{n} \leq 45$ e para áreas residenciais circunvizinhas a um aeroporto, grande infraestrutura de transporte, o limite máximo permitido é de $\mathrm{L}_{n} \leq 55$. Desse modo, adotando esses limites da CE como referência, constata-se que: 3.813 pessoas estão expostas a uma curva de ruído aéreo no limite $60<\mathrm{L}_{n} \leq 65$, e 5.435 indivíduos estão expostos para esse limite na curva de ruído rodoviário. Sendo assim, o ruído proveniente do modal rodoviário expõem um maior número de pessoas a limites superiores ao $\mathrm{L}_{n} 60$ impactando significativamente a paisagem sonora da região.

Com respeito ao modal rodoviário, as curvas $\mathrm{L}_{n} 45$ e $\mathrm{L}_{n} 50$ possuem 4.981 pessoas com distúrbios no sono, 10.544 pessoas com o sono levemente perturbado e 1.980 pessoas com o sono altamente perturbado. Destas curvas, de acordo com norma NBR 10.151 (ABNT,2000), não são esperadas reclamações, reações ou queixas esporádicas por parte da população exposta. Já a curva $\mathrm{L}_{n} 55$ e $\mathrm{L}_{n} 60$ possuem 4.003 pessoas com distúrbios no sono, 7.366 pessoas com o sono levemente perturbado e 1.847 pessoas com o sono altamente perturbado e de acordo com esta norma, a curva $L_{n} 55$ é aceitável para regiões de área mista sendo inadequado para regiões sensíveis e com referência a curva $\mathrm{L}_{n} 60$ é esperado queixas generalizadas.

A partir do analise das Cartas de Ruído Aéreo e Rodoviário para as duas métricas $\mathrm{L}_{n} \mathrm{e} \mathrm{L}_{d e n}$ no Cenário Acústico Atual, percebe-se que nas populações do Lago Sul e Núcleo Bandeirante que se encontram em locais das curvas de ruído que estão em desacordo com as normas, podem sofrer danos à saúde. O modal aéreo pode ser alvo de ações contrárias às operações aéreas em alguns horários ou até mesmo por algumas rotas. Além da possibilidade de conflitos entre a comunidade e os gestores do aeroporto e do transporte no DF.

\subsubsection{Cenário Acústico Futuro}

Esse cenário acústico possui como característica a redução de $20 \%$ do tráfego rodoviário nas vias de estudo com a possível implantação do modal ferroviário. As cartas de ruído foram confeccionadas as métrica $\mathrm{L}_{d e n}$, a Figura 4.8 é exposto a Carta de Ruído Rodoviário, na Figura 4.9 a Carta de Ruído Ferroviário e na Figura 4.10 a Carta de Ruído Combinado. 


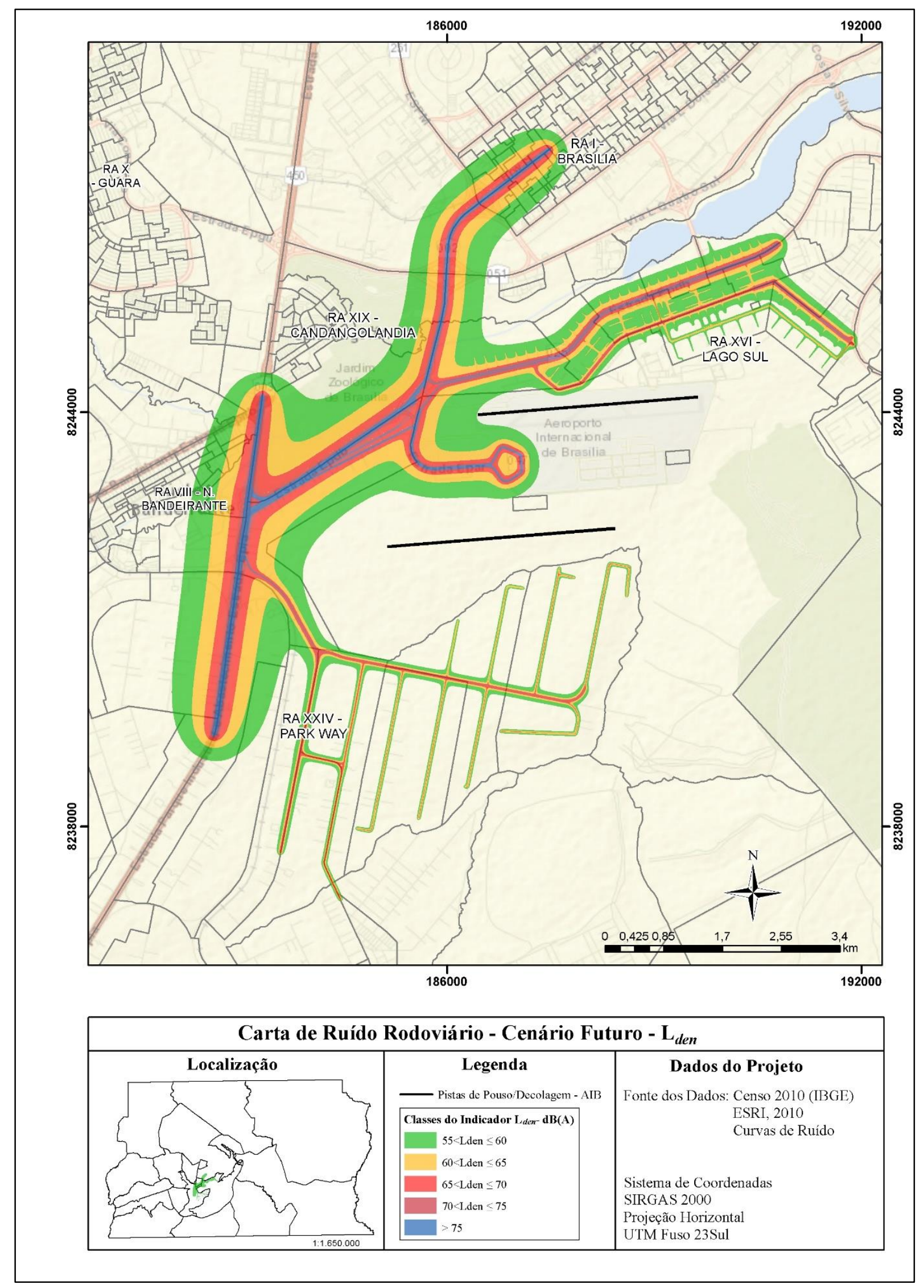

Figura 4.8: Carta de Ruído Rodoviário - Cenário Futuro $\left(\mathrm{L}_{d e n}\right)$ 


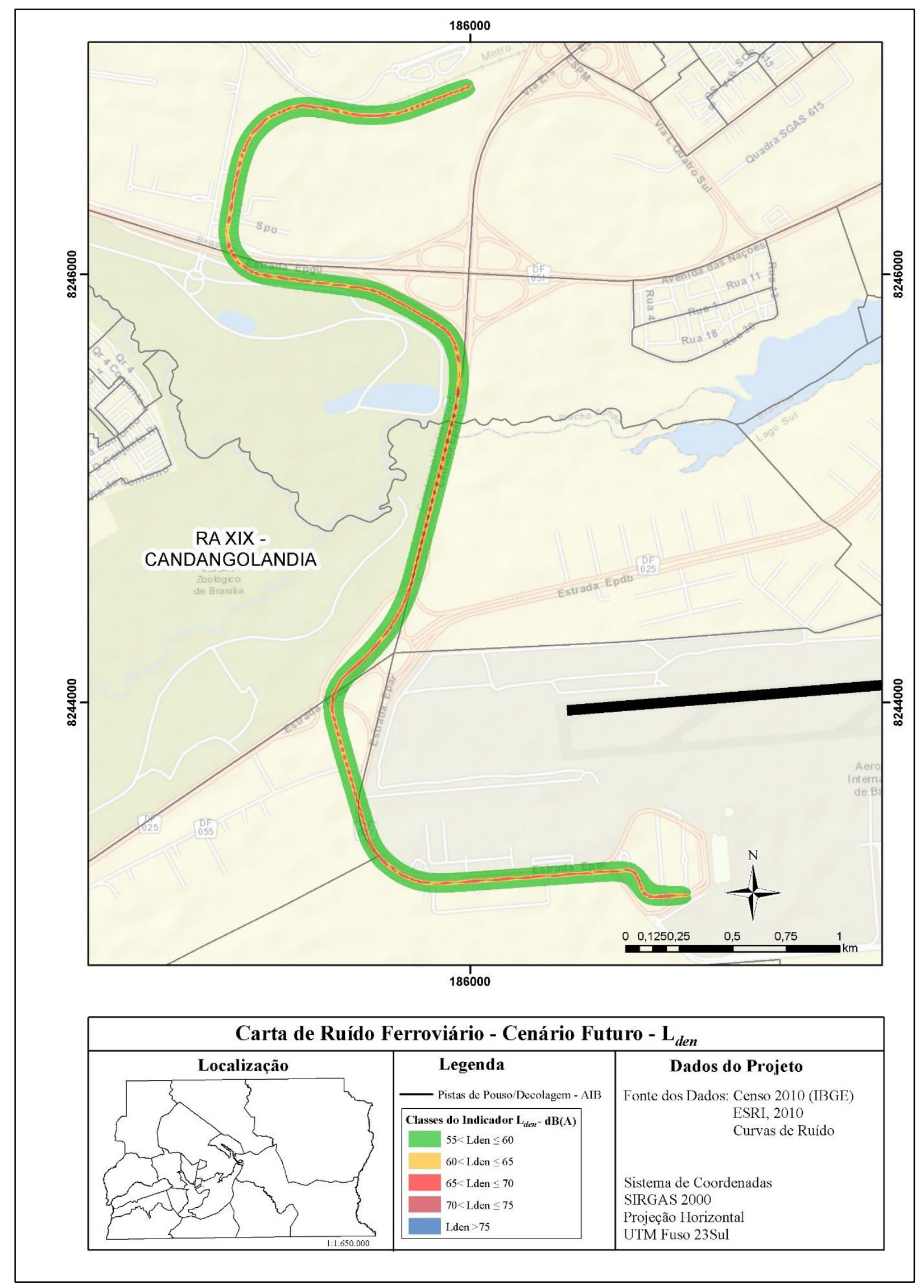

Figura 4.9: Carta de Ruído Ferroviário - Cenário Futuro $\left(\mathrm{L}_{d e n}\right)$ 


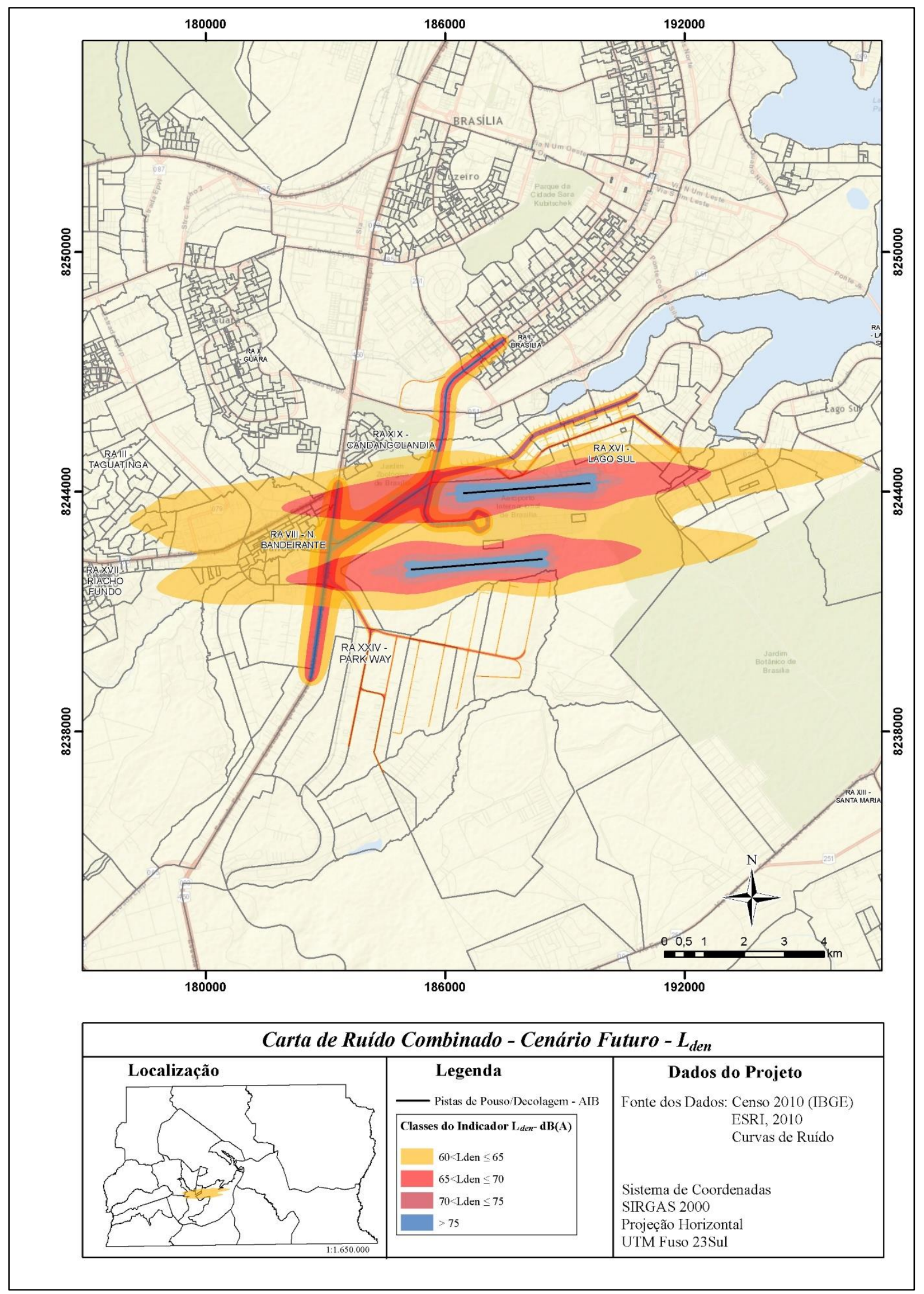

Figura 4.10: Carta de Ruído Combinado (Aéreo, Rodoviário e Ferroviário) - Cenário Futuro $\left(\mathrm{L}_{d e n}\right)$ 
A Figura 4.10 mostra a sobreposição das curvas de ruído aéreo e rodoviário+VLT, ou seja, sobreposição das curvas de ruído mostradas nas Figuras 4.8 e 4.9. Dessa figura, pode-se observar que as curvas no limite $65<\mathrm{L}_{d e n} \leq 75$ estão mais próximas ao sítio aeroportuário e áreas circunvizinhas. Já as curvas maiores que o $\mathrm{L}_{d e n} 75$ estão no entorno das pistas do SBBR.

Na Tabela 4.7 expõem a área sobre cada faixa das curvas de ruído rodoviário para a métrica $\mathrm{L}_{d e n}$.

Tabela 4.7: Área das Curvas de Ruído Rodoviário - Cenário Futuro ( $\left.\mathrm{L}_{d e n}\right)$

\begin{tabular}{c|c|c}
\hline Curvas & Limites & Área $\left(\mathbf{k m}^{2}\right)$ \\
\hline $\mathrm{L}_{d e n} 55$ & $55<\mathrm{L}_{d e n} \leq 60$ & 10,9 \\
$\mathrm{~L}_{d e n} 60$ & $60<\mathrm{L}_{d e n} \leq 65$ & 8,5 \\
$\mathrm{~L}_{d e n} 65$ & $65<\mathrm{L}_{d e n} \leq 70$ & 4,1 \\
$\mathrm{~L}_{d e n} 70$ & $70<\mathrm{L}_{d e n} \leq 75$ & 1,7 \\
$\mathrm{~L}_{d e n} 75$ & $\mathrm{~L}_{d e n}>75$ & 1,5 \\
\hline
\end{tabular}

Por meio da Tabela 4.7, percebe-se que as áreas das faixas das curvas de ruído $\mathrm{L}_{d e n} 70$ e $\mathrm{L}_{d e n}$ 75 possui valores próximos e que as curvas do tráfego rodoviário se encontram restritas ao sítio aeroportuário e regiões circunvizinhas.

Através das áreas de cada curva de ruído para o tráfego rodoviário, foi possível obter a População Exposta por faixa de cada curva de ruído, em relação as populações das Regiões Administrativas expostas, sendo apresentada na Tabela 4.8. Por questão de aparência e não apresentar nenhum dado, o $\mathrm{L}_{\text {den }} 75$ não consta na Tabela.

Tabela 4.8: Pop. Exposta Curva de Ruído Rodoviário - Cenário Futuro $\left(\mathrm{L}_{d e n}\right)$

\begin{tabular}{l|r|r|r|r|r}
\hline \multicolumn{1}{c|}{ RA } & Pop. RA & $\mathbf{L}_{\text {den }} \mathbf{5 5}$ & $\mathbf{L}_{\text {den }} \mathbf{6 0}$ & $\mathbf{L}_{\text {den }} \mathbf{6 5}$ & $\mathbf{L}_{\text {den }} \mathbf{7 0}$ \\
\hline Brasília & 221.223 & 6.985 & 4.339 & 2.994 & 1.256 \\
Candangolândia & 16.799 & 1.026 & 299 & - & - \\
Guará & 125.808 & 342 & - & - & - \\
Lago Sul & 31.206 & 2.906 & 3.125 & 2.830 & - \\
N. Bandeirante & 23.714 & 9.391 & 6.853 & 6.161 & 2.345 \\
\hline \multicolumn{1}{c|}{ TOTAL } & 418.750 & 20.650 & 14.616 & 11.985 & 3.601 \\
\hline
\end{tabular}

A partir Tabela 4.8, pode-se observar que a curva $\mathrm{L}_{d e n} 55$ possui a maior Área e "PE" em relação as demais curvas de ruído, expondo 20.650 pessoas ao ruído do tráfego rodoviário. Vale destacar que as curvas $\mathrm{L}_{d e n} 55$ e $\mathrm{L}_{d e n} 60$ abrangem parte de regiões densamente habitadas expondo uma população de 35.608 pessoas pertencentes a algumas Regiões Administrativas. A curva $\mathrm{L}_{d e n} 65$ expõem a população de 11.985 nas Regiões Administrativas Brasília, Lago Sul e Núcleo Bandeirante, já a curvas $\mathrm{L}_{d e n} 70$ e $\mathrm{L}_{d e n} 75$ encontram-se nas faixas de rolamento das vias. A curva $\mathrm{L}_{d e n} 70$ possui 3.601 pessoas expostas da população residente em suas proximidades e a $\mathrm{L}_{d e n} 75$ não expõem a população. 
A Tabela 4.9 apresenta o número de pessoas incomodadas (I) e o número de pessoas altamente incomodadas (AI) para o incômodo sonoro com base no nível de ruído.

Tabela 4.9: Pop. Incomodada Ruído Rodoviário - Cenário Futuro $\left(\mathrm{L}_{d e n}\right)$

\begin{tabular}{c|r|r|r}
\hline $\mathbf{L}_{\text {den }}$ & \multicolumn{1}{|c|}{$\mathbf{P E}$} & \multicolumn{1}{c|}{$\mathbf{I}^{*}$} & \multicolumn{1}{c}{$\mathbf{A I}^{*}$} \\
\hline 55 & 20.650 & 3.618 & 1.320 \\
60 & 14.616 & 3.750 & 1.507 \\
65 & 11.985 & 4.251 & 1.939 \\
70 & 3.601 & 1.696 & 891 \\
75 & - & - & - \\
\hline TOTAL & 50.852 & 13.315 & 5.656 \\
\hline
\end{tabular}

*Percentual determinado com base nos Polinômios da Tabela 2.10

Da Tabela 4.9, as curvas de ruído rodoviário no limite $55<\mathrm{L}_{d e n} \leq 60$ possuem, respectivamente 7.368 pessoas incomodadas e 2.827 pessoas altamente incomodadas A curva no limite $65<\mathrm{L}_{d e n} \leq 70$, possui 5.947 pessoas incomodadas e 2.831 pessoas altamente incomodadas.

A Diretiva Europeia 2002/49/CE estabelece como valores limites de exposição para áreas estritamente residenciais um valor de $\mathrm{L}_{d e n} \leq 55$ e para áreas residenciais circunvizinhas a um aeroporto, grande infraestrutura de transporte, o limite máximo permitido é de $\mathrm{L}_{d e n} \leq 65$. Desse modo, adotando esses limites da CE como referência, constata-se que: 3.601 pessoas estão expostas a um valor superior ao $\mathrm{L}_{\text {den }} 65$ para o ruído rodoviário, impactando significativamente a paisagem sonora da região.

Com respeito Figura 4.9, que apresenta a Carta de Ruído Ferroviário $\mathrm{L}_{d e n}$, percebe-se que o Trecho 1, inicialmente proposto, não passa por áreas habitadas, não sendo necessário determinar as áreas das curvas de ruído por faixa e nem a população exposta. Esse trecho passa por uma área de proteção ambiental, o Santuário da Vida Silvestre do Riacho Fundo (ARIE), sendo necessário um cuidado especial na implantação do sistema. Também contempla a região comercial do AIB, acarretando alterações no clima acústico da região e modificando, assim o NPS em frente aos comércios, mas a tendência é não impactar significativamente as áreas vizinhas a linha planejada.

Com as curvas de ruído para a métrica $\mathrm{L}_{n}$ foram confeccionadas as cartas de ruído, a Figura 4.11 é exposto a Carta de Ruído Rodoviário, na Figura 4.12 a Carta de Ruído Ferroviário e na Figura 4.13 a Carta de Ruído Combinado. 


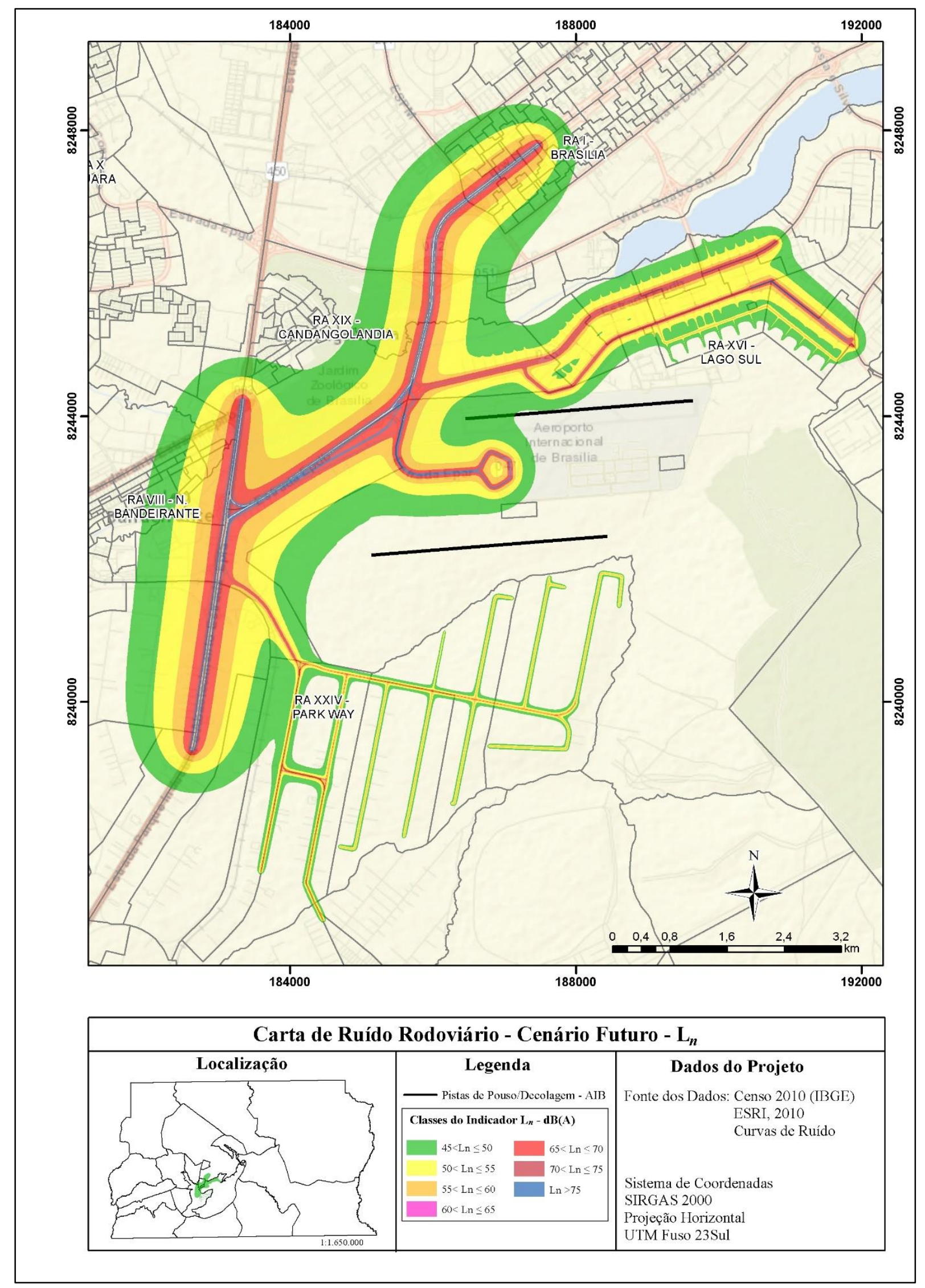

Figura 4.11: Carta de Ruído Rodoviário - Cenário Futuro $\left(\mathrm{L}_{n}\right)$ 


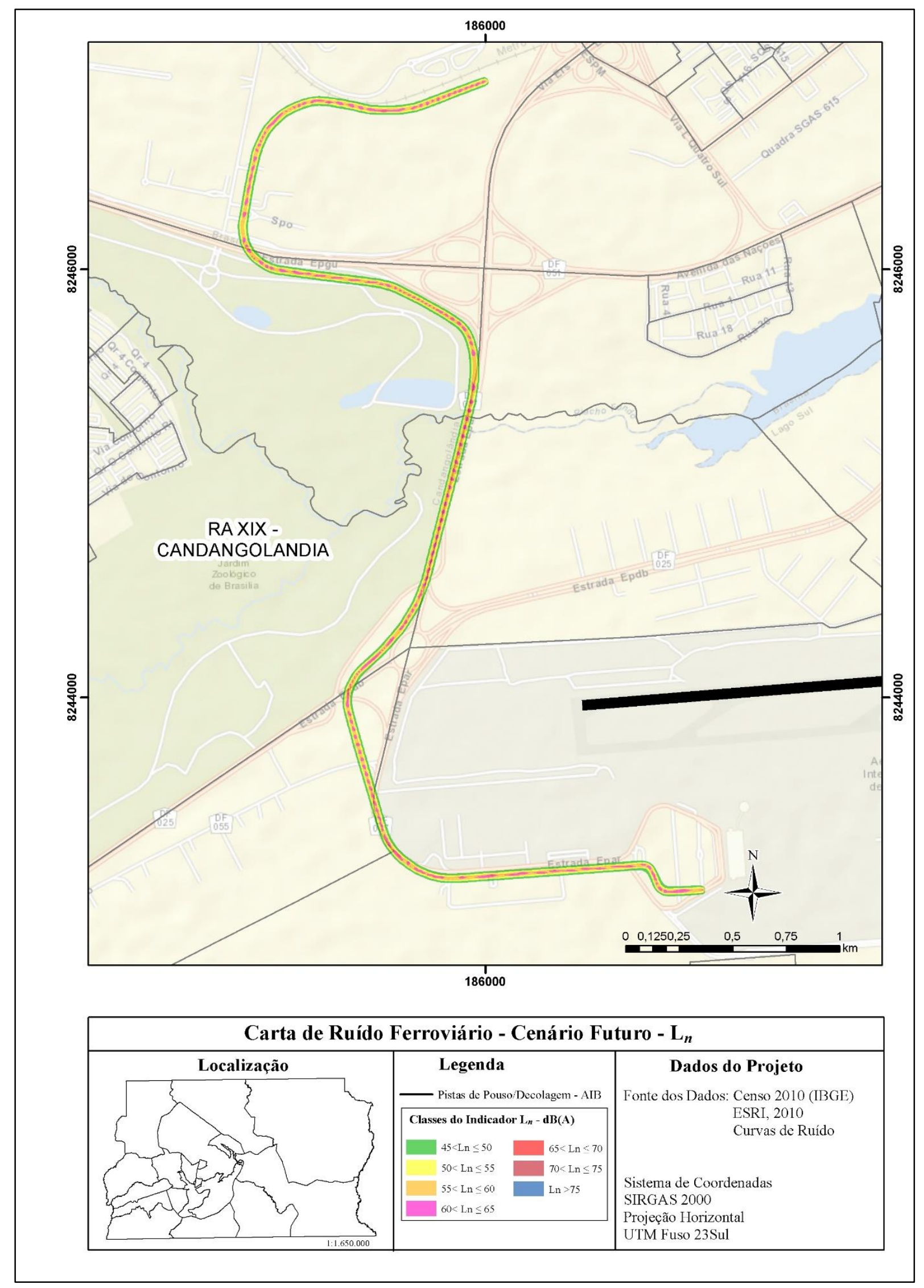

Figura 4.12: Carta de Ruído Ferroviário - Cenário Futuro $\left(\mathrm{L}_{n}\right)$ 


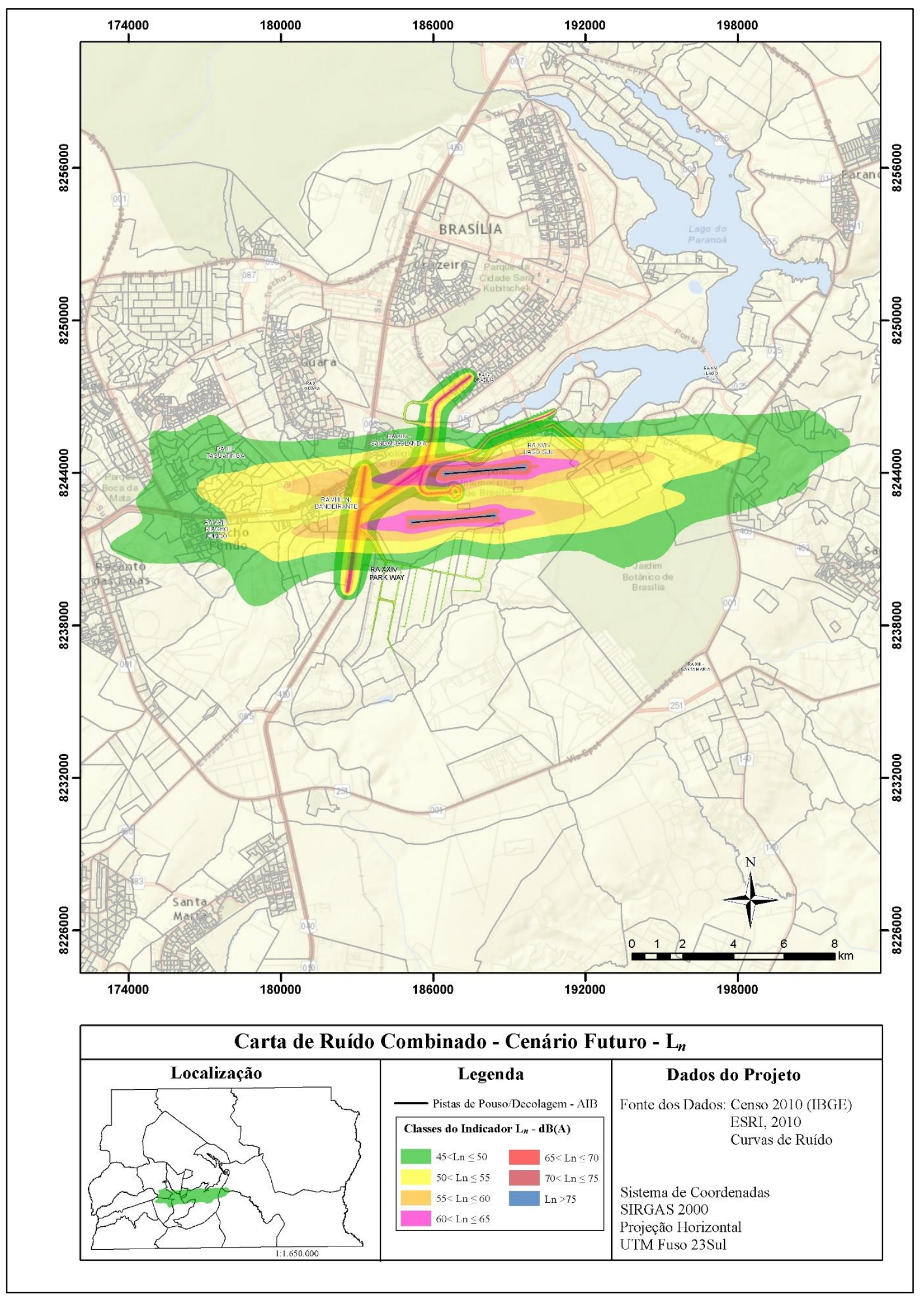

Figura 4.13: Carta de Ruído Combinado (Aéreo, Rodoviário e Ferroviário) - Cenário Futuro $\left(\mathrm{L}_{n}\right)$ 
A Figura 4.13 mostra a sobreposição das curvas de ruído aéreo e rodoviário+VLT, ou seja, sobreposição das curvas de ruído mostradas nas Figuras 4.11 e 4.12. Dessa figura, pode-se observar que as curvas no limite $55<\mathrm{L}_{n} \leq 65$ estão mais próximas ao sítio aeroportuário e áreas circunvizinhas, principalmente sobre as vias DF 047 e DF 025. Já as curvas maiores que o $\mathrm{L}_{n} 70$ estão no entorno das pistas do SBBR.

Na Tabela 4.10 expõem a área sobre cada faixa das curvas de ruído rodoviário para a métrica $\mathrm{L}_{n}$.

Tabela 4.10: Área das Curvas de Ruído Rodoviário - Cenário Futuro $\left(\mathrm{L}_{n}\right)$

\begin{tabular}{c|c|c}
\hline Curvas & Limites & Área $\left(\mathbf{k m}^{2}\right)$ \\
\hline $\mathrm{L}_{n} 45$ & $45<\mathrm{L}_{n} \leq 50$ & 10,2 \\
$\mathrm{~L}_{n} 50$ & $50<\mathrm{L}_{n} \leq 55$ & 7,1 \\
$\mathrm{~L}_{n} 55$ & $55<\mathrm{L}_{n} \leq 60$ & 2,4 \\
$\mathrm{~L}_{n} 60$ & $60<\mathrm{L}_{n} \leq 65$ & 1,4 \\
$\mathrm{~L}_{n} 65$ & $65<\mathrm{L}_{n} \leq 70$ & 0,7 \\
$\mathrm{~L}_{n} 70$ & $\mathrm{~L}_{n}>70$ & 0,4 \\
\hline
\end{tabular}

Por meio da Tabela 4.10, percebe-se que as áreas das faixas das curvas de ruído $\mathrm{L}_{n} 65$ e $\mathrm{L}_{n}$ 70 para o modal rodoviário possui valores próximos. A partir das áreas de cada curva de ruído, foi possível obter a População Exposta, em relação as populações das Regiões Administrativas, sendo apresentada na Tabela 4.11. Por não apresentar População Exposta, o $\mathrm{L}_{n} 65$ e $\mathrm{L}_{n} 70$ não constam nesta Tabela.

Tabela 4.11: Pop. Exposta para Curva de Ruído Rodoviário - Cenário Futuro $\left(\mathrm{L}_{n}\right)$

\begin{tabular}{|c|c|c|c|c|c|c|c|c|c|}
\hline \multirow{2}{*}{$\mathbf{R A}$} & \multirow{2}{*}{$\begin{array}{c}\text { Pop. } \\
\text { RA }\end{array}$} & \multicolumn{2}{|c|}{$\mathrm{L}_{n} 45$} & \multicolumn{2}{|c|}{$\mathbf{L}_{n} \mathbf{5 0}$} & \multicolumn{2}{|c|}{$\mathbf{L}_{n} 55$} & \multicolumn{2}{|c|}{$\mathrm{L}_{n} 60$} \\
\hline & & PE & $\% \mathbf{P E}$ & PE & $\% \mathrm{PE}$ & $\mathbf{P E}$ & $\% \mathrm{PE}$ & $\mathbf{P E}$ & $\% \mathrm{PE}$ \\
\hline Brasília & 221.223 & 5.184 & 2,3 & 3.100 & 1,4 & 2.382 & 1,1 & 1.931 & 0,9 \\
\hline Candangolândia & 16.799 & 467 & 2,8 & 214 & 1,3 & - & - & - & - \\
\hline Guará & 125.808 & 244 & 0,2 & 244 & 0,2 & - & - & - & - \\
\hline Lago Sul & 31.206 & 2.227 & 7,1 & 2.232 & 7,2 & 2.021 & 6,5 & 1.324 & 4,3 \\
\hline N. Bandeirante & 23.714 & 6.551 & 27,6 & 4.520 & 19,1 & 4.144 & 17,5 & 213 & 0,8 \\
\hline TOTAL & 418.750 & 14.673 & 3,5 & 10.310 & 2,5 & 8.547 & 2,1 & 3.468 & 0,9 \\
\hline
\end{tabular}

Através da Tabela 4.11 percebe-se que a curva $\mathrm{L}_{n} 45$ possui a maior Área e "PE" em relação as demais curvas de ruído, expondo 14.673 pessoas ao ruído do tráfego rodoviário. Vale destacar que as curvas $\mathrm{L}_{n} 45, \mathrm{~L}_{n} 50$ e $\mathrm{L}_{n} 55$ abrangem parte de regiões densamente habitadas expondo uma população de 33.530 pessoas pertencentes a algumas Regiões Administrativas. A curva $\mathrm{L}_{n} 60$ expõem a população de 3.468 pessoas nas Regiões Administrativas Brasília, Lago Sul e Núcleo Bandeirante, já as curvas $\mathrm{L}_{n} 65$ e $\mathrm{L}_{n} 70$ encontram-se nas faixas de rolamento das vias, influenciando a população residente em suas proximidades.

A Tabela 4.12 apresenta o número de pessoas com o sono levemente perturbado (PSLP), 
quantidade de pessoas com distúrbios no sono (PDS), e o número de pessoas com o sono altamente perturbado (PSAP).

Tabela 4.12: Ruído Rodoviário Cenário Futuro $\mathrm{L}_{n}$ - Pessoas com Distúrbios no Sono

\begin{tabular}{c|r|r|r|r}
\hline $\mathbf{L}_{n}$ & \multicolumn{1}{|c|}{ PE } & PSLP* & PDS* & PSAP* \\
\hline $\mathrm{L}_{n} 45$ & 14.673 & 3.037 & 1.379 & 528 \\
$\mathrm{~L}_{n} 50$ & 10.310 & 2.742 & 1.351 & 557 \\
$\mathrm{~L}_{n} 55$ & 8.547 & 2.829 & 1.504 & 675 \\
$\mathrm{~L}_{n} 60$ & 3.468 & 1.391 & 794 & 388 \\
$\mathrm{~L}_{n} 65$ & - & - & - & - \\
$\mathrm{L}_{n} 70$ & - & - & - & - \\
\hline TOTAL & 38.960 & 9.999 & 5.028 & 2.149 \\
\hline
\end{tabular}

*Percentual determinado com base nos Polinômios da Tabela 2.11

Da Tabela 4.12, tem-se que as curvas rodoviárias no limite $45<\mathrm{L}_{n} \leq 50$ possuem respectivamente 2.730 pessoas com distúrbios no sono, 5.779 pessoas com o sono levemente perturbado e 1.085 pessoas com o sono altamente perturbado. Destas curvas, de acordo com norma NBR 10.151 (ABNT,2000), não são esperadas reclamações, reações ou queixas esporádicas por parte da população exposta, Já a curva $55<\mathrm{L}_{n} \leq 60$ possuem 2.298 pessoas com distúrbios no sono, 4.220 pessoas com o sono levemente perturbado e 1.063 pessoas com o sono altamente perturbado e de acordo são esperadas queixas generalizadas e possíveis ações da comunidade, podendo ocorrer principalmente na curva $L_{n} 60$.

A Diretiva Europeia 2002/49/CE estabelece como valores limites de exposição para áreas estritamente residenciais um valor de $\mathrm{L}_{n} \leq 45$ e para áreas residenciais circunvizinhas a um aeroporto, grande infraestrutura de transporte, o limite máximo permitido é de $\mathrm{L}_{n} \leq 55$. Desse modo, adotando esses limites da CE como referência, constata-se que 3.468 pessoas estão expostas a uma curva de ruído rodoviário no limite $60<\mathrm{L}_{n} \leq 65$ expondo um número de pessoas a limites superiores ao $\mathrm{L}_{n} 60$ e impactando significativamente a paisagem sonora da região.

A partir do analise das Cartas de Ruído Aéreo e Rodoviário para as duas métricas $\mathrm{L}_{n}$ e $\mathrm{L}_{d e n}$ no Cenário Atual, percebe-se que as populações do Lago Sul e Núcleo Bandeirante que se encontram em locais das curvas de ruído que estão em desacordo com as normas, podem sofrer danos à saúde. O modal aéreo pode ser alvo de ações contrárias às operações aéreas em alguns horários ou até mesmo por algumas rotas. Além da possibilidade de conflitos entre a comunidade e os gestores do aeroporto e do transporte no DF. 
A Figura 4.12, apresenta a Carta de Ruído Ferroviário $\mathrm{L}_{n}$, como foi citado anteriormente, devido a ferrovia não passar por áreas habitadas, não é necessário determinar as áreas das curvas por faixa e nem a população exposta. Para o período noturno a tendência é de não impactar significativamente as áreas vizinhas a linha planejada.

\subsubsection{Diferenças entre os Cenários Acústicos}

A Tabela 4.13 exibe a diferença da "PE" entre os Cenários para as curvas de ruído rodoviário e a Tabela 4.14 apresenta a Diferença entre a população incomodada para as curvas de ruído rodoviário, para a métrica $\mathrm{L}_{d e n}$.

Tabela 4.13: Diferença "PE" entre os Cenários para o Modal Rodoviário $\left(\mathrm{L}_{d e n}\right)$

\begin{tabular}{l|r|r|r|r|r}
\hline \multicolumn{1}{c|}{$\mathbf{R A}$} & $\mathbf{L}_{\boldsymbol{d e n}} \mathbf{5 5}$ & $\mathbf{L}_{\boldsymbol{d e n}} \mathbf{6 0}$ & $\mathbf{L}_{\boldsymbol{d e n}} \mathbf{6 5}$ & $\mathbf{L}_{\boldsymbol{d e n}} \mathbf{7 0}$ & $\mathbf{L}_{\boldsymbol{d e n}} \mathbf{7 5}$ \\
\hline Brasília & 445 & 103 & 420 & 179 & - \\
Candangolândia & 24 & 7 & - & - & - \\
Guará & 8 & 350 & - & - & - \\
Lago Sul & 69 & 74 & 67 & 1.432 & 732 \\
N. Bandeirante & -2 & 162 & 146 & 409 & - \\
\hline TOTAL & 546 & 696 & 633 & 2.020 & 732 \\
\hline
\end{tabular}

Tabela 4.14: Diferença Pop. Incomodada entre os Cenários para o Modal Rodoviário $\left(\mathrm{L}_{d e n}\right)$

\begin{tabular}{c|r|r|r}
\hline $\mathbf{L}_{\text {den }}$ & \multicolumn{1}{|c|}{ PE } & \multicolumn{1}{|c|}{ I } & \multicolumn{1}{c}{ AI } \\
\hline 55 & 546 & 95 & 35 \\
60 & 606 & 179 & 72 \\
65 & 633 & 225 & 102 \\
70 & 2.020 & 951 & 500 \\
75 & 732 & 444 & 269 \\
\hline TOTAL & 4.627 & 1.894 & 977 \\
\hline
\end{tabular}

Por meio dessas Tabelas, é possível perceber uma pequena redução da população exposta, principalmente das incomodadas para a métrica $\mathrm{L}_{d e n}$. Essa redução é perceptível ao compararmos as Cartas de Ruído Rodoviário nos dois Cenários. É importante essa diminuição e tem como característica uma pequena melhora do clima acústico na região para esse período e modal, podendo assim, diminuir a possibilidade de queixas generalizadas para os habitantes residentes nas curvas $\mathrm{L}_{d e n} 65, \mathrm{~L}_{d e n} 70$ e $\mathrm{L}_{d e n} 75$, além da possível diminuição de pessoas com problemas de saúde.

A Tabela 4.15 exibe a diferença da "PE" entre os Cenários para as curvas de ruído rodoviário e a Tabela 4.16 apresenta a Diferença entre a população incomodada para as curvas de ruído rodoviário, para a métrica $\mathrm{L}_{n}$. 
Tabela 4.15: Diferença PE entre os Cenários para o Modal Rodoviário $\left(\mathrm{L}_{n}\right)$

\begin{tabular}{l|r|r|r|r|r|r}
\hline \multicolumn{1}{c}{$\mathbf{R A}$} & \multicolumn{1}{c}{$\mathbf{L}_{\boldsymbol{n}} \mathbf{4 5}$} & \multicolumn{1}{c}{$\mathbf{L}_{\boldsymbol{n}} \mathbf{5 0}$} & \multicolumn{1}{c}{$\mathbf{L}_{\boldsymbol{n}} \mathbf{5 5}$} & \multicolumn{1}{c}{$\mathbf{L}_{\boldsymbol{n}} \mathbf{6 0}$} & $\mathbf{L}_{\boldsymbol{n}} \mathbf{6 5}$ & $\mathbf{L}_{\boldsymbol{n}} \mathbf{7 0}$ \\
\hline Brasília & 4.065 & 2.583 & 1.985 & 1.414 & - & - \\
Candangolândia & 389 & 178 & 0 & 0 & - & - \\
Guará & 204 & 204 & 0 & 0 & - & - \\
Lago Sul & 1.855 & 1.861 & 1.685 & 335 & - & - \\
N. Bandeirante & 5.459 & 3.767 & 3.453 & 218 & - & - \\
\hline TOTAL & 11.972 & 8.591 & 7.123 & 1.967 & - & - \\
\hline
\end{tabular}

Tabela 4.16: Diferença Distúrbios no Sono entre os Cenários para o Modal Rodoviário $\left(\mathrm{L}_{n}\right)$

\begin{tabular}{c|r|r|r|r}
\hline $\mathbf{L}_{n}$ & \multicolumn{1}{|c|}{ PE } & PSLP & PDS & PSAP \\
\hline 45 & 11.972 & 2.479 & 1.126 & 431 \\
50 & 8.591 & 2.286 & 1.125 & 464 \\
55 & 7.123 & 2.358 & 1.254 & 563 \\
60 & 1.967 & 788 & 451 & 221 \\
65 & - & - & - & - \\
70 & - & - & - & - \\
\hline TOTAL & 27.691 & 7.911 & 3.956 & 1.678 \\
\hline
\end{tabular}

Por meio destas Tabelas, é possível perceber a redução significativa da população exposta, principalmente das que possuem distúrbios no sono. Ao compararmos as Cartas de Ruído Rodoviário nos dois Cenários, é perceptível essa diminuição e tem como principal importância a melhoria do clima acústico na região para esse período, podendo assim, diminuir a possibilidade de queixas generalizadas para os habitantes residentes nas curvas $\mathrm{L}_{n} 55$ e $\mathrm{L}_{n} 60$, além da possível diminuição de pessoas com problemas de saúde.

A Tabela 4.17 apresenta os resultados e diferenças entre os valores simulados para o ruído combinado dos cenários apresentados nas Figuras 4.4 e 4.10. A tabela mostra apenas os pontos que possuem alterações dos valores, a partir das especificidades dos cenários. Estes são referentes as curvas de ruído com a métrica $\mathrm{L}_{d e n}$. Os resultados dos demais pontos se encontram no Apêndice " C". 
Tabela 4.17: Resultados Ruído Combinado $\mathrm{L}_{d e n}-\mathrm{dB}(\mathrm{A})$

\begin{tabular}{c|ccc|ccc|c}
\hline \multirow{2}{*}{ Pontos } & \multicolumn{3}{|c|}{ Cenário Atual } & \multicolumn{3}{c|}{ Cenário Futuro } & \multirow{2}{*}{ Diferença } \\
\cline { 2 - 6 } & Rodoviário & Aéreo & Combinado & Rod. + VLT & Aéreo & Combinado & \\
\hline RC03 & 71,3 & 64,9 & 72,2 & 70,4 & 64,9 & 71,5 & 0,7 \\
RC04 & 68,7 & 64,9 & 70,2 & 67,9 & 64,9 & 69,7 & 0,5 \\
RC25 & 74,8 & 67,7 & 75,6 & 74,5 & 67,7 & 75,3 & 0,2 \\
RC26 & 70,4 & 64,8 & 71,5 & 70,2 & 64,8 & 71,3 & 0,2 \\
RC27 & 62,6 & 65,9 & 67,6 & 61,7 & 65,9 & 67,3 & 0,3 \\
RC28 & 72,0 & 62,8 & 72,5 & 71,0 & 62,8 & 71,6 & 0,9 \\
RC41 & 77,9 & 68,4 & 78,4 & 77,3 & 68,4 & 77,8 & 0,5 \\
RC42 & 74,3 & 70,8 & 75,9 & 73,4 & 70,8 & 75,3 & 0,6 \\
RC43 & 68,3 & 66,1 & 70,3 & 67,4 & 66,1 & 69,8 & 0,5 \\
RC44 & 68,9 & 65,8 & 70,6 & 68,0 & 65,8 & 70,0 & 0,6 \\
RC45 & 70,3 & 65,8 & 71,6 & 69,3 & 65,8 & 70,9 & 0,7 \\
RC46 & 75,3 & 65,9 & 75,8 & 73,4 & 65,9 & 74,1 & 1,7 \\
RC47 & 70,8 & 65,5 & 71,9 & 70,2 & 65,5 & 71,5 & 0,5 \\
RC48 & 72,6 & 65,5 & 73,4 & 71,7 & 65,5 & 72,6 & 0,7 \\
RC49 & 69,4 & 65,5 & 70,9 & 68,9 & 65,5 & 70,5 & 0,3 \\
RC50 & 71,1 & 62,7 & 71,7 & 70,2 & 62,7 & 70,9 & 0,8 \\
RC51 & 72,4 & 63,0 & 72,9 & 71,4 & 63,0 & 72,0 & 0,9 \\
RC52 & 73,9 & 63,5 & 74,3 & 72,9 & 63,5 & 73,4 & 0,9 \\
RC53 & 73,7 & 64,3 & 74,2 & 72,8 & 64,3 & 73,4 & 0,8 \\
RC54 & 78,4 & 69,1 & 78,9 & 78,3 & 69,1 & 78,8 & 0,1 \\
RC55 & 68,4 & 69,9 & 72,2 & 67,5 & 69,9 & 71,9 & 0,4 \\
RC56 & 73,3 & 70,4 & 75,1 & 72,5 & 70,4 & 74,6 & 0,5 \\
RC57 & 57,6 & 49,4 & 58,2 & 57,0 & 49,4 & 57,7 & 0,5 \\
RC58 & 67,5 & 49,4 & 67,6 & 66,7 & 49,4 & 66,8 & 0,8 \\
RC59 & 67,9 & 69,9 & 72,0 & 67,3 & 69,9 & 71,8 & 0,2 \\
RC60 & 54,6 & 53,3 & 57,0 & 53,9 & 53,3 & 56,6 & 0,4 \\
\hline & & & & & & &
\end{tabular}

Por meio desta tabela, é possível perceber que a maioria dos valores de NPS para estes pontos dos Cenários Atual e Futuro se encontram elevados, sendo visível nas Figura 4.4 e 4.10. Este fato é devido a maioria dos pontos se encontrarem próximos as vias. A maior diferença foi de $1,7 \mathrm{~dB}(\mathrm{~A})$ e ocorreu no ponto RC46. Outras diferenças também ocorram nos pontos RC28, RC51 e RC52 sendo de 0,9 dB(A) e os pontos RC50, RC53 e RC58 com uma diferença de $0,8 \mathrm{~dB}(\mathrm{~A})$.

A Tabela 4.18 apresenta os resultados e diferenças entre os valores simulados para o ruído combinado dos cenários apresentados nas Figuras 4.7 e 4.13. A tabela mostra apenas os pontos que possuem alterações dos valores, a partir das especificidades dos cenários. Estes são referentes as curvas de ruído com a métrica $L_{n}$. Os resultados dos demais pontos se encontram no Apêndice " C". 
Tabela 4.18: Resultados Ruído Combinado $\mathrm{L}_{n}-\mathrm{dB}(\mathrm{A})$

\begin{tabular}{c|ccc|ccc|c}
\hline \multirow{2}{*}{ Pontos } & \multicolumn{3}{|c|}{ Cenário Atual } & \multicolumn{3}{c|}{ Cenário Futuro } & \multirow{2}{*}{ Diferença } \\
\cline { 2 - 6 } & Rodoviário & Aéreo & Combinado & Rod. + VLT & Aéreo & Combinado & \\
\hline RC03 & 58,8 & 56,2 & 60,7 & 58,0 & 56,2 & 60,2 & 0,5 \\
RC04 & 56,0 & 56,2 & 59,1 & 55,8 & 56,2 & 59,0 & 0,1 \\
RC25 & 61,4 & 59,0 & 63,4 & 61,0 & 59,0 & 63,1 & 0,2 \\
RC26 & 56,4 & 56,4 & 59,4 & 56,2 & 56,4 & 59,3 & 0,1 \\
RC27 & 49,9 & 57,5 & 58,2 & 49,2 & 57,5 & 58,1 & 0,1 \\
RC28 & 59,3 & 54,2 & 60,5 & 58,4 & 54,2 & 59,8 & 0,7 \\
RC41 & 65,2 & 60,2 & 66,4 & 65,5 & 60,2 & 66,6 & $-0,2$ \\
RC42 & 61,6 & 62,7 & 65,2 & 60,9 & 62,7 & 64,9 & 0,3 \\
RC43 & 55,6 & 57,8 & 59,8 & 55,0 & 57,8 & 59,6 & 0,2 \\
RC44 & 56,3 & 57,4 & 59,9 & 55,4 & 57,4 & 59,5 & 0,4 \\
RC45 & 57,6 & 57,4 & 60,5 & 56,7 & 57,4 & 60,1 & 0,4 \\
RC46 & 62,5 & 57,5 & 63,7 & 62,8 & 57,5 & 63,9 & $-0,2$ \\
RC47 & 58,1 & 57,1 & 60,6 & 58,4 & 57,1 & 60,8 & $-0,2$ \\
RC48 & 59,9 & 57,0 & 61,7 & 59,1 & 57,0 & 61,2 & 0,5 \\
RC49 & 56,6 & 57,0 & 59,8 & 56,7 & 57,0 & 59,9 & 0,0 \\
RC50 & 58,4 & 54,1 & 59,8 & 57,5 & 54,1 & 59,1 & 0,6 \\
RC51 & 59,6 & 54,5 & 60,8 & 58,7 & 54,5 & 60,1 & 0,7 \\
RC52 & 61,2 & 55,0 & 62,1 & 60,3 & 55,0 & 61,4 & 0,7 \\
RC53 & 61,6 & 55,9 & 62,6 & 60,7 & 55,9 & 61,9 & 0,7 \\
RC54 & 64,0 & 60,4 & 65,6 & 63,8 & 60,4 & 65,4 & 0,1 \\
RC55 & 56,3 & 61,9 & 63,0 & 55,4 & 61,9 & 62,8 & 0,2 \\
RC56 & 63,4 & 62,4 & 65,9 & 62,8 & 62,4 & 65,6 & 0,3 \\
RC57 & 47,7 & 40,9 & 48,5 & 47,4 & 40,9 & 48,3 & 0,2 \\
RC58 & 57,6 & 40,9 & 57,7 & 56,9 & 40,9 & 57,0 & 0,7 \\
RC59 & 56,9 & 61,8 & 63,0 & 56,5 & 61,8 & 62,9 & 0,1 \\
RC60 & 44,7 & 44,8 & 47,8 & 44,2 & 44,8 & 47,5 & 0,2 \\
\hline
\end{tabular}

Por meio desta tabela, é possível perceber que a maioria dos valores de NPS para estes pontos dos Cenários Atual e Futuro se encontram elevados para o período noturno, sendo visível nas Figura 4.7 e 4.13. Este fato é devido os pontos estarem próximos as vias. A maior diferença foi de 0,7 dB(A) e ocorreu nos pontos RC28, RC51 e RC52. Os pontos RC41, RC46 e RC47 obtiveram -0,2 dB(A), significando que o Cenário Futuro nestes pontos ficaram mais ruidosos, como o valor é muito pequeno, pode-se dizer que nestes pontos não ocorreram alterações.

\subsection{RELAÇAO RUÍDO E POLO GERADOR DE VIAGENS}

Uma das características do PGV aeroporto é ocasionar impactos indesejáveis e de diferentes intensidades em seu sítio aeroportuário e entorno. Como exemplo, congestionamentos em sua área de influência, poluições sonoras e atmosféricas, bem como o aumento de estacionamentos irregulares, conflitos entre o tráfego local e de passagem e dificuldades nas operações de embarque e desembarque de passageiros e mercadorias. Tais impactos variam de acordo com as características e dimensões, sendo importante conhecer as causas destes, para que assim, medidas mitigadoras possam ser propostas. 
O aumento da utilização do modal aéreo nos últimos anos, tem intensificado o tráfego rodoviário de veículos particulares, no deslocamento de passageiros ao acesso/egresso à região aeroportuária. Em conjunto com esta movimentação, as cidades têm crescido ao redor dos sítios aeroportuários e também gerando uma maior utilização do modal rodoviário em seu entorno, penalizando, assim, ainda mais o seu clima acústico.

Como consequência, com a intensificação da utilização dos meios de transportes, têm alterado o "clima acústico" da região do AIB e propiciado discussões entre comunidade, governo e gestores do PGV aeroporto. Como resultado dessas discussões e com o intuito de reduzir o ruído principalmente no período noturno, pode ser exigido pelo órgão fiscalizador, alterações dos horários de funcionamento do aeroporto, dos tipos de aviões e das rotas utilizadas para pouso e decolagem. Neste sentido, é necessário compreender a influência de um PGV aeroporto no clima acústico da região onde ele se encontra.

A partir das simulações realizadas neste trabalho, as quais resultaram a determinação do panorama acústico da região do AIB devido ao ruído gerado por vários modais (ruído combinado), é possível observar nas Figuras 4.4, 4.7, 4.10 e 4.11, que as áreas mais impactadas pelo ruído, encontram-se especificamente no PGV Aeroporto Internacional de Brasília e sua circunvizinhança. Isto ocorre devido a influência do volume de tráfego por suas vias e também pelas operações aéreas diárias. Podendo assim, relacionar geração de viagens rodoviárias à emissão de ruído, ocasionadas por um PGV aeroporto. Portanto, essa relação, PGV aeroporto com ruído combinado entre os modais de transportes (aéreo, rodoviário e ferroviário) em sua região de influência, deve atender as necessidades de deslocamentos, de forma a ofertar múltiplas escolhas aos usuários, proporcionando assim, mobilidade e acessibilidade, bem como a atenuação do clima acústico da região. 


\section{CAPÍTULO 5. CONCLUSÕES E RECOMENDAÇÕES}

\subsection{CONCLUSÕES}

Atualmente no Brasil, os estudos em "acústica ambiental" analisados nesse trabalho, estão voltados apenas para o ruído proveniente de um único modal, e não foram encontradas até o momento, pesquisas que relacionem PGV aeroporto com ruído combinado. Sendo assim, percebe-se que apenas o modal rodoviário tem atendido as movimentações nas regiões destes PGV's. Como consequência, as vias estão sobrecarregadas, prejudicando a locomoção da população nesta região, e assim, gerando incômodo. Em outros países como a China, Índia Japão e Emirados Árabes (Dubai), o tema: efeitos de ruídos combinado é estudado, de modo a ressaltar a alteração do clima acústico em uma determinada região e como ele é modificado ao combinar os ruídos emitidos pelos modais.

É importante salientar a necessidade de se avaliar ao mesmo tempo, o ruído procedente dos modais, no intuito de quantificar as suas influências sobre a população, bem como os impactos no meio ambiente e na saúde das pessoas. A modificação na paisagem sonora na região aeroportuária pode proporcionar efeitos nocivos à saúde humana que contribuem diretamente com a perda auditiva e o desenvolvimento de doenças como hipertensão, problemas cardíacos, psicológicos, emocionais, estresses e males associados aos distúrbios no sono.

Neste sentido, este estudo determinou o nível de pressão sonora, devido ao ruído combinado dos modais de transportes aéreo, rodoviário e ferroviário na região do PGV Aeroporto Internacional de Brasília, e assim as devidas cartas de ruído combinado. Sendo também identificado a partir das cartas de ruído a Região Administrativa do Núcleo Bandeirante e do Lago Sul como as mais afetadas pelos ruídos dos modais.

O impacto sonoro para o período dia-entardecer-noite, permitiu verificar a existência da alteração do clima acústico da região do PGV AIB. Essa alteração é devido ao ruído combinado dos modais de transporte, possuindo maior intensidade nas curvas de ruído $\mathrm{L}_{d e n}$ 65, L den 70 e $\mathrm{L}_{\text {den }}$ 75. Já a avaliação do impacto sonoro para o período noturno, apresenta potencial de gerar incômodos podendo ocasionar perturbações no sono principalmente no interior das curvas de ruído $\mathrm{L}_{n} 55$ e $\mathrm{L}_{n}$ 60, consideradas mais críticas, e ainda com possibilidade de queixas generalizadas com possíveis ações comunitárias. 
No Brasil, não há termos de referências de estudos ambientais que contemplem a métrica $\mathrm{L}_{d e n}$, a qual é sugerida pela Comunidade Europeia para avaliação do impacto sonoro. Desta forma, propõe-se aqui, que esta métrica seja empregada em avaliações destes impactos. Sendo assim, é necessário que sejam adotadas, no plano diretor das cidades brasileiras, a utilização de cartas acústicas com a finalidade de avaliar o clima acústico.

Utilizando o estudo realizado como referência é possível afirmar que uma alternativa para viabilizar os acessos/egressos aos PGV aeroportos no Brasil, é a adoção de um modelo de transporte que facilite a mobilidade e acessibilidade. A implantação de um modal sustentável e de alta capacidade, no caso o modal ferroviário (VLT ou metrô), é o mais adequado para os grandes centros urbanos. A integração entre os modais pode significar uma redução de tempo no acesso, bem como suscitar uma escolha coerente, proporcionando, assim, benefícios significativos não só para o meio ambiente, mas também para as pessoas que residem no entorno deste Polo Gerador de Viagens.

Por fim, espera-se que este estudo, realizado com o objetivo de elaborar cartas acústicas e identificar as áreas mais afetadas pelo ruído combinado dos modais, sejam úteis no planejamento de transportes na região de um PGV aeroporto.

\subsection{LIMITAÇÕES DO ESTUDO}

Como limitação deste estudo, destaca-se da falta da integração entre os softwares CadnaA e INM, isso devido à licença disponibilizada para as simulações e modelagens do estudo, impossibilitando a simulação do ruído combinado entre os modais aéreo, rodoviário e ferroviário. Também, como fator limitante a dificuldade de encontrar estudos que relacionem PGV com ruído. Outro fator de limitação do estudo foi a baixa densidade populacional ao redor das vias estudas e do próprio sítio aeroportuário e sua região circunvizinha, obtendo resultados de pouca expressividade entre os cenários propostos.

\subsection{RECOMENDAÇÕES PARA TRABALHOS FUTUROS}

Recomenda-se para trabalhos futuros:

- Relacionar a taxa de geração de viagens por passageiro hora pico com o ruído combinado da região do Aeroporto Internacional de Brasília. 
- Realizar a integração entre a carta de ruído acústica devido ao modal rodoviário com a avaliação dose-respostas, para determinar os níveis de incômodo e de distúrbio no sono na região do Aeroporto Internacional de Brasília, devido ao este modal.

- Aplicar este estudo em um aeroporto que possua em seu sítio aeroportuário e região circunvizinha uma densidade populacional maior do que o AIB. 


\section{REFERÊNCIAS BIBLIOGRÁFICAS}

Abdala, P. J. P. (2005): Método para Dimensionar Curvas de Ruído para Zoneamento no Entorno de Pequenos Aeródromos. Dissertação de Mestrado. Universidade Federal do Rio de Janeiro (UFRJ). Rio de Janeiro Agência Nacional de Aviação Civil (2014) - ANAC: Anuário do Transporte Aéreo 2013: Dados Estatísticos e Econômicos. Disponível em: http://www2.anac.gov.br/estatistica/anuarios.asp (Acesso em 12 de novembro de 2014).

Alarcão, D.; Coelho, J. L. B. (2008): Modelação de Ruído de Tráfego Ferroviário. Acústica 2008, Universidade de Coimbra, Portugal.

Albuquerque, S. M.: Ferrovias (2011): Aspectos Técnicos de Projeto. Instituto Tecnológico de Aeronáutica, São José dos Campos.

Almeida M., Bragança L., Nogueira M. (2004): Mapa de ruído de Guimarães, Comparação e Validação dos Resultados Obtidos Através de um Método de Simulação Automático, Acústica 2004, Guimarães, Portugal.

Alves, B. B.; Strambi, O. (2011): Escolha de Modo no Acesso Terrestre a Aeroportos Considerando a Confiabilidade no Tempo de Viagem. Transportes, Vol. XIX, nº 1, p. 59-67.

Aniceto, C. A. (2010): Avaliação de Impactes Urbanísticos do Novo Aeroporto de Lisboa na Península de Setúbal Nascente. Dissertação de Mestrado. Faculdade de Ciências Sócias e Humanas - Universidade Nova de Lisboa. Portugal.

Agência Portuguesa do Ambiente - APA (2011): Diretrizes para Elaboração de Mapas de Ruídos. Disponível: http://www.apambiente.pt/_zdata/DAR/Ruido/NotasTecnicas_EstudosReferencia/DirectrizesMapasDe z2011_todo_pdf. Acesso em: 02/11/2012.

ABNT. NBR (1990) - 11.145: Acústica - Ruído Aeronáutico. Associação Brasileira de Normas Técnicas, Rio de Janeiro.

ABNT. NBR (1995) - 13.368: Acústica - Ruído Gerado por Aeronaves - monitoração. Associação Brasileira de Normas Técnicas, Rio de Janeiro.

ABNT. NBR (2000) - 10.151: Acústica - Avaliação de ruído em áreas habitadas, visando o conforto da comunidade - procedimento. Associação Brasileira de Normas Técnicas, Rio de Janeiro.

Babisch W. (2002): The Noise/Stress Concept, Risk Assessment and Research Needs. Noise \& Health 4: 1-11. Babisch, W.; Houthuijs, D.; Pershagen, G.; Cadum, E.; Katsouyanni, K.; Velonakis, M.; Dudley, M. L.; Marohn, H. D.; Swart, W.; Breugelmans, O.; Bluhm, G.; Selander, J.; Vigna-Taglianti, F.; Pisani, S.; Haralabidis, A.; Dimakopoulou, K.; Zachos, I.; Jarup, L (2009): Annoyance Due to Aircraft Noise has Increased Over the Years-Results of the HYENA Study. Environment Internacional. V. 35, n. 8, p. 11691176.

Banks, S. e Dinges, D. F. (2007): Behavioral and Physiological Consequences Of Sleep Restriction. Journal of Clinical Sleep Medicine, v.3, p. 519-528.

Barbosa, A. R. (2011): Influência do Ruído Aeronáutico na População que Reside nas Imediações da Base Área de Santa Maria. (Dissertação de Mestrado) Departamento de Engenharia Civil, Universidade de Santa Maria, Santa Maria, Brasil. 
Basner, M.; Müller, U.; Elmenhorst, E. M. (2011): Single and Combined Effects of Air, Road, and Rail Traffic Noise on Sleep and Recuperation. Sleep, v. 34, p. 11-23.

Basner, M.; Babisch, W.; Davis, A.; Brink, M.; Clark, C.; Janssen, S.; Stansfeld, S. (2013): Auditory and NonAuditory Effects of Noise on Health. Disponível em: http://dx.doi.org/10.1016/S0140-6736(13)61613$\mathrm{X}$ (Acesso em 27 de fevereiro de 2015)

Bento, E. F. M. (2011): A Incomodidade do Ruído: Relações com o Nível de Exposição Sonoro e Identidade de Lugar. Dissertação de Mestrado Integrado em Psicologia. Universidade de Lisboa. Lisboa, Portugal.

Bistafa, S. R. (2011): Acústica Aplicada ao Controle do Ruído. 2a Edição, Editora Edgar Blücher, São Paulo, Brasil.

Bonatto, A. S. (2013): Caracterização e Simulação do Ruído Aerodinâmico Gerado por Slats. (Dissertação de Mestrado), Escola Politécnica da Universidade de São Paulo, Departamento de Engenharia Mecânica USP. São Paulo, Brasil.

Brink, M; Lercher, P. (2007): The Effect of Noise from Combined Traffic Noise Sources on Annoyance-The Interaction Between Aircraft and Road Traffic Noise. In: Proceedings of Internoise 2007. Istanbul, Turquia.

Calixto, A. (2002): O Ruído Gerado pelo Tráfego de Veículos em Rodovias-Grandes-Avenidas Situadas Dentro do Perímetro Urbano de Curitiba, Analisado Sob Parâmetros Acústicos Objetivos e Seus Impacto Ambiental. Dissertação de Mestrado, Pós Graduação em Engenharia Mecânica, Setor de Tecnologia da Universidade Federal do Paraná, Curitiba, Brasil.

Carvalho Jr., E. B.; Garavelli, S. L.(2010a): Ruído Ambiental e Seus Efeitos: O Ruído Aeronáutico no Entorno do Aeroporto Internacional de Brasília, PLURIS.

Carvalho Jr., E. B.; Garavelli, S. L. (2010b): Avaliação do Ruído Aeronáutico em Regiões Circunvizinhas ao Aeroporto Internacional de Brasília, PLURIS.

Carvalho Jr, E. B., Garavelli, S. L. e Maroja, A. M. (2012a): Análise dos Efeitos do Ruído Aeronáutico em Zonas Residenciais Circunvizinhas ao Aeroporto Internacional de Brasília. Journal of Transport Literature, vol. 6, n. 4, pp. 59-81.

Carvalho Jr., E. B.; Garavelli, S. L.; Smozinski, F. V. ; Maroja, A. M.; Melo, W. C. (2013b): Análise das Principais Métricas Utilizadas no Zoneamento Acústico de Áreas Próximas a Aeródromos. Journal of Transport Literature, v. 7, p. 175-198.

Carvalho Jr., E. B. (2015): Quantificação do Incômodo Gerado pelo Ruído Aeronáutico por Meio de Modelos Dose-Resposta. Tese de Doutorado em Transportes, Departamento de Engenharia Civil e Ambiental, Universidade de Brasília, Brasília, DF, 182 p.

Carvalho, L., A. (2010): Ferramenta de Auxílio à Aplicação da Abordagem Equilibrada em Aeroportos Brasileiros. Dissertação de Mestrado, UFRJ/COOPE, Rio de Janeiro, Brasil.

Coelho, P. I. S.(2011): Proposta de Procedimento para Analisar o efeito da Qualidade do Ar no Entorno do Aeroporto Internacional Antônio Carlos Jobim. (Tese de Doutorado) COPPE/UFRJ, Rio de Janeiro.

Coelho, P. I. S.; Portugal, L. S. (2012): Procedimento para Analisar os Impactos na Qualidade do Ar em Função da Divisão Modal no Acesso a Aeroportos. In. Licinio da Silva Portugal. (Org.) Polos Geradores de Viagens Orientados à Qualidade de Vida e Ambiental: Modelos e Taxas de Geração de Viagens. $1^{\text {a }}$ Edição. Rio de Janeiro: Interciência, v. 1, p. 567-598. 
Companhia de Engenharia de Tráfego - CET-SP (1983): Polos Geradores de Tráfego. Boletim Técnico n. 32, São Paulo.

Conselho Nacional de Meio Ambiente - CONAMA (1986). Resolução No 001, de 23 de janeiro de 1986. Brasília, Brasil.

Costa, C., A. (2011): Previsão dos Ruídos Ambientais no Setor Noroeste/Brasília-DF. Dissertação de Mestrado, Programa de Pós Graduação em Planejamento Ambiental, UCB, Brasília, Brasil.

Departamento Nacional de Trânsito - DENATRAN (2001). Manual de Procedimentos para o Tratamento de Polos Geradores de Tráfego. Brasília, Brasil.

Departamento de Trânsito do Distrito Federal - DETRAN-DF (2015). Frota de Veículos Registrados no Distrito Federal, 2015. Disponível em: <http://www.detran.df.gov.br/images/07-Junho_Frota.pdf > Acesso em: 20 de fevereiro de 2015.

Distrito Federal. Lei Distrital No 4.092, de 12 de março de 2008. Dispõe Sobre o Controle da Poluição Sonora e os Limites Máximos de Intensidade da Emissão de Sons e Ruídos Resultantes de Atividades Urbanas e Rurais. Disponível em http://www.sedhab.df.gov.br/sites/300/379/00000924.pdf. Acesso em 25 de julho de 2012.

(GDF). Metrô Leve de Brasília (VLT) Brasília; (2012). Disponível em http://www.vlt.df.gov.br/. Acesso em 28 de junho de 2012.

. Lei Distrital No 1.890, de 13 de fevereiro de 1998: (1998). Estabelece o Número Mínimo de Vagas de Estacionamento ou Garagem de Veículos Dentro dos Limites do Lote nas e Edificações que Especifica. Disponível em: http://www.sinj.df.gov.br/SINJ/Arquivo.ashx?id_norma_consolidado=49849. Acesso em 25 de agosto de 2014.

. Secretaria de Estado de Transportes do Distrito Federal (2010). Plano Diretor de Transporte Urbano do Distrito Federal e Entorno. Disponível em: http://www.st.df.gov.br/programas-projetos/pdtu.html. Acesso em 20 de junho de 2014.

Diretiva 2002/49/CE (2002) Diretiva do Parlamento Europeu e do Conselho da União Européia Relativa à Avaliação e Gestão do Ruído Ambiente. Jornal Oficial das Comunidades Europeias, v. L 189/12, p. 48. EC (2002) Position Paper on Dose-Response Relationships Between Transportation Noise and Annoyance. European Comission - EU's Future Noise Policy, WG2 - Dose/Effect. Disponível em: http://ec.europa.eu/environment/noise/pdf/noise_expert_network.pdf Data de acesso: 09 de abril de 2011.

EC (2004) Position Paper on Dose-Effect Relationships for Night Time Noise. European Commission Working Group on Health and Socio-Economic Aspects Disponível em: http://ec.europa.eu/environment/noise/pdf/positionpaper.pdf Data de acesso: 12 de abril de 2011.

Elmehdi, H. M. (2014): Using Mathematical Models to Predict Annoyance from Combined Noise Sources in the City of Dubai. Inter-Noise 2014, Melbourne Australia.

Empresa Brasileira De Infraestrutura Aeroportuária - INFRAERO (2015): Estatística dos Aeroportos, 2015. Disponível em: http://www.infraero.gov.br/index.php/br/estatística-dos-aeroportos.html.

European Environment Agency - EEA. (2010) Good Practice Guide on Noise Exposure and Potential Health Effects. Office for Official Publications of the European Communities, European Environment Agency, Copenhagen, Dinamarca. 
Federação Internacional de Educação Física - FIEP. (2011) Efeito do Ruído na Saúde do Ser Humano. Disponível em: http://www.fiepbrasil.org/colunas/ergonomia-e-ginastica-laboral/652/efeito-ruido-nasaude-ser-humano. (Acesso em 07 de fevereiro de 2015).

Federal Aviation Administration - FAA (2011). Noise and its Effect on People. Disponível em: http://www.faa.gov/about/office_org/headquarters_offices/ato/service_units/systemops/aaim/organizat ions/env ir_programs/mase/media/ApxH_NoiseAndItsEffectOnPeople_122805.pdf. Acessado em 01 nov. 2011.

Garavelli, S. L.; Maroja, A. M.; Costa, C. A.; Carvalho Jr., E. B.; Melo, W. C.; Silva, E. F. F. (2013): Mapa de Ruído de Brasília. Relatório Técnico. IBRAN/UNESCO, Brasil.

Goldner, L. G.; Goldner, N. (2006): Estudos dos Padrões de Viagens Terrestres em Dois Aeroportos do Sul do Brasil. V SITRAER -Simpósio de Transporte Aéreo. São Paulo: EPUSP.

Goldner, L. G., Nascimento A. M, Pinto I. M. D. (2014): Análise do Aeroporto Salgado Filho como Polo Gerador de Viagens. Journal of Transport Literature, v. 8, n. 3, p. 229-249.

Gonçalves, F. S.; Lemos, D. S. C. F.; Kneib, E. C.; Portugal, L. S. (2012): Caracterização dos Polos Geradores de Viagens. Polos Geradores de Viagens Orientadas à Qualidade de Vida e Ambiental; Modelo e Taxas de Geração de Viagens/Oganizador: Licinio da Silva Portugal. p. 3-43.Rio de Janeiro, Brasil.

GROUP, W. A. (2003): Nighttime Noise Criteria and Land-Use Guidelines for the City of High Point. Wyle Report. Arlington, Virginia: P. 36.

Heleno, T., A. (2010): Uma Nova Metodologia de Zoneamento Aeroportuário com o Objetivo de Reduzir o Encroachment e os Efeitos Adversos do Ruído. Dissertação de Mestrado, Departamento de Engenharia Mecânica, UFRJ/COPPE, Rio de Janeiro. 2010.

Instituto Brasileiro de Geografia e Estatística - IBGE (2015): Sinopse do Censo Demográfico. Disponível em: http://www.ibge.gov.br/estadosat/perfil.php?sigla=df (Acesso em 13 de fevereiro de 2015).

ISO 9613-2 (1996) - Acústica - Atenuação do Som Durante a Propagação ao ar Livre. Disponível em: http://www.iso.org/iso/home/store/catalogue_tc/catalogue_detail.htm?csnumber=20649. Acesso: 04 de abril de 2014

Ising, H.; Babischi, W; Guski, R.; Kruppa, B.; Maschke, C. (2005): Exposure and Effect Indicators of Environmental Noise. Berliner Zentrum Public Health, Berlin-Germany: WHO.

Institute of Transport Engineers - ITE (2008): Transportation Impact Analysis for Site Development. Washington, 2008.

Jones, K. (2009): Aircraft Noise and Sleep Disturbance. A Review. Environmental Research and Consultancy Department (ERCD). UK. Report 0905.

Kasarda, J. D. (2006): New Urban Development at and Around Airports. Presentation to CIFAL-Liveraging Airports for Economic Development. Atlanta, USA, 2006.

Kneib, E. C. (2004): Caracterização de Empreendimentos Geradores de Viagens: Contribuição Conceitual à Análise de seus Impactos no Uso, Ocupação e Valorização do Solo Urbano. Universidade de Brasília, Brasília, 2004.

Kneib, E. C.; Taco, P. W. G.; Silva, P. C. M. (2006): Identificação e Avaliação de Impactos na Mobilidade: Análise Aplicada a Polos Geradores de Viagens. In. Pluris - 2 Congresso Luso Brasileiro para o Planejamento Urbano, Regional, Integrado, Sustentável, Braga, Portugal. 
Kohler, R.; Specht, L. P.; Bronzati, G. D. (2012): Ruído Causado pelo Transporte Ferroviário em um Segmento Urbano: Estudo de Caso da Cidade de Ijuí-RS. ISSN 1677-3047. Teoria e Prática na Engenharia Civil, n. 19, p. 13-23, Editora Dunas.

Lam, K. C., Chan P. K., Chan, T. C., Au W. H., Hui W. C. (2008): Annoyance Response to Mixed Transportation Noise in Hong Kong. Applied Acoustics, Volume: 70, p. 1-10, 2008.

Li, B., Tao, S., Dawson, R., W. (2002): Evaluation and Analysis of Traffic Noise from Main Urban Roads in Beijing. Applied Acoustics, v. 63 n. 10, p. 1137-1142.

Mamede, D. A.; Alves, C. J. P. (2009): Estudo Sobre a Acessibilidade de Aeroportos no Brasil. Anais do $15^{\circ}$ Encontro de Iniciação Científica e Pós-Graduação do ITA-XV ENCITA/2009. Instituto Tecnológico de Aeronáutica. São José dos Campos, SP, Brasil.

Mardones, M. D. M. (2009): Mapeamento dos Níveis de Ruído em Copacabana, Rio de Janeiro, Através de Simulação Computacional. Dissertação de Mestrado, UFRJ/COPPE, Rio de Janeiro, Brasil.

Maroja, A. M., Garavelli, S. L., Carvalho Jr., E. B. (2011): Noise Mapping Using Vehicles Electronic Speed Controllers. In: 18th International Congress on Sound and Vibration; Rio de Janeiro, Brasil.

Maroja, A. M.; Santos, F. S.; Garavelli, S. L.; Carvalho Jr., E. B. (2013): Veículo Leve sobre Trilhos: Impacto Ambiental Acústico em Brasília-DF. In: XXVII ANPET - Congresso de Pesquisa e Ensino em Transportes, Belém-PA.

Maroja, A. M.; Santos, F. S.; Carvalho Jr., E. B.; Garavelli, S. L. (2014): Análise Espacial do Impacto Ambiental Acústico Provocado pela Implantação do VLT em Brasília - DF In: $6^{0}$ Congresso LusoBrasileiro de Planejamento Urbano, Regional e Integração Sustentável, Lisboa-PT. Livro de Actas, v. 1. Lisboa, Portugal.

Miedema, H. M. E. e Vos, H. (1998). Exposure-Response Relationships for Transportation Noise. Journal of the Acoustical Society of America. v. 104, n. 6, p. 3432 - 3445.

Miedema, H. M. E. e Oudshoorn, C. G (2001): Annoyance From Transportation Noise: Relationships With Exposure Metrics Dnl And Denl And Their Confidence Intervals. Environmental Health Perspectives. v. 109 , n. 4 , p. $409-416$.

Miedema, H. M. E, Passchier-Vermeer W.,Vos, H (2003): Elements For A Position Paper On Night-Time Transportation Noise And Sleep Disturbance. TNO Inro, Delft, 2002-59.

Miedema, H. M. E e Vos, H. (2007): Associations Between Self-Reported Sleep Disturbance and Environmental Noise Based on Reanalyses of Pooled Data From 24 Studies. Behavioral Sleep Medicine, v. 5, n. 1, p. 1 - 20.

Monteiro, A. R., Goldner L. G. (2011): Taxas de Geração de Viagens para Aeroportos: Estudo de Caso no Aeroporto Hercilio Luz em Florianópolis/SC. In: XXV Congresso de Pesquisa e Ensino em Transportes-ANPET. Belo Horizonte, Minas Gerais, Brasil, 2011.

Münzel, T.; Gori, T.; Babisch, W.; Basner, M. (2014): Cardiovascular Effects of Environmental Noise Exposure. European Heart Jounal Advance. European Society of Cardiology.

Nguyen, T. L.; Nguyen, H. Q.; Yano, T.; Nishimura, T.; Sato, T.; Morihara, T.; Hashimoto, Y.: Comparison of Models to Predict Annoyance From Combined Noise in Ho Chi Minh City and Hanoi. Journal Appl. Acoust., v. 73 p. 952-859, 2012 
Öhrström, E.; Barregard, L.; Andersson, E.; Skanberg, A.; Svensson, H.; Ängerheim, P. (2007): Annoyance Due to Single and Combined Soud Exposure From Railway and Road Traffic. Journal Acoust Society of America, v. 122 p. 2642-2652.

Ouis, D. (2001): Annoyance from Road Traffic Noise: A Review. Journal of Environmental Psychology, p. 101-120.

Paozalyte, I., Grubliauskas, R., Vaitiekunas, P. (2012): Modelling the Noise Generated by Railway Transport: Statistical Analysis of Modelling Results Applying CadnaA and IMMI Programs. Journal of Environmental Engineering and Landscape Mangement, p. 206.

Paul, S. (2010): Som e Ruído - Releituras Críticas de Textos. XXII Encontro da Sociedade Brasileira de Acústica-SOBRAC. P. 9.

Plano Diretor de Transporte Urbano e Mobilidade do Distrito Federal e Entorno - PDTU-DF (2011) Disponível em: http://editais.st.df.gov.br/pdtu/andamento/rel_and_4.pdf. Acesso: 11/03/2014.

Pinto, F. R.; Guedes, M.; Leite, M. J. (2004): Projecto-Piloto de Demonstração de Mapas de Ruído. Escalas Municipal e Urbana. Lisboa: Instituto do Ambiente, 53 p.

Portugal, L. S.; Coelho, P. I. S.; Ribeiros, S. K. (2007): Proposta de um Procedimento de Análise de Aeroporto como Pólo Gerador de Viagem (PGV). In: V Rio de Transportes, Rio de Janeiro.

Portugal, L. S. (2012): Polos Geradores de Viagens Orientados a Qualidade de Vida e Ambiental: Modelos e Taxas de Geração de Viagens. Organizador; Licinio da Silva Portugal. Editora Interciência, Rio de Janeiro.

Regulamento Brasileiro Da Aviação Civil - RBAC- 161 (2011): Planos de Zoneamento de Ruído de Aeródromos. Aprovado na resolução n. 202, de 28 de setembro de 2011, publicado no Diário Oficial da União de 29 de setembro de 2011, Seção 1, pg. 25. 2011.

Rede Ibero-Americana De Estudo Em Polos Geradores De Viagem - REDE PGV (2014). Disponível em http://redpgv.coppe.ufrj.br. Acesso em: 22/09/2014.

Regulamento Geral do Ruído - RGR (2007). Decreto Lei n..$^{\circ}$ 9/2007, 17 de Janeiro de 2007, retificado pela Declaração de Retificação n. ${ }^{\circ}$ 18/2007 de 16 de Março. Portugal.

Rocha, R.; Slama, J. (2008): Adequação do Zoneamento Urbano ao Zoneamento Sonoro dos Aeroportos. VII SITRAER, 629-640 p. - Tr. 512.

Rocha, R. B.(2009): Um Método para Adequação do Zoneamento Urbano à Influência Sonora dos Aeroportos com Auxílio de Sistemas de Informação Geográfica: Caso do Aeroporto de Congonhas. (Dissertação de Mestrado) Departamento de Engenharia Mecânica, Universidade Federal do Rio de Janeiro, Rio de Janeiro, Brasil.

Santos, L. S. (2009): Análise da Influência da Variação Espacial da Oferta de Um Modo de Transporte Público Urbano no Comportamento de Viagens de Seus Usuários. Dissertação de Mestrado - Faculdade de Tecnologia. Universidade de Brasília.

Santos, L. S.; Taco, P. W. G.; Silva, A. H. (2009): Análise do Comportamento de Viagem dos Possíveis Usuários de um Veículo Leve Sobre Trilhos na Avenida W3-Brasília-DF. 5 Concurso de Monografia CBTU 2009 - A Cidade nos Trilhos. Brasília, Brasil. 
Scherer, M., J. (2005): Estudo do Isolamento Sonoro de Vidros de Diferentes Tipos e Espessuras, em Vitragem Simples e Dupla. Dissertação de Mestrado, Pós Graduação em Engenharia Civil, Universidade Federal de Santa Maria, Santa Maria, 2005.

Silva, J. M. (2008): Implementação e Desenvolvimento de Aeroportos Industriais. (Dissertação de Mestrado). Departamento de Engenharia de Produção, Universidade Federal de Minas Gerais, Belo Horizonte, Brasil.

Silva, V. C. (2010): Poluição Sonora no Meio Ambiente Urbano: Perspectivas na Rua Gonçalves Chaves no Munícipio de Pelotas-RS. Dissertação de Mestrado, Pós Graduação em Política Social, Universidade Católica de Pelotas, Pelotas-RS, Brasil.

Szwarc, M.; Kostek, B.; Kotus, J.; Szczodrak, M.; Czyzewski, A. (2011): Problems of Railway Noise: A Case Study. International Journal of Occupational Safety and Ergonomics, vol. 17, No 3, 309-325, Poland.

Tavares, D. M. (2011): Método para Análise de Polos Geradores de Viagem Utilizando Ferramentas de Microssimulação. Dissertação de Mestrado, Faculdade de Tecnologia, Departamento de Engenharia Civil e Ambiental, Universidade de Brasília, Brasília, Brasil.

Taylor, S. M.: A (1982): Comparison of Models to Predict Annoyance Reactions to Noise from Mixed Sources. Journal Sound Vib. P. 123-138.

Torbjörn, Å.; Babisch, W.; Beaumont, J. (2009): WHO Regional Office for - Night Noise Guidelines for Europe. ISBN 9789289041737.

Vasconcelos, L. F. S. (2007): O Aeroporto como Integrante de um Projeto de Desenvolvimento Regional: A Experiência Brasileira. (Dissertação de Mestrado) Departamento de Engenharia Civil e Ambiental, Universidade de Brasília, Brasília, Brasil.

WHO (2007): The World Health Report 2007: A Safer Future: Global Public Health Security in the 21 st Century. Disponível em: http://www.who.int/whr/2007/whr07_en.pdf. Acesso em 16/09/2014.

WHO (2011): Burden of Disease from Environmental Noise-Quantification of Healthy Years Lost in Europe. World Health Organization, 2011.2 Diponível em: http://scholar.google.com/scholar?hl=en\&btnG=Search\&q=intitle:Burden+of+disease+from+environ mental+noise+Quantification+of+healthy+life+years+lost+in+Europe\#4. Acesso em 12/03/2013.

Yano, T.; Nguyen, T. L.; Nguyen, H. Q.; Nishimura, H.; Fukushima, T.; Sato, T.; Morihara, T.; Hashimoto, Y. (2011): Community Response to Aircraft Noise in Ho Chi Minh City and Hanoi. Journal Appl. Acoust., v. 72 p. $814-822$. 
APÊNDICES 


\section{APÊNDICE A - DADOS DE ENTRADA SIMULAÇÃO AÉREA}

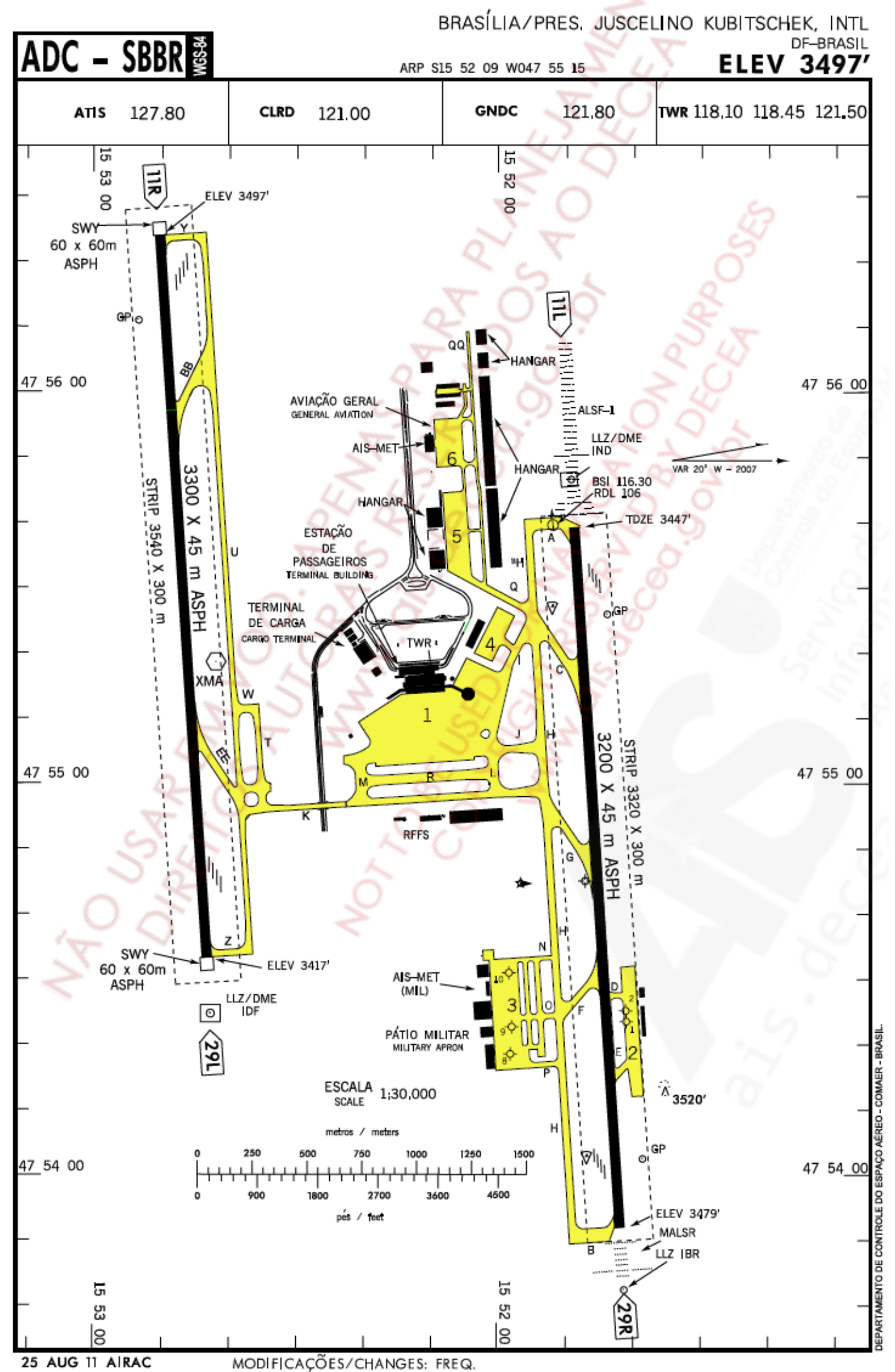

Figura A.1: Aeroporto Internacional de Brasília

Fonte: Carta do Aeródromo SBBR (ADC) 


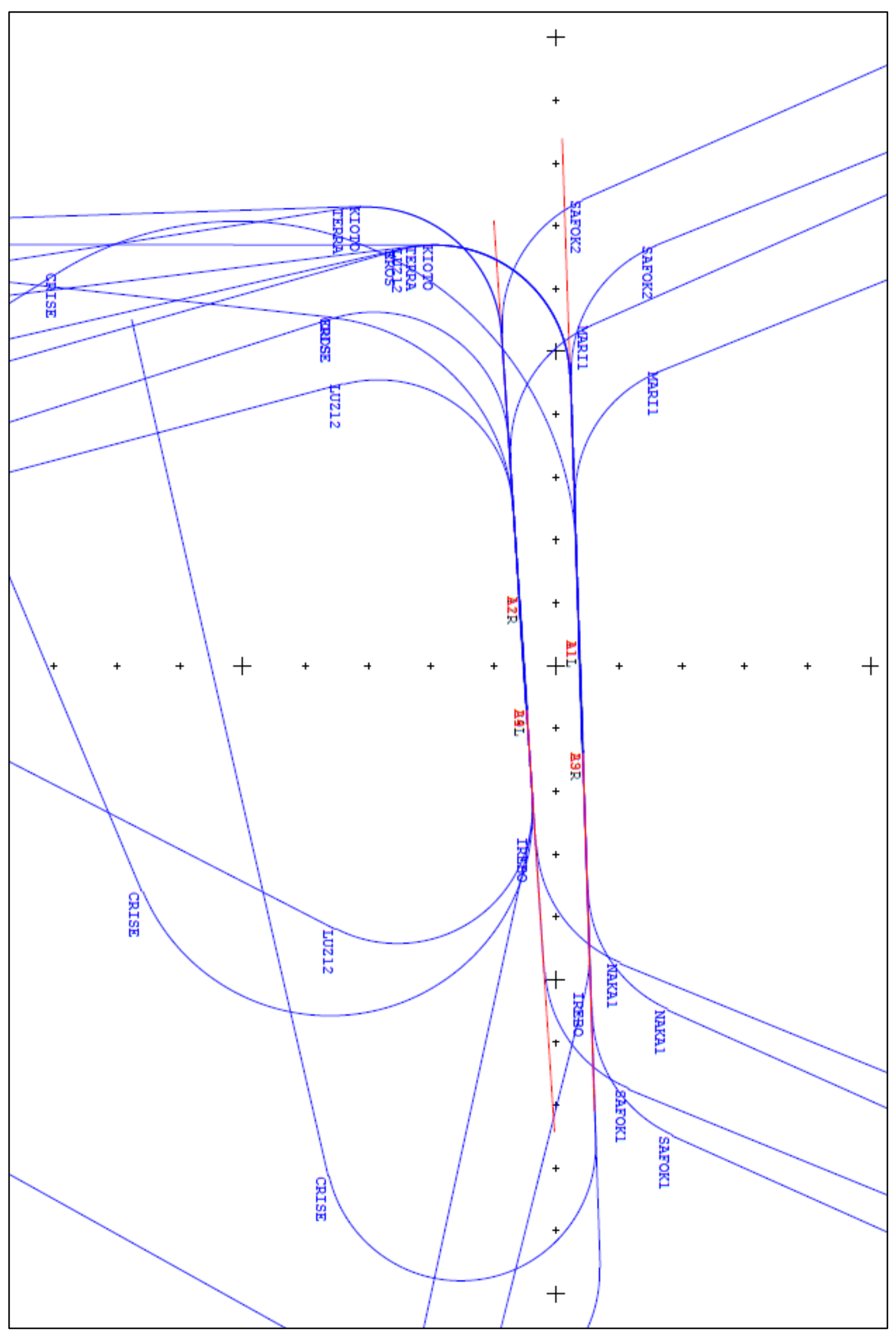

Figura A.2: Rotas de Chegadas e Saídas do SBBR por Cabeceiras Fonte: Carta do aeródromo SBBR (ADC) Adaptada 
O SBBR desde de 2012 é administrado pelo Consórcio Inframérica Aeroportos. Possui mais de 130 lojas e 29 pontes de embarque, sendo atualmente o mais movimentado da Região Centro-Oeste (ANAC, 2014). De acordo com a Inframérica (2015), atualmente é realizado em média 15 mil movimentações (pousos e decolagens) por mês, destes, 97 \% são voos domésticos e $3 \%$ são voos internacionais. A Figura A.3 retrata o aumento na movimentação de passageiros dos últimos 10 anos.

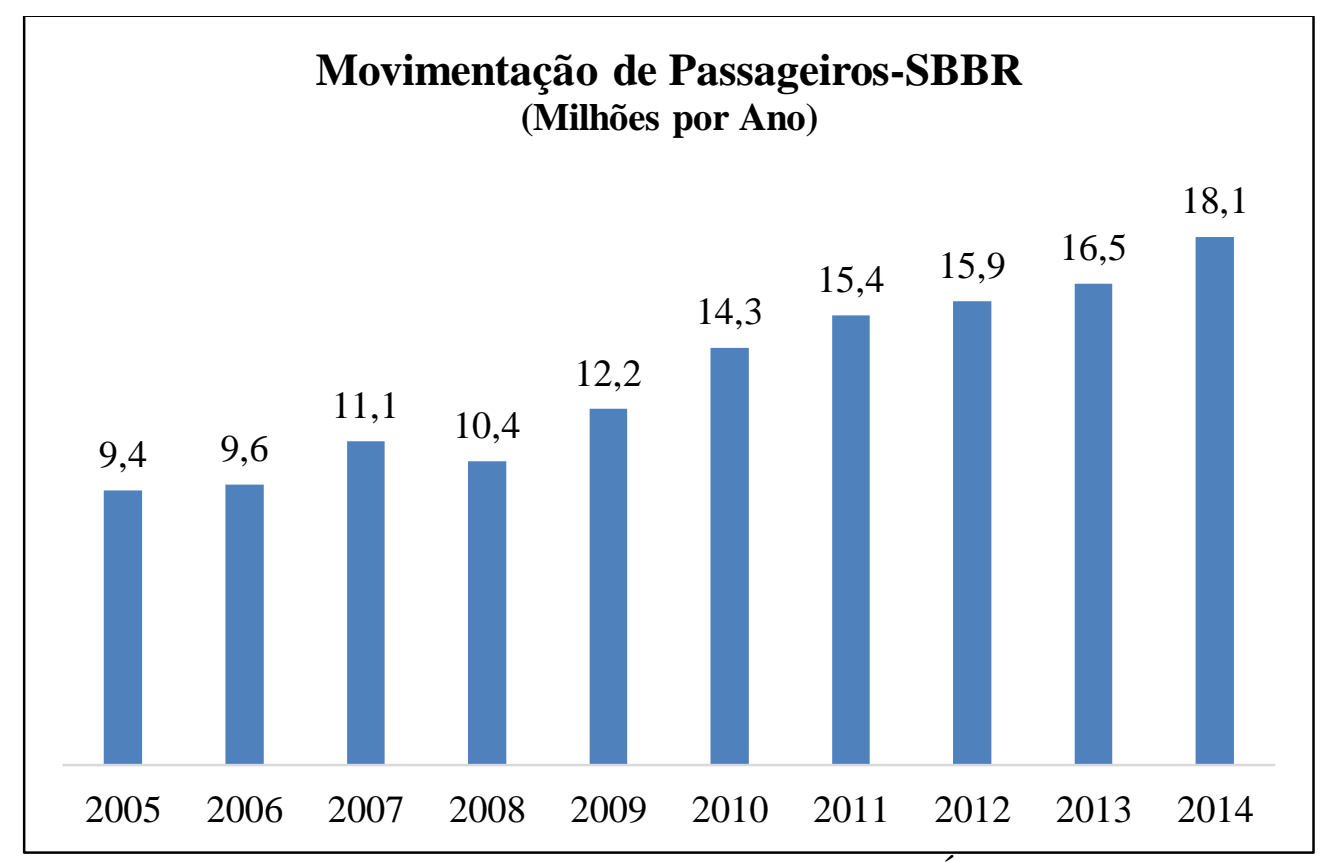

Figura A.3: Movimentação de Passageiros-SBBR Últimos 10 Anos

Fonte: INFRAERO, 2015.

Em 2014 o SBBR obteve a movimentação recorde de 18.146.405 passageiros a partir da movimentação (pouso ou decolagem) de 183,8 mil aeronaves, com uma média de movimentação diária de 49 mil passageiros. Neste ano, o aeroporto quase dobrou a movimentação de passageiros em relação ao ano de 2005.

O sítio aeroportuário do AIB possui área total de aproximadamente $28.930 .886 \mathrm{~m}^{2}$. É um aeroporto compartilhado, isto é, com operações civis e militares. A área militar é de 18.977.685 $\mathrm{m}^{2}$ e a área patrimonial civil de 9.947.559 $\mathrm{m}^{2}$ (INFRAERO, 2002). Sua infraestrutura física conta com vias de acesso, estacionamentos, área de apoio, hangares, pátio de manobras, pista de taxiamento, pista de pouso e decolagem e terminais de passageiros com estabelecimentos comerciais e área administrativa, técnica e de passageiros e área de terminal de cargas. Possui também instalações militares na área militar da Base Aérea de Brasília. A Figura A.4 representa a movimentação das aeronaves nos últimos 10 anos, que tem mantido valores bem próximos desde 2010 . 


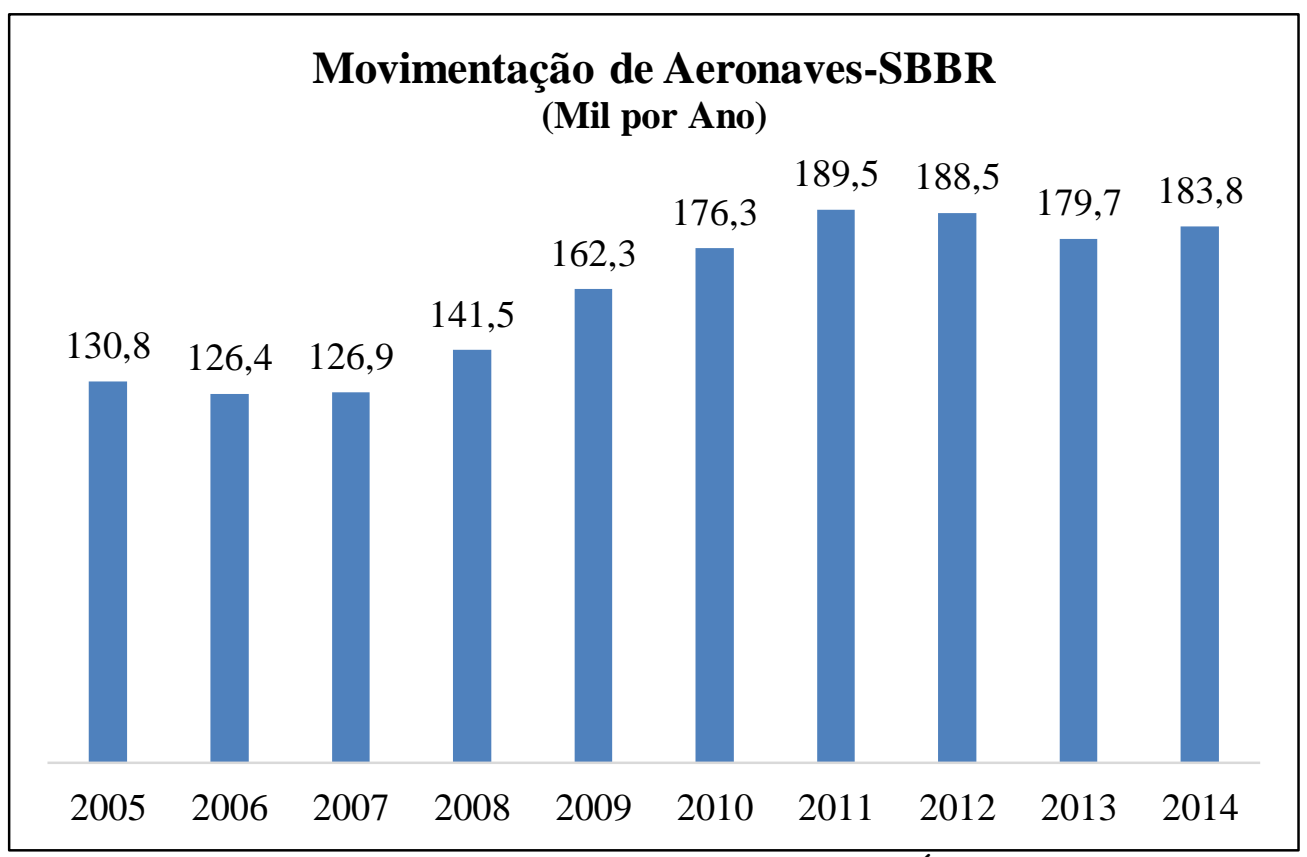

Figura A.4: Movimentação de Aeronaves-SBBR Últimos 10 Anos

Fonte: INFRAERO, 2015.

O AIB apresentou, nos últimos dez anos, um crescimento de $90 \%$ na demanda de passageiros e de $40 \%$ na de voos. Este crescimento é mostrado na Figura A.3 e na Figura A.4, e reflete o aumento do nível de desenvolvimento da economia regional bem como a saturação dos terminais da região sudeste do país, que tem obrigado as companhias aéreas a fazer de Brasília um novo ponto concentrador de conexões e de passageiros. A Tabela A.1 mostra os dados operacionais, a Tabela A.2 relata os dados das pistas e a Tabela A.3 mostra o percentual de operações por cabeceira. Já a Tabela A.4 mostra a composição da frota de aeronaves e a Tabela A.5 resume as rotas de pouso e decolagens.

Tabela A.1: Dados Operacionais

\begin{tabular}{ll}
\hline \multicolumn{1}{c}{ Dado Operacional } & Total \\
\hline Número de movimentos anual (pousos + decolagens) & 200.000 \\
Percentual de operações diurnas & $85 \%$ \\
Percentual de operações noturnas & $15 \%$ \\
\hline
\end{tabular}

Fonte: INFRAMÉRICA, 2013

Tabela A.2: Dados das Pistas

\begin{tabular}{cccccc}
\hline Pista & Comprimento & Cabeceira & Altitude $(\mathbf{m})$ & Latitude & Longitude \\
\hline \multirow{2}{*}{$11 \mathrm{~L} / 29 \mathrm{R}$} & \multirow{2}{*}{$3.200 \mathrm{~m}$} & $11 \mathrm{~L}$ & 1051 & $15^{\circ} 51^{\prime} 49 \mathrm{~S}$ & $47^{\circ} 55^{\prime} 39 \mathrm{O}$ \\
& & $29 \mathrm{R}$ & 1060 & $15^{\circ} 51^{\prime} 42 \mathrm{~S}$ & $47^{\circ} 53^{\prime} 52 \mathrm{O}$ \\
\hline \multirow{2}{*}{$11 \mathrm{R} / 29 \mathrm{~L}$} & \multirow{2}{*}{$3.300 \mathrm{~m}$} & $11 \mathrm{R}$ & 1066 & $15^{\circ} 52^{\prime} 50 \mathrm{~S}$ & $47^{\circ} 56^{\prime} 24 \mathrm{O}$ \\
& & $29 \mathrm{~L}$ & 1042 & $15^{\circ} 52^{\prime} 43 \mathrm{~S}$ & $4^{\circ} 54^{\prime} 33 \mathrm{O}$ \\
\hline
\end{tabular}

Fonte: Carta do aeródromo SBBR (ADC) 
Tabela A.3: Percentuais de Operações nas Cabeceiras

\begin{tabular}{ccc}
\hline Cabeceiras & Decolagem & Pouso \\
\hline $11 \mathrm{~L}$ & 16 & 67 \\
$29 \mathrm{R}$ & 60 & 9 \\
$11 \mathrm{R}$ & 20 & 2 \\
29L & 4 & 22 \\
\hline
\end{tabular}

Fonte: INFRAMÉRICA, 2013

Tabela A.4: Composição da Frota de Aeronaves em 2012

\begin{tabular}{lccc}
\hline Aeronave & Movimentos (Ano) & Movimentos (Diários & \% \\
\hline A319 & 24.206 & 66 & $12 \%$ \\
A320 & 50.429 & 138 & $25 \%$ \\
A321 & 6.051 & 17 & $3 \%$ \\
B727-200 & 2.017 & 6 & $1 \%$ \\
B737-300 & 8.069 & 22 & $4 \%$ \\
B737-700 & 24.206 & 66 & $12 \%$ \\
B737-800 & 50.429 & 138 & $25 \%$ \\
BEC58 & 4.034 & 11 & $2 \%$ \\
C-208 & 4.034 & 11 & $2 \%$ \\
ERJ-145 & 10.086 & 28 & $5 \%$ \\
ERJ-190 & 10.086 & 28 & $5 \%$ \\
F 100 & 8.069 & 22 & $4 \%$ \\
\hline
\end{tabular}

Fonte: ANAC, 2013

Tabela A.5: Principais Rotas de Pouso de Decolagem

\begin{tabular}{ccl}
\hline Rotas & Cabeceiras & \multicolumn{1}{c}{ Características } \\
\hline Pousos & Todas & Linha reta para todas cabeceiras no pouso \\
\hline \multirow{3}{*}{ Decolagem } & $11 \mathrm{~L}$ & Quatro rotas com curva à direita e duas rotas com curva à esquerda \\
& $11 \mathrm{R}$ & Quatro rotas com curva à direita e duas rotas com curva à esquerda \\
& $29 \mathrm{~L}$ & Cinco rotas com curva à esquerda e três rotas com curva à direita \\
& $29 \mathrm{R}$ & Cinco rotas com curva à esquerda e três rotas com curva à direita \\
\hline
\end{tabular}

Fonte: Cartas de Voo SBBR

\section{Validação das Curvas de Ruído Aéreo}

Neste estudo, para a validação das curvas de ruído provenientes do modal aéreo, os resultados foram calibrados por meio do estudo realizado por Carvalho Jr. (2015). Após a confecção das curvas de ruído, o RBAC 161 (2013) não recomenda a validação das curvas com o resultado proveniente de medidas físicas. Todavia, a validação é essencial para conferir a precisão e garantir confiabilidade às curvas simuladas. Nesta tese, a validação ocorreu por meio de medidas físicas de longa duração (24h). Essas medidas são provenientes das Estações de Monitoramento de Ruído (EMR's) instaladas em pontos que representam as principais áreas afetadas pela operação do SBBR, e de forma a captar com precisão e confiabilidade o ruído gerado pelas aeronaves.

As EMR's estão equipadas com sonômetros do tipo CUBE Smart Noise Terminal da 01 dB. Esse medidor é controlado tanto por um teclado integrado e uma tela com alta resolução e contraste, quanto remotamente usando comunicação sem fio. Esse sistema é aplicado com 
sucesso para medição de ruído aeronáutico, sendo atualmente utilizado no Brasil no aeroporto Santos Dumont, no Rio de Janeiro, desde março de 2013. Os dados obtidos pelas EMR's foram processados com uso do software dBTRAIT, da $01 \mathrm{~dB}$, que permite retorno do histórico no tempo, transferência de dados, codificação de fontes, cálculos estatísticos, dentre outras possibilidades. Para a validação dos mapas acústicos é necessário que a diferença entre os valores calculados (retirados dos mapas acústicos elaborados) e os valores medidos não ultrapasse $\pm 2 \mathrm{~dB}(\mathrm{~A})$, conforme indica a APA (2011).

Os dados utilizados das EMR's foram obtidos durante os meses de fevereiro e março de 2015. A Tabela A.6 mostra as coordenadas e a Figura A.5 mostra a localização das EMR's, das pistas e cabeceiras do SBBR. Cabe destacar que estão previstas a instalação de mais 3 estações de monitoramento para o SBBR.

Tabela A.6: Locais das EMR's do SBBR

\begin{tabular}{c|l|c|c}
\hline Ponto & \multicolumn{1}{|c|}{ Local } & \multicolumn{1}{|c}{ Latitude } & \multicolumn{1}{|c}{ Longitude } \\
\hline EMR1 & Quartel de Bombeiros Núcleo Bandeirante & $15^{\circ} 52^{\prime} 7 \mathrm{~S}$ & $47^{\circ} 57^{\prime} 44 \mathrm{~W}$ \\
EMR2 & CINDACTA & $15^{\circ} 51^{\prime} 27 \mathrm{~S}$ & $47^{\circ} 54^{\prime} 9 \mathrm{~W}$ \\
EMR3 & Seminário - Lago Sul & $15^{\circ} 51^{\prime} 42 \mathrm{~S}$ & $47^{\circ} 52^{\prime} 17 \mathrm{~W}$ \\
\hline
\end{tabular}

* Sistema de coordenadas WGS 84

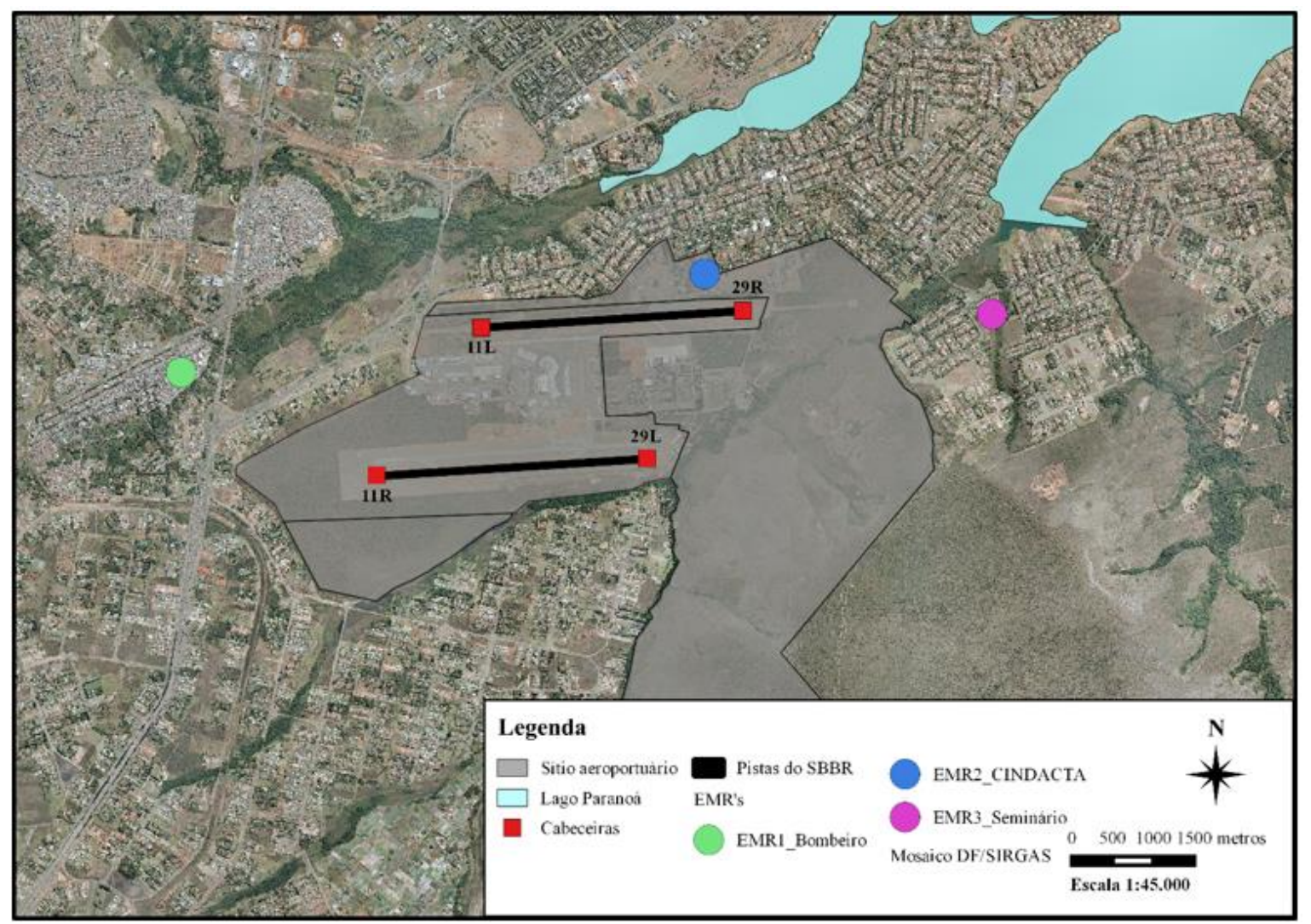

Figura A.5: Localização dos pontos de medidas

Fonte: Carvalho Jr., 2015 
De acordo com a NBR 10.151 (ABNT, 2000), o período noturno foi considerado entre $22 \mathrm{~h}$ e 7 h do dia seguinte, o diurno foi considerado entre 7 e 22 horas. Os parâmetros sonoros foram avaliados: $\mathrm{L}_{d}, \mathrm{~L}_{n}$, e $D N L$ :

Para a validação das curvas de ruído foram utilizados dados provenientes das EMR's do SBBR. A Tabela 30 expressa os valores medidos para o $\mathrm{L}_{d}, \mathrm{~L}_{n}$ e $D N L$ e também mostra os valores simulados no INM.

Tabela A.7: Indicadores Acústicos Calculados para a Validação das Cartas Acústicas

\begin{tabular}{c|cccc|c}
\hline \multicolumn{7}{c}{ Dados da EMR_1 } \\
\hline Data & $\mathrm{L}_{d}$ & $\mathrm{~L}_{n}$ & $D N L^{a}$ & $D N L^{b}$ & $D N L^{c}$ \\
\hline a $21 / 03 / 2015$ & 61,5 & 56,9 & 64,4 & 64,3 & $-0,1$ \\
\hline \multicolumn{7}{c}{ Dados da EMR_2 } \\
01 a 03/03/2015 & $\mathrm{L}_{d}$ & $\mathrm{~L}_{n}$ & $D N L^{a}$ & $D N L^{b}$ & $D N L^{c}$ \\
\hline \multicolumn{7}{c}{ Dados da EMR_3 } & 57,9 & 64,6 & 66,3 & $-1,7$ \\
\hline Data & $\mathrm{L}_{d}$ & $\mathrm{~L}_{n}$ & $D N L^{a}$ & $D N L^{b}$ & $D N L^{c}$ \\
\hline & 58,8 & 58,1 & 64,6 & 64,4 & $-0,2$ \\
\hline
\end{tabular}

Nota: "Resultados em dB(A) / $D N L^{a}: D N L$ medido / $D N L^{b}: D N L$ simulado / $D N L^{c}: D N L^{b}-D N L^{a}$

Na Tabela A.7, a comparação realizada entre os valores medidos e os simulados é possível constatar que a diferença não ultrapassou $\pm 2 \mathrm{~dB}(\mathrm{~A})$, conforme indica a APA (2011). Desse modo, as curvas de ruído foram validadas conferindo confiabilidade ao mapa acústico. 


\section{APENDICE B - DADOS DE ENTRADA SIMULAÇÃO RODOVIÁRIA}

Após a filmagem os veículos foram divididos em leves e pesados. As motos e os veículos pequenos foram chamados de veículos leves e possuem massa de até $2.800 \mathrm{~kg}$. Já os veículos médios e grandes, como pesados. Os veículos leves são caracterizados como veículos com massa de até $2.800 \mathrm{~kg}$, incluindo moto, acima disto é caracterizado como pesados (Costa, 2011; Maroja et al., 2011). A partir da contagem volumétrica os dados foram separados por períodos (Dia e Entardecer) e por modalidade (Leve, Pesado, Total e \% de Pesado).

A Tabela B.1 mostra o volume de tráfego em veículos/hora para o horário do dia e a Tabela B.2 o volume de tráfego veículos/hora para o horário entardecer, Tabela B.1 os pontos das contagens do volume de tráfego rodoviário e por meio da Figura B.1 pode ser visualizado os pontos de coletas.

Tabela B.1: Volume de Tráfego Veículo/Hora - Dia

\begin{tabular}{ccccccc}
\hline Local & Data & Hora & Leves & Pesados & Total & \% Pesados \\
\hline P01 & $9 / 2$ & $18: 45 \mathrm{~h}-19: 00 \mathrm{~h}$ & 1860 & 220 & 2080 & 10,58 \\
\hline P05 & $10 / 2$ & $17: 58 \mathrm{~h}-18: 13 \mathrm{~h}$ & 4936 & 188 & 5124 & 03,67 \\
\hline P06 & $10 / 2$ & $18: 21 \mathrm{~h}-18: 36 \mathrm{~h}$ & 3784 & 172 & 3956 & 04,35 \\
\hline P07 & $10 / 2$ & $18: 38 \mathrm{~h}-18: 53 \mathrm{~h}$ & 908 & 48 & 956 & 05,02 \\
\hline P05/A & $11 / 2$ & $07: 17 \mathrm{~h}-07: 33 \mathrm{~h}$ & 920 & 80 & 1000 & 08,00 \\
\hline P05/B & $11 / 2$ & $07: 17 \mathrm{~h}-07: 33 \mathrm{~h}$ & 2748 & 128 & 2876 & 04,45 \\
\hline P01 & $11 / 2$ & $07: 17 \mathrm{~h}-07: 33 \mathrm{~h}$ & 1568 & 24 & 1592 & 01,51 \\
\hline P02 & $11 / 2$ & $07: 47 \mathrm{~h}-08: 03 \mathrm{~h}$ & 1228 & 56 & 1284 & 04,36 \\
\hline P03/A & $11 / 2$ & $08: 08 \mathrm{~h}-08: 23 \mathrm{~h}$ & 536 & 32 & 568 & 05,63 \\
\hline P03/B & $11 / 2$ & $08: 08 \mathrm{~h}-08: 23 \mathrm{~h}$ & 152 & 0 & 152 & 00,00 \\
\hline P04/A & $11 / 2$ & $08: 35 \mathrm{~h}-08: 50 \mathrm{~h}$ & 804 & 32 & 836 & 03,83 \\
\hline P04/B & $11 / 2$ & $08: 35 \mathrm{~h}-08: 50 \mathrm{~h}$ & 348 & 16 & 364 & 04,40 \\
\hline P06 & $11 / 2$ & $08: 56 \mathrm{~h}-09: 11 \mathrm{~h}$ & 3520 & 244 & 3764 & 06,48 \\
\hline
\end{tabular}

Tabela B.2: Volume de Tráfego Veículo/Hora - Entardecer

\begin{tabular}{ccccccc}
\hline Local & Data & Hora & Leves & Pesados & Total & \% Pesados \\
\hline P01 & $9 / 2$ & $19: 00 \mathrm{~h}-19: 15 \mathrm{~h}$ & 1176 & 12 & 1188 & 01,01 \\
\hline P02 & $9 / 2$ & $19: 18 \mathrm{~h}-19: 33 \mathrm{~h}$ & 1088 & 32 & 1120 & 02,86 \\
\hline P03/A & $9 / 2$ & $19: 35 \mathrm{~h}-19: 50 \mathrm{~h}$ & 540 & 16 & 556 & 02,88 \\
\hline $\mathrm{P} 03 / \mathrm{B}$ & $9 / 2$ & $19: 35 \mathrm{~h}-19: 50 \mathrm{~h}$ & 100 & 4 & 104 & 03,85 \\
\hline $\mathrm{P} 03 / \mathrm{C}$ & $9 / 2$ & $19: 35 \mathrm{~h}-19: 50 \mathrm{~h}$ & 88 & 4 & 92 & 04,35 \\
\hline P04/A & $9 / 2$ & $19: 54 \mathrm{~h}-20: 09 \mathrm{~h}$ & 484 & 0 & 484 & 00,00 \\
\hline P04/B & $9 / 2$ & $19: 54 \mathrm{~h}-20: 09 \mathrm{~h}$ & 140 & 0 & 140 & 00,00 \\
\hline P08/A & $10 / 2$ & $19: 00 \mathrm{~h}-19: 15 \mathrm{~h}$ & 128 & 0 & 128 & 00,00 \\
\hline P08/B & $10 / 2$ & $19: 00 \mathrm{~h}-19: 15 \mathrm{~h}$ & 40 & 0 & 40 & 00,00 \\
\hline P07/A & $10 / 2$ & $19: 17 \mathrm{~h}-19: 32 \mathrm{~h}$ & 1392 & 32 & 1424 & 02,25 \\
\hline P07/B & $10 / 2$ & $19: 17 \mathrm{~h}-19: 32 \mathrm{~h}$ & 572 & 0 & 572 & 00,00 \\
\hline P09/A & $10 / 2$ & $19: 34 \mathrm{~h}-19: 49 \mathrm{~h}$ & 3692 & 48 & 3740 & 01,28 \\
\hline P09/B & $10 / 2$ & $19: 34 \mathrm{~h}-19: 49 \mathrm{~h}$ & 1888 & 56 & 1944 & 02,88 \\
\hline P06 & $10 / 2$ & $19: 57 \mathrm{~h}-20: 13 \mathrm{~h}$ & 2252 & 140 & 2392 & 05,85 \\
\hline P05/A & $10 / 2$ & $20: 17 \mathrm{~h}-20: 32 \mathrm{~h}$ & 820 & 52 & 872 & 05,96 \\
\hline P05/B & $10 / 2$ & $20: 17 \mathrm{~h}-20: 32 \mathrm{~h}$ & 2412 & 72 & 2484 & 02,90 \\
\hline
\end{tabular}


Tabela B.3: Pontos das Contagens do Volume de Tráfego Rodoviário

\begin{tabular}{cclcc}
\hline $\mathbf{N}^{\circ}$ & Índice & \multicolumn{1}{c}{ Local } & \multicolumn{2}{c}{ Coordenadas Geográficas } \\
\hline 1 & P01 & DF-055 Estação Floricultura & $15^{\circ} 52^{\prime} 51.76^{\prime \prime} \mathrm{S}$ & $47^{\circ} 57^{\prime} 32.73^{\prime \prime} \mathrm{O}$ \\
\hline 2 & P02 & DF-055 SMPW Qd. 14 (EPVB) & $15^{\circ} 53^{\prime} 30.14 " \mathrm{~S}$ & $47^{\circ} 57^{\prime} 04.97^{\prime \prime} \mathrm{O}$ \\
\hline 3 & P03 & SMPW Quadra 20 & $15^{\circ} 53^{\prime} 53.37^{\prime \prime} \mathrm{S}$ & $47^{\circ} 55^{\prime} 57.15^{\prime \prime} \mathrm{O}$ \\
\hline 4 & P04 & SMPW Quadra 16 & $15^{\circ} 53^{\prime} 49.70^{\prime \prime} \mathrm{S}$ & $47^{\circ} 56^{\prime} 37.24^{\prime \prime} \mathrm{O}$ \\
\hline 5 & P05 & DF-025 EPIA/ Balão do Aeroporto & $15^{\circ} 52^{\prime} 18.90^{\prime \prime} \mathrm{S}$ & $47^{\circ} 57^{\prime} 05.78^{\prime \prime} \mathrm{O}$ \\
\hline 6 & P06 & DF-047 EPAR/Aeroporto & $15^{\circ} 52^{\prime} 11.73^{\prime \prime} \mathrm{S}$ & $47^{\circ} 56^{\prime} 05.28^{\prime \prime} \mathrm{O}$ \\
\hline 7 & P07 & DF-025 QI 01 & $15^{\circ} 51^{\prime} 31.19^{\prime \prime} \mathrm{S}$ & $47^{\circ} 55^{\prime} 34.03^{\prime \prime} \mathrm{O}$ \\
\hline 8 & P08 & SHIS QI 03 & $15^{\circ} 51^{\prime} 35.23^{\prime \prime} \mathrm{S}$ & $47^{\circ} 55^{\prime} 04.50^{\prime \prime} \mathrm{O}$ \\
\hline 9 & P09 & DF-002 & $15^{\circ} 51^{\prime} 13.48^{\prime \prime} \mathrm{S}$ & $47^{\circ} 55^{\prime} 57.62^{\prime \prime} \mathrm{O}$ \\
\hline
\end{tabular}

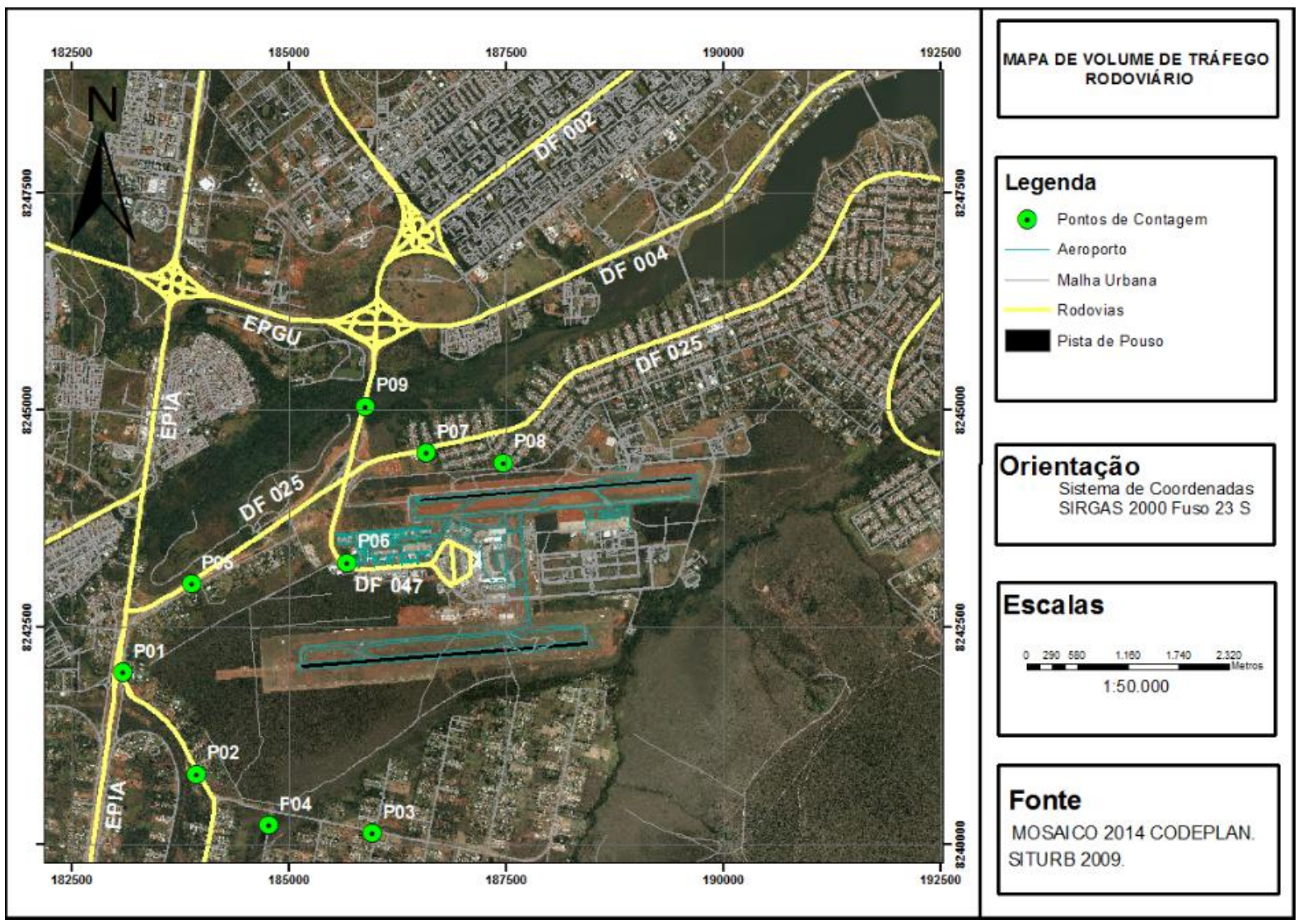

Figura B.1: Pontos das Contagens do Volume de Tráfego Rodoviário

Os dados cedidos pelo DETRAN-DF e o DER/DF dos contadores eletrônicos de velocidade instalados na região circunvizinha ao AIB para este estudo, constam na Tabela B.4, estes pontos foram identificados através das coordenadas geográficas e podem ser visualizados na Figura B.2 e na Figura B.3. Esses dados são referentes ao mês de março de 2014, devido o ano de 2014 ter sido atípico, pois além de Brasília ter sido uma das cidades sede da Copa do Mundo 2014, os contratos do DETRAN e do DER/DF com as empresas que realizavam manutenção dos equipamentos (pardais e barreiras eletrônicas) foram finalizados, acarretando no desligamento dos equipamentos entre agosto e dezembro de 2014. 
Os dados dos outros meses do ano de 2014 não representam fielmente o volume de tráfego rodoviário mensal, devido a ocorrência de meses de férias (janeiro, fevereiro e julho), o próprio mês da realização da Copa do Mundo (junho) e abril e maio terem feriados. Assim foi escolhido os dados deste mês, por não ser um mês atípico, não ter feriados e nem ser um mês de férias. Estes dados cedidos são referentes ao mês de março, também foram separados por períodos (Dia, Entardecer e Noite), por modalidade (Leve, Pesado, Total e \% de Pesado) e constam nas tabelas: Tabela B.5, Tabela B.6 e Tabela B.7.

Tabela B.4: Pontos dos Contadores Fixos do DETRAN-DF

\begin{tabular}{c|c|l|c|c}
\hline $\mathbf{N}^{\circ}$ & Índice & \multicolumn{1}{c|}{ Local } & \multicolumn{2}{c}{ Coordenadas Geográficas } \\
\hline 1 & DETRAN-01 & Setor de Chácara Sent. Aeroporto/Dom Orione & $15^{\circ} 51^{\prime} 06.95^{\prime \prime} \mathrm{S}$ & $47^{\circ} 52^{\prime} 50.72^{\prime \prime} \mathrm{O}$ \\
\hline 2 & DETRAN-02 & Setor de Chácara Sent. Dom Orione/Aeroporto & $15^{\circ} 51^{\prime} 05.70^{\prime \prime} \mathrm{S}$ & $47^{\circ} 52^{\prime} 51.68^{\prime \prime} \mathrm{O}$ \\
\hline 3 & DETRAN-03 & SHIS QI 01 Sent. EPDB/VI COMAR & $15^{\circ} 51^{\prime} 31.12^{\prime \prime} \mathrm{S}$ & $47^{\circ} 55^{\prime} 08.17^{\prime \prime} \mathrm{O}$ \\
\hline 4 & DETRAN-04 & SHIS QI 03 Sent. VI COMAR/EPDB & $15^{\circ} 51^{\prime} 32.01^{\prime \prime S}$ & $47^{\circ} 55^{\prime} 06.84^{\prime \prime} \mathrm{O}$ \\
\hline 5 & DETRAN-05 & SHIS QI 05 Lago Sul Altura da Chácara 92 & $15^{\circ} 50^{\prime} 51.61^{\prime \prime S}$ & $47^{\circ} 53^{\prime} 24.26^{\prime \prime} \mathrm{O}$ \\
\hline 6 & DER-PD558 & DF-055 SMPW 14 (EPVB) & $15^{\circ} 53^{\prime} 30.25^{\prime \prime} \mathrm{S}$ & $47^{\circ} 57^{\prime} 04.33^{\prime \prime} \mathrm{O}$ \\
\hline 7 & DER-PD222 & DF-025 Balão do Aeroporto Sentido EPIA SUL & $15^{\circ} 52^{\prime} 08.97^{\prime \prime S}$ & $47^{\circ} 56^{\prime} 43.57^{\prime \prime O}$ \\
\hline 8 & DER-PD223 & DF-025 EPIA SUL Sentido Balão do Aeroporto & $15^{\circ} 52^{\prime} 06.65^{\prime \prime} \mathrm{S}$ & $47^{\circ} 56^{\prime} 48.97^{\prime \prime} \mathrm{O}$ \\
\hline 9 & DER-PD392 & DF-025 Balão do Aeroporto & $15^{\circ} 50^{\prime} 57.61^{\prime \prime S}$ & $47^{\circ} 54^{\prime} 24.13^{\prime \prime} \mathrm{O}$ \\
\hline 10 & DER-PD224 & DF-025 Balão do Aeroporto Gilberto Salomão & $15^{\circ} 51^{\prime} 49.47^{\prime \prime S}$ & $47^{\circ} 56^{\prime} 11.75^{\prime \prime} \mathrm{O}$ \\
\hline
\end{tabular}

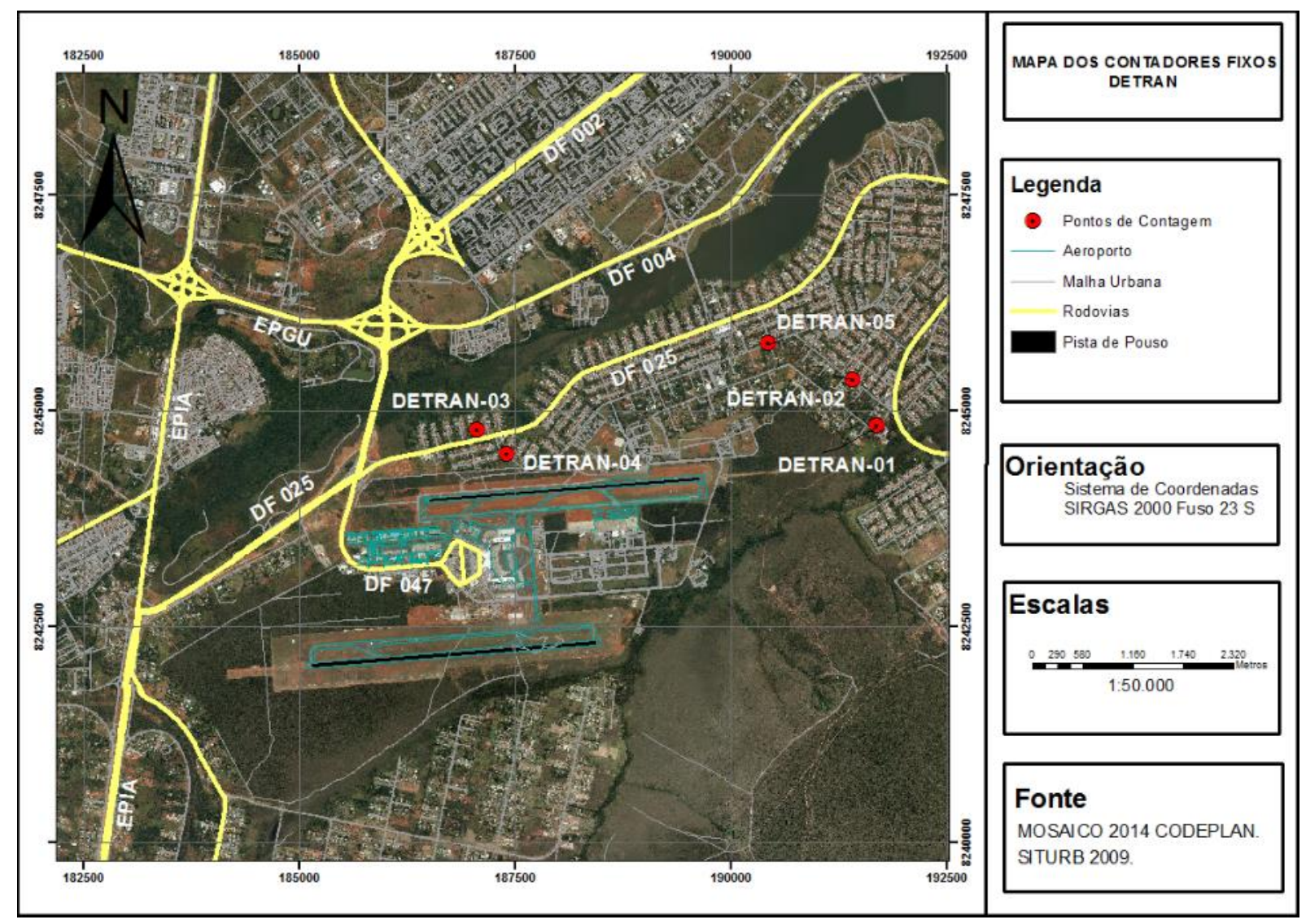

Figura B.2: Pontos dos Contadores Fixos do DETRAN-DF 


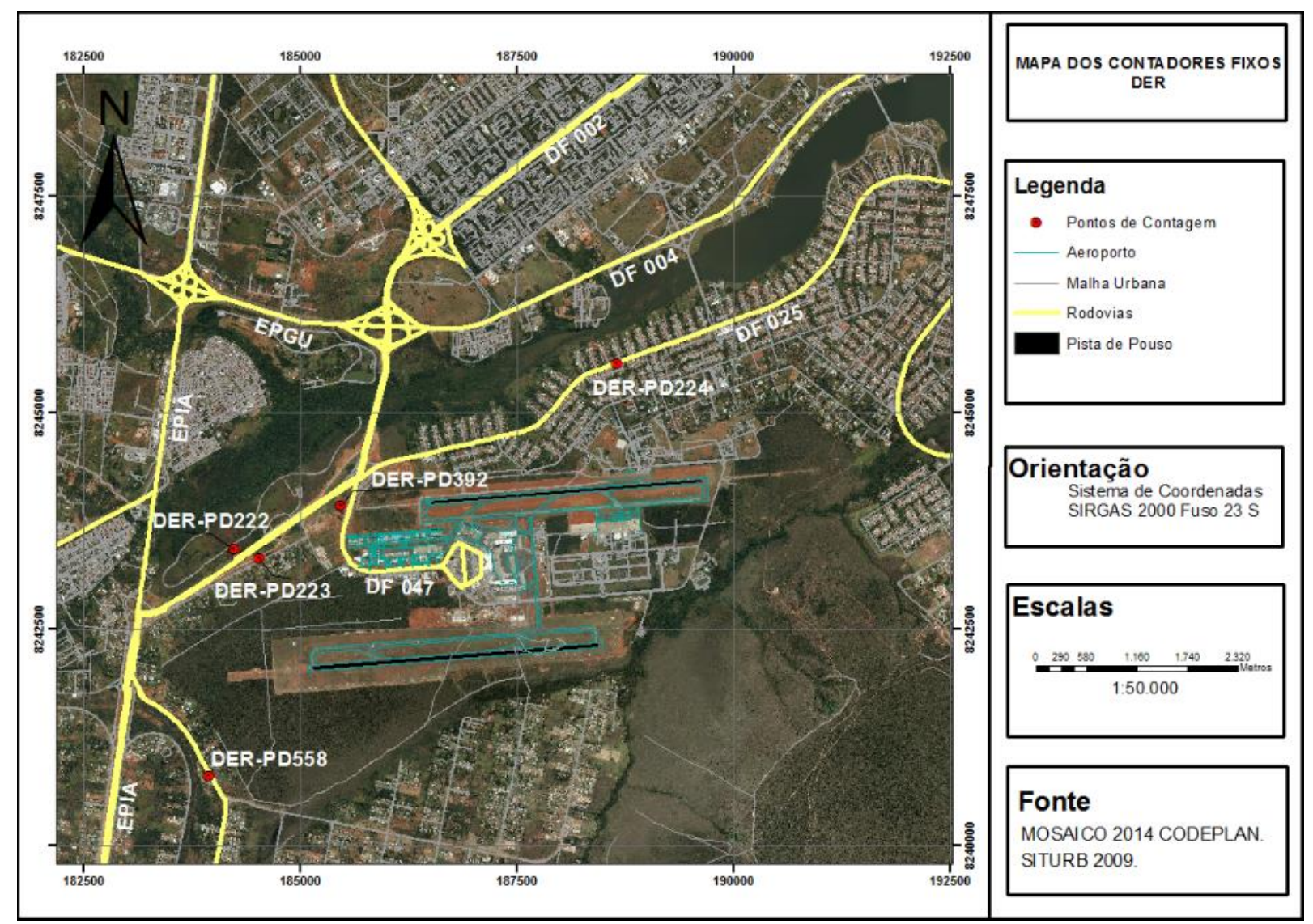

Figura B.3: Pontos dos Contadores Fixos do DER/DF

Tabela B.5: Dados Contadores DETRAN-DF e DER/DF Veículo/Hora - Dia

\begin{tabular}{ccccc}
\hline \multicolumn{5}{c}{ Volume de Tráfego Total Veículos/Hora - DIA } \\
\hline Local & Leves & Pesados & Total & \% Pesados \\
\hline DETRAN-01 & 569 & 22 & 591 & 04,00 \\
\hline DETRAN-02 & 244 & 32 & 276 & 11,50 \\
\hline DETRAN-03 & 112 & 5 & 117 & 04,00 \\
\hline DETRAN-04 & 133 & 11 & 144 & 08,00 \\
\hline DETRAN-05 & 129 & 22 & 151 & 14,50 \\
\hline DER-PD222 & 1337 & 46 & 1383 & 03,42 \\
\hline DER-PD223 & 784 & 14 & 798 & 01,79 \\
\hline DER-PD224 & 548 & 15 & 563 & 02,70 \\
\hline DER-PD392 & 1147 & 20 & 1168 & 01,78 \\
\hline DER-PD558 & 439 & 16 & 455 & 03,61 \\
\hline
\end{tabular}

Tabela B.6: Dados Contadores DETRAN-DF e DER/DF Veículo/Hora - Entardecer

\begin{tabular}{ccccc}
\hline \multicolumn{4}{c}{ Volume de Tráfego Total Veículos/Hora - ENTARDECER } \\
\hline Local & Leves & Pesados & Total & \% Pesados \\
\hline DETRAN-01 & 342 & 12 & 555 & 02,00 \\
\hline DETRAN-02 & 176 & 15 & 191 & 08,00 \\
\hline DETRAN-03 & 46 & 2 & 48 & 04,00 \\
\hline DETRAN-04 & 65 & 7 & 72 & 10,00 \\
\hline DETRAN-05 & 61 & 14 & 75 & 18,50 \\
\hline DER-PD222 & 1641 & 40 & 1681 & 02,44 \\
\hline DER-PD223 & 629 & 5 & 635 & 00,85 \\
\hline DER-PD224 & 264 & 4 & 268 & 01,55 \\
\hline DER-PD392 & 299 & 5 & 304 & 01,63 \\
\hline DER-PD558 & 433 & 4 & 438 & 00,95 \\
\hline
\end{tabular}


Tabela B.7: Dados Contadores DETRAN-DF e DER/DF Veículo/Hora - Noite

\begin{tabular}{ccccc}
\hline \multicolumn{5}{c}{ Volume de Tráfego Total Veículos/Hora - NOITE } \\
\hline Local & Leves & Pesados & Total & \% Pesados \\
\hline DETRAN-01 & 117 & 3 & 120 & 02,50 \\
\hline DETRAN-02 & 65 & 6 & 71 & 08,50 \\
\hline DETRAN-03 & 20 & 2 & 22 & 09,00 \\
\hline DETRAN-04 & 16 & 3 & 19 & 16,00 \\
\hline DETRAN-05 & 16 & 2 & 18 & 11,00 \\
\hline DER-PD222 & 418 & 9 & 426 & 02,07 \\
\hline DER-PD223 & 120 & 1 & 122 & 01,11 \\
\hline DER-PD224 & 111 & 2 & 113 & 02,13 \\
\hline DER-PD392 & 349 & 5 & 354 & 01,49 \\
\hline DER-PD558 & 103 & 4 & 107 & 03,47 \\
\hline
\end{tabular}

O DFTrans cedeu para a realização deste estudo o número total de viagens realizadas por dia pelo BRT, dividido entre os períodos: Dia, Entardecer e Noite. Com esses dados foi possível encontrar o número de viagens realizado por Hora, e assim alimentar o software CadnaA para realização da simulação rodoviária devido ao BRT.

A linha BRT Gama - Rodoviária do Plano Piloto utiliza as numerações 2201 e 2202 e são operadas pela Viação Pioneira, segue na Tabela B.8 o número de veículos por período. A linha BRT Santa Maria - Rodoviária do Plano Piloto utiliza as numerações 2301 e 2302 e são operadas pela Viação Pioneira, segue na Tabela B.9 o número de veículos por período.

Tabela B.8: BRT Gama-Rodoviária do Plano Piloto

\begin{tabular}{|c|c|}
\hline Saída & Rodoviária do Plano Piloto \\
\hline Período & Total \\
\hline Dia & 100 \\
\hline Entardecer & 25 \\
\hline Noite & 34 \\
\hline Saída & Terminal de Integração BRT Gama \\
\hline Período & Total \\
\hline Dia & 104 \\
\hline Entardecer & 29 \\
\hline Noite & 22 \\
\hline \multicolumn{2}{|c|}{ Tabela B.9: BRT Santa Maria-Rodoviária do Plano Piloto } \\
\hline Saída & Rodoviária do Plano Piloto \\
\hline Período & Total \\
\hline Dia & 126 \\
\hline Entardecer & 29 \\
\hline Noite & 36 \\
\hline Saída & Terminal de Integração BRT Santa Maria \\
\hline Período & Total \\
\hline Dia & 121 \\
\hline Entardecer & 40 \\
\hline Noite & 26 \\
\hline
\end{tabular}

No trecho onde foi realizado as simulações possui uma pista de concreto exclusiva para o BRT com dois sentidos, onde trafegam os veículos destinados as rotas Gama - Rodoviária 
do Plano Piloto e Santa Maria - Rodoviária do Plano Piloto, portanto será somado o número total de veículos por períodos e destinos, proveniente da Tabela B.8 e Tabela B.9.

Após realizar a somatória de acordo com os períodos, se for referente ao Período Dia será dividido por 12 (referente às 12 horas deste período), se for referente ao Entardecer será dividido por 4 (referente às 4 horas deste período) e ser for referente ao período noite será dividido por 8 (referente às 8 horas deste período), assim foi determinado a quantidade de veículos por hora que trafegam nesta região devido ao BRT, na Tabela B.10 é apresentado os resultados que foram utilizados como dados de entrada para a simulação da curva de ruído proveniente o BRT.

Tabela B.10: BRT Gama/Santa Maria/Rodoviária do Plano Piloto

\begin{tabular}{|c|c|c|}
\hline \multicolumn{3}{|c|}{ Veículos por Hora } \\
\hline Saída & \multicolumn{2}{|c|}{ Rodoviária do Plano Piloto } \\
\hline Período & Total & Veículo/Hora \\
\hline Dia & 226 & 18,83 \\
\hline Entardecer & 54 & 13,50 \\
\hline Noite & 60 & 07,50 \\
\hline Saída & \multicolumn{2}{|c|}{ Terminal de Integração BRT: Gama ou Santa Maria } \\
\hline Período & Total & Veículo/Hora \\
\hline Dia & 225 & 18,75 \\
\hline Entardecer & 69 & 17,25 \\
\hline Noite & 48 & 06,00 \\
\hline
\end{tabular}

Para a simulação das curvas de ruído rodoviário foi levando em conta a atenuação do ruído devido ao coeficiente de absorção do solo "G" (ground factor): O coeficiente "G" tem variação de zero a um, sendo: $\mathrm{G}=0$ para solos duros, como asfalto e água, onde a onda sonora incidente é completamente refletida. $\mathrm{G}=1$ para solos macios, como areia e grama, onde a onda incidente é completamente absorvida. A atenuação varia de 0,05 a $0,1 \mathrm{~dB} / \mathrm{m}$. Nas regiões com vegetação será considerada uma atenuação de $0,05 \mathrm{~dB} / \mathrm{m}$, já que a densidade da vegetação é baixa, nas demais regiões apenas a atenuação devido à atmosfera conforme a ISO-9613 (1996).

Para a criação do modelo digital do terreno foi incluída a cartografia base, a altimetria do terreno (curvas de nível cotadas) e a localização das fontes de ruídos, que neste caso são as vias de transporte rodoviário, que são tratadas como linhas de emissão ao longo do comprimento da via. A cartografia base é do SICAD 2010 (SIRGAS_2000_UTM_Zone_23L) do DF, dados cedidos gentilmente pelo Instituto Brasília Ambiental (IBRAM). Foram utilizados os dados referentes à altimetria e vias. O software 
permite a importação de arquivos vetorizados usado por sistemas de informações geográficos (shapefile - arquivos tipo CAD (Computer Aided Design).

\section{Validação das Curvas de Ruído Rodoviário}

Neste estudo, para a validação das curvas de ruído provenientes do modal rodoviário, os resultados foram calibrados por meio do estudo realizado por Garavelli et al.(2013). A validação dos mapas foi feita comparando os resultados obtidos com a simulação e os dados medidos in situ. Na Tabela B.11, são apresentados os dados referentes às validações.

Tabela B.11: Validação do Mapa de Ruído Rodoviário

\begin{tabular}{|c|c|c|c|c|c|c|c|}
\hline & Ponto & Local & $\begin{array}{r}\text { Coord } \\
\text { Geográf }\end{array}$ & $\begin{array}{l}\text { enadas } \\
\text { cas UTM, } \\
\text { 3L }\end{array}$ & $\begin{array}{c}\mathbf{L}_{e q}(s) \\
\mathrm{dB}(\mathrm{A})\end{array}$ & $\begin{array}{l}L_{e q}(m) \\
\operatorname{dB}(A)\end{array}$ & $\begin{array}{c}\text { Dif. } \\
\text { dB(A) }\end{array}$ \\
\hline \multirow{5}{*}{$\begin{array}{c}\text { Área } \\
\text { Central }\end{array}$} & $\mathrm{P} 1$ & Praça dos Três Poderes & 193444.92 & 8251044.90 & 62,8 & 61,1 & 1,7 \\
\hline & $\mathrm{P} 2$ & Câmara dos Deputados & 192819.51 & 8251233.27 & 60,5 & 58,8 & 1,7 \\
\hline & P3 & Torre de TV & 190077.19 & 8252085.44 & 59,4 & 59,4 & 0,0 \\
\hline & $\mathrm{P} 4$ & Memorial JK & 187881.51 & 8252768.59 & 64,7 & 62,3 & 2,4 \\
\hline & P5 & Nossa Senhora da Paz & 186532.02 & 8253174.13 & 61,1 & 61,8 & $-0,7$ \\
\hline \multirow{6}{*}{$\begin{array}{l}\text { Asa } \\
\text { Sul }\end{array}$} & 01 & Eixão Sul & 190140.79 & 8249973.67 & 74,9 & 73,9 & 1,0 \\
\hline & 02 & Eixão Sul & 188483.44 & 8248557.12 & 74,3 & 73,9 & 0,3 \\
\hline & 03 & Eixo L Sul & 189571.17 & 8249593.57 & 73,2 & 70,3 & 2,9 \\
\hline & 04 & L2 Sul & 190620.90 & 8249500.34 & 68,1 & 65,1 & 3,0 \\
\hline & 05 & W3 Sul & 188119.27 & 8249259.68 & 72,9 & 72,2 & 0,7 \\
\hline & 06 & W3 Sul & 189208.71 & 8250173.10 & 75,5 & 72,6 & 2,9 \\
\hline \multirow{6}{*}{$\begin{array}{c}\text { Asa } \\
\text { Norte }\end{array}$} & 01 & Eixão/Eixinho W & 190439.75 & 8256718.49 & 73,2 & 71,1 & $-2,1$ \\
\hline & 02 & Eixão/Eixinho L & 190511.88 & 8256751.06 & 72,1 & 69,8 & $-2,3$ \\
\hline & 03 & 711 Norte & 189833.9 & 8256089.93 & 67,8 & 66,9 & $-0,9$ \\
\hline & 04 & 609/610 Norte & 191469.13 & 8256079.02 & 61,3 & 63,5 & 2,2 \\
\hline & 05 & 611 Norte & 191271.97 & 8256793.14 & 53,4 & 53,3 & $-0,1$ \\
\hline & 06 & 412/413 Norte & 190975.89 & 8257056.12 & 51,3 & 52,6 & 1,3 \\
\hline
\end{tabular}

Nota: $\mathrm{L}_{e q}(\mathrm{~s})$ - é o nível de pressão sonora equivalente simulado; $\mathrm{L}_{e q}(\mathrm{~m})-$ nível de pressão sonora equivalente medido

Os resultados comparativos entre os valores previsto através da simulação e os medidos in situ, apresentados na Tabela B.11, a diferença entre os parâmetros simulados e medidos é abaixo ou igual a $3,0 \mathrm{~dB}(\mathrm{~A})$. 


\section{APENDICE C - RESULTADOS DAS SIMULAÇÕES}

Tabela C.1: Pontos de Medidas - Ruído Combinado

\begin{tabular}{|c|c|c|c|c|}
\hline $\mathbf{N}^{\circ}$ & Índice & Local & \multicolumn{2}{|c|}{ Coordenadas Geográficas } \\
\hline 1 & $\mathrm{RC} 01$ & SMPW Quadra 25 Conj. 3/4 & $15^{\circ} 53^{\prime} 01.50^{\prime \prime S}$ & $47^{\circ} 54^{\prime} 36.32^{\prime \prime} \mathrm{O}$ \\
\hline 2 & $\mathrm{RC} 02$ & DF-055 Estação Floricultura & $15^{\circ} 52^{\prime} 52.29^{\prime \prime S}$ & $47^{\circ} 57^{\prime} 32.16^{\prime \prime O}$ \\
\hline 3 & $\mathrm{RC} 03$ & DF-047 Cabeceira 11L & $15^{\circ} 51^{\prime} 50.96 " \mathrm{~S}$ & $47^{\circ} 56^{\prime} 07.17^{\prime \prime O}$ \\
\hline 4 & $\mathrm{RC} 04$ & DF-047 Concessionária VW & $15^{\circ} 52^{\prime} 15.73^{\prime \prime S}$ & $47^{\circ} 55^{\prime} 55.43 " \mathrm{O}$ \\
\hline 5 & $\mathrm{RC} 05$ & SHIS QI 03 Conjunto 3 & $15^{\circ} 51^{\prime} 35.03 " \mathrm{~S}$ & $47^{\circ} 55^{\prime} 00.27^{\prime \prime O}$ \\
\hline 6 & RC06 & SHIS QI 07 & $15^{\circ} 51^{\prime} 06.63^{\prime \prime} \mathrm{S}$ & $47^{\circ} 54^{\prime} 03.16^{\prime \prime O}$ \\
\hline 7 & $\mathrm{RC} 07$ & SHIS QI 15 Cindacta-I & $15^{\circ} 51 ' 24.21 " \mathrm{~S}$ & $47^{\circ} 52^{\prime} 43.98^{\prime \prime O}$ \\
\hline 8 & $\mathrm{RC} 08$ & SHIS QI 02 & $15^{\circ} 51 ' 29.05^{\prime \prime S}$ & $47^{\circ} 55^{\prime} 38.87^{\prime \prime O}$ \\
\hline 9 & RC09 & Av. Central AE 19/NB & $15^{\circ} 51^{\prime} 56.32 " \mathrm{~S}$ & $47^{\circ} 57^{\prime} 33.60^{\prime \prime O}$ \\
\hline 10 & $\mathrm{RC} 10$ & SMPW Quadra 6 Trecho 2 & $15^{\circ} 52^{\prime} 58.47^{\prime \prime S}$ & $47^{\circ} 57^{\prime} 53.15^{\prime \prime O}$ \\
\hline 11 & $\mathrm{RC} 11$ & Av. Contorno CAESB/NB & $15^{\circ} 52^{\prime} 07.63 " \mathrm{~S}$ & $47^{\circ} 57^{\prime} 40.92^{\prime \prime O}$ \\
\hline 12 & $\mathrm{RC} 12$ & Av. Central Bl. 379/NB & $15^{\circ} 52^{\prime} 08.82^{\prime \prime S}$ & $47^{\circ} 57^{\prime} 56.48^{\prime \prime O}$ \\
\hline 13 & $\mathrm{RC} 13$ & SMPW Quadra 6 Trecho 1 & $15^{\circ} 52 ' 23.64 " \mathrm{~S}$ & $47^{\circ} 57^{\prime} 41.89^{\prime \prime O}$ \\
\hline 14 & $\mathrm{RC} 14$ & SMPW Quadra 6 Trecho 2 & $15^{\circ} 52^{\prime} 44.34 " \mathrm{~S}$ & $47^{\circ} 57^{\prime} 40.61 " \mathrm{O}$ \\
\hline 15 & $\mathrm{RC} 15$ & Metropolitana Rua 3/NB & $15^{\circ} 52^{\prime} 48.36^{\prime \prime S}$ & $47^{\circ} 58^{\prime} 23.73^{\prime \prime O}$ \\
\hline 16 & $\mathrm{RC} 16$ & SMPW Viveiro Novacap/NB & $15^{\circ} 52^{\prime} 44.26 " \mathrm{~S}$ & $47^{\circ} 58^{\prime} 05.13 " \mathrm{O}$ \\
\hline 17 & $\mathrm{RC} 17$ & DF-055 SMPW Quadra 14 & $15^{\circ} 53 ' 21.16^{\prime \prime S}$ & $47^{\circ} 57^{\prime} 08.06 " \mathrm{O}$ \\
\hline 18 & $\mathrm{RC} 18$ & SMPW Quadra 25 Conj. 1/2 & $15^{\circ} 53^{\prime} 32.49^{\prime \prime S}$ & $47^{\circ} 54^{\prime} 43.25^{\prime \prime O}$ \\
\hline 19 & $\mathrm{RC} 19$ & SMPW Quadra 21 & $15^{\circ} 53^{\prime} 17.19^{\prime \prime S}$ & $47^{\circ} 55^{\prime} 27.64 " \mathrm{O}$ \\
\hline 20 & $\mathrm{RC} 20$ & SMPW Quadra 19 & $15^{\circ} 53^{\prime} 48.93^{\prime \prime S}$ & $47^{\circ} 56^{\prime} 12.40^{\prime \prime} \mathrm{O}$ \\
\hline 21 & $\mathrm{RC} 21$ & SMPW Quadra 15 & $15^{\circ} 53^{\prime} 47.17^{\prime \prime S}$ & $47^{\circ} 566^{\prime} 58.33^{\prime \prime O}$ \\
\hline 22 & $\mathrm{RC} 22$ & SMPW Quadra 16 & $15^{\circ} 54^{\prime} 59.62 " \mathrm{~S}$ & $47^{\circ} 56^{\prime} 52.37^{\prime \prime O}$ \\
\hline 23 & $\mathrm{RC} 23$ & SMPW Quadra 26 & $15^{\circ} 53 ' 24.85^{\prime \prime S}$ & $47^{\circ} 57^{\prime} 38.01^{\prime \prime O}$ \\
\hline 24 & $\mathrm{RC} 24$ & SMPW Quadra 7 & $15^{\circ} 53^{\prime} 58.04 " \mathrm{~S}$ & $47^{\circ} 57^{\prime} 47.47^{\prime \prime O}$ \\
\hline 25 & $\mathrm{RC} 25$ & DF-025 SMPW Qd. 14/ Trecho 1 & $15^{\circ} 52 ' 26.00^{\prime \prime S}$ & $47^{\circ} 57^{\prime} 14.45^{\prime \prime O}$ \\
\hline 26 & $\mathrm{RC} 26$ & DF-025 SMPW Qd. 14 Trecho 2 & $15^{\circ} 52^{\prime} 04.68^{\prime \prime S}$ & $47^{\circ} 56^{\prime} 31.28^{\prime \prime O}$ \\
\hline 27 & $\mathrm{RC} 27$ & DF-047 Estacionamento - AIB & $15^{\circ} 52^{\prime} 12.38^{\prime \prime S}$ & $47^{\circ} 55^{\prime} 24.28 " \mathrm{O}$ \\
\hline 28 & $\mathrm{RC} 28$ & Terminal 2 - AIB & $15^{\circ} 52^{\prime} 12.11 " \mathrm{~S}$ & $47^{\circ} 55^{\prime} 44.70^{\prime \prime O}$ \\
\hline 29 & $\mathrm{RC} 29$ & SHIS & $2.46 " \mathrm{~S}$ & $47^{\circ} 55^{\prime} 19.84^{\prime \prime} \mathrm{O}$ \\
\hline 30 & $\mathrm{RC} 30$ & SHIS QI 04 & $15^{\circ} 51^{\prime} 09.23 " \mathrm{~S}$ & $47^{\circ} 54^{\prime} 46.76^{\prime \prime O}$ \\
\hline 31 & $\mathrm{RC} 31$ & SHIS QI 03 Conjunto 8 & $15^{\circ} 51^{\prime} 18.26 " \mathrm{~S}$ & $47^{\circ} 54^{\prime} 42.83^{\prime \prime O}$ \\
\hline 32 & $\mathrm{RC} 32$ & SHIS QI 05 Base Aérea (Entrada) & $15^{\circ} 51^{\prime} 13.16 " \mathrm{~S}$ & $47^{\circ} 54^{\prime} 25.86 " \mathrm{O}$ \\
\hline 33 & $\mathrm{RC} 33$ & SHIS QI 05 Conjunto 9 & $15^{\circ} 50^{\prime} 56.04 " \mathrm{~S}$ & $47^{\circ} 54^{\prime} 17.62^{\prime \prime O}$ \\
\hline 34 & RC34 & SHIS QI 06 & $15^{\circ} 50^{\prime} 44.44 " \mathrm{~S}$ & $47^{\circ} 54^{\prime} 00.29 " \mathrm{O}$ \\
\hline 35 & $\mathrm{RC} 35$ & SHI & $15^{\circ} 50^{\prime} 59.59^{\prime \prime S}$ & $47^{\circ} 53^{\prime} 16.45^{\prime \prime O}$ \\
\hline 36 & $\mathrm{RC} 36$ & SHIS QI 15 & $15^{\circ} 51^{\prime} 18.85^{\prime \prime S}$ & $47^{\circ} 53^{\prime} 02.98^{\prime \prime} \mathrm{O}$ \\
\hline 37 & $\mathrm{RC} 37$ & SHIS QI 15 Conjunto 7 & $15^{\circ} 51^{\prime} 03.64 " \mathrm{~S}$ & $47^{\circ} 52^{\prime} 55.28^{\prime \prime O}$ \\
\hline 38 & $\mathrm{RC} 38$ & SHIS QI 05 Conjunto 14 & $15^{\circ} 51^{\prime} 09.53 " \mathrm{~S}$ & $47^{\circ} 53^{\prime} 46.25^{\prime \prime O}$ \\
\hline 39 & $\mathrm{RC} 39$ & SHIS QI 01/03 & $15^{\circ} 51^{\prime} 20.57^{\prime \prime S}$ & $47^{\circ} 54^{\prime} 57.00^{\prime \prime O}$ \\
\hline 40 & RC40 & Base Aérea/SHIS QI 05 & $15^{\circ} 51^{\prime} 17.86 " \mathrm{~S}$ & $47^{\circ} 533^{\prime} 54.90 " \mathrm{O}$ \\
\hline 41 & $\mathrm{RC} 41$ & DF-047 Via de Acesso - AIB & $15^{\circ} 52^{\prime} 02.96 " \mathrm{~S}$ & $47^{\circ} 56^{\prime} 12.04 " \mathrm{O}$ \\
\hline 42 & $\mathrm{RC} 42$ & DF-047 Concessionária GM & $15^{\circ} 52^{\prime} 08.30^{\prime \prime S}$ & $47^{\circ} 56^{\prime} 09.20^{\prime \prime} \mathrm{O}$ \\
\hline 43 & $\mathrm{RC} 43$ & DF-047 Concessionária Audi & $15^{\circ} 52^{\prime} 14.07 " \mathrm{~S}$ & $47^{\circ} 56^{\prime} 07.57^{\prime \prime O}$ \\
\hline 44 & $\mathrm{RC} 44$ & DF-047 Via de Acesso - AIB & $15^{\circ} 52^{\prime} 12.23 " \mathrm{~S}$ & $47^{\circ} 55^{\prime} 59.82^{\prime \prime O}$ \\
\hline 45 & $\mathrm{RC} 45$ & Estacionamento Terminal 2 - AIB & $15^{\circ} 52^{\prime} 12.15^{\prime \prime S}$ & $47^{\circ} 55^{\prime} 51.08^{\prime \prime O}$ \\
\hline 46 & $\mathrm{RC} 46$ & DF-047 Concessionária Bali & $15^{\circ} 52^{\prime} 14.27 " \mathrm{~S}$ & $47^{\circ} 55^{\prime} 48.06 " \mathrm{O}$ \\
\hline 47 & $\mathrm{RC} 47$ & DF-047 Concessionária Honda & $15^{\circ} 52^{\prime} 14.50^{\prime \prime S}$ & $47^{\circ} 55^{\prime} 40.94 " \mathrm{O}$ \\
\hline 48 & $\mathrm{RC} 48$ & DF-047 Correios & $15^{\circ} 52^{\prime} 11.82^{\prime \prime S}$ & $47^{\circ} 55^{\prime} 37.37^{\prime \prime} \mathrm{O}$ \\
\hline 49 & RC49 & DF-047 Via de Acesso - AIB & $15^{\circ} 51^{\prime} 57.29^{\prime \prime S}$ & $47^{\circ} 56^{\prime} 12.56^{\prime \prime O}$ \\
\hline 50 & $\mathrm{RC} 50$ & DF-047 Hotel & $15^{\circ} 52^{\prime} 15.89^{\prime \prime S}$ & $47^{\circ} 55^{\prime} 31.62^{\prime \prime O}$ \\
\hline 51 & RC51 & DF-047 Terminal 1 - AIB & $15^{\circ} 52^{\prime} 12.29^{\prime \prime S}$ & $47^{\circ} 55^{\prime} 18.97 " \mathrm{O}$ \\
\hline 52 & RC52 & DF-047 Posto de Gasolina - AIB & $15^{\circ} 52^{\prime} 09.94 " \mathrm{~S}$ & $47^{\circ} 55^{\prime} 32.14 " \mathrm{O}$ \\
\hline 53 & RC53 & DF-025 Sentido EPIA & $15^{\circ} 52^{\prime} 12.87^{\prime \prime S}$ & $47^{\circ} 57^{\prime} 00.35^{\prime \prime O}$ \\
\hline
\end{tabular}




\begin{tabular}{c|l|l|c|c}
\hline 54 & RC54 & DF-025 Balão EPIA & $15^{\circ} 52^{\prime} 31.61^{\prime \prime} \mathrm{S}$ & $47^{\circ} 57^{\prime 2} 25.01^{\prime \prime} \mathrm{O}$ \\
\hline 55 & RC55 & DF-025 Sentido EPIA & $15^{\circ} 51^{\prime} 45.18^{\prime \prime} \mathrm{S}$ & $47^{\circ} 56^{\prime} 21.29^{\prime \prime} \mathrm{O}$ \\
\hline 56 & RC56 & DF-047 Canteiro Central & $15^{\circ} 51^{\prime} 54.344^{\prime \prime} \mathrm{S}$ & $47^{\circ} 56^{\prime} 10.00^{\prime \prime} \mathrm{O}$ \\
\hline 57 & RC57 & Terminal de Integração & $15^{\circ} 50^{\prime} 20.83^{\prime \prime} \mathrm{S}$ & $47^{\circ} 56^{\prime} 03.98^{\prime \prime} \mathrm{O}$ \\
\hline 58 & RC58 & Zoológico & $15^{\circ} 50^{\prime} 57.29^{\prime \prime} \mathrm{S}$ & $47^{\circ} 55^{\prime} 57.89^{\prime \prime} \mathrm{O}$ \\
\hline 59 & RC59 & Baão do Aeroporto & $15^{\circ} 51^{\prime} 40.19^{\prime \prime} \mathrm{S}$ & $47^{\circ} 56^{\prime} 06.07^{\prime \prime} \mathrm{O}$ \\
\hline 60 & RC60 & Hípica & $15^{\circ} 50^{\prime} 30.53 " \mathrm{~S}$ & $47^{\circ} 56^{\prime} 12.69^{\prime \prime} \mathrm{O}$ \\
\hline
\end{tabular}

Tabela C.2: Resultados das Simulações para os Modais - dB(A)

\begin{tabular}{|c|c|c|c|c|c|c|c|c|c|c|c|c|}
\hline \multirow{3}{*}{$\begin{array}{l}\text { Curvas } \\
\text { Pontos }\end{array}$} & \multicolumn{6}{|c|}{ Cenário Atual } & \multicolumn{6}{|c|}{ Cenário Futuro } \\
\hline & \multicolumn{3}{|c|}{ Aéreo } & \multicolumn{3}{|c|}{ Rodoviário } & \multicolumn{3}{|c|}{ Rodoviário } & \multicolumn{3}{|c|}{ Ferroviário } \\
\hline & $\mathbf{L}_{e q}$ & $\mathbf{L}_{n}$ & $\mathbf{L}_{d e n}$ & $\mathbf{L}_{e q}$ & $\mathbf{L}_{n}$ & $\mathbf{L}_{d e n}$ & $\mathbf{L}_{e q}$ & $\mathbf{L}_{n}$ & $\mathbf{L}_{d e n}$ & $\mathbf{L}_{e q}$ & $\mathbf{L}_{n}$ & $\mathbf{L}_{d e n}$ \\
\hline RC01 & 57,4 & 53,7 & 62,3 & 65,7 & 52,1 & 66,1 & 65,7 & 52,1 & 66,1 & 65,7 & 52,1 & 66,1 \\
\hline $\mathrm{RC} 02$ & 72,6 & 68,7 & 77,4 & 71,7 & 59,9 & 71,7 & 71,6 & 59,9 & 71,7 & 71,6 & 59,9 & 71,7 \\
\hline $\mathrm{RC} 03$ & 60,0 & 56,2 & 64,9 & 70,5 & 58,8 & 71,3 & 69,6 & 58,0 & 70,4 & 69,6 & 58,0 & 70,4 \\
\hline RC04 & 60,0 & 56,2 & 64,9 & 67,8 & 56,0 & 68,7 & 66,9 & 55,0 & 67,7 & 67,0 & 55,8 & 67,9 \\
\hline $\mathrm{RC} 05$ & 60,0 & 56,2 & 64,9 & 59,6 & 50,0 & 61,5 & 59,6 & 50,0 & 61,5 & 59,6 & 50,0 & 61,5 \\
\hline RC06 & 60,2 & 56,7 & 65,2 & 60,0 & 50,1 & 61,8 & 60,0 & 50,1 & 61,8 & 60,0 & 50,1 & 61,8 \\
\hline $\mathrm{RC} 07$ & 62,0 & 58,6 & 67,1 & 58,5 & 47,6 & 59,7 & 58,5 & 47,6 & 59,7 & 58,5 & 47,6 & 59,7 \\
\hline RC08 & 62,0 & 58,6 & 67,1 & 67,2 & 56,0 & 69,1 & 67,2 & 55,9 & 69,1 & 67,2 & 55,9 & 69,1 \\
\hline RC09 & 62,0 & 58,6 & 67,1 & 61,9 & 53,3 & 63,8 & 60,6 & 52,3 & 62,9 & 60,6 & 52,3 & 62,9 \\
\hline $\mathrm{RC} 10$ & 61,0 & 57,2 & 65,9 & 58,1 & 48,0 & 59,1 & 58,0 & 47,9 & 59,0 & 58,0 & 47,9 & 59,0 \\
\hline RC11 & 59,2 & 56,8 & 64,8 & 59,1 & 49,9 & 60,7 & 58,0 & 49,1 & 59,9 & 58,0 & 49,1 & 59,9 \\
\hline $\mathrm{RC} 12$ & 58,9 & 56,5 & 64,4 & 53,0 & 43,4 & 54,4 & 52,3 & 42,8 & 53,8 & 52,3 & 42,8 & 53,8 \\
\hline RC13 & 57,0 & 53,9 & 62,2 & 61,6 & 51,5 & 62,7 & 61,1 & 51,2 & 62,4 & 61,1 & 51,2 & 62,4 \\
\hline RC14 & 59,9 & 56,1 & 64,8 & 64,8 & 54,7 & 65,8 & 64,8 & 54,6 & 65,8 & 64,8 & 54,6 & 65,8 \\
\hline RC15 & 58,3 & 54,6 & 63,3 & 47,1 & 36,9 & 48,1 & 47,0 & 36,8 & 48,0 & 47,0 & 36,8 & 48,0 \\
\hline RC16 & 59,9 & 56,1 & 64,8 & 52,8 & 42,7 & 53,8 & 52,7 & 42,5 & 53,7 & 52,7 & 42,5 & 53,7 \\
\hline RC17 & 58,2 & 54,3 & 63,1 & 63,8 & 51,3 & 64,5 & 63,8 & 51,3 & 64,5 & 63,8 & 51,3 & 64,5 \\
\hline RC18 & 48,0 & 44,1 & 52,8 & 66,3 & 52,7 & 66,6 & 66,3 & 52,7 & 66,6 & 66,3 & 52,7 & 66,6 \\
\hline RC19 & 51,1 & 47,2 & 56,0 & 65,1 & 53,3 & 66,1 & 65,1 & 53,3 & 66,1 & 65,1 & 53,3 & 66,1 \\
\hline RC20 & 46,9 & 43,1 & 51,8 & 68,4 & 51,0 & 68,0 & 68,4 & 51,0 & 68,0 & 68,4 & 51,0 & 68,0 \\
\hline RC21 & 50,6 & 46,7 & 55,5 & 61,1 & 46,5 & 61,9 & 61,1 & 46,5 & 61,9 & 61,1 & 46,5 & 61,9 \\
\hline RC22 & 42,9 & 39,0 & 47,8 & 65,8 & 51,8 & 64,8 & 65,8 & 51,8 & 64,8 & 65,8 & 51,8 & 64,8 \\
\hline RC23 & 60,6 & 56,7 & 65,4 & 71,0 & 60,7 & 71,7 & 71,0 & 60,7 & 71,7 & 71,0 & 60,7 & 71,7 \\
\hline RC24 & 47,3 & 43,4 & 52,2 & 73,4 & 64,3 & 75,3 & 73,4 & 64,3 & 75,3 & 73,4 & 64,3 & 75,3 \\
\hline RC25 & 62,8 & 59,0 & 67,7 & 75,3 & 61,4 & 74,8 & 75,1 & 61,0 & 74,5 & 75,1 & 61,0 & 74,5 \\
\hline RC26 & 59,6 & 56,4 & 64,8 & 71,3 & 56,4 & 70,4 & 71,2 & 56,2 & 70,2 & 71,2 & 56,2 & 70,2 \\
\hline RC27 & 60,9 & 57,5 & 65,9 & 61,7 & 49,9 & 62,6 & 60,8 & 48,9 & 61,6 & 60,8 & 49,2 & 61,7 \\
\hline $\mathrm{RC} 28$ & 57,9 & 54,2 & 62,8 & 71,2 & 59,3 & 72,0 & 70,2 & 58,3 & 71,0 & 70,2 & 58,4 & 71,0 \\
\hline RC29 & 56,1 & 52,6 & 61,1 & 57,3 & 45,5 & 58,1 & 57,3 & 45,4 & 58,0 & 57,3 & 45,4 & 58,0 \\
\hline RC30 & 62,0 & 58,6 & 67,0 & 67,5 & 56,3 & 69,5 & 67,5 & 56,3 & 69,5 & 67,5 & 56,3 & 69,5 \\
\hline RC31 & 60,3 & 56,9 & 65,4 & 60,2 & 48,2 & 61,6 & 60,2 & 48,2 & 61,6 & 60,2 & 48,2 & 61,6 \\
\hline RC32 & 64,3 & 61,0 & 69,4 & 62,5 & 55,3 & 64,4 & 62,5 & 55,3 & 64,4 & 62,5 & 55,3 & 64,4 \\
\hline RC33 & 57,9 & 54,4 & 62,9 & 71,3 & 58,1 & 71,2 & 71,3 & 58,1 & 71,2 & 71,3 & 58,1 & 71,2 \\
\hline RC34 & 55,5 & 52,1 & 60,6 & 60,1 & 47,4 & 61,4 & 60,1 & 47,4 & 61,4 & 60,1 & 47,4 & 61,4 \\
\hline RC35 & 58,5 & 55,2 & 63,6 & 63,5 & 52,3 & 64,6 & 63,5 & 52,3 & 64,6 & 63,5 & 52,3 & 64,6 \\
\hline RC36 & 58,3 & 55,1 & 63,5 & 57,0 & 45,7 & 59,1 & 57,0 & 45,7 & 59,1 & 57,0 & 45,7 & 59,1 \\
\hline RC37 & 59,0 & 55,9 & 64,2 & 69,5 & 62,1 & 71,4 & 69,5 & 62,1 & 71,4 & 69,5 & 62,1 & 71,4 \\
\hline RC38 & 69,7 & 66,5 & 74,8 & 64,0 & 52,7 & 65,1 & 64,0 & 52,7 & 65,1 & 64,0 & 52,7 & 65,1 \\
\hline RC39 & 60,2 & 56,7 & 65,2 & 72,5 & 60,9 & 74,0 & 72,5 & 60,9 & 74,0 & 72,5 & 60,9 & 74,0 \\
\hline $\mathrm{RC} 40$ & 62,8 & 59,5 & 67,9 & 55,1 & 43,7 & 57,1 & 55,1 & 43,7 & 57,1 & 55,1 & 43,7 & 57,1 \\
\hline RC41 & 63,0 & 60,2 & 68,4 & 77,1 & 65,2 & 77,9 & 76,1 & 64,3 & 76,9 & 76,3 & 65,5 & 77,3 \\
\hline $\mathrm{RC} 42$ & 65,5 & 62,7 & 70,8 & 73,5 & 61,6 & 74,3 & 72,5 & 60,6 & 73,3 & 72,6 & 60,9 & 73,4 \\
\hline RC43 & 60,9 & 57,8 & 66,1 & 67,5 & 55,6 & 68,3 & 66,6 & 54,7 & 67,4 & 66,6 & 55,0 & 67,4 \\
\hline RC44 & 60,7 & 57,4 & 65,8 & 68,1 & 56,3 & 68,9 & 67,2 & 55,3 & 68,0 & 67,2 & 55,4 & 68,0 \\
\hline
\end{tabular}




\begin{tabular}{l|lll|lll|lll|lll}
\hline RC45 & 60,7 & 57,4 & 65,8 & 69,5 & 57,6 & 70,3 & 68,5 & 56,6 & 69,3 & 68,5 & 56,7 & 69,3 \\
\hline RC46 & 60,8 & 57,5 & 65,9 & 74,4 & 62,5 & 75,3 & 71,8 & 60,0 & 72,7 & 72,2 & 62,8 & 73,4 \\
\hline RC47 & 60,4 & 57,1 & 65,5 & 70,0 & 58,1 & 70,8 & 69,1 & 57,2 & 69,9 & 69,2 & 58,4 & 70,2 \\
\hline RC48 & 60,4 & 57,0 & 65,5 & 71,8 & 59,9 & 72,6 & 70,8 & 59,0 & 71,7 & 70,9 & 59,1 & 71,7 \\
\hline RC49 & 60,4 & 57,0 & 65,5 & 69,0 & 56,6 & 69,4 & 68,3 & 55,9 & 68,7 & 68,4 & 56,7 & 68,9 \\
\hline RC50 & 57,7 & 54,1 & 62,7 & 70,3 & 58,4 & 71,1 & 69,3 & 57,4 & 70,1 & 69,3 & 57,5 & 70,2 \\
\hline RC51 & 58,0 & 54,5 & 63,0 & 71,6 & 59,6 & 72,4 & 70,6 & 58,7 & 71,4 & 70,6 & 58,7 & 71,4 \\
\hline RC52 & 58,5 & 55,0 & 63,5 & 73,1 & 61,2 & 73,9 & 72,1 & 60,2 & 72,9 & 72,1 & 60,3 & 72,9 \\
\hline RC53 & 59,1 & 55,9 & 64,3 & 71,9 & 61,6 & 73,7 & 71,0 & 60,7 & 72,8 & 71,0 & 60,7 & 72,8 \\
\hline RC54 & 64,3 & 60,4 & 69,1 & 79,5 & 64,0 & 78,4 & 79,4 & 63,8 & 78,3 & 79,4 & 63,8 & 78,3 \\
\hline RC55 & 64,5 & 61,9 & 69,9 & 66,7 & 56,3 & 68,4 & 65,8 & 55,4 & 67,5 & 65,8 & 55,4 & 67,5 \\
\hline RC56 & 65,0 & 62,4 & 70,4 & 70,6 & 63,4 & 73,3 & 69,8 & 62,7 & 72,5 & 69,9 & 62,8 & 72,5 \\
\hline RC57 & 44,4 & 40,9 & 49,4 & 54,6 & 47,7 & 57,6 & 53,8 & 46,9 & 56,8 & 54,0 & 47,4 & 57,0 \\
\hline RC58 & 44,4 & 40,9 & 49,4 & 64,5 & 57,6 & 67,5 & 63,7 & 56,8 & 66,7 & 63,7 & 56,9 & 66,7 \\
\hline RC59 & 64,5 & 61,8 & 69,9 & 65,8 & 56,9 & 67,9 & 65,3 & 56,4 & 67,3 & 65,3 & 56,5 & 67,3 \\
\hline RC60 & 48,2 & 44,8 & 53,3 & 51,6 & 44,7 & 54,6 & 50,8 & 43,9 & 53,8 & 50,9 & 44,2 & 53,9 \\
\hline
\end{tabular}

Tabela C.3: Resultados Ruído Combinado $\mathrm{L}_{n}-\mathrm{dB}(\mathrm{A})$

\begin{tabular}{c|ccc|ccc|c}
\hline \multirow{2}{*}{ Pontos } & \multicolumn{3}{|c|}{ Cenário Atual } & \multicolumn{3}{c|}{ Cenário Futuro } & \multirow{2}{*}{ Diferença } \\
\cline { 2 - 7 } & Rodoviário & Aéreo & Combinado & Rod. + VLT & Aéreo & Combinado & \\
\hline RC01 & 52,1 & 53,7 & 56,0 & 52,1 & 53,7 & 56,0 & 0,0 \\
\hline RC02 & 59,9 & 68,7 & 69,2 & 59,9 & 68,7 & 69,2 & 0,0 \\
\hline RC03 & 58,8 & 56,2 & 60,7 & 58,0 & 56,2 & 60,2 & 0,5 \\
\hline RC04 & 56,0 & 56,2 & 59,1 & 55,8 & 56,2 & 59,0 & 0,1 \\
\hline RC05 & 50,0 & 56,2 & 57,1 & 50,0 & 56,2 & 57,1 & 0,0 \\
\hline RC06 & 50,1 & 56,7 & 57,6 & 50,1 & 56,7 & 57,6 & 0,0 \\
\hline RC07 & 47,6 & 58,6 & 58,9 & 47,6 & 58,6 & 58,9 & 0,0 \\
\hline RC08 & 56,0 & 58,6 & 60,5 & 55,9 & 58,6 & 60,5 & 0,0 \\
\hline RC09 & 53,3 & 58,6 & 59,7 & 52,3 & 58,6 & 59,5 & 0,2 \\
\hline RC10 & 48,0 & 57,2 & 57,7 & 47,9 & 57,2 & 57,7 & 0,0 \\
\hline RC11 & 49,9 & 56,8 & 57,6 & 49,1 & 56,8 & 57,5 & 0,1 \\
\hline RC12 & 43,4 & 56,5 & 56,7 & 42,8 & 56,5 & 56,7 & 0,0 \\
\hline RC13 & 51,5 & 53,9 & 55,9 & 51,2 & 53,9 & 55,8 & 0,1 \\
\hline RC14 & 54,7 & 56,1 & 58,5 & 54,6 & 56,1 & 58,4 & 0,0 \\
\hline RC15 & 36,9 & 54,6 & 54,7 & 36,8 & 54,6 & 54,7 & 0,0 \\
\hline RC16 & 42,7 & 56,1 & 56,3 & 42,5 & 56,1 & 56,3 & 0,0 \\
\hline RC17 & 51,3 & 54,3 & 56,1 & 51,3 & 54,3 & 56,1 & 0,0 \\
\hline RC18 & 52,7 & 44,1 & 53,3 & 52,7 & 44,1 & 53,3 & 0,0 \\
\hline RC19 & 53,3 & 47,2 & 54,3 & 53,3 & 47,2 & 54,3 & 0,0 \\
\hline RC20 & 51,0 & 43,1 & 51,7 & 51,0 & 43,1 & 51,7 & 0,0 \\
\hline RC21 & 46,5 & 46,7 & 49,6 & 46,5 & 46,7 & 49,6 & 0,0 \\
\hline RC22 & 51,8 & 39,0 & 52,0 & 51,8 & 39,0 & 52,0 & 0,0 \\
\hline RC23 & 60,7 & 56,7 & 62,2 & 60,7 & 56,7 & 62,2 & 0,0 \\
\hline RC24 & 64,3 & 43,4 & 64,3 & 64,3 & 43,4 & 64,3 & 0,0 \\
\hline RC25 & 61,4 & 59,0 & 63,4 & 61,0 & 59,0 & 63,1 & 0,2 \\
\hline RC26 & 56,4 & 56,4 & 59,4 & 56,2 & 56,4 & 59,3 & 0,1 \\
\hline RC27 & 49,9 & 57,5 & 58,2 & 49,2 & 57,5 & 58,1 & 0,1 \\
\hline RC28 & 59,3 & 54,2 & 60,5 & 58,4 & 54,2 & 59,8 & 0,7 \\
\hline RC29 & 45,5 & 52,6 & 53,4 & 45,4 & 52,6 & 53,4 & 0,0 \\
\hline RC30 & 56,3 & 58,6 & 60,6 & 56,3 & 58,6 & 60,6 & 0,0 \\
\hline RC31 & 48,2 & 56,9 & 57,4 & 48,2 & 56,9 & 57,4 & 0,0 \\
\hline RC32 & 55,3 & 61,0 & 62,0 & 55,3 & 61,0 & 62,0 & 0,0 \\
\hline RC33 & 58,1 & 54,4 & 59,6 & 58,1 & 54,4 & 59,6 & 0,0 \\
\hline RC34 & 47,4 & 52,1 & 53,4 & 47,4 & 52,1 & 53,4 & 0,0 \\
\hline RC35 & 52,3 & 55,2 & 57,0 & 52,3 & 55,2 & 57,0 & 0,0 \\
\hline RC36 & 45,7 & 55,1 & 55,6 & 45,7 & 55,1 & 55,6 & 0,0 \\
\hline & & & & & & & \\
\hline
\end{tabular}




\begin{tabular}{l|lll|lll|l}
\hline RC37 & 62,1 & 55,9 & 63,0 & 62,1 & 55,9 & 63,0 & 0,0 \\
\hline RC38 & 52,7 & 66,5 & 66,7 & 52,7 & 66,5 & 66,7 & 0,0 \\
\hline RC39 & 60,9 & 56,7 & 62,3 & 60,9 & 56,7 & 62,3 & 0,0 \\
\hline RC40 & 43,7 & 59,5 & 59,6 & 43,7 & 59,5 & 59,6 & 0,0 \\
\hline RC41 & 65,2 & 60,2 & 66,4 & 65,5 & 60,2 & 66,6 & $-0,2$ \\
\hline RC42 & 61,6 & 62,7 & 65,2 & 60,9 & 62,7 & 64,9 & 0,3 \\
\hline RC43 & 55,6 & 57,8 & 59,8 & 55,0 & 57,8 & 59,6 & 0,2 \\
\hline RC44 & 56,3 & 57,4 & 59,9 & 55,4 & 57,4 & 59,5 & 0,4 \\
\hline RC45 & 57,6 & 57,4 & 60,5 & 56,7 & 57,4 & 60,1 & 0,4 \\
\hline RC46 & 62,5 & 57,5 & 63,7 & 62,8 & 57,5 & 63,9 & $-0,2$ \\
\hline RC47 & 58,1 & 57,1 & 60,6 & 58,4 & 57,1 & 60,8 & $-0,2$ \\
\hline RC48 & 59,9 & 57,0 & 61,7 & 59,1 & 57,0 & 61,2 & 0,5 \\
\hline RC49 & 56,6 & 57,0 & 59,8 & 56,7 & 57,0 & 59,9 & 0,0 \\
\hline RC50 & 58,4 & 54,1 & 59,8 & 57,5 & 54,1 & 59,1 & 0,6 \\
\hline RC51 & 59,6 & 54,5 & 60,8 & 58,7 & 54,5 & 60,1 & 0,7 \\
\hline RC52 & 61,2 & 55,0 & 62,1 & 60,3 & 55,0 & 61,4 & 0,7 \\
\hline RC53 & 61,6 & 55,9 & 62,6 & 60,7 & 55,9 & 61,9 & 0,7 \\
\hline RC54 & 64,0 & 60,4 & 65,6 & 63,8 & 60,4 & 65,4 & 0,1 \\
\hline RC55 & 56,3 & 61,9 & 63,0 & 55,4 & 61,9 & 62,8 & 0,2 \\
\hline RC56 & 63,4 & 62,4 & 65,9 & 62,8 & 62,4 & 65,6 & 0,3 \\
\hline RC57 & 47,7 & 40,9 & 48,5 & 47,4 & 40,9 & 48,3 & 0,2 \\
\hline RC58 & 57,6 & 40,9 & 57,7 & 56,9 & 40,9 & 57,0 & 0,7 \\
\hline RC59 & 56,9 & 61,8 & 63,0 & 56,5 & 61,8 & 62,9 & 0,1 \\
\hline RC60 & 44,7 & 44,8 & 47,8 & 44,2 & 44,8 & 47,5 & 0,2 \\
\hline
\end{tabular}

Tabela C.4: Resultados Ruído Combinado $\mathrm{L}_{d e n}-\mathrm{dB}(\mathrm{A})$

\begin{tabular}{c|ccc|ccc|c}
\hline \multirow{2}{*}{ Pontos } & \multicolumn{3}{|c|}{ Cenário Atual } & \multicolumn{3}{c|}{ Cenário Futuro } & \multirow{2}{*}{ Diferença } \\
\cline { 2 - 7 } & Rodoviário & Aéreo & Combinado & Rod. + VLT & Aéreo & Combinado & \\
\hline RC01 & 66,1 & 62,3 & 67,6 & 66,1 & 62,3 & 67,6 & 0,0 \\
\hline RC02 & 71,7 & 77,4 & 78,4 & 71,7 & 77,4 & 78,4 & 0,0 \\
\hline RC03 & 71,3 & 64,9 & 72,2 & 70,4 & 64,9 & 71,5 & 0,7 \\
\hline RC04 & 68,7 & 64,9 & 70,2 & 67,9 & 64,9 & 69,7 & 0,5 \\
\hline RC05 & 61,5 & 64,9 & 66,5 & 61,5 & 64,9 & 66,5 & 0,0 \\
\hline RC06 & 61,8 & 65,2 & 66,8 & 61,8 & 65,2 & 66,8 & 0,0 \\
\hline RC07 & 59,7 & 67,1 & 67,8 & 59,7 & 67,1 & 67,8 & 0,0 \\
\hline RC08 & 69,1 & 67,1 & 71,2 & 69,1 & 67,1 & 71,2 & 0,0 \\
\hline RC09 & 63,8 & 67,1 & 68,8 & 62,9 & 67,1 & 68,5 & 0,3 \\
\hline RC10 & 59,1 & 65,9 & 66,7 & 59,0 & 65,9 & 66,7 & 0,0 \\
\hline RC11 & 60,7 & 64,8 & 66,2 & 59,9 & 64,8 & 66,0 & 0,2 \\
\hline RC12 & 54,4 & 64,4 & 64,8 & 53,8 & 64,4 & 64,8 & 0,1 \\
\hline RC13 & 62,7 & 62,2 & 65,5 & 62,4 & 62,2 & 65,3 & 0,2 \\
\hline RC14 & 65,8 & 64,8 & 68,3 & 65,8 & 64,8 & 68,3 & 0,0 \\
\hline RC15 & 48,1 & 63,3 & 63,4 & 48,0 & 63,3 & 63,4 & 0,0 \\
\hline RC16 & 53,8 & 64,8 & 65,1 & 53,7 & 64,8 & 65,1 & 0,0 \\
\hline RC17 & 64,5 & 63,1 & 66,9 & 64,5 & 63,1 & 66,9 & 0,0 \\
\hline RC18 & 66,6 & 52,8 & 66,8 & 66,6 & 52,8 & 66,8 & 0,0 \\
\hline RC19 & 66,1 & 56,0 & 66,5 & 66,1 & 56,0 & 66,5 & 0,0 \\
\hline RC20 & 68,0 & 51,8 & 68,1 & 68,0 & 51,8 & 68,1 & 0,0 \\
\hline RC21 & 61,9 & 55,5 & 62,8 & 61,9 & 55,5 & 62,8 & 0,0 \\
\hline RC22 & 64,8 & 47,8 & 64,9 & 64,8 & 47,8 & 64,9 & 0,0 \\
\hline RC23 & 71,7 & 65,4 & 72,6 & 71,7 & 65,4 & 72,6 & 0,0 \\
\hline RC24 & 75,3 & 52,2 & 75,3 & 75,3 & 52,2 & 75,3 & 0,0 \\
\hline RC25 & 74,8 & 67,7 & 75,6 & 74,5 & 67,7 & 75,3 & 0,2 \\
\hline RC26 & 70,4 & 64,8 & 71,5 & 70,2 & 64,8 & 71,3 & 0,2 \\
\hline RC27 & 62,6 & 65,9 & 67,6 & 61,7 & 65,9 & 67,3 & 0,3 \\
\hline RC28 & 72,0 & 62,8 & 72,5 & 71,0 & 62,8 & 71,6 & 0,9 \\
\hline & & & & & & &
\end{tabular}




\begin{tabular}{|c|c|c|c|c|c|c|c|}
\hline RC29 & 58,1 & 61,1 & 62,9 & 58,0 & 61,1 & 62,8 & 0,0 \\
\hline RC30 & 69,5 & 67,0 & 71,4 & 69,5 & 67,0 & 71,4 & 0,0 \\
\hline RC31 & 61,6 & 65,4 & 66,9 & 61,6 & 65,4 & 66,9 & 0,0 \\
\hline RC32 & 64,4 & 69,4 & 70,6 & 64,4 & 69,4 & 70,6 & 0,0 \\
\hline RC33 & 71,2 & 62,9 & 71,8 & 71,2 & 62,9 & 71,8 & 0,0 \\
\hline RC34 & 61,4 & 60,6 & 64,0 & 61,4 & 60,6 & 64,0 & 0,0 \\
\hline RC35 & 64,6 & 63,6 & 67,1 & 64,6 & 63,6 & 67,1 & 0,0 \\
\hline RC36 & 59,1 & 63,5 & 64,8 & 59,1 & 63,5 & 64,8 & 0,0 \\
\hline RC37 & 71,4 & 64,2 & 72,2 & 71,4 & 64,2 & 72,2 & 0,0 \\
\hline RC38 & 65,1 & 74,8 & 75,2 & 65,1 & 74,8 & 75,2 & 0,0 \\
\hline RC39 & 74,0 & 65,2 & 74,5 & 74,0 & 65,2 & 74,5 & 0,0 \\
\hline $\mathrm{RC} 40$ & 57,1 & 67,9 & 68,2 & 57,1 & 67,9 & 68,2 & 0,0 \\
\hline RC41 & 77,9 & 68,4 & 78,4 & 77,3 & 68,4 & 77,8 & 0,5 \\
\hline $\mathrm{RC} 42$ & 74,3 & 70,8 & 75,9 & 73,4 & 70,8 & 75,3 & 0,6 \\
\hline RC43 & 68,3 & 66,1 & 70,3 & 67,4 & 66,1 & 69,8 & 0,5 \\
\hline RC44 & 68,9 & 65,8 & 70,6 & 68,0 & 65,8 & 70,0 & 0,6 \\
\hline RC45 & 70,3 & 65,8 & 71,6 & 69,3 & 65,8 & 70,9 & 0,7 \\
\hline RC46 & 75,3 & 65,9 & 75,8 & 73,4 & 65,9 & 74,1 & 1,7 \\
\hline RC47 & 70,8 & 65,5 & 71,9 & 70,2 & 65,5 & 71,5 & 0,5 \\
\hline RC48 & 72,6 & 65,5 & 73,4 & 71,7 & 65,5 & 72,6 & 0,7 \\
\hline RC49 & 69,4 & 65,5 & 70,9 & 68,9 & 65,5 & 70,5 & 0,3 \\
\hline RC50 & 71,1 & 62,7 & 71,7 & 70,2 & 62,7 & 70,9 & 0,8 \\
\hline RC51 & 72,4 & 63,0 & 72,9 & 71,4 & 63,0 & 72,0 & 0,9 \\
\hline RC52 & 73,9 & 63,5 & 74,3 & 72,9 & 63,5 & 73,4 & 0,9 \\
\hline RC53 & 73,7 & 64,3 & 74,2 & 72,8 & 64,3 & 73,4 & 0,8 \\
\hline RC54 & 78,4 & 69,1 & 78,9 & 78,3 & 69,1 & 78,8 & 0,1 \\
\hline RC55 & 68,4 & 69,9 & 72,2 & 67,5 & 69,9 & 71,9 & 0,4 \\
\hline RC56 & 73,3 & 70,4 & 75,1 & 72,5 & 70,4 & 74,6 & 0,5 \\
\hline RC57 & 57,6 & 49,4 & 58,2 & 57,0 & 49,4 & 57,7 & 0,5 \\
\hline RC58 & 67,5 & 49,4 & 67,6 & 66,7 & 49,4 & 66,8 & 0,8 \\
\hline RC59 & 67,9 & 69,9 & 72,0 & 67,3 & 69,9 & 71,8 & 0,2 \\
\hline RC60 & 54,6 & 53,3 & 57,0 & 53,9 & 53,3 & 56,6 & 0,4 \\
\hline
\end{tabular}

